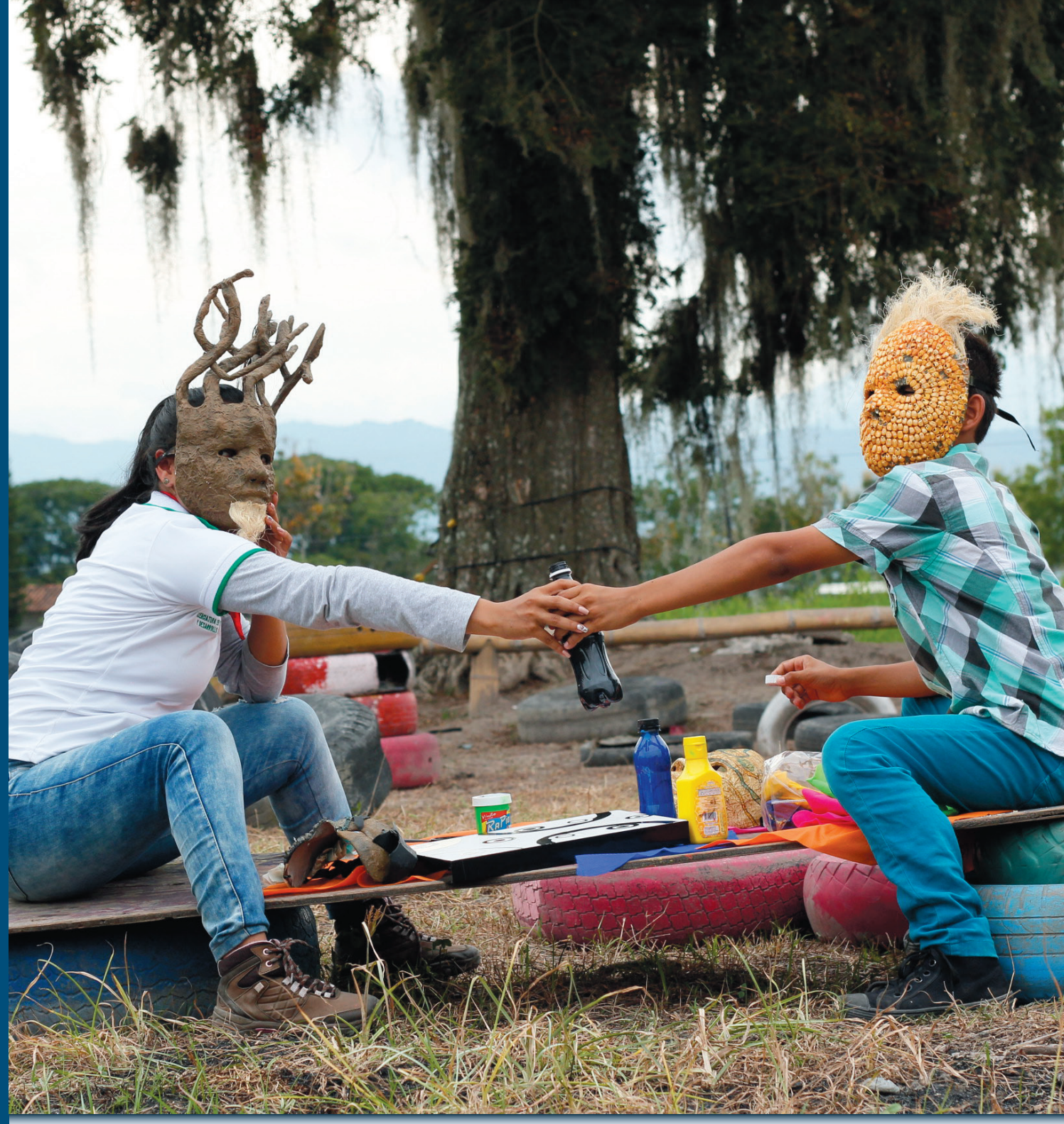

\title{
Contribución al desarrollo social a través de la extensión universitaria
}

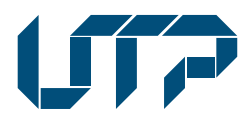

Universidad Tecnológica de Pereira

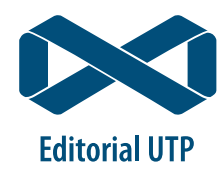

Autores Varios 



\section{Contribución al desarrollo social a través de la extensión universitaria}

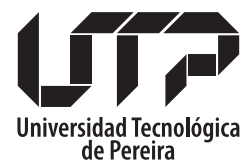

Vicerrectoría de Investigaciones, Innovación y Extensión Colección Trabajos de Extensión 2021 
Contribución al desarrollo social a través de la extensión

universitaria / Roberto Millán Gaviria y otros. -- Pereira

Editorial Universidad Tecnológica de Pereira, 2021.

278 páginas. -- (Colección Trabajos de investigación).

e-ISBN: 978-958-722-523-5

1. Derecho deportivo colombiano 2. Energía renovable

3. Viviendas ecosostenibles 4. Energía - Consumo 5.

Risaralda - Diversidad cultural 6. Lectura - Enseñanza 7.

Mujeres - Ciencia y tecnología 8. Astronomía - Observatorios

CDD. 306.0972

Contribución al desarrollo social a través de la extensión universitaria

(C) Vicerrectoría de Investigaciones, Innovación y Extensión

(C) Universidad Tecnológica de Pereira

Publicación Mayo 2021

eISBN: 978-958-722-523-5

Imagen de cubierta: Fuente: Elaboración Propia - Proyecto Reconstruyendo la historia desde adentro - una Experiencia significativa en la ciudad de Pereira, Risaralda: San Isidro, Puerto Caldas a cargo de Claudia Viviana Hurtado Loaiza

Universidad Tecnológica de Pereira

Vicerrectoría de Investigaciones, Innovación y Extensión

Editorial Universidad Tecnológica de Pereira

Pereira, Colombia

Coordinador editorial:

Luis Miguel Vargas Valencia

luismvargas@utp.edu.co

Teléfono 3137381

Edificio 9, Biblioteca Central "Jorge Roa Martínez"

Cra. 27 No. 10-02 Los Álamos, Pereira, Colombia

www.utp.edu.co

Montaje y producción:

María Alejandra Henao Jiménez

Universidad Tecnológica de Pereira

Pereira 



\section{CONTENIDO}

Prólogo

Gestión de una base de datos especializada en derecho deportivo colombiano. Base de datos especializada en normas y jurisprudencia del derecho deportivo

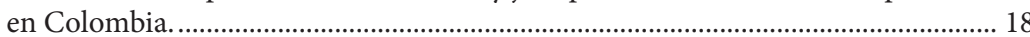

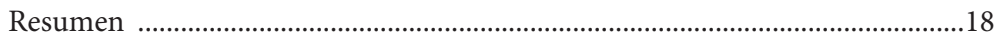

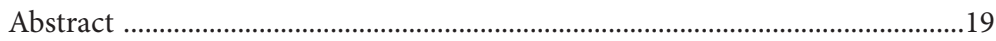

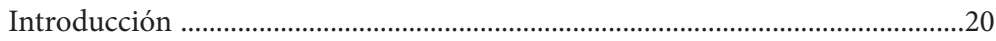

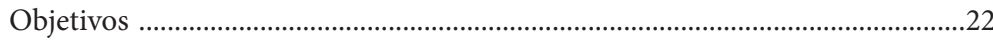

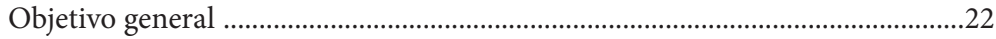

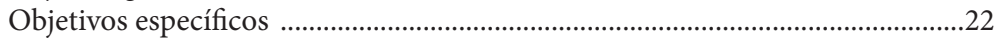

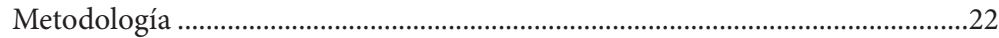

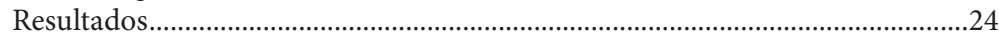

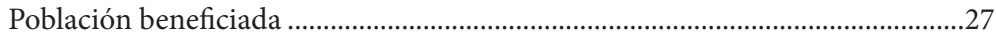

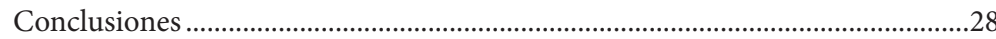

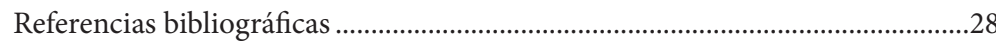

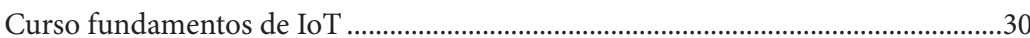

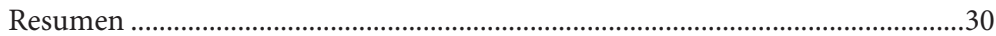

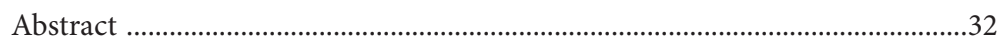

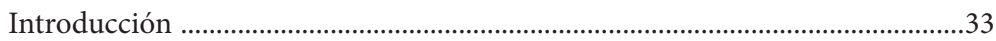

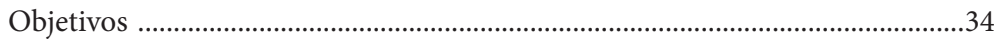

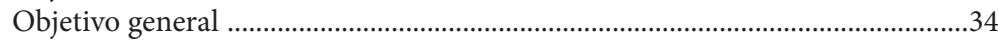

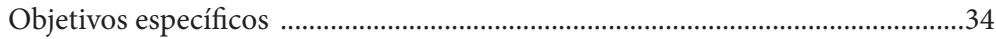

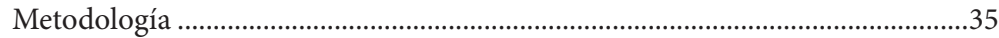

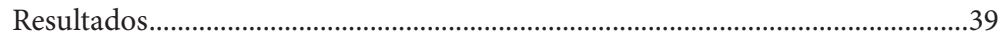

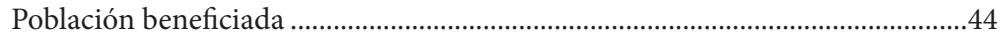

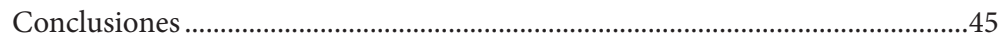

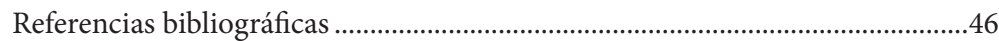

Implementación y apropiación de un sistema renovable para cubrir demanda

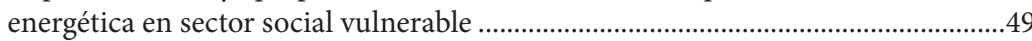

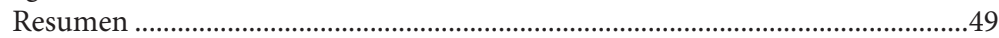

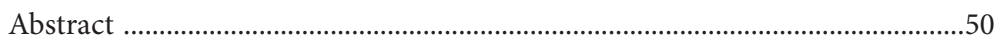

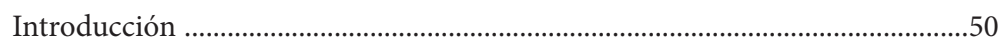

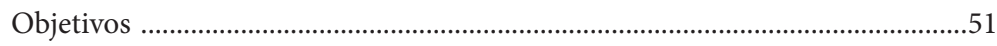

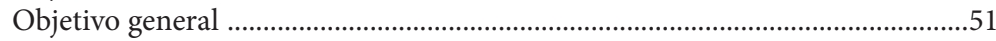

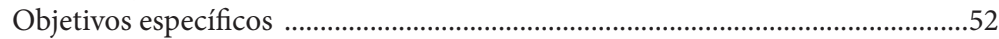

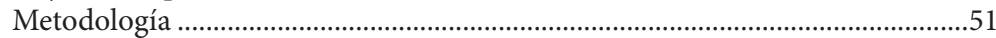

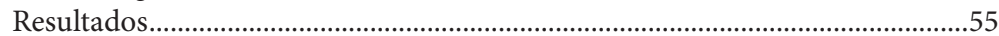

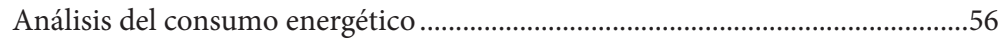

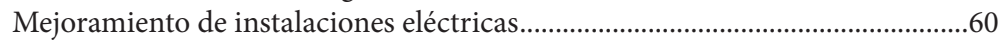

Implementación del sistema renovable ...................................................................62

Formación y sensibilización de la comunidad........................................................65 


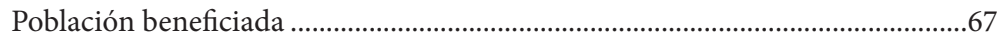

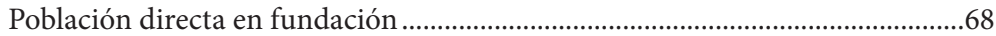

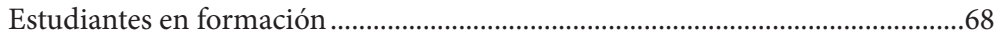

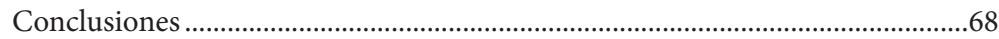

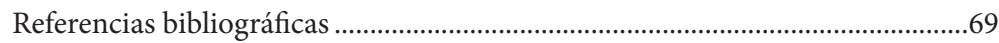

Astroviernes y los cien años de la Unión Astronómica Internacional .......................71

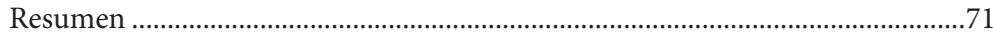

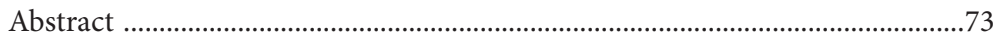

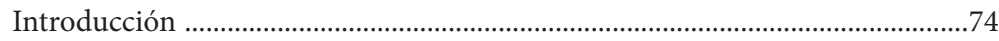

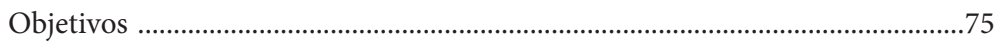

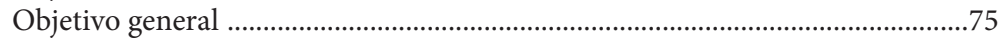

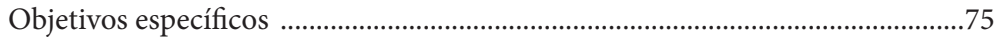

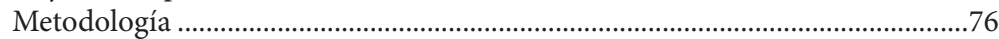

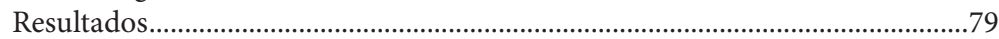

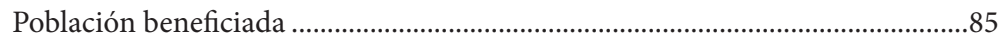

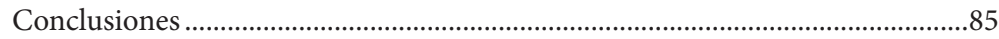

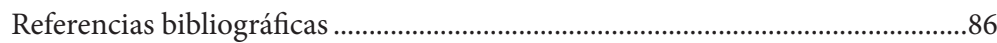

Sabores de Risaralda: construcción de un inventario intercultural del patrimonio

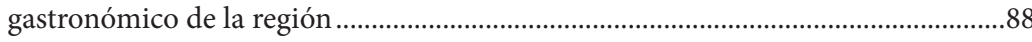

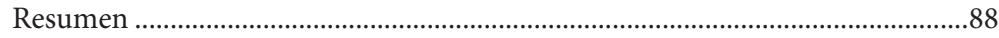

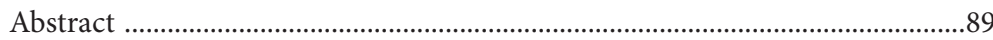

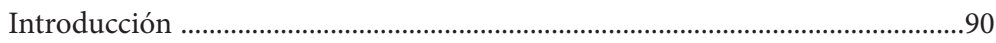

La gastronomía y el patrimonio cultural inmaterial............................................90

Políticas culturales y elaboración de inventarios del patrimonio cultural

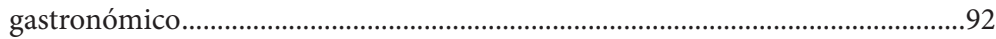

El departamento de Risaralda: entre la diversidad geográfica, étnica

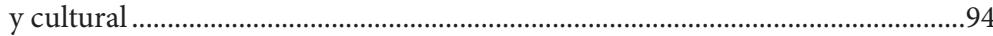

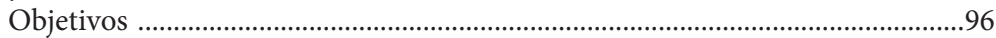

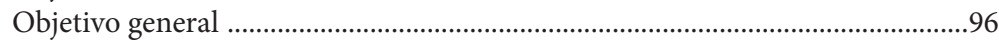

Objetivos específicos ......................................................................................96

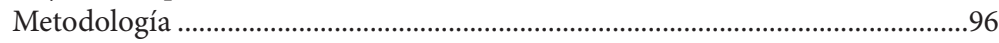

Fase nro. 1. Documentar y concretar ...............................................................97

Fase nro. 2. Trabajo de campo............................................................................98

Fase nro. 3. Desarrollo de los talleres de socialización y retroalimentación con los grupos de los municipios ......................................................................99

Fase nro. 4. Evaluación de la información, registro e

inventario del patrimonio gastronómico de los municipios.................................99

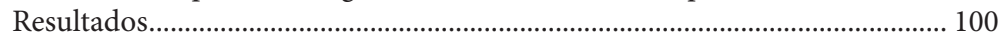

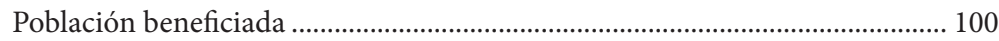

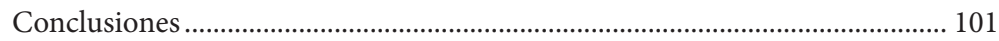

Referencias bibliográficas .............................................................................. 104

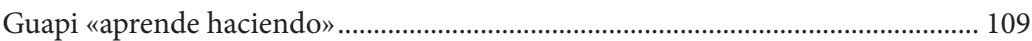

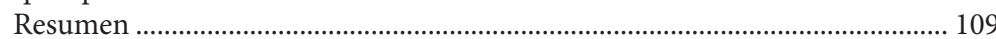

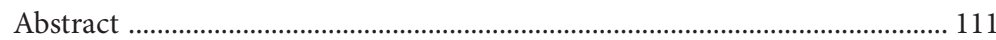

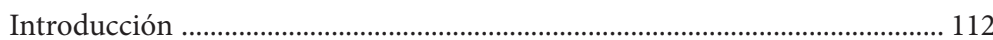




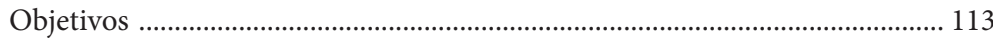

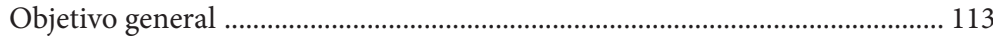

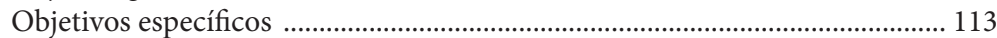

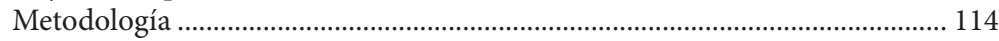

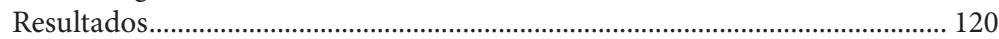

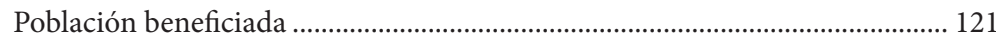

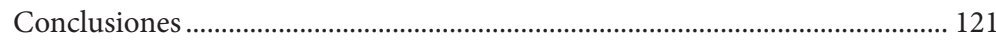

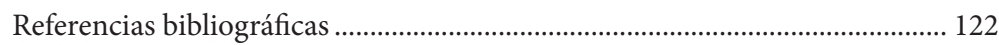

Enseñar a hablar, leer y escribir. Una propuesta para la transformación didáctica

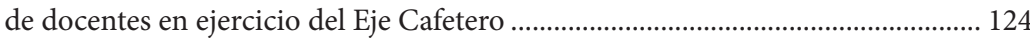

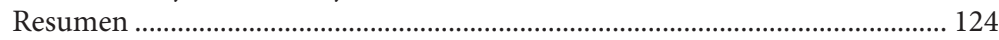

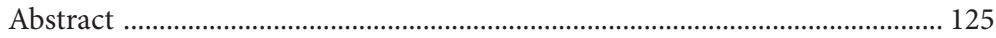

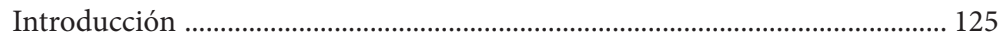

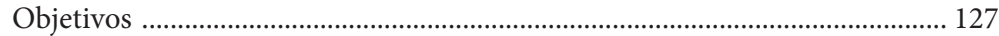

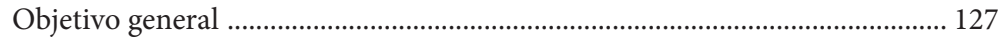

Objetivos específicos .................................................................................. 127

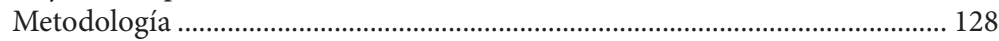

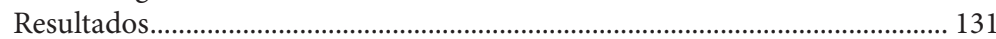

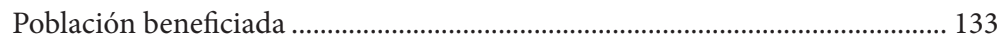

Conclusiones ................................................................................................. 134

Referencias bibliográficas ................................................................................ 135

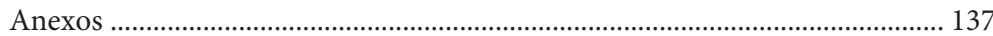

Curso herramientas para la gestión de la innovación: design thinking

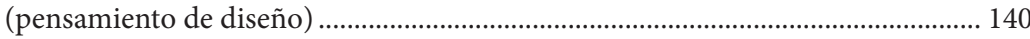

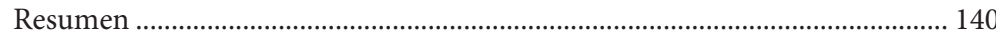

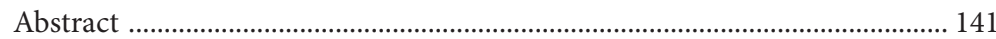

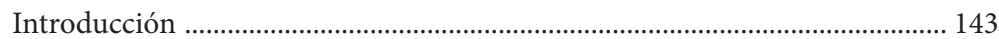

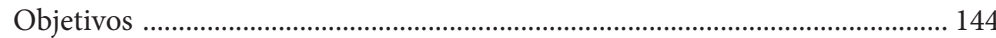

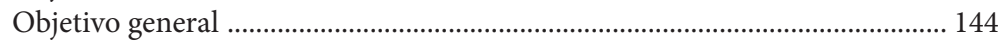

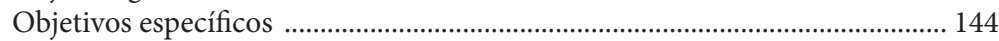

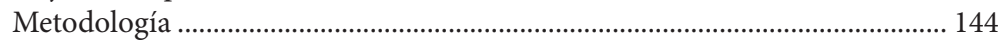

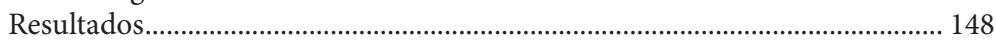

Población beneficiada ................................................................................ 149

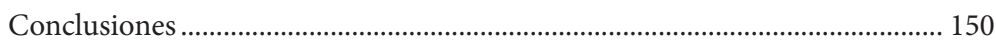

Referencias bibliográficas ........................................................................... 150

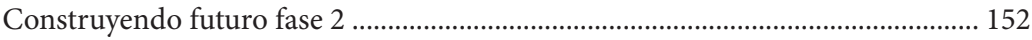

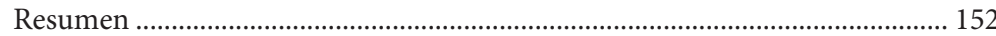

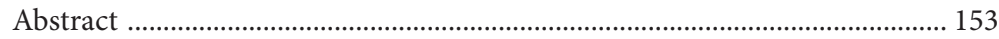

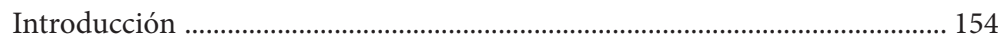

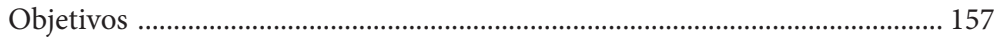

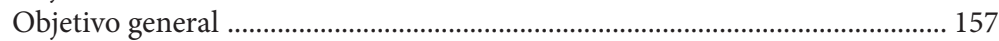

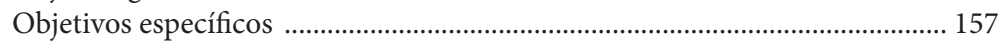

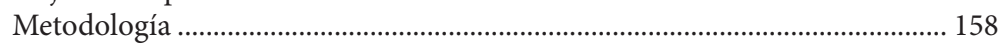

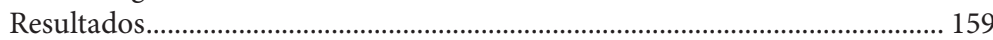

Afinación de la metodología de los talleres....................................................... 159 


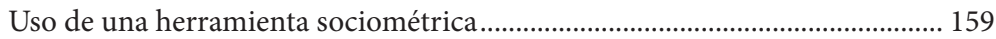

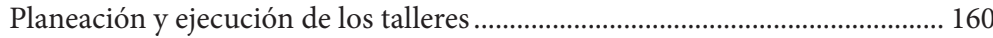

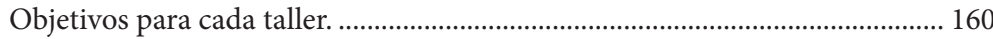

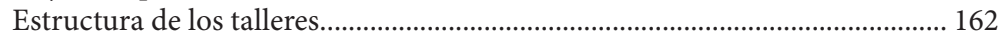

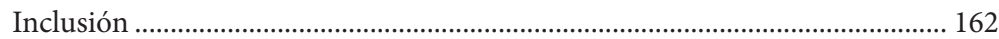

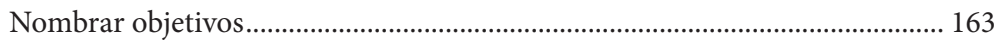

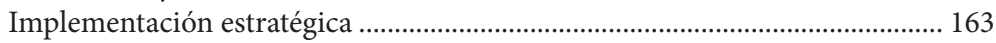

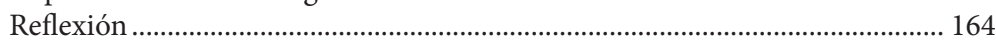

Reconocimiento ............................................................................................. 164

Recolección y archivo de evidencias .................................................................. 164

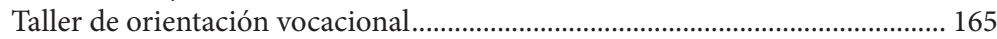

Estructura del taller de orientación vocacional................................................. 165

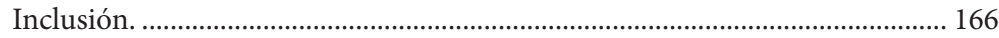

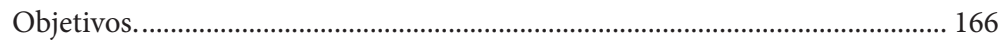

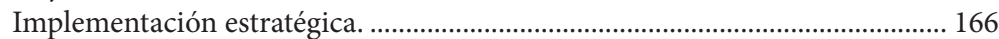

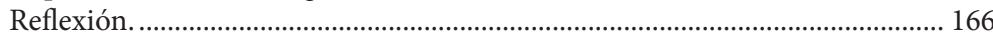

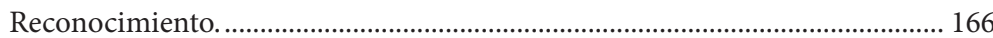

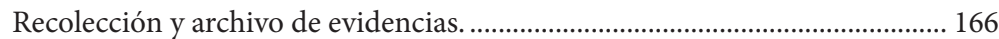

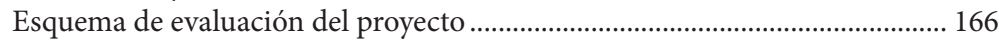

Evaluación de los jóvenes de colegios ................................................................ 169

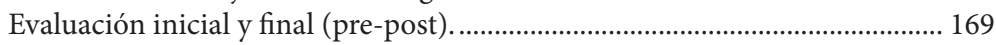

Evaluación del proceso...................................................................................... 172

Evaluación de los jóvenes universitarios facilitadores...................................... 172

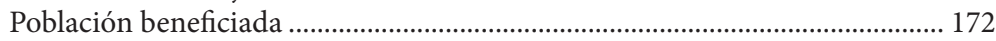

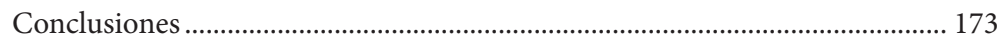

Referencias bibliográficas ............................................................................... 174

Creating Culturally Enriched Environments to Foster English Reading and Writing Habits Among Students in the Bilingual English Teacher

Preparation Program ........................................................................................ 176

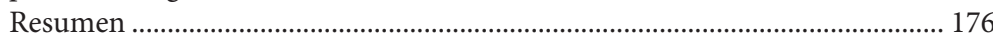

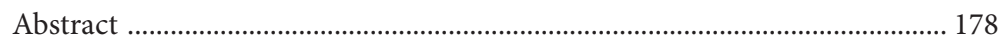

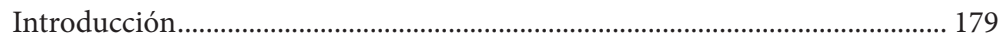

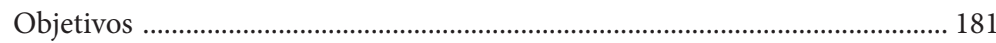

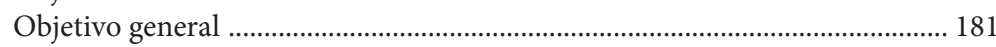

Objetivos específicos ...................................................................................... 181

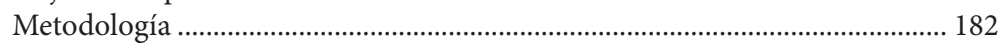

Campaña de concientización del Centro de Escritura Académica................... 182

Preparando el escenario......................................................................................... 182

Unir experiencias de lectura con producciones escritas ................................... 184

Adoptar un enfoque cultural en las sesiones del Centro de Escritura

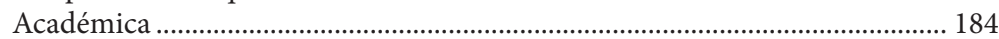

Construir capacidad y sostenibilidad .......................................................... 185

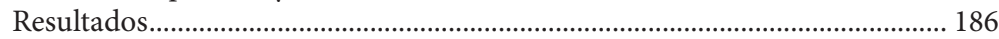

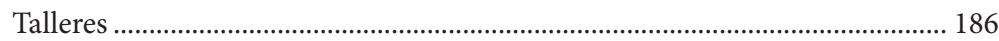

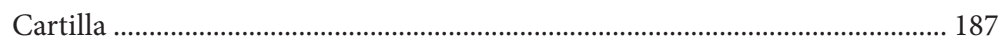

Población beneficiada ................................................................................. 187 


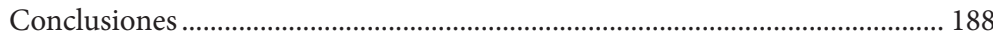

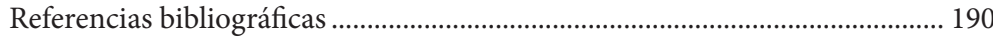

Desarrollo de estrategias de motivación para fomentar la participación de mujeres en carreras de ciencia y tecnología................................................................ 193

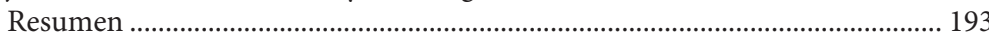

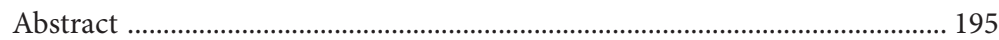

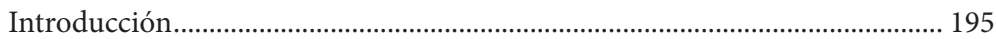

Objetivos ................................................................................................ 197

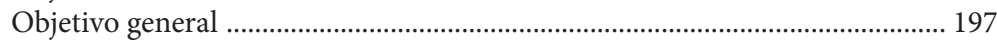

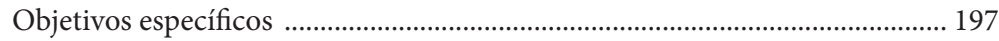

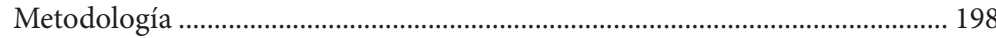

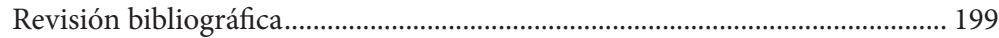

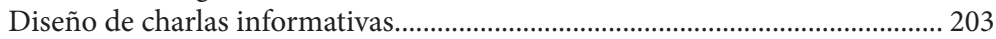

Capacitación y motivación del equipo de trabajo ................................................ 206

Ejecución de la estrategia en colegios ................................................................ 208

Evaluación de la estrategia implementada ..................................................... 211

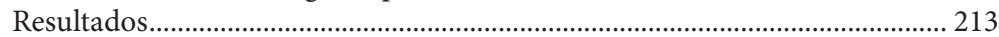

Población beneficiada .................................................................................... 213

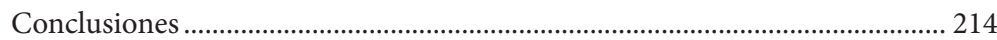

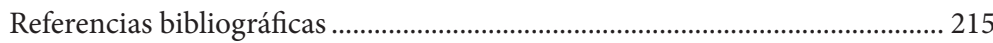

Cartillas para la calidad de vida de los padres y/o cuidadores de pacientes con enfermedad de Hirschsprung o malformaciones anorrectales ............................... 217

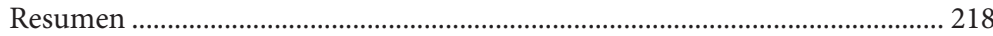

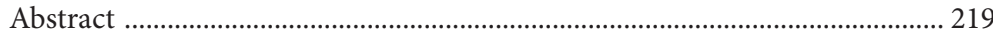

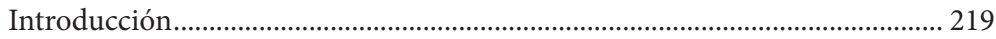

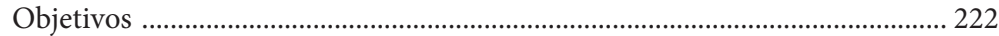

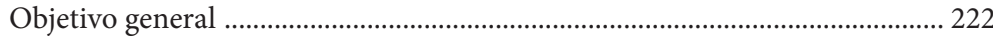

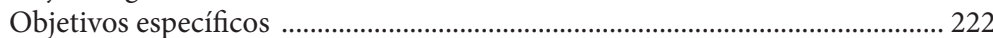

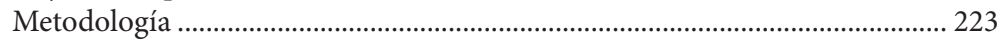

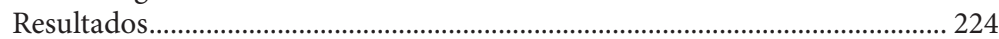

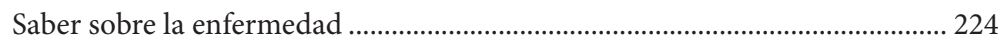

Los cuidados más difíciles .................................................................................... 224

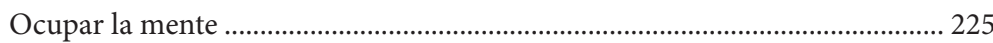

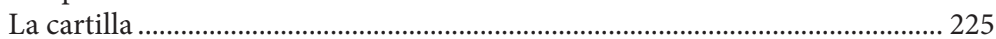

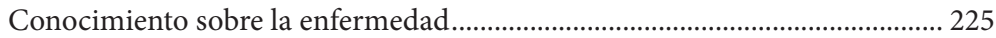

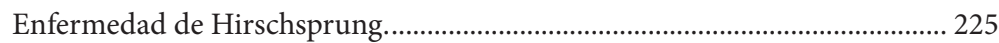

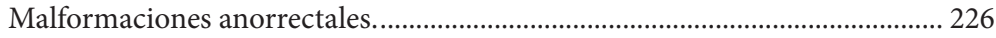

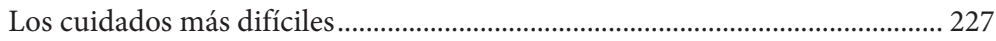

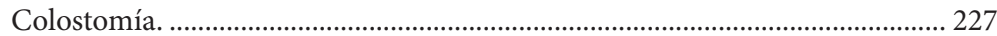

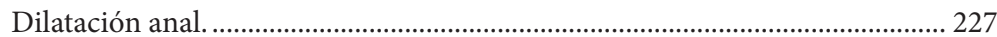

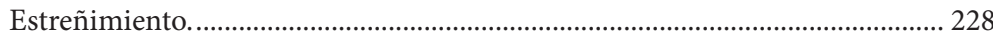

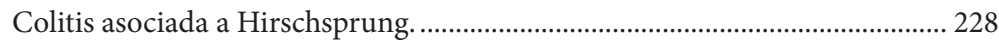

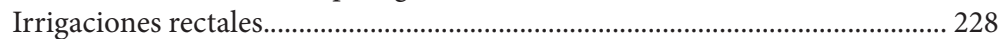

«Estas enfermedades transforman la vida» .......................................................... 228

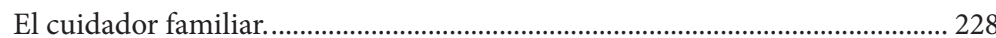

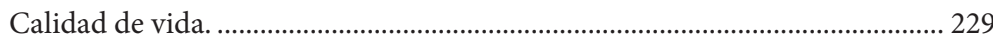




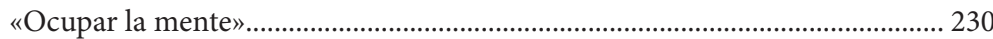

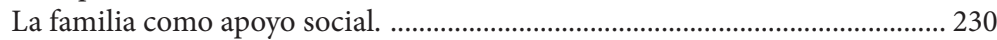

Apoyo social. ................................................................................................... 230

Hacer parte de una red de apoyo social. .......................................................... 230

Practicar el autocuidado. .................................................................................... 231

Promoción de la calidad de vida de padres y cuidadores de niños con eh

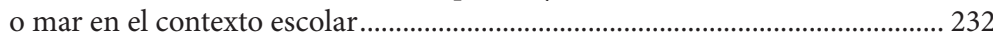

Conocer acerca de los cuidados de la enfermedad del niño............................. 232

Cuidados generales del niño con patologías de colon y recto ............................ 233

Entrenamiento para ir al baño y guía para la escuela ......................................... 233

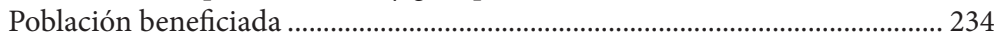

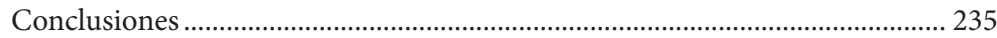

Referencias bibliográficas ............................................................................... 235

La apropiación social del conocimiento de la avifauna en la Institución Educativa

Hugo Ángel Jaramillo como estrategia de educación ambiental............................ 239

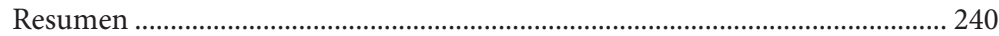

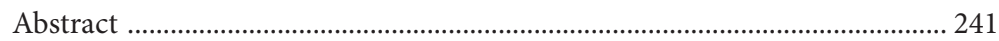

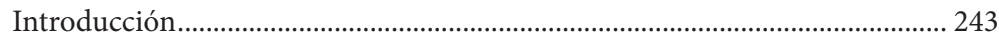

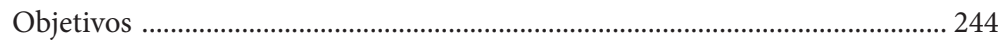

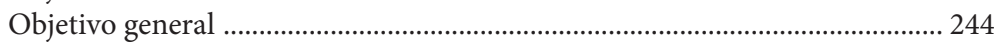

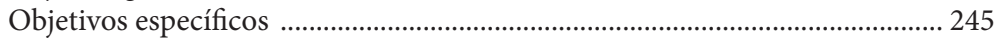

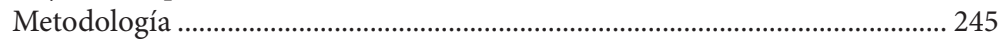

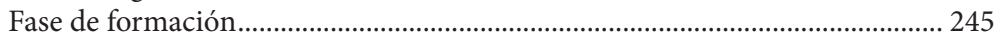

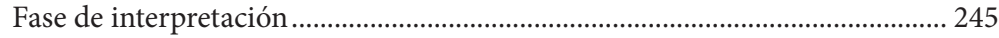

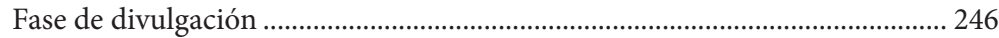

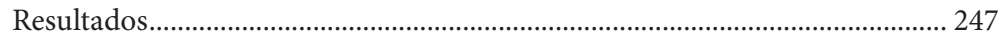

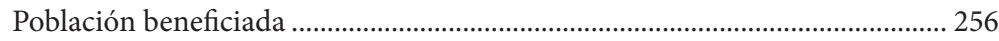

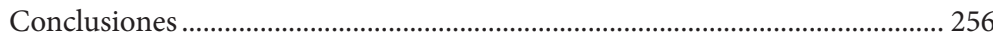

Referencias bibliográficas ............................................................................ 257

Reconstruyendo la historia desde adentro. Una experiencia significativa en la ciudad de Pereira, Risaralda: San Isidro, Puerto Caldas........................................... 259

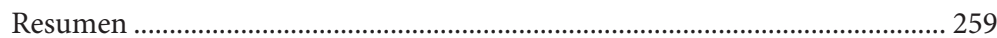

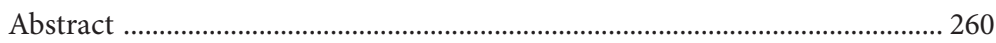

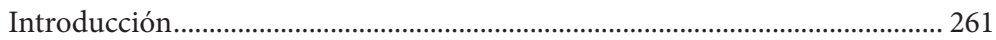

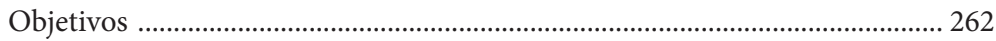

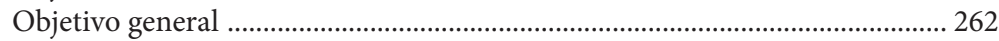

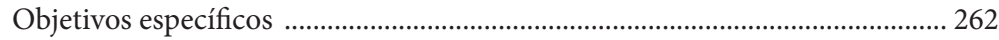

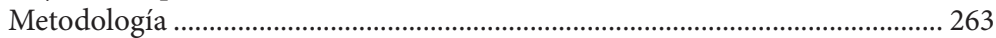

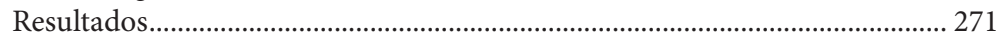

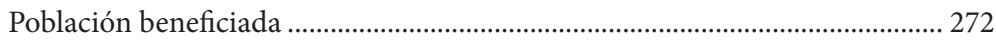

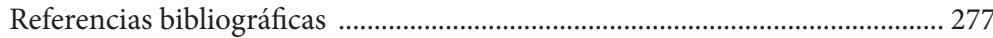




\section{Índice de figuras}

Gestión de una base de datos especializada en derecho deportivo colombiano. Base de datos especializada en normas y jurisprudencia del derecho deportivo en Colombia.

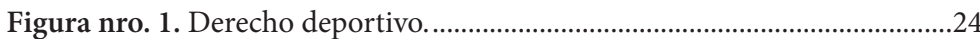

Figura nro. 2. Estadística de consulta de base de datos al 2020 .........................26

Figura nro. 3. Sentencias Corte Constitucional.................................................27

Curso fundamentos de IoT

Figura nro. 1. Póster de la primera vez que fue dictado el curso. .......................36

Figura nro. 2. Presentación inicial de una sesión. ...............................................41

Figura nro. 3. Presentación de la teoría del MQTT. ............................................42

Figura nro. 4. Cajas de implementos para el curso..............................................4

Figura nro. 5. Montaje de Raspberry con DHT11 e higrómetro. ........................44

Implementación y apropiación de un sistema renovable para cubrir demanda energética en sector social vulnerable

Figura nro. 1. Sistema de $1 \mathrm{~kW}$ híbrido ya implementado. ................................53

Figura nro. 2. Ubicación de los electrodomésticos a medir.................................56

Figura nro. 3. Algunas imágenes de los electrodomésticos medidos e

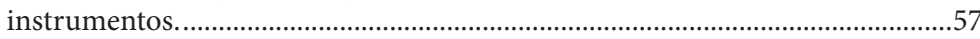

Figura nro. 4. Factura de energía de la fundación. .............................................59

Figura nro. 5. Malas conexiones, fuentes de fugas eléctricas...............................60

Figura nro. 6. Estudiantes de la Facultad de Tecnología realizando

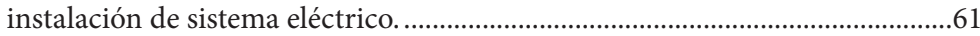

Figura nro. 7. Instalación de línea tierra. ............................................................62

Figura nro. 8. Instalación de microinversor y su esquema de conexión...........63

Figura nro. 9. Montaje de paneles y ficha técnica de uno de ellos.....................64

Figura nro. 10. Tableros de conexión (cargas y protecciones equipos),

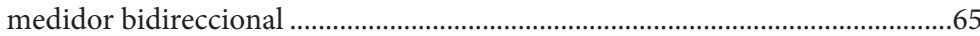

Figura nro. 11. Comunidad Kyrios como parte intergral del proyecto.............67

Astroviernes y los cien años de la Unión Astronómica Internacional

Figura nro.1. Cantidad de visitantes al programa de Astroviernes.

Guapi «aprende haciendo»

Figura nro. 1. Prueba inicial y final realizada a los estudiantes en el curso. . 115

Figura nro. 2. Caratula de la cartilla digitalizada e impresa entregada a los

docentes de Guapi. ........................................................................................... 116

Figura nro. 3. Curso desarrollado con los estudiantes de la Institución

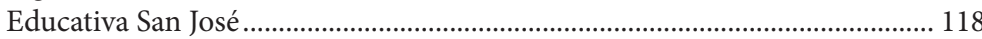

Figura nro. 4. Muestra del proyecto final del curso.......................................... 118

Figura nro. 5. Inicio del Foro Robótica y STEAM en la comunidad y en las aulas de clase 
Creating Culturally Enriched Environments to Foster English Reading and Writing Habits among Students in the Bilingual English Teacher Preparation Program

Figura nro. 1. Club literario.............................................................................. 189

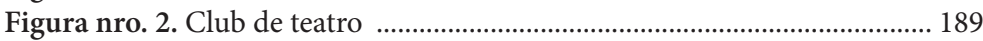

Figura nro. 3. Actividades club de teatro .............................................................. 190

Desarrollo de estrategias de motivación para fomentar la participación de mujeres en carreras de ciencia y tecnología

Figura nro. 1. Estudiantes inscritos en pregrado por género

en la UTP.

Figura nro. 2. Mujeres graduadas en la UTP en ingenierías

(Eléctrica, Electrónica, Física y Sistemas) y mecánica. 200

Figura nro. 3. Mujeres graduadas en la UTP en posgrados

STEM (2002-2019). 201

Figura nro. 4. Porcentaje de graduados a nivel nacional de Ingeniería Eléctrica y afines según género.

Figura nro. 5. Porcentaje de graduados a nivel nacional de Ingeniería Eléctrica y afines según género.

Figura nro. 6. Porcentaje de graduados a nivel nacional de Ingeniería

Mecánica y afines según género.

Figura nro. 7. Creación de folletos informativos para estudiantes

de colegios.

Figura nro. 8. Conversatorio mujeres UTP en la ciencia, Marzo 2019. ........ 206

Figura nro. 9. Foro: Mujeres ingenieras, mujeres que transforman................ 207

Figura nro. 10. Charlas y talleres desarrollados en diversos colegios de la región.

Figura nro. 11. Orientación profesional de estudiantes en colegios

intervenidos.

Cartillas para la calidad de vida de los padres y/o cuidadores de pacientes con enfermedad de Hirschsprung o malformaciones anorrectales

Figura nro. 1. Población beneficiada del proyecto.

La apropiación social del conocimiento de la avifauna en la Institución Educativa Hugo Ângel Jaramillo como estrategia de educación ambiental

Figura nro. 1. Matriz metodológica.

Figura nro. 2. Ilustraciones realizadas por los estudiantes de la Institución

Educativa Hugo Ángel Jaramillo.

Figura nro. 3. Visita de estudiantes de la Institución Educativa Hugo Ángel

Jaramillo al Jardín Botánico de la UTP.

Figura nro. 4. Observación de aves en el Jardín Botánico de la UTP. ............ 250

Figura nro. 5. Exposición de dibujo y pintura en el Jardín Botánico UTP. .. 251

Figura nro. 6. Ponencia oral: apropiación social del conocimiento sobre avifauna como estrategia de educación ambiental en Pereira Risaralda, presentada en el 4.o Congreso Nacional de Ciencias Ambientales.

Figura nro. 7. Portada del folleto ilustrado: «Las aves de mi colegio».......... 253

Figura nro. 8. Proceso de elaboración de mural.............................................. 254 
Figura nro. 9. Mural elaborado en la Institución Educativa Hugo Ángel Jaramillo.

Figura nro. 10. Presentación de video a los estudiantes de la Institución

Educativa.

Figura nro. 11. Entrega de certificados de participación en el proyecto a los estudiantes de la Institución Educativa.

Reconstruyendo la historia desde adentro. Una experiencia significativa en la ciudad de Pereira, Risaralda: San Isidro, Puerto Caldas

Figura nro. 1. Capacitación en técnicas de trabajo comunitario para estudiantes, integrantes de la comunidad y miembros de la Corporación El Comienzo del Arco Iris, en la Universidad Tecnológica de Pereira 265 Figura nro. 2. Técnicas interactivas de investigación social implementadas en el desarrollo del proyecto. 266

Figura nro. 3. Técnicas interactivas de investigación social que permitieron la articulación entre la Investigación Acción Participación y la sistematización de experiencias

Figura nro. 4. Equipo de trabajo de la Universidad Tecnológic de Pereira. 268

Figura nro. 5. Logo elaborado para el material usado en el proyecto 269

Figura nro. 6. Equipo de trabajo conformado por integrantes de la comunidad de San Isidro, de la Corporación El Comienzo del Arco Iris y de la Universidad Tecnológica de Pereira.

Figura nro. 7. Encuentro juvenil. San Isidro-Puerto Caldas.

Figura nro. 8. Encuentro con líderes de la comunidad (San Isidro-Puerto Caldas)

Figura nro. 9. Análisis e interpretación del territorio (San Isidro-Puerto Caldas)

Figura nro. 10. Sistematización de experiencias (San Isidro

Puerto-Caldas)

\section{Índice de tablas}

Gestión de una base de datos especializada en derecho deportivo colombiano. Base de datos especializada en normas y jurisprudencia del derecho deportivo en Colombia.

Tabla nro.1. Estadística de consulta de base de datos.

Implementación y apropiación de un sistema renovable para cubrir demanda energética en sector social vulnerable

Tabla nro. 1. Registro de potencia y energía de cada electrodoméstico en la fundación.

Astroviernes y los cien años de la Unión Astronómica Internacional

Tabla nro. 1. Capacitaciones del equipo de Astroviernes. 
«Sabores de Risaralda: construcción de un inventario intercultural del patrimonio gastronómico de la región»

Tabla nro. 1. Asistentes a los talleres de socialización realizados 101

Curso herramientas para la gestión de la innovación: design thinking (pensamiento de diseño)

Tabla nro. 1. Sesión número uno.

Tabla nro. 2. Sesión número dos.

Construyendo futuro fase 2

Tabla nro. 1. Metodología para el logro de los objetivos.

Tabla nro. 2. Objetivos para cada taller.

Tabla nro. 3. Conceptualización del esquema evaluativo de Construyendo Futuro.

Tabla nro. 4. Autoevaluación de habilidades socio-emocionales 170

Desarrollo de estrategias de motivación para fomentar la participación de mujeres en carreras de ciencia y tecnología

Tabla nro. 1. Instituciones educativas abordadas en el proyecto. 208

Reconstruyendo la historia desde adentro. Una experiencia significativa en la ciudad de Pereira, Risaralda: San Isidro, Puerto Caldas

Tabla nro. 1. Resumen de la metodología del proyecto.

\section{Índice de anexos}

Enseñar a hablar, leer y escribir. Una propuesta para la transformación didáctica de docentes en ejercicio del Eje Cafetero

Anexo nro. 1. Folleto Diplomado en Didáctica 137

Anexo nro. 2. Fotografía: primera sesión de la 3.a cohorte del Diplomado en Didáctica

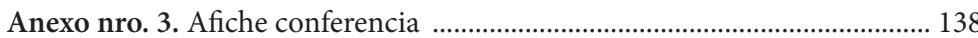

Anexo nro. 4. Afiche Primer Congreso Nacional DIOLEE ............................ 139 



\section{Prólogo}

La Universidad Tecnológica de Pereira (UTP), a través de la Vicerrectoría de Investigaciones Innovación y Extensión, busca promover la extensión universitaria como una estrategia que permite el intercambio, la aplicación y la integración del conocimiento científico, tecnológico, artístico y cultural; al igual que la vinculación con la realidad social, cultural, económica y productiva de la región y del país, al darle valor a las capacidades institucionales y al generar una articulación e integración entre la docencia y la investigación, la cual permita la identificación de problemáticas y la propuesta de alternativas de solución; además de las oportunidades en el sector externo para realizar intervenciones y alianzas que conduzcan a fortalecer y aportar al desarrollo económico, cultural y el bienestar de la comunidad en general.

En este sentido, para el año 2018 se ofertó, a los miembros de la comunidad universitaria, la «Convocatoria interna para la financiación de proyectos de extensión social, cultural y artístico» cuya ejecución se realizaría en el año 2019 y cuyo objetivo era 
fomentar el desarrollo de proyectos de carácter social, cultural, artístico, los cuales permitieran la solución y transformación de problemáticas que involucraran o beneficiaran sectores de diferentes comunidades.

En esta convocatoria fueron financiados catorce proyectos que involucran a diferentes estamentos de la sociedad civil en torno al planteamiento y a la discusión de problemáticas, conflictos y sus posibles soluciones, así como a la identificación de oportunidades de progresos tecnológicos, ambientales, educativos o de creación artística, los cuales involucren o beneficien sectores de diferentes comunidades.

El presente libro busca realizar una descripción general de cada proyecto y conocer los resultados y productos derivados de la ejecución de los mismos; así como su impacto y contribución al mejoramiento y desarrollo de las comunidades atendidas. A continuación, se relacionan los proyectos financiados:

1. Enseñar a hablar, leer y escribir. Una propuesta para la transformación didáctica de docentes en ejercicio del Eje Cafetero.

2. La apropiación social del conocimiento de la avifauna en la Institución Educativa Hugo Ángel Jaramillo como estrategia de educación ambiental.

3. Astroviernes y los cien años de la Unión Astronómica Internacional.

4. Sabores de Risaralda: construcción de un inventario intercultural del patrimonio gastronómico de la región.

5. Gestión de una base de datos especializada en derecho deportivo colombiano. Base de datos especializada en normas y jurisprudencia del derecho deportivo en Colombia.

6. Construyendo futuro fase dos. 
7. Desarrollo de estrategias de motivación para fomentar la participación de mujeres en carreras de ciencia y tecnología.

8. Implementación y apropiación de un sistema renovable para cubrir demanda energética en sector social vulnerable.

9. Guapi «Aprende Haciendo».

10. Reconstruyendo la historia desde adentro. Una Experiencia significativa en la ciudad de Pereira, Risaralda: San Isidro, Puerto Caldas.

11. Curso Fundamentos de IoT.

12. Creating Culturally Enriched Environments to Foster English Reading and Writing Habits Among Students in the Bilingual English Teacher Preparation Program.

13. Curso herramientas para la gestión de la innovación: Design Thinking (pensamiento de diseño).

14. Cartillas para la calidad de vida de los padres y/o cuidadores de pacientes con enfermedad de Hirschsprung o malformaciones anorrectales. 


\title{
Gestión de una base de datos especializada en derecho deportivo colombiano. Base de datos especializada en normas y jurisprudencia del derecho deportivo en Colombia
}

\author{
ROBERTo MiLlán GaViria \\ ÁNGELA JASMÍN Gómez HINCAPIÉ \\ Universidad Tecnológica de Pereira
}

Resumen

Esta base de datos, la cual administra el grupo de investigación, es la única herramienta que compila e indexa la normativa relacionada con el derecho del deporte en Colombia.

Derecho deportivo colombiano es una base de datos especializada, compilada en un aplicativo de consulta y disponible para su indagación abierta en una página web. 
Está compuesta por las normas constitucionales, legales, «...Decretos, Resoluciones, Jurisprudencia y Procedimientos que competen al ámbito deportivo en la República de Colombia, indexados de forma dinámica, permitiendo relacionar términos y conceptos con un contenido particular» (Universidad Tecnológica de Pereira [UTP], Grupo de Investigación en Gerencia Deportiva [GIGEDE], s.f.).

Este aplicativo es una herramienta necesaria e indispensable para el desarrollo de la asignatura de «Legislación Deportiva» del programa de pregrado «Ciencias del Deporte y la Recreación» en el módulo del mismo nombre.

Los objetivos de dicha asignatura y las habilidades que se buscan desarrollar a través de ella requieren de la consulta permanente del aplicativo, toda vez que requieren acudir a las fuentes del derecho para sustentar y apoyar decisiones y conceptos.

La razón de ser de estas Tecnologías de la Información y la Comunicación (TIC) es que los usuarios tengan la plena garantía de su permanente actualización y evolución de sus contenidos, para ofrecer la información más completa y relevante con una funcionalidad intuitiva y sencilla.

Es una base de datos especializada disponible para toda la comunidad académica, científica y deportiva del país, alojada en una página web de libre uso y consulta.

Palabras clave: derecho, deportivo, colombiano, normas, jurisprudencia.

\section{Abstract}

This database managed by the research group is the only tool that collects and indexes the regulations related to sports law in Colombia. 
Colombian Sports Law is a specialized database, compiled in a query application and available for open consultation on a web page.

It is composed of constitutional, legal, decrees, resolutions, jurisprudence and procedures that procedures that concern the sports field the sports field in the Republic of Colombia, dynamically indexed, allowing the linking of terms and concepts with a particular content.

This application is a necessary and indispensable tool for the development of the "Sports Legislation" subject of the undergraduate program "Sports and Recreation Sciences" in the sports legislative module.

The objectives of the subject and the skills they seek to develop through it, require the permanent consultation of the application, each time they have to go to the sources of law to support and uphold decisions and concepts.

The reason of the existence of these tools (ICT) is that its users have the full guarantee of their permanent updating and evolution of their contents, seeking to offer the most complete and relevant information hands in hand with intuitive and simple functionality.

It is a specialized database available to the entire academic, scientific and sports community of the country, hosted on a web page, free to use and consult.

Keywords: Sport law Colombian Rules, Jurisprudence.

\section{Introducción}

El grupo de investigación Cultura de la Salud (línea GIGEDE), en sus proyectos investigativos, detectó que una de las causas del 
bajo nivel de la gestión deportiva en el país era el desconocimiento del marco jurídico regulador del Sistema Nacional del Deporte.

Dentro de las acciones correctivas se determinó ampliar el módulo de legislación en el currículo de pregrado y posgrado, al igual que diseñar y ofrecer capacitaciones a este grupo de interés (seminarios, cursos y congresos) ${ }^{1}$.

Como complemento a estas acciones se formuló y ejecutó el proyecto denominado «Base de datos especializada en derecho deportivo colombiano», el cual constituye una herramienta indispensable para el cumplimiento los objetivos de las asignaturas de pregrado y posgrado. Así mismo, se ha convertido en material de consulta para la dirigencia deportiva y los funcionarios de entidades públicas del Sistema Nacional del Deporte en Colombia.

El proyecto nació en el año 2010 y ha sido objeto de varias actualizaciones y versiones, las cuales han aumentado su contenido y han garantizado la actualización permanente de su información.

Estas se encuentran alojadas en la página web de acceso libre www.derechodeportivocolombiano.com.co.

Esta base de datos contiene las normas de carácter constitucional, legal y administrativas, tales como decretos, resoluciones y circulares externas relacionadas con el deporte, la recreación, la actividad física y el aprovechamiento del tiempo libre en Colombia.

Durante el año 2019 fue consultada 73227 veces, con un promedio de 6102 consultas mensuales y 203 al día. El mes de noviembre tuvo su periodo más alto de consulta con 10361 . Cifras contundentes que evidencian la penetración y confianza generada por el producto dentro del grupo de interés al cual va destinado.

1 El grupo de investigación dentro de sus productos de extensión ofrece: el Congreso Nacional de Gerencia Deportiva, el Congreso Nacional de Derecho Deportivo, el Seminario de los Derechos de los Niños en el Proceso de Formación Deportiva y cursos de gestión para dirigentes deportivos. 


\section{Objetivos}

\section{Objetivo general}

Ofrecer a la comunidad académica una base de datos especializada en el derecho del deporte en Colombia, permanentemente actualizada, con índices normativos y temáticos de alta confiabilidad y permanente consulta.

\section{Objetivos específicos}

Garantizar la existencia del portal de consulta de toda la comunidad académica relacionada con el Sistema Nacional de Deporte en Colombia.

Asegurar la calidad de la información que se descargue de la base de datos, en cuanto a su contenido y vigencia.

Consolidar el único producto que contiene una base de datos especializada en derecho del deporte en Colombia, el cual sea de acceso libre y gratuito.

\section{Metodología}

La base de datos se construyó a partir de la selección del material a incluir, para garantizar el contenido integral de todo el marco jurídico del derecho deportivo colombiano y dar como resultado doce módulos así:

- Normas constitucionales.

- Leyes.

- Decretos.

- Resoluciones. 
- Circulares externas.

- Sentencias Corte Constitucional.

- Sentencias Consejo de Estado.

- Sentencias Corte Suprema de Justicia.

- Índice temático.

- Índice normativo.

- Procedimientos.

- Módulo de descarga para consulta fuera de línea.

Con un trabajo de consulta - de las fuentes primariassobre la producción normativa en Colombia, especialmente en el Congreso, en las Altas Cortes, en la Imprenta Nacional, en la Presidencia de la República y en los Ministerios de Educación y Deporte se seleccionan todas las normas vigentes y las sentencias con mayor relevancia en la actualidad. Se organiza y sistematiza toda la información, para luego indexar todos los temas contenidos dela base de datos y dar como resultado 3869 temáticas organizadas alfabéticamente, con un link que direcciona a la norma respectiva.

Así mismo, se elaboraron flujogramas con los procedimientos administrativos de inspección, vigilancia y control, y con los procesos disciplinarios de primera y segunda instancia con el fin de facilitar la comprensión de estos. 
Figura NRO. 1. Derecho deportivo.

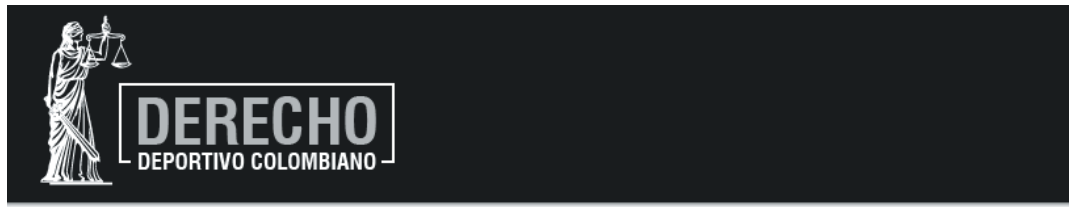

Derecho Deportivo Colombiano es un compendio integral de las Leyes, Decretos, Resoluciones, Jurisprudencia y Procedimientos que competen al ámbito deportivo en la República de Colombia, indexados de forma dinámica, permitiendo relacionar términos y conceptos con un contenido particular.
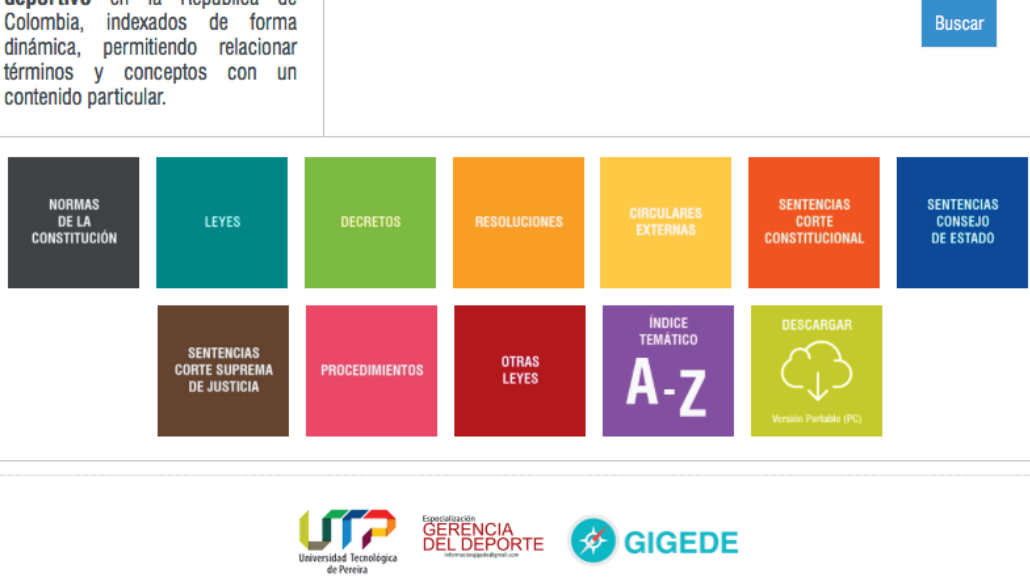

도 2010 - 2019 | Términos y condiciones | Contáctenos

Tomada de Universidad Tecnológica de Pereira [UTP], Grupo de Investigación Gerencia Deportiva [GIGEDE] (s.f.).

\section{Resultados}

- Una base de datos indexada y permanentemente actualizada mensualmente- que contiene toda la normativa y jurisprudencia del deporte, la recreación, la actividad física y el aprovechamiento del tiempo libre en Colombia.

- La base de datos está alojada en la web. Su consulta, utilización y descarga es gratuita. 
- La base de datos permite una descarga integral para ser utilizada en aquellos sitios de difícil conexión a la web.

- La base de datos es utilizada permanentemente por los alumnos de los programas académicos de pregrado y posgrado de todas las universidades del país.

- La página web que aloja la base de datos tiene un módulo de estadística. Este permite llevar el registro de las consultas diarias.

- Durante el año 2019 fue consultada 73227 veces, con un promedio de 6102 consultas mensuales y 201 consultas al día.

TABLA NRO. 1. Estadística de consulta de base de datos.

\begin{tabular}{|lll|}
\hline \multicolumn{3}{|c|}{ Estadística de consulta base de datos } \\
\hline \multicolumn{3}{|c|}{ www.derechodeportivocolombiano.com.co } \\
\hline Mes & Consultas & Promedio diario \\
\hline Enero & 3500 & 113 \\
\hline Febrero & 4360 & 156 \\
\hline Marzo & 5295 & 171 \\
\hline Abril & 5707 & 190 \\
\hline Mayo & 4581 & 148 \\
\hline Junio & 4548 & 152 \\
\hline Julio & 5473 & 177 \\
\hline Agosto & 9294 & 300 \\
\hline Septiembre & 8350 & 278 \\
\hline Octubre & 7364 & 238 \\
\hline Noviembre & 10361 & 345 \\
\hline Diciembre & 4394 & 142 \\
\hline Total 2019 & 73227 & 201 \\
\hline
\end{tabular}

Elaboración propia. 
El mes de noviembre tuvo su periodo más alto de consulta con 10 361. Esta cifra es una evidencia contundente sobre la penetración y confianza que genera el producto dentro del grupo de interés al cual va destinado.

La base de datos tiene los siguientes elementos a la fecha:

- 35 leyes sobre deporte vigentes al 31 de diciembre de 2019.

- 44 decretos reglamentarios vigentes.

- 25 resoluciones expedidas por el Ministerio del Deporte.

- 7 circulares externas de la Superintendencia de Sociedades.

- 40 sentencias del Consejo de Estado.

- 9 sentencias de la Corte Suprema de Justicia.

- 3 flujogramas con procedimientos.

- 14 leyes de otros sectores respecto a normas relacionadas con el deporte.

- 3869 títulos del índice temático.

FigurA NRO. 2. Estadística de consulta de base de datos al 2020

\section{DERECHO DEPORTIVO COLOMBIANO}

Registro de número de usuarios por años www.derechodeportivocolombiano.com.co
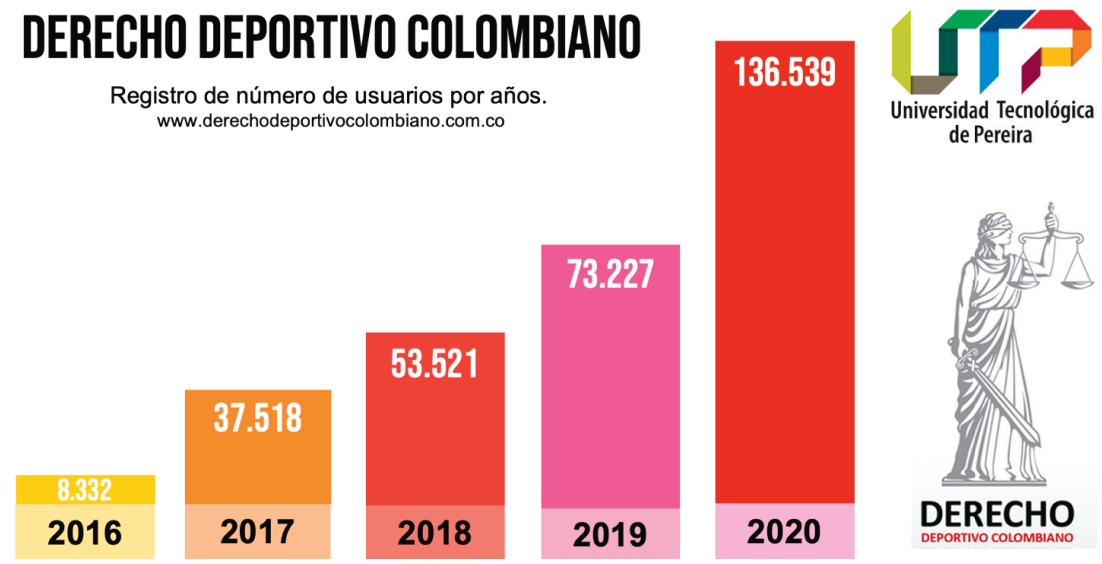
de Pereira

Elaboración propia. 
Figura NRo. 3. Sentencias Corte Constitucional.

\section{$\equiv \quad$ Sentencias Corte Constitucional}

Contenidos indexados: 73

\begin{tabular}{|c|}
\hline 001.- C-005/93 \\
\hline $\begin{array}{l}\text { Derecho a la recreación vS Deber de } \\
\text { protección a los menores }\end{array}$ \\
\hline 004.- C-099/96 \\
\hline $\begin{array}{l}\text { Demanda a la ley } 049 \text { de } 1993 \text { Disciplina } \\
\text { deportiva, inspección, control y } \\
\text { vigilancia. }\end{array}$ \\
\hline 007.- C-320/97 \\
\hline $\begin{array}{l}\text { Dignidad humana y los derechos } \\
\text { deportivos en Colombia. }\end{array}$ \\
\hline 010.- C-713/98 \\
\hline $\begin{array}{l}\text { Democratización de la propiedad de los } \\
\text { clubes deportivos. }\end{array}$ \\
\hline 013.- C-325/00 \\
\hline $\begin{array}{l}\text { Trabajo infantil como limitación para el } \\
\text { ejercicio del derecho al deporte y la } \\
\text { recreación. }\end{array}$ \\
\hline 016.- C-758/02 \\
\hline $\begin{array}{l}\text { Suspensión de los dirigentes deportivos } \\
\text { por apertura de investigación en su } \\
\text { contra. }\end{array}$ \\
\hline
\end{tabular}

\begin{tabular}{|c|}
\hline 002.- C-296/95 \\
\hline $\begin{array}{l}\text { Monopolio de las armas por el estado, } \\
\text { Clubes de Tiro y Caza, armas deportivas. }\end{array}$ \\
\hline 005.- C-625/96 \\
\hline $\begin{array}{l}\text { Conversión de las Juntas } \\
\text { Administradoras locales a entes } \\
\text { deportivos departamentales. }\end{array}$ \\
\hline 008.- C-581/97 \\
\hline $\begin{array}{l}\text { Ley que ordena la construcción de un } \\
\text { escenario deportivo. }\end{array}$ \\
\hline 011.- C-032/99 \\
\hline $\begin{array}{l}\text { Demanda contra el Articulo } 89 \text { de la Ley } \\
181 \text { de } 1995 .\end{array}$ \\
\hline 014.- C-802/00 \\
\hline $\begin{array}{l}\text { Restricciones del orden territorial para la } \\
\text { conformación de ligas deportivas } \\
\text { departamentales. }\end{array}$ \\
\hline 017.- C-449/03 \\
\hline $\begin{array}{l}\text { La recreación como un derecho } \\
\text { fundamental por conexidad. }\end{array}$ \\
\hline
\end{tabular}

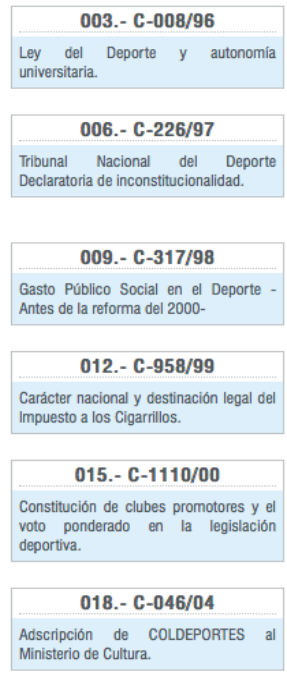

Elaboración propia.

\section{Población beneficiada}

- Estudiantes de pregrado y posgrado, los cuales hacen parte de los programas relacionados con deporte y educación física en Colombia.

- Docentes del área del deporte y la educación física de todos los niveles educativos.

- Investigadores del área del deporte y la educación física en Colombia.

- Dirigentes deportivos de clubes, ligas y federaciones de Colombia.

- Servidores públicos de los niveles municipal, departamental y nacional. 
En total fueron 73227 usuarios de la base de datos en el año 2019.

\section{Conclusiones}

- Elaboración y publicación de la base de datos en una página web de libre acceso y consulta.

- Revisión y actualización mensual de la base de datos para garantizar su vigencia.

- Utilización permanente de la base de datos por parte de alumnos en niveles de pregrado y posgrado, y dirigentes deportivos.

- Reconocimiento nacional del grupo de investigación y la universidad debido al producto.

\section{Bibliografía}

Congreso de la República de Colombia y Secretaría General del Senado. (s.f.). Leyes de la República. http:// www.secretariasenado.gov.co/index.php/leyes-de-larepublica.

Consejo de Estado de Colombia. (s.f.). Relatoría del Consejo de Estado. http://relatoria.consejodeestado.gov.co.

Corte Constitucional de Colombia. (2019). Relatoría. https:// www.corteconstitucional.gov.co/relatoria/.

Corte Suprema de Justicia. (s.f.). Consulta jurisprudencia. http://consultajurisprudencial.ramajudicial.gov.co:8080/ WebRelatoria/csj/index.xhtml.

Imprenta Nacional de Colombia. (s.f.). Diario oficial. http:// svrpubindc.imprenta.gov.co/diario/. 
Ministerio de Educación Nacional. (s.f.). Normograma. https://www.mineducacion.gov.co/portal/Normatividad/.

Ministerio de Justicia. (s.f.). Sistema único de información normativa (SuinJuriscol). http://www.suin-juriscol.gov.co.

Ministerio del Deporte de Colombia. Inspección, control y vigilancia. Normatividad. https://www.mindeporte.gov.co/ index.php?idcategoria $=1170$.

Universidad Tecnológica de Pereira [UTP], Grupo de Investigación en Gerencia Deportiva [GIGEDE]. (s.f.). Derecho deportivo colombiano. http://www. derechodeportivocolombiano.com.co/. 


\title{
Curso Fundamentos de IoT
}

\author{
Carlos Alberto Ocampo Sepúlveda \\ Carlos Arturo Moreno Tabares \\ FELIPE GUTIÉRREZ ISAZA \\ Universidad Tecnológica de Pereira
}

\section{Resumen}

El medio ambiente está rodeado de información, la cual puede ser capturada por medio de diferentes herramientas. A medida que avanza la tecnología, se hace más común que los dispositivos electrónicos cuenten con algún medio de conexión para transmitir información extraída del medio y para almacenarla con la finalidad de un uso posterior, a fin de realizar un análisis o desencadenamiento de acciones, entre otros asuntos. Un conjunto de dispositivos, los cuales hacen parte de un mismo sistema en el cual se generan datos del mismo tipo sobre el espacio que los rodea y que luego los envían a un área común de almacenamiento, para luego desencadenar diferentes acciones basadas en decisiones resultado de análisis de los datos tomados, se define como 
Internet de las cosas (IoT). Para tener una idea de lo que se trata, se introduce al participante en una fundamentación teórica y se hace énfasis en elementos principales como: generación de datos, transmisión de datos y análisis de datos.

Con el objetivo de facilitar la comprensión del IoT, se da uso del dispositivo electrónico «Raspberry $\mathrm{Pi}$ » $\mathrm{u}$ ordenador de placa reducida (SBC), el cual puede obtener datos del ambiente a través de sensores que se le conecten y representar la activación de sistemas de control mediante el encendido LED, debido a que tiene las características de un computador que utiliza el protocolo de comunicación MQTT para la transmisión de datos generados por los sensores y el uso de un servicio de almacenamiento temporal como lo es Adafruit que permite llevar a cabo un análisis de datos a un nivel "sencillo»; así, el medio por donde recibe los datos es el protocolo de comunicación MQTT. Las implementaciones requieren elaborarse en la Raspberry por medio de programación. Este dispositivo soporta varios lenguajes de este proceso entre los cuales existe uno con una curva de aprendizaje alta y de rápida implementación como lo es Python. Dicho lenguaje es apto tanto para quienes ya conocen la programación como para los que no, sin embargo, el conocimiento previo de este facilita el proceso de aprendizaje.

Finalmente, para afianzar el conocimiento adquirido, se elaboran actividades donde se dispone de diversos retos, los cuales implican el uso de las herramientas dadas en la fundamentación teórica como el control de un jardín, de forma tal que solo se aplican riegos cuando el jardín lo requiera; todo ello al generar el proyecto "Sistema de riego inteligente»y al incluir un sistema de estimación de actividad, el cual permita elaborar un mapa de actividad del sitio (mapa de calor). Con esta guía se pretende poner a prueba los conocimientos adquiridos para comprender y/o hacerse una idea de lo que es el IoT, bien sea por el lado empresarial, de investigación o de ambos. Este se hace cada vez más común gracias al avance tecnológico y a la aplicación de 
la estrategia «divide y vencerás» en un sistema que se requiere control y recolección de datos.

Palabras clave: Internet of Things, Raspberry Pi, Adafruit, MQTT, análisis de datos.

\begin{abstract}
The environment is surrounded with data, these can be get by electronic devices, observation, tools among others. as technology evolves it becomes more common that electronic device has something for establish connection and send data to be storage for later use in analysis, activate triggers, etc. A set of devices that are part of the same system where generate the same kind of data, each device generate data in the area where this are placed and these data are sent by each one through ethernet connection to a same storage device, this known as Internet of Things (IoT). In order to get an idea of what this subject is all about, it introduces to its theoretical foundation, emphasizing in these principal element such as creation and collection of data, data transmission and data analysis.
\end{abstract}

To facilitate understanding of the IoT is used an electronic device Raspberry $\mathrm{Pi}$, this is a single board computer, this can get data from environment through connected sensors that this have and also can represent the activation or deactivation of others systems through turning on or off a LED, Raspberry Pi can send data gotten from sensors through communication protocol MQTT to any other system that are configured with this protocol, for storage data are used a service of Adafruit this can temporary storage data which allows data analysis to be carried out at a "simple" level and this receive data through MQTT protocol. Implementations on Raspberry Pi require the use of a programing language, this device support several programming languages, between those have python, this programming language has a high learning curve and is fast coding, this is suitable both for those 
who know and those don't know about programming, however, prior knowledge makes the learning process easier.

Finally, in order to refine the acquired knowledge, a series of activities are executed, these have a several challenges where imply the use of tools learned previously on the theoretical foundation, activities such as the control of a garden, as well as activate the irrigation system only when the plants require increase their soil moisture, project being "Smart Garden" and a system for activity estimation which allows a site activity map to be drawn up (heat map). The learning strategy of this guide is test acquired knowledge understand and/or get an idea about what IoT is, either on the business side, the research side or both, the presence of IoT becomes more common due to technological progress and the application of technique «divide and conquer» in systems that requires control and data gathering.

Keywords: Internet of Things, Raspberry Pi, Adafruit, MQTT, Data analysis.

\section{Introducción}

El Internet de las cosas (IoT) es una arquitectura que está siendo cada vez más común. La necesidad de realizar estudios sobre algunos comportamientos, algunas actividades $\mathrm{u}$ otros elementos es creciente, sin embargo, uno de los problemas que se tienen para realizar estos análisis es que la adquisición de datos puede ser un proceso robusto, complejo y costoso. El avance de la tecnología, en especial del IoT, hace posible que existan dispositivos pequeños los cuales pueden obtener datos del medio que los rodea para lograr transmitir, por algún medio de comunicación y unir varios dispositivos de bajo consumo en un sistema específico. Los datos para el análisis también pueden ser obtenidos por medio de dispositivos de uso común, los cuales generan información que cuenta con conexión a Internet como lavadoras, neveras, autos, entre otras. 
Para comprender qué es el IoT, además del fundamento teórico, se llevan a cabo unas actividades que requieren del uso de múltiples dispositivos pequeños, luego se da uso de transmisión de datos, por medio de un protocolo de comunicación y un servicio de almacenamiento de los mismos para llevar a cabo el análisis; todo ello para lograr un mejor entendimiento del Internet de las cosas.

\section{Objetivos}

\section{Objetivo general}

Capacitar a estudiantes y egresados en fundamentos del IoT que les permita desarrollar habilidades en el diseño, la programación y el despliegue usando Raspberry Pi.

\section{Objetivos específicos}

Convocar a estudiantes y egresados de programas de ingenierías de la Universidad Tecnológica de Pereira, con el fin de capacitarlos en el uso de tecnologías asociadas al IoT.

Desarrollar un curso introductorio en el uso de Internet de las cosas, con el fin de establecer un lenguaje común y conocer los componentes fundamentales de esta tecnología.

Implementar laboratorios prácticos, como parte del curso Fundamentos de IoT, para afianzar en los estudiantes las habilidades concebidas en el desarrollo de este.

Evaluar el contenido impartido, el desempeño de los profesores y el impacto en los participantes. 


\section{Metodología}

- Elaborar la estructura de un curso de cuarenta horas, en el cual se enseñe lo requerido para el entendimiento de la tecnología IoT.

Una forma para enseñar alguna temática es por medio de un curso que, para ser dictado, primero requiere formar su propia estructura. En este se determina el contenido y el orden de los temas para que el conocimiento de las temáticas sea bien transmitido, el contenido del curso se basa en los elementos de los cuales se dispone, entre esos está la Raspberry Pi, sensores, leds y un laboratorio con monitores y computadores.

- Elaborar y repartir publicidad sobre el curso de fundamentos Internet de las cosas.

Un curso para cumplir con su propósito requiere tener integrantes, para ello se dan a conocer sus fechas y horarios a través de publicidad, la cual se da por medio físico - con pósters- y virtual -difusión de correos electrónicos a la comunidad de la UTP_, con el fin de permitir que cada uno de los cursos dictados tenga estudiantes. El siguiente póster (FIgURA NRO. 1) fue uno de los distribuidos. 
Figura Nro. 1. Póster de la primera vez que fue dictado el curso.

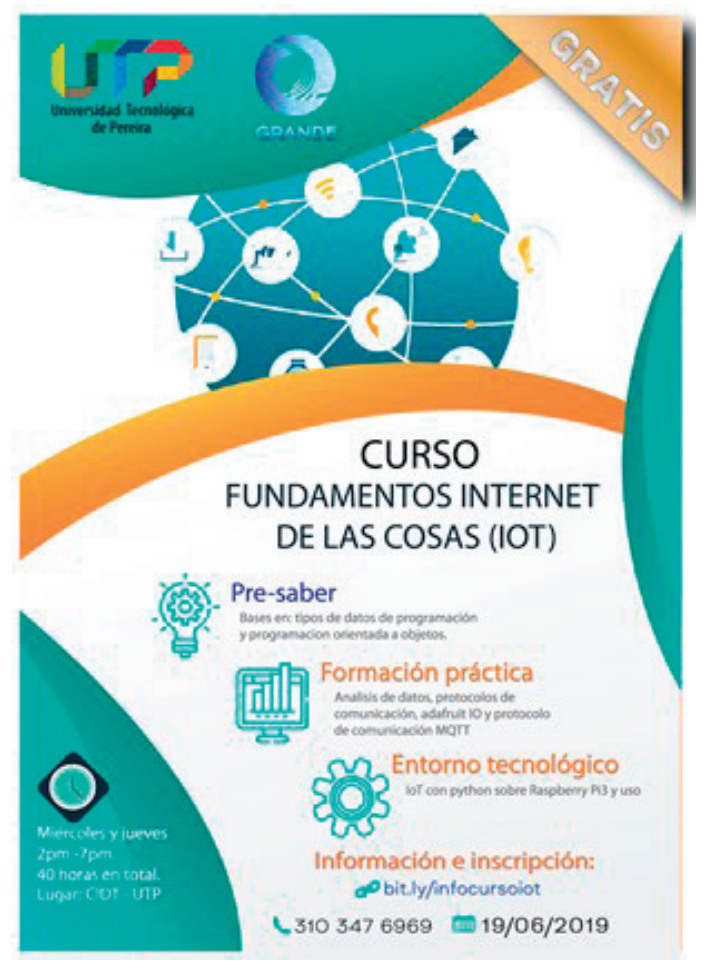

Elaboración propia.

- Redactar y compartir sobre el fundamento teórico de Internet de las cosas.

La fundamentación teórica y los conceptos de la temática se requieren para comprender de qué trata el Internet de las cosas y entender cuando un dispositivo hace parte de este sistema. Junto con esta información, las redes físicas y lógicas más comunes en IoT (medios de transmisión de datos), así como The Things Network [14], MQTT [8] y algunos servicios para el almacenamiento de datos como Adafruit [4], son para realizar análisis «simple».

- Diseñar y orientar clases de programación básica con Python. 
La programación es necesaria para obtener datos de la Raspberry Pi y tratarlos, por lo cual una de las primeras sesiones son conceptos y sintaxis básica de programación se hace en un lenguaje fácil de aprender como Python [9].

- Diseñar y orientar clases de programación orientada a objetos.

La programación orientada a objetos es un paradigma muy utilizado en varios de los módulos de Python para la Raspberry en la extracción de datos de los sensores y al utilizar protocolos o comunicar servicios; por esto, primero es requerido saber sobre dicho paradigma, antes de ver implementaciones o ejemplos en Python [7].

- Elaborar una guía ilustrativa y detallada sobre la instalación del sistema operativo Raspbian.

La Raspberry Pi es un mini computador, por lo cual puede instalarse software en él. Entre esos, un sistema operativo como lo es el Raspbian, al ser el más común para utilizar en estos aparatos [10], facilita el uso de dispositivos electrónicos que se conectan a la Raspberry. Así, la guía ilustrativa indica el proceso necesario y pertinente sobre lo que se debe hacer cuando se tiene una Raspberry nueva, sin embargo, es solo con fines de mostrar el proceso que se requiere realizar a aquel elemento, en caso de contar con una propia.

- Diseñar y orientar clases sobre cómo utilizar los diferentes elementos de la Raspberry.

En la Raspberry dispone de una serie de pines que permiten la elaboración de circuitos, estos a su vez admiten el funcionamiento de dispositivos electrónicos como sensores, los cuales son utilizados por un proceso en el sistema operativo, dado a que hay una gran cantidad de ellos. Por tal motivo, solo se da la explicación sobre el uso de los pines a manera general de entrada y salida (GPIO) [1], se enfatiza en sensores como el higrómetro, 
el DHT11, el ultrasónico, el PIR y el Linear Magnetic de efecto hall; y se brinda la configuración para usarlos con pines GPIO y protocolos [11].

- Diseñar y orientar clases sobre el uso de publicación y suscripción del protocolo de comunicación MQTT con lenguaje Python.

El Internet de las cosas dispone de diferentes medios y técnicas para transmitir información, uno de esos es el MQTT. De este protocolo se requiere conocer su funcionamiento esencial - sin entrar en detalles-; pues este cuenta con implementaciones en distintos lenguajes [2]. El que se explicará detalladamente a nivel de código fuente es Python [6].

- Redactar y compartir acerca de Adafruit (servicio de almacenamiento temporal especializado para IoT) que facilite realizar un análisis de datos y otros servicios similares.

Una de las actividades más importantes que se efectúa a un conjunto de datos es el análisis, por lo que existen una serie de servicios diseñados para esta labor. Unos son muy útiles solo para generar prototipos a una escala pequeña (menos de diez fuentes de datos) y otros están hechos para proyectos a gran escala (más de mil fuentes de datos). De esta manera, algunos solo serán nombrados y se entrará en detalle en un servicio considerado simple, el cual puede manejar protocolos como MQTT y cuenta con módulos soportados con Python. Ese servicio es Adafruit [4], el cual es básico, sencillo y contiene lo necesario para comprender la necesidad de almacenamiento y así llevar a cabo un proceso sobre análisis de datos.

- Diseñar y orientar clases sobre cómo realizar envío de información al servicio de Adafruit para que este lo almacene. Como visualizarla y cómo utilizarla con Python.

Adafruit recibe información por medio del protocolo MQTT a través de una estructura, sin embargo, cuenta con su 
propia librería para enviar información, puesto que todo puede implementarse con lenguaje Python [13]. Ahora bien, en la plataforma web de Adafruit se cuenta con las herramientas necesarias para ilustrar los datos almacenados en gráficas y con una serie de botones, los cuales permiten interactuar en el sistema [12] y brindar facilidades para crear otro estilo de proyectos que apliquen para el IoT.

- Diseñar y orientar clases donde se elaboren proyectos que utilicen tecnologías y técnicas del IoT.

Para recapitular y reforzar todo el conocimiento compartido se plantean proyectos que pueden abordarse con Internet de las cosas [5]. En ellos se comparte el estado del arte del proyecto y se delimita el alcance para que se pueda elaborar una parte de un prototipo funcional a pequeña escala (usando una sola fuente de datos), además de instruir sobre cómo utilizar los sensores requeridos para cada proyecto.

Uno es un proyecto de un jardín «inteligente», en el cual se toman datos de un jardín, de un área controlada como un invernadero [3] y, a razón de este, se activan los sistemas de control. El otro es «detección de actividad en un centro comercial» donde, por medio de sensores de detección de movimiento, se estima la actividad del lugar.

\section{Resultados}

Para enseñar sobre el Internet de las cosas se diseñó un curso de cuarenta horas, el cual se estructuró por medio de investigaciones en esta área y la Raspberry Pi [10]; y se basó en el libro "Intelligent IoT Projects in 7 Days» [5]. Se tomaron algunos de esos proyectos y se describieron los conocimientos previos y los materiales requeridos, además se realizó una serie de modificaciones y adecuaciones para hacer dichos proyectos más «sencillos» (utilizando lenguaje Python, estructura sencilla) y 
alcanzables (para realizar en seis horas). El curso se dictó un total de tres veces donde se formaron a setenta personas. Las fechas y horarios en que fueron dictados fueron:

- Curso 1: del 19 de junio de 2019 al 12 de julio de 2019.

Miércoles y jueves de 14:00 a 19:00.

- Curso 2: del 23 de julio de 2019 al 15 de agosto de 2019. Martes y jueves de 14:00 a 19:00.

- Curso 3: del 01 de octubre de 2019 al 31 de octubre de 2019. Martes, miércoles y jueves de 18:00 a 21:30.

En cada sesión se presentaban los patrocinadores del curso que eran el Centro de Innovación y Desarrollo Tecnológico (CIDT), la Vicerrectoría de Investigación de la Universidad Tecnológica de Pereira, también se exhibía al Grupo de Avanzada en Desarrollo de Software (GRANDE) como creador del curso. En cada sesión se indicaba el estado de la clase donde se decían, de forma resumida, los aspectos más importantes de las sesiones anteriores, luego se indicaba el contenido resumido de dicha sesión y se procedía a orientar. La Figura NRO. 2 es de la presentación de una de las sesiones donde se muestran los implicados y patrocinadores del curso. 
FiguRA NRO. 2. Presentación inicial de una sesión.

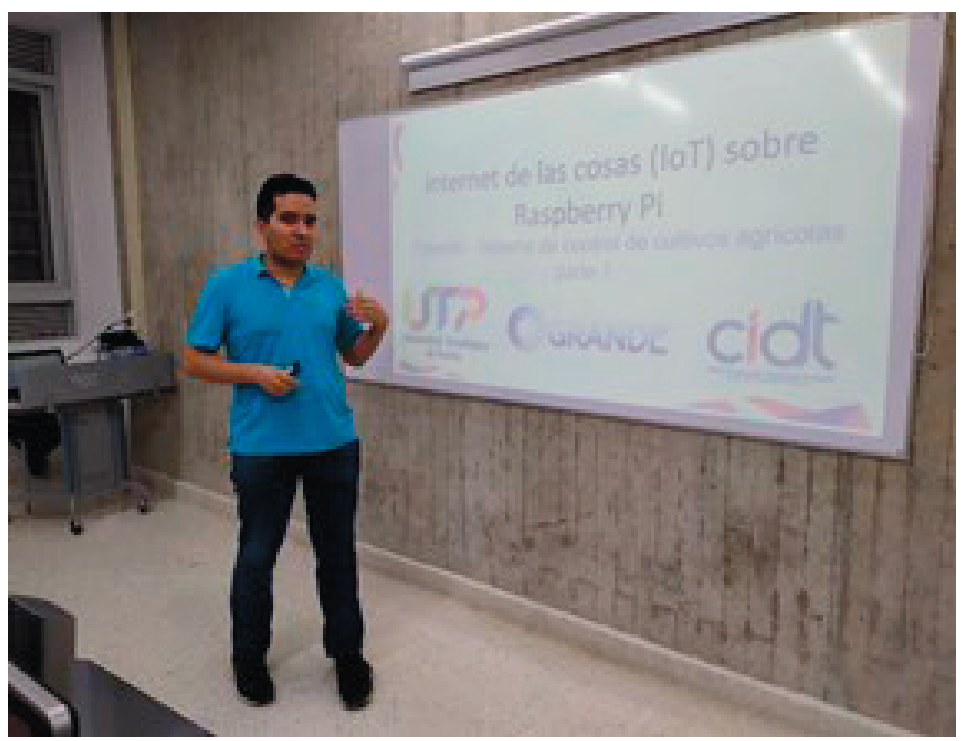

Elaboración propia.

Todas las veces que fue dictado el curso, en cada una de las sesiones, se hizo con la siguiente estructura:

- Fundamentación teórica.

- Contexto de caso cercano a la realidad del ejemplo a explicar.

- Explicación del ejemplo.

- Desarrollo de una actividad.

Cada sesión del curso está diseñada para cinco horas, sin embargo, también se tiene adaptada para tres horas; en cada una de ellas se sigue la estructura indicada anteriormente, no obstante, a medida que se avanza en el curso, aumentan las actividades a realizar. La FIgURA NRO. 3 corresponde a la sesión de MQTT donde se dicta la parte teórica. 
Figura NRO. 3. Presentación de la teoría del MQTT.

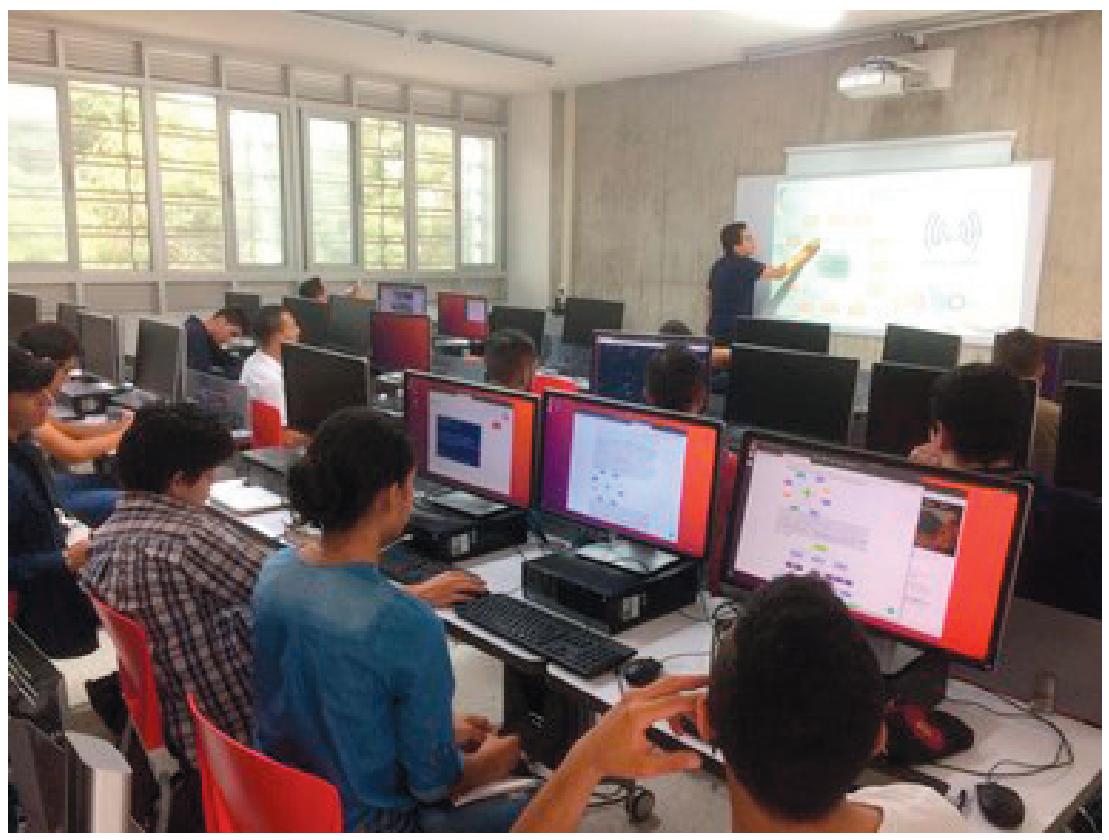

Elaboración propia.

Las sesiones para orientar los cursos requieren de un espacio físico como un salón. Por tal motivo, al CIDT se le solicitó un espacio para orientar los cursos. Uno de los sitios a disposición era la sala multipropósito $15 \mathrm{D}-403$, la cual contaba con treinta y dos equipos de cómputo, situación que facilitaba el uso de las Raspberry, el desarrollo de programación en Python y la elaboración de las implementaciones. En algunas sesiones se dio uso de la Raspberry Pi y se elaboraron circuitos gracias a algunos implementos prestados por el programa de Ingeniería de Sistemas y Computación, otros por el laboratorio Smart Grids del CIDT y otros (la mayoría de sensores, cables para protoboard, extensiones, cables HDMI entre otros) comprados con los recursos obtenidos del proyecto; además de unas cajas para facilitar su almacenamiento. La Figura NRo. 4 muestra el espacio donde se almacenaban las cajas con los implementos utilizados en el curso. 
Figura NRO. 4. Cajas de implementos para el curso.

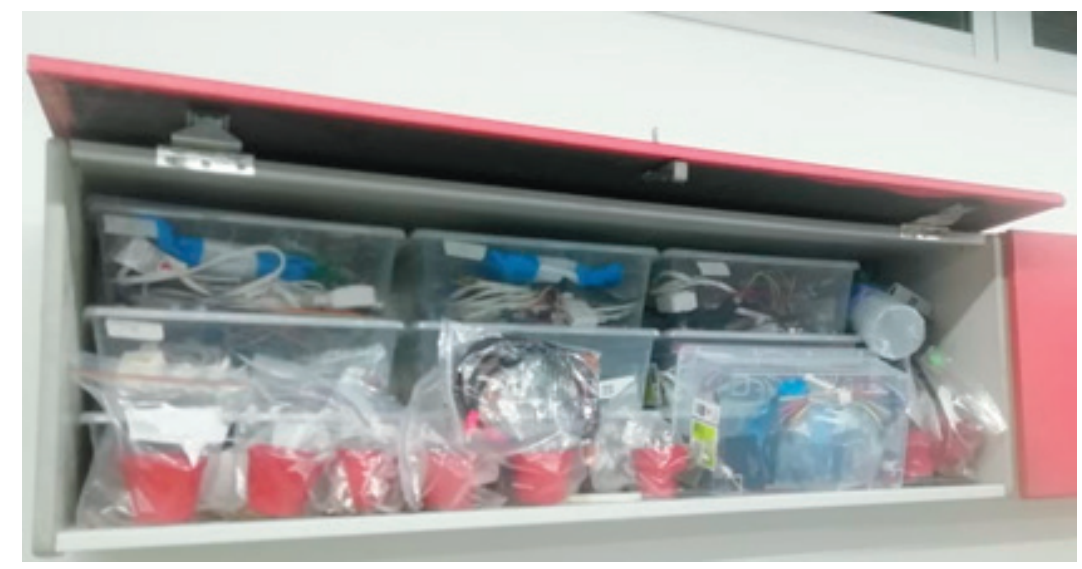

Elaboración propia.

Para que los estudiantes pudieran obtener su certificado de asistencia, se les indicó que debían asistir a un $80 \%$ del curso, por lo cual se aplicó un control de asistencia donde firmaron al inicio y al final de cada sesión para así contabilizar las horas de asistencia. Las actividades planteadas fueron para que los alumnos las resolvieran en la misma sesión. La finalidad de estas era para que con los temas vistos de la sesión y de las sesiones anteriores se generaran preguntas al respecto y, de esta forma, mejoraran el aprendizaje adquirido; sin embargo, en cada actividad del curso se apoya la elaboración de estos. La Figura NRO. 5 muestra una Raspberry montada por un equipo al probar los sensores higrómetro y DHT11. 
FigURA NRO. 5. Montaje de Raspberry con DHT11 e higrómetro.

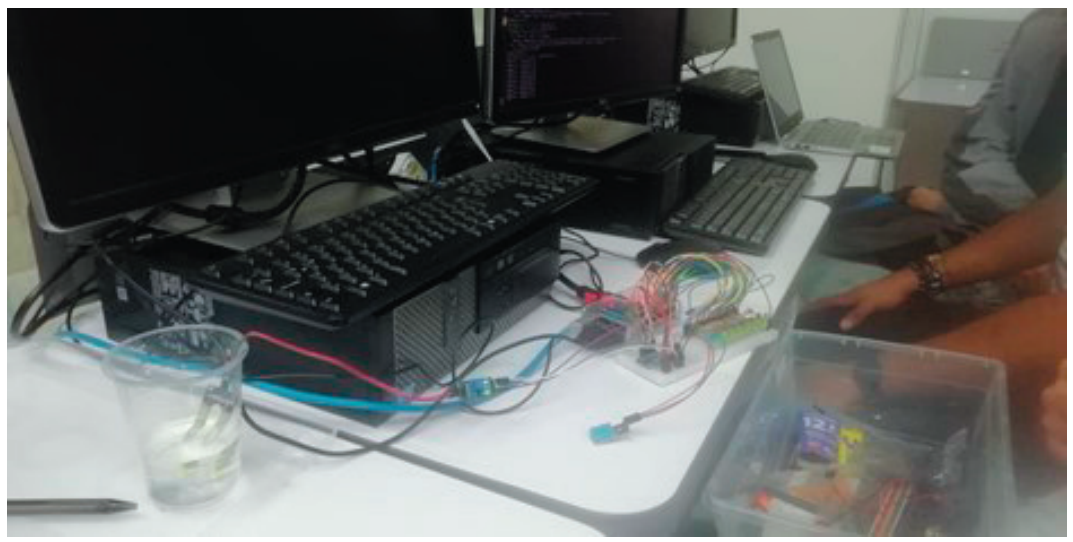

Elaboración propia.

Las sesiones que corresponden al desarrollo de los proyectos ponen a prueba el conocimiento adquirido en el curso. En ellas se acompaña el proceso de elaboración donde se enseñan técnicas de programación avanzadas y se retroalimenta el conocimiento entre estudiantes y el tutor del curso. A medida que las clases eran diseñadas y luego dictadas, se elaboró una cartilla con el contenido de todo el curso, los capítulos de esta fueron dados en el mismo orden de los temas tratados, donde el contenido fue detallado e instructivo. Así, a base de ella se puede replicar dicho curso, dado que la misma se elaboró para el cumplimiento de los productos esperados y se lograron un total de ciento cuarenta páginas con guías paso a paso de instalación del Raspbian, librerías, el uso de Adafruit, además de una guía minuciosa de cómo desarrollar las actividades y los proyectos elaborados.

\section{Población beneficiada}

Este curso está orientado para estudiantes de Ingeniería de Sistemas, este se enfoca más al ámbito investigativo (compartir información) que a formar para el desarrollo de implementaciones. Como ya se indicó, la Raspberry es un dispositivo que facilita la 
comprensión de las temáticas, sin embargo, en los tres cursos no solo hubo estudiantes de la ingeniería nombrada, también hubo estudiantes de otras carreras, empresarios, tutores; específicamente el público que se tuvo fue:

- Estudiantes de Ingeniería de Sistemas de la UTP.

- Estudiantes de Mecatrónica de la UTP.

- Estudiantes de Ingeniería Eléctrica de la UTP.

- Estudiantes de Tecnología Eléctrica de la UTP.

- Estudiantes de Ingeniería Industrial de la UTP.

- Instructores del Servicio Nacional de Aprendizaje (SENA).

- Estudiantes del SENA.

- Docentes de la UTP,

- Estudiantes de maestría de la Universidad Autónoma de Cali.

- Empresarios.

\section{Conclusiones}

El Internet de las cosas es una arquitectura que, para aplicarla, requiere conocimientos sobre programación, electrónica y análisis de datos. Esto hace que sea de gran interés, donde el contenido variado atrae a personas con diferentes intereses. La forma en la cual fue diseñado el curso facilita que los asistentes puedan aprender sobre la Raspberry, un protocolo de comunicación y electrónica; con el cual adquieren competencias para elaborar implementaciones de IoT.

El curso puede apoyar el conocimiento que se adquiere en diferentes carreras como electrónica, mecatrónica, sistemas y 
computación; el contenido dictado relacionaba algún aspecto de los proyectos realizados en sus carreras, es decir, este curso como materia de los programas mencionados es un buen complemento. El uso de implementos físicos, como es en este caso la Raspberry, motiva a los estudiantes en el proceso de aprendizaje y más cuando es algo que puede utilizarse de manera «sencilla», por ejemplo, al domotizar en el hogar.

Un problema del curso es que requiere de implementos costosos para una sola persona, además pueden ser muy variados, así como son los laboratorios en electrónica; para poder implementarlo con treinta personas, se forman grupos de tres individuos con un máximo de diez grupos para dividir los implementos. Si se utilizan los mismos utensilios del curso dictado en este proyecto, cada equipo de trabajo tendría un costo aproximado de cuatrocientos mil pesos, por ende, diez veces sumaría un costo total de cuatro millones de pesos. Se debe tener presente que los presaberes de este curso son de varias temáticas, es decir, para plantearlo como parte de una materia de una carrera es ideal para el final de esta.

\section{Referencias bibliográficas}

[1] Croston, B. (2014). GPIO-Raspberry Pi Documentation [online]. Raspberrypi.org. Available at: https://www. raspberrypi.org/documentation/usage/gpio/ [Accessed 19 Oct. 2019].

[2] Eclipse Foundation. (2016). Paho-MQTT and MQTT-SN software [online]. Available at: https://www.eclipse.org/paho/ [Accessed 19 Oct. 2019].

[3] Ecología Hoy. (2018). Agricultura-¿Qué es? Historia y tipos de agricultura [online]. Available at: https://www.ecologiahoy. com/agricultura [Accessed 19 Oct. 2019]. 
[4] Adafruit. (2019). The Internet of Things for the Easiest Way to Stream, log, and Interact with Your Data [online]. Available at: https://io.adafruit.com/ [Accessed 19 Oct. 2019].

[5] Kurniawan, A. (2017). Intelligent IoT Projects in 7 Days: Build Exciting Projects Using Smart Devices.

[6] Light, R. (2018). Paho-mqtt 1.5.1. [online]. PyPI. Available at: https://pypi.org/project/paho-mqtt/ [Accessed 19 Oct. 2019].

[7] Lutz, M. (2010). Programming Python: Powerful ObjectOriented Programming «O’Reilly Media, Inc».

[8] Mетт. (2019). Documentation MQTT [online]. Available at: http://mqtt.org/documentation [Accessed 19 Oct. 2019].

[9] Python. (2019). Python for Beginners [online]. Available at: https://www.python.org/about/gettingstarted/ [Accessed 19 Oct. 2019].

[10] RASPBERRYPI. (2019). Raspberrypi.org [online]. Available at: https://www.raspberrypi.org/ [Accessed 19 Oct. 2019].

[11] RasPi.TV. (2016). RPi.GPIO basics 5-Setting up and Using Outputs with RPi.GPIO [online]. Available at: https://raspi. tv/2013/rpi-gpio-basics-5-setting-up-and-using-outputswith-rpi-gpio [Accessed 19 Oct. 2019].

[12] Rubell, B. (2018). Python Code [online]. Adafruit Learning System. Available at: https://learn.adafruit.com/adafruit-iohouse-lights-and-temperature/python-code [Accessed 19 Oct. 2019].

[13] Rubell, B. (2018). Adafruit IO Python [online] Available at: https://adafruit-io-python-client.readthedocs.io/en/latest/ [Accessed 19 Oct. 2019]. 
[14] The Things Network. (2019). Construyendo una red LoRaWAN abierta global [online]. Available at: https://www. thethingsnetwork.org/ [Accessed 19 Oct. 2019]. 


\title{
Implementación y apropiación de un sistema renovable para cubrir demanda energética en sector social vulnerable ${ }^{2}$
}

\author{
Edgar Alonso Salazar Marín \\ SANTIAGO GómEZ ESTRADA \\ Universidad Tecnológica de Pereira
}

\section{Resumen}

El proyecto consistió en la instalación de un sistema solar fotovoltaico de $2 \mathrm{~kW}$, pico para suplir demanda energética de la Fundación Kyrios. Los ahorros energéticos provocados permitieron reducir gastos en dicho espacio, el cual carece de algún apoyo gubernamental. Así, el proyecto involucró a los integrantes a través de capacitaciones en eficiencia energética y buen uso del sistema. Además, permitió brindar experiencia a los estudiantes,

2 Este proyecto hace parte de una reescritura del informe final presentado a la «Convocatoria interna para la financiación de proyectos de extensión social, cultural y artístico» por E. A. Salazar Marín [10]. 
de los programas en Tecnología Eléctrica y Tecnología Mecánica, y en los cursos de Taller Eléctrico y Energías Renovables, quienes participaron en la reinstalación de nuevos circuitos eléctricos de la casa e implementación del sistema.

El impacto social además del ambiental se ve reflejado en el siguiente vídeo:_https://www.youtube.com/ watch? $\mathrm{v}=$ HbeyI2nABDA.

Palabras clave: energía renovable, impacto social, población vulnerable, viviendas ecosostenibles.

\begin{abstract}
The project consisted of the installation of a $2 \mathrm{~kW}$ peak photovoltaic solar system to supply energy demand from the Kyrios foundation. The energy savings allowed costs reducing of the foundation, which lacks some government support. This project involves the members of the foundation through training in energy efficiency and good use of the system. The project allowed providing experience to students of the Electrical Technology and Mechanical Technology programs in the Electrical Workshop and Renewable Energies courses, who participated in the reinstallation of new electrical circuits in the house and implementation of the system.
\end{abstract}

The social impact and environmental impact is reflected in the video: https:/www.youtube.com/watch?v=HbeyI2nABDA.

Keywords: Renewable Energy, Vulnerable Population, Ecosustainable Housing.

\title{
Introducción
}

La UTP ha realizado un esfuerzo por estar en sintonía con tendencias internacionales en cuanto a eficiencia energética y dar 
así más razones a su reconocimiento como universidad verde, según indicadores nacionales e internacionales. Evidencia de ello es la instalación del $600 \mathrm{kVA}$ de paneles fotovoltaicos sobre diferentes techos de este espacio universitario, paneles térmicos para el calentamiento del agua de piscinas, sistema de $20 \mathrm{~kW}$ híbrido del vivero y diversas aplicaciones puntuales con fuentes renovables de energía. El proyecto de extensión busca incrementar este tipo de planes con un alto impacto y beneficio social. La Fundación Kyrios es un centro de restauración de personas víctimas de diversas problemáticas sociales (desplazamiento, drogadicción, abandono, maltrato infantil, entre otros). Actualmente el establecimiento cuenta con 70 personas, principalmente madres cabeza de hogar y niños.

Con esta propuesta se ha implementado un sistema de 2 kWp de energía fotovoltaica con una proyección energética de $240 \mathrm{kWh} / \mathrm{mes}$ que les permitirá ahorros importantes debido a reducción energética mensual. Además de esta implementación, se realizó una reinstalación de todo el circuito eléctrico del lugar, para así mejorar la eficiencia y reducir las fugas eléctricas ocasionadas previamente por malas conexiones. Asimismo, se efectuaron jornadas de sensibilización en eficiencia ambiental, uso racional de la energía y buen manejo de los equipos para garantizar sostenibilidad del sistema.

\section{Objetivos}

\section{Objetivo general}

Implementar un modelo de sostenibilidad energética, en un contexto social vulnerable, con la instalación adecuada de un sistema renovable de $2 \mathrm{kWp}$ y la sensibilización (formación) en uso racional de energía y cambio climático. 


\section{Objetivos específicos}

Caracterizar energéticamente toda la instalación eléctrica, equipos y electrodomésticos de la Fundación Kyrios.

Instalar y adecuar un sistema óptimo de generación fotovoltaica que supla $240 \mathrm{kWh} /$ mes de energía.

Mejorar las acometidas eléctricas de la vivienda principal de la fundación para optimizar la reducción en la demanda energética.

Establecer un programa de formación-sensibilización a la comunidad para apropiar con sentido de pertenencia esta tecnología y cambiar sus hábitos ineficientes de consumo.

Desarrollar una cartilla sobre el modelo implementado para que sirva de guía a la comunidad y pueda ser replicado a otras comunidades de contexto similar y a la sociedad en general.

\section{Metodología}

Para el logro de los objetivos propuestos fue necesario ejecutar las siguientes actividades:

- Inicialmente se efectuó un diagnóstico exhaustivo de las causas que generan los altos niveles de consumo en la Fundación. Para ello se efectuaron mediciones, en las cuales se cuantificó la potencia y energía que demanda cada uno de los equipos y electrodomésticos instalados y se discriminó el componente, la potencia consumida, las horas de funcionamiento, la energía diaria y las posibles causas del alto consumo. Las mediciones se efectuaron de manera análoga y con verificación discreta, a partir de sensores que estudiantes del Semillero de Investigación en Energías Renovables han desarrollado. Esto permitió la detección de señales transitorias en encendido de motores eléctricos, de compresor en neveras y motores en lavadoras. Dichas señales representan los mayores 
porcentajes en el consumo total energético. El diagnóstico implica la revisión y medición termográfica, tensiones y corrientes parásitas en toda la red eléctrica de la vivienda.

- Una vez obtenido el diagnóstico completo de las causas de alto consumo, se efectuó la corrección de la instalación al cambiar el cableado (según norma del Reglamento Técnico de Instalaciones Eléctricas [RETIE]); al modificar nuevos tomas, interruptores y protecciones en tablero principal; y al realizar los empalmes, aterrizaje y aislamiento correctos. Se sugirió, para ciertos componentes y equipos - si fuera posible-, cambios por equipos de mejores condiciones, bombillería incandescente por bombillos led y optimización del uso de lavadoras y neveras en mejores condiciones que las demás. En esta etapa de instalación de acometida eléctrica, participaron activamente estudiantes y profesores de la Tecnología Eléctrica al aprovechar la interdisciplinariedad que ofrece la Facultad de Tecnología.

- Paralelo al mejoramiento de la acometida eléctrica, se instaló el sistema fotovoltaico de $1 \mathrm{~kW}$ y se amplió la cobertura actual que tiene un sistema ya implementado también de $1 \mathrm{~kW}$ (ver Figura NRO. 1).

Figura nRo. 1. Sistema de $1 \mathrm{~kW}$ híbrido ya implementado.

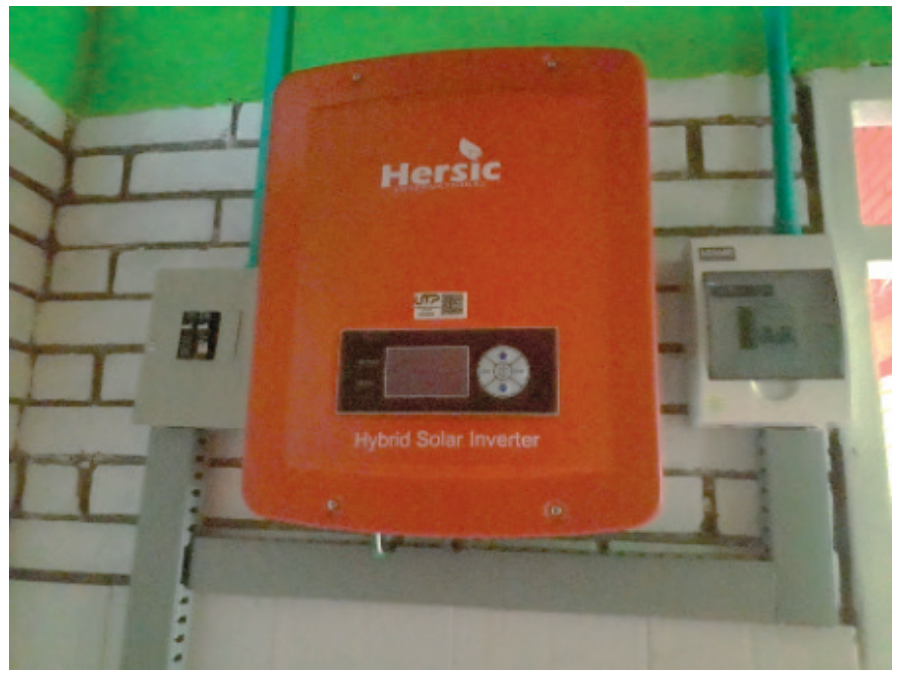




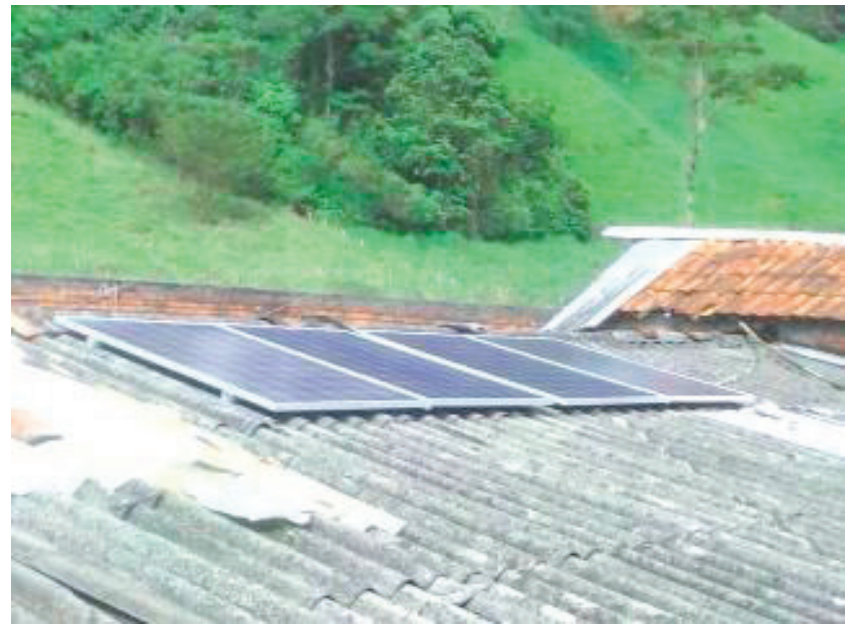

Elaboración propia.

- Se contaba con 4 paneles de $260 \mathrm{Wp}$ que serían ampliados a 4 adicionales similares para establecer un sistema de 2.08 kWp. Dicho sistema adicional se encontraba conformado por 1 microinversor de $1200 \mathrm{~W}$ cada uno, los cuales trabajarían sincronizadamente con el sistema híbrido ya incorporado. Esta situación configuraría dos sistemas paralelos de $1 \mathrm{kWp}$ cada uno e inyectarían a red un banco de baterías de 2400 Wh. En síntesis, el sistema fue principalmente on-grid (con inyección a red) con un pequeño soporte de almacenamiento, el cual fue empleado para alimentar toda la iluminación led en la noche como carga off-grid. El procedimiento estuvo monitoreado (tiempo real) desde la UTP para tener visualización y atención continua con el desempeño del sistema. Se efectuaron análisis de la energía demandada, la entregada a red y el consumo neto para verificar los balances económicos y los impactos ambientales representados.

- Con el sistema incorporado y adecuaciones eléctricas óptimas, se implementó un programa de formación y sensibilización conformado por ocho sesiones en las que se formó en uso racional de la energía, energía solar, sistemas fotovoltaicos y, en particular, en el implementado, los cuidados sobre el sistema, el mantenimiento y las buenas prácticas de consumo energético. Esta capacitación fue acompañada de un folleto, además del 
manual de operación del sistema. La experiencia fue consignada en un informe que, junto con un folleto de formación, podrá ser replicable en cualquier contexto social de similares características.

\section{Resultados}

Con el cumplimiento de los objetivos planteados, dentro de los resultados obtenidos se registran los siguientes:

- Un análisis del consumo energético de la fundación como punto de partida para medición del impacto del sistema a implementar.

- Cambio del cableado eléctrico y de diferentes componentes bajo la norma del RETIE, para garantizar la reducción de pérdidas energéticas y minimizar riesgos de incendios por cortocircuitos y posibles peligros a las personas (principalmente niños).

- Sistema de generación renovable conformado por dos tipos de tecnologías de inyección a red:

1. Inversor híbrido de $\mathbf{1} \mathbf{~ k W}$ (interconectado a red y con almacenamiento de baterías de $50 \mathrm{Ah}-48 \mathrm{Vdc}$ ) y 4 paneles de 290 Wp cada uno.

2. Microinversor de $1 \mathrm{~kW}$ conectado con 4 paneles de $320 \mathrm{Wp}$ cada uno.

- Montaje y adecuación de un medidor bidireccional que permite la medición de energía de consumo de red y la entregada a red por generación solar.

- Un cambio de percepción hacia un consumo energético más responsable mediante capacitación y sensibilización de las personas que habitan la fundación.

- Un modelo de investigación tecnológica con impacto social, el cual puede replicarse en cualquier contexto de condiciones semejantemente desfavorables. 
A continuación, se registran algunas evidencias de estos resultados:

\section{Análisis del consumo energético}

Para este objetivo se emplearon equipos de medición portátil que definen variables: potencia (W), energía (Wh), tensión de red $(\mathrm{V})$ y corriente $(\mathrm{A})$. Para la determinación del consumo global de la fundación, se seleccionaron los electrodomésticos estimados como de mayor consumo. Así, el plano de la Figura NRO. 2 presenta la distribución de habitaciones de aquel espacio y la ubicación de los electrodomésticos principales. Las fotos de la Figura NRO. 3 muestran algunos de los equipos seleccionados y el respectivo dispositivo de medición. Los cálculos se efectuaron al dejar los equipos conectados durante un mes, todo ello para establecer un consumo de "tipo" mensual; sin desconocer que pueden existir meses de mayor o menor consumo. La TABLA NRO. 1 presenta una síntesis de los consumos medidos:

FigURA NRO. 2. Ubicación de los electrodomésticos a medir.
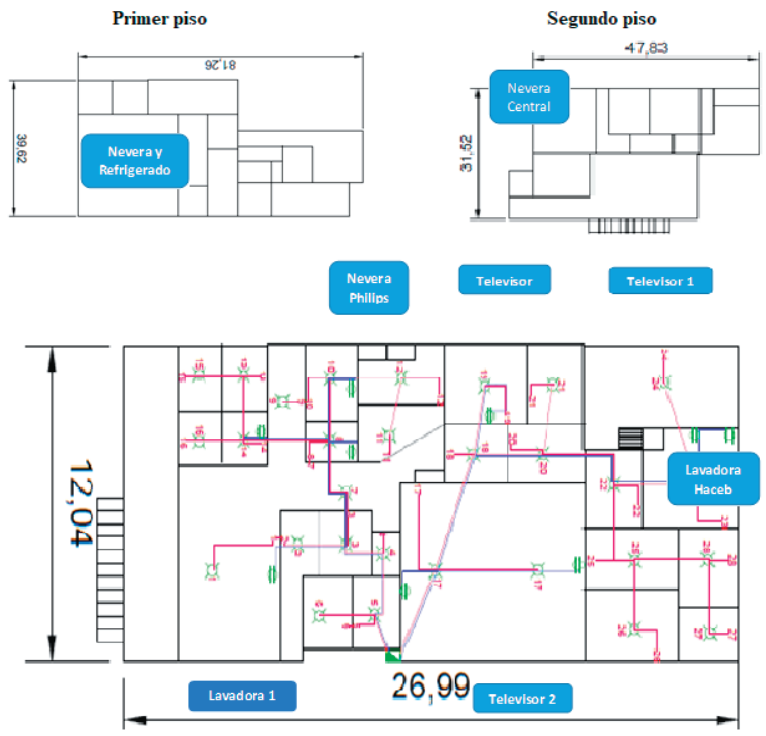

Elaboración propia. 
Figura NRo. 3. Algunas imágenes de los electrodomésticos medidos e instrumentos.
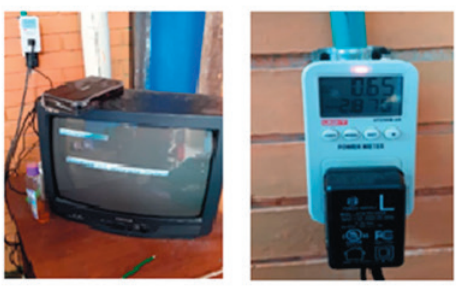

a) Televisor 1 con medidor electrónico
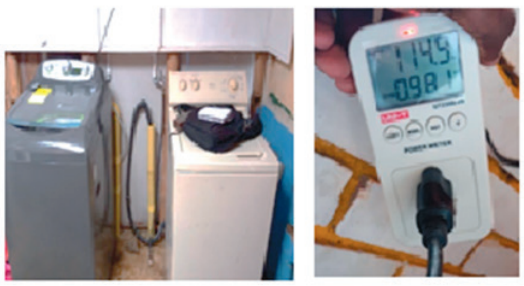

b) Televisor 2 con medidor electrónico Elaboración propia.

TABLA NRo. 1. Registro de potencia y energía de cada electrodoméstico en la fundación.

\begin{tabular}{|c|c|c|c|}
\hline \multirow[t]{2}{*}{ Electrodoméstico } & \multicolumn{2}{|c|}{$\begin{array}{l}\text { Potencia eléctrica } \\
\text { máxima (Watts) }\end{array}$} & \multirow{2}{*}{\begin{tabular}{|l} 
Energía \\
medida \\
KWh \\
(mes) \\
\end{tabular}} \\
\hline & Watts & KW & \\
\hline Televisor 1 & 36.7 & 0.0367 & 5.74 \\
\hline Televisor 2 & 77.3 & 0.0773 & 4.962 \\
\hline Televisor 3 & 34.5 & 0.0345 & 3.894 \\
\hline Nevera Philips & 87.1 & 0.0871 & 70.36 \\
\hline Nevera Central & 118.8 & 0.1188 & 45.297 \\
\hline $\begin{array}{l}\text { Nevera y } \\
\text { refrigerador LG }\end{array}$ & 827.1 & 0.8271 & 129.66 \\
\hline $\begin{array}{l}\text { Lavadoras atrás } \\
\text { Haceb }\end{array}$ & 2025 & 2.025 & 34.8 \\
\hline Lavadoras 1 & 358.3 & 0.3583 & 20.54 \\
\hline \multirow{2}{*}{$\begin{array}{l}\text { Bombilla } \\
\text { (fluorescente) de } \\
27 \mathrm{~W}\end{array}$} & 27 & 0.027 & 7.45 \\
\hline & \multicolumn{2}{|c|}{ Energía total del mes } & $\begin{array}{lll}3 & 2 & 2 \\
\mathrm{kWh}\end{array}$ \\
\hline
\end{tabular}

Elaboración propia. 
Las horas de consumo de los diferentes electrodomésticos son muy variadas, por ello no se registró un número de horas por día. Como se estimaba, los mayores consumos los registraron los electrodomésticos que generan frío (neveras y refrigerador), seguidos por las lavadoras, las cuales son basadas en motores eléctricos. El uso de las neveras está asociado a la necesidad de conservar los alimentos que las personas (benefactores) donan a la fundación; caso particular de ello son los huevos toteados desechados por la empresa pimpollo, los cuales son donados a la fundación con la necesidad inminente de conservar para su consumo. De igual forma, al ser este un espacio conformado fundamentalmente por madres cabeza de hogar y niños en estado vulnerable, se presenta una exigencia continua de lavado de ropa. Sin embargo, esta se ha incentivado en la máquina de mejor estado y en las horas diurnas que permiten mejor aprovechamiento (con mayor eficiencia) del sistema solar. Se compara entonces este consumo medido con el registrado en la factura de energía (ver Figura NRO. 4).

El mes de medición fue julio cuyo reporte, según la empresa de energía, fue de $396 \mathrm{kWh}, 73 \mathrm{kWh}$ por encima del valor medido. Esta diferencia la conforman algunos aparatos como lámparas de noche, radios, entre otros elementos que no se midieron. No obstante, es muy alto el consumo para este tipo de aparatos.

Se efectuaron pruebas de medición energética en contador de energía (conexión a red) con el total de aparatos apagados y desconectados en la fundación. Aún con todo desenergizado se tomaron mediciones de corrientes de fuga de $4 \mathrm{~A}$ en la salida al contador principal. Indicador de las pérdidas energéticas debidas a malas conexiones, puntos calientes, cables desnudos, uniones débiles, entre otros. (La FIgURA NRO. 5 presenta algunas imágenes). Es razonable que para este contexto (muy pobre), se realicen conexiones con cable económico, reciclado (generalmente dúplex) y sin el aislamiento adecuado. Parte de la capacitación es hacerles entender las pérdidas energéticas que esto genera y el alto riesgo para la comunidad. 
FigURA NRo. 4. Factura de energía de la fundación.

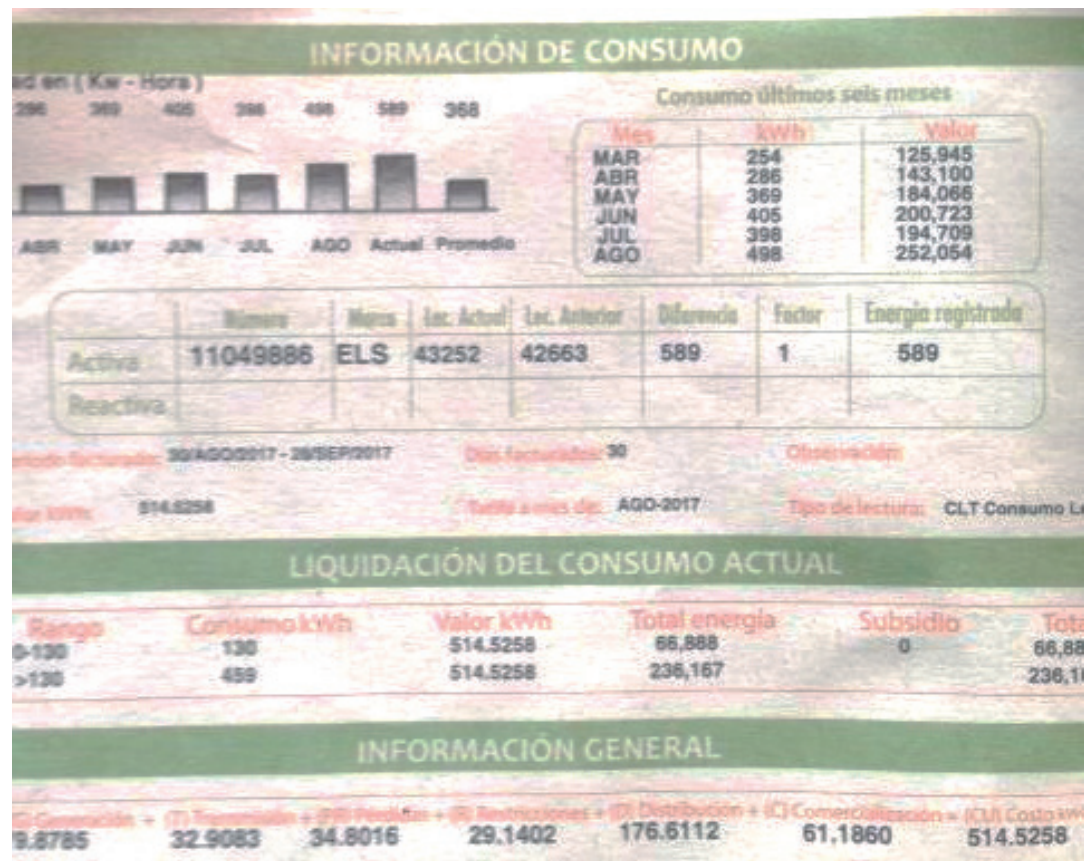

Elaboración propia.

RED - 220 2Fases, 1 Neutro

Esto demuestra que la energía pagada en una vivienda muchas veces no tiene que ver con el consumo, sino con malas instalaciones eléctricas, las cuales pueden generar riesgo de incendios por chispas y riesgo al contacto humano (principalmente niños). 
FigurA NRO. 5. Malas conexiones, fuentes de fugas eléctricas.
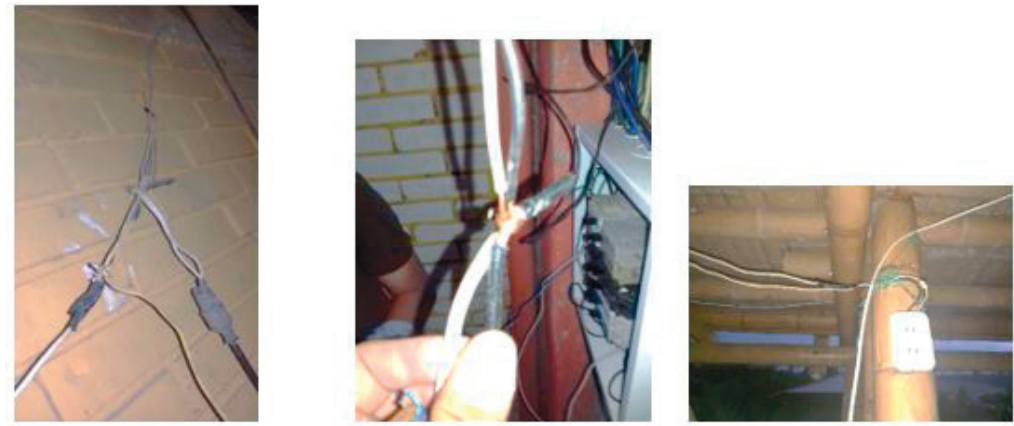

Elaboración propia.

Mejoramiento de instalaciones eléctricas

Para este resultado, todo el mérito lo tiene el profesor Santiago Gómez (como integrante del proyecto) quien, con treinta estudiantes de los grupos del curso de «Taller eléctrico 1» del programa de Tecnología Eléctrica, logró realizar un notable mejoramiento de las instalaciones eléctricas de la fundación. Para tal efecto fue necesario el levantamiento de planos con medidas de las habitaciones, salones y pasillos de dicho espacio, con el fin de establecer los puntos de conexión (tomacorrientes) e interruptores para iluminación. De esta forma, se cuantificaron los diferentes componentes, es decir, tuberías, uniones, terminales y cable necesario. Así, los estudiantes con orientación del profesor empezaron el proceso de instalación de tuberías, conexiones, tomas e interruptores para después instalar cableado. La fontanería empleada fue metálica, tal como lo pide la norma a fin de tener mayor hermeticidad, evitar riesgos de incendios y limitar las conexiones empíricas mal hechas. La FigurA NRO. 6 presenta algunas imágenes de esta labor. 
Figura NRO. 6. Estudiantes de la Facultad de Tecnología realizando instalación de sistema eléctrico.
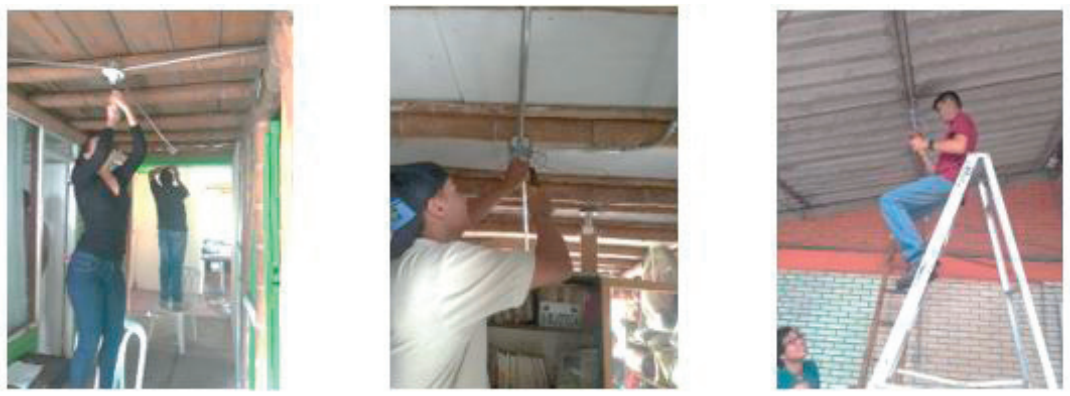

Elaboración propia.

En esta actividad participaron treinta estudiantes, de dos grupos del «Taller eléctrico 1» perteneciente al programa de Tecnología Eléctrica, durante cuarenta horas de labores (cinco semanas), donde pudieron interiorizar los conceptos vistos en clase con relación a la instalación de sistemas eléctricos domiciliarios. De igual manera, efectuaron la instalación de la línea tierra (ver FIgURA NRO. 8) necesaria en la protección eléctrica del sistema, para ello buscaron en terreno la perforación con varilla de cobre a $1.8 \mathrm{~m}$ de profundidad, tal como lo exige la norma RETIE para este tipo de instalación. Esta, al ser de línea tierra, es mucho más necesaria para este sistema, debido al alto riesgo de cortos (por malas conexiones futuras por parte de la comunidad), de descargas eléctricas (zona de altas precipitaciones) y la necesidad de incrementar la protección de los equipos (tanto del sistema fotovoltaico como de electrodomésticos en general). 
FIGURA NRO. 7. Instalación de línea tierra.
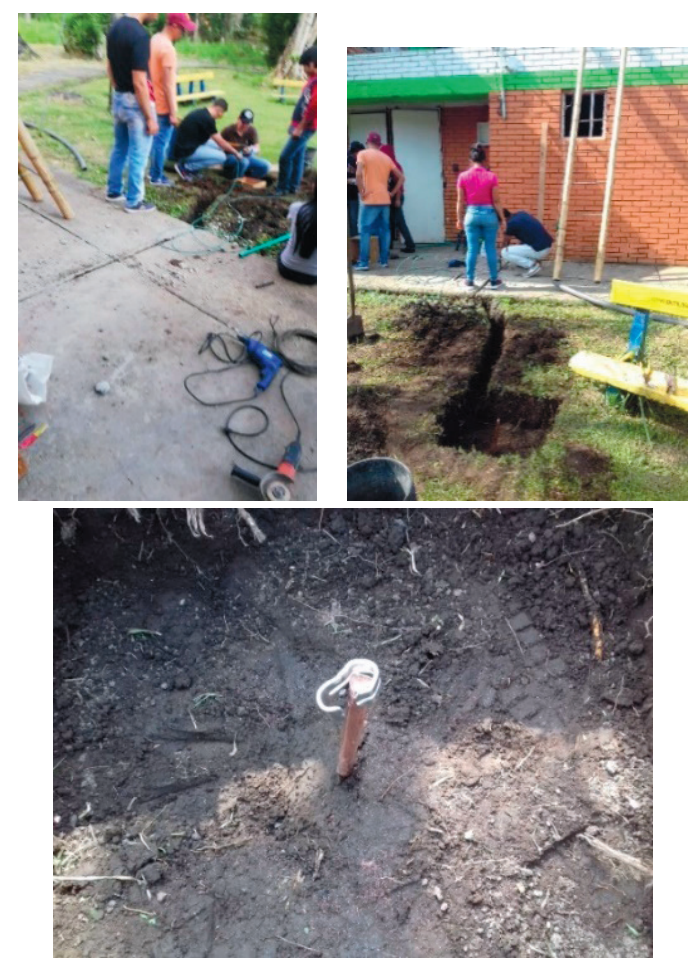

Elaboración propia.

\section{Implementación del sistema renovable}

Para el logro de este resultado, se buscó la tecnología más eficiente en términos de costo frente a beneficio. Para sistemas pequeños interconectados, la mejor opción es el microinversor. Su costo, su facilidad de instalación, su bajo tamaño y su peso lo convierten en la elección preferible. La Figura NRO. 8 muestra la imagen del microinversor instalado y el esquema de conexión.

Dicho microinversor es de interconexión a la red eléctrica compatible con redes inteligentes y sistemas avanzados de monitoreo para asegurar la máxima eficiencia y alta confiabilidad 
con cuatro entradas MPPT independientes, potencia máxima de salida de CA que llega a $1200 \mathrm{~W}$. Los datos técnicos de este equipo son:

- MPPT independiente por canal y monitorización de cada módulo.

- Potencia de módulo PV recomendada 250 Wp-375 Wp.

- Rango de voltaje MPPT 22V-48V.

- Rango de voltaje de operación 16V-55V.

- Corriente máxima del bus de CA 20A.

- Comunicación de ZigBee y monitorización gratuita.

- Diez años de garantía, ampliable a veinte años opcionales.

- IP67.

Figura NRO. 8. Instalación de microinversor y su esquema de conexión.

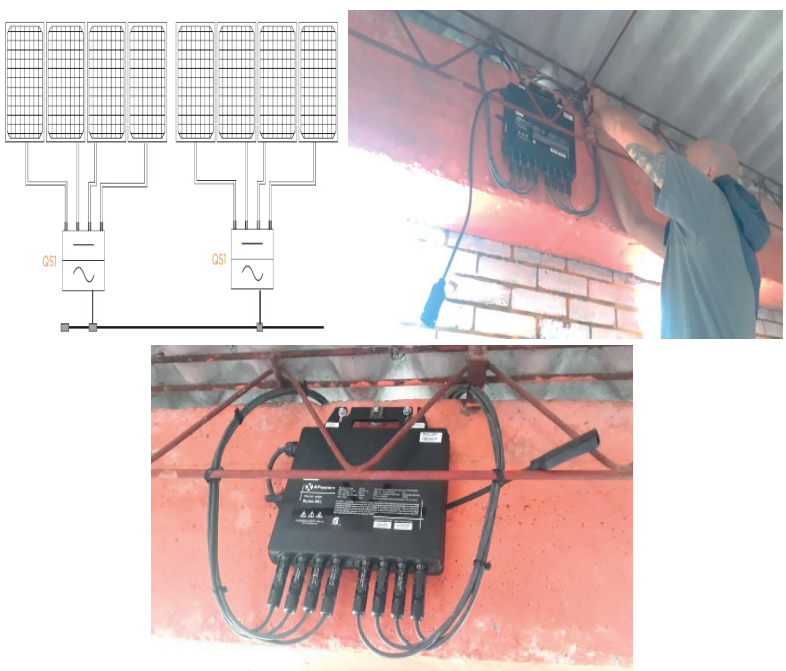

Elaboración propia. 
El microinversor está conectado a cuatro paneles de $290 \mathrm{Wp}$. La Figura NRo. 9 presenta una imagen del montaje de los paneles y su ficha técnica.

Figura NRO. 9. Montaje de paneles y ficha técnica de uno de ellos.
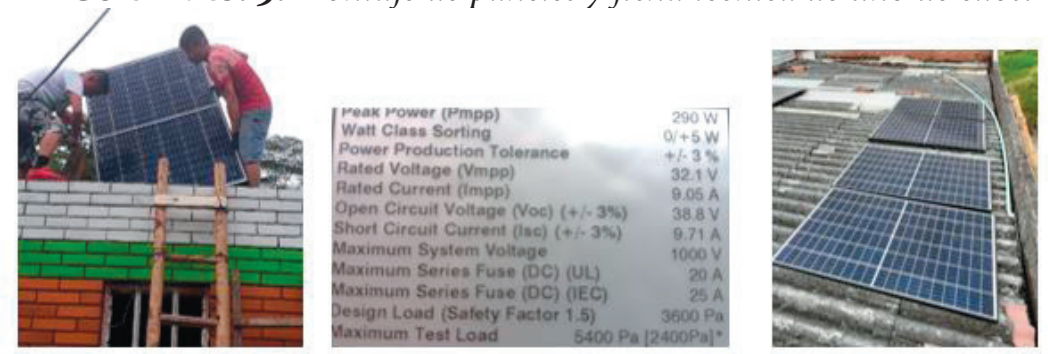

\section{Elaboración propia.}

Por otro lado, se encuentra instalado el inversor híbrido Hersic a cuatro paneles de $260 \mathrm{Wp}$. El total de estos son dispuestos en el mismo techo con la misma pendiente (10\%) y dirigidos hacia el sur. Cabe mencionar que tanto el inversor híbrido como el micro inversor requieren una conexión a red de 220 Vac bifásica. Durante la ejecución del proyecto la acometida eléctrica que viene desde el transformador sufrió un corte por caída de árboles debido a intensos aguaceros. Esta situación obligó a buscar la manera de recuperar las tres líneas de tensión que garantizaran dos fases y un neutro. Una vez se logró instalar las primeras, se procedió a conectar y verificar el funcionamiento del microinversor, al igual que la comprobación de funcionamiento del inversor híbrido, el cual había sufrido un daño en el fusible al entrar en corto en los daños de acometida.

Esta conexión requirió un nuevo tablero de circuitos. El tablero ya existente se movió hacia el interior de la vivienda - para mayor protección contra la intemperie y los daños externos-. De esta forma, se instalaron dos tableros de nueve circuitos cada uno. El primero destinado a la conexión de interruptores para cargas distribuidas en toda la vivienda y el segundo para las protecciones y acometida de los dos inversores (híbrido y microinversor). 
Para el correcto desempeño del sistema fue necesaria la instalación de un medidor bidireccional, el cual permite el registro de la energía que el sistema solar de ocho paneles puede entregar a la red eléctrica externa, la energía que la carga de la vivienda - no suplida por el sol- demanda de la red. Esto permitirá alcanzar los ahorros energéticos que se persiguen con el proyecto (ver FIGURA NRO. 10).

Figura nRo. 10. Tableros de conexión (cargas y protecciones equipos), medidor bidireccional.

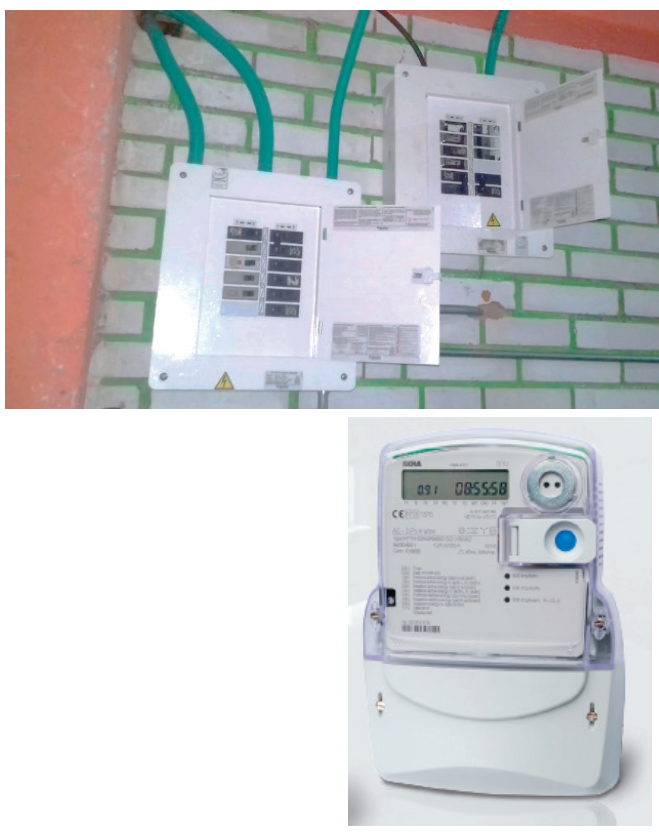

Elaboración propia.

Formación y sensibilización de la comunidad

Para darle verdadera utilidad y sostenibilidad al proyecto, se hace necesario involucrar a la comunidad mediante la sensibilización y capacitación para un buen manejo del sistema implementado. La temática que se ha enseñado comprende: 
Eficiencia energética básica: se busca que la comunidad adquiera consciencia del uso racional de los recursos $y$, en particular, del uso de la energía. Para ello se intensifican algunos consejos básicos como:

- Apagar luces que no se requieran (hacer uso de la luz solar en el día).

- Evitar al máximo tener abiertas las puertas de las neveras.

- Optimizar el uso de equipos como la lavadora minimizando el número de lavadas y el tiempo de operación.

- Evitar el uso de resistencias eléctricas.

- No usar bombillos incandescentes, entre otros.

Sensibilización sobre el cambio climático y el daño a los ecosistemas: se busca que apropien una cultura del ahorro consciente teniendo en cuenta el daño del planeta con el desperdicio de energía, además del gasto económico. Para ello se les enseñan los niveles de potencia y energía que consumen los diversos aparatos, al priorizar los de mayor consumo para que optimicen su uso. Se les explica la diferencia de estos dos elementos, con el fin de que entiendan que no solo importa qué tanto consume un equipo instantemente, sino además el tiempo de funcionamiento.

Funcionamiento y cuidado de los sistemas: es muy importante que la comunidad asimile de una forma sencilla el funcionamiento de los sistemas, la captación de paneles y la importancia de su limpieza periódica, el cuidado de los tableros de protección, la función que cumplen los interruptores, la línea tierra, la forma de trabajo de los inversores, el cuidado de las baterías y la necesidad de evitar a toda costa conexiones mal hechas que puedan generar pérdidas y posibles cortos que atenten contra los equipos. 
La Figura NRO. 11 presenta algunas imágenes de la comunidad en formación y sensibilización.

Figura NRo. 11. Comunidad Kyrios como parte intergral del proyecto.

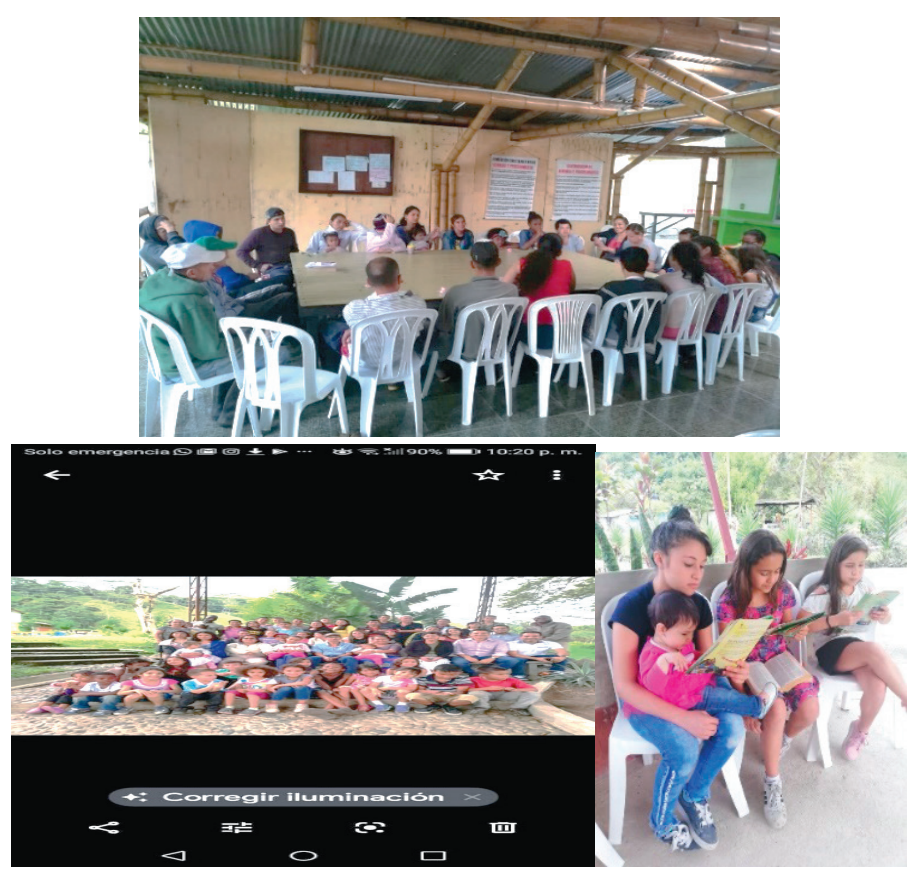

Elaboración propia.

En la actualidad las últimas facturas han mostrado una reducción notable en el consumo energético. Al promediar valores cercanos a $200 \mathrm{kWh}$, se representan ahorros cercanos a 80000 pesos, valor importantísimo en el aprovechamiento del recurso para alimento y sustento diario de la comunidad.

\section{Población beneficiada}

La población beneficiada se clasifica en varios contextos: 


\section{Población directa en fundación}

Se ha impactado un total de 70 personas entre adultos, adultos mayores, madres cabeza de hogar y, principalmente, niños en estado vulnerado y vulnerable. La adecuación de un sistema que les permite ahorrar energía equivalente en dinero a 200000 pesos mensuales representados en 100000 pesos por generación fotovoltaica y 100000 pesos en eficiencia energética y nuevas conexiones eléctricas. Ahora este dinero - antes gastado en energía- puede ser aprovechado en mayor alimento y cubrimiento de necesidades básicas de vida.

\section{Estudiantes en formación}

El proyecto involucró un total de treinta estudiantes de los cursos de taller eléctrico del programa de Tecnología Eléctrica, quienes, con prácticas reales de montaje de redes eléctricas, lograron apropiar mucho mejor los conocimientos adquiridos en la asignatura.

De igual manera, nueve estudiantes del curso Energías Renovables se han beneficiado al asimilar, de manera práctica, los conceptos recibidos de sistemas fotovoltaicos interconectados a red y su instalación.

\section{Conclusiones}

- Este tipo de proyectos se convierten en un referente importante de investigación para la sociedad y el medio ambiente, donde la universidad debe jugar un papel preponderante dentro de su misión.

- La energía solar fotovoltaica ha adquirido un alto interés en el país, ya que la nueva reglamentación (CREG), la reducción de precios (por incremento de oferta-demanda) y las nuevas tecnologías (equipos más compactos) han permitido la viabilidad 
técnica y económica (retornos de inversión más cortos) en la implementación de sistemas en sectores residencial, comercial e industrial.

- El sistema implementado y un eficiente uso de la energía posibilitará ahorros que pueden superar los 300000 pesos mensuales en una fundación de este tipo. De esta manera, se permite mejorar la calidad de vida de los residentes, además del impacto en huella de carbono. Tanto el sistema como los módulos habitacionales sostenibles, los cuales fueron construidos, deben ser tomados en cuenta por entes gubernamentales para proyectos de vivienda de interés social.

- El impacto positivo en personas con un pasado difícil como lo refleja el video, justifican de sobra los esfuerzos realizados por el grupo de investigación. Esto muestra que personas que se ven en la calle si tienen posibilidades de resocialización, si se aporta como universidad.

https://www.youtube.com/watch?v=HbeyI2nABDA.

\section{Bibliografía}

[1] Unidad de Planeación Mineroenergética (UPME). Integración de las energías Renovables en Colombia. Convenio ATN/FM-12825-CO, 2015.

[2] IANAS Red Interamericana de Academias de Ciencias. Guía hacia un futuro energético sustentable para las américas, 2018.

[3] H. Garcias, et al. Análisis costo beneficio de energías renovables no convencionales en Colombia. Fedesarrollo, Centro de Investigación Económica y Social, 2013. 
[4] L. Vega, et al. «La red de conocimiento Prideras una estrategia para promover la energización rural en Colombia». Prospect. vol. 13, no. 1, pp. 24-31, Enero-Junio, 2015.

[5] O. H. Álvarez, Energías renovables. Apuntes para un libro texto. Editorial Académica Española, 2017.

[6] Unidad de Planeación Mineroenergética (UPME), Corporación para la energía y el medio ambiente (Corpoema). Formulación de un plan de desarrollo para las fuentes no convencionales de energía en Colombia (PDFNCE), vol. 1, Bogotá, diciembre 30 de 2010.

[7] S. Belmonte, et al. Experiencias de energías renovables en Argentina, una mirada desde el territorio. UNSa Editorial Universitaria, 2017.

[8] Colegio Oficial de Ingenieros de Telecomunicaciones. Energía solar fotovoltaica. Colegio Oficial de Ingenieros de Telecomunicación, 2002.

[9] Catálogos equipos. Solar Inverter Hersic de $1 \mathrm{~kW}$. MicroInversor APSystemsde 1kW. Paneles Seraphim de 345 W. Medidor bidireccional MT174, 2019.

[10] E. A. Salazar Marín, Convocatoria interna para la financiación de proyectos de extensión social, cultural y artístico [En línea]. Disponible en: https://www.academia. edu/41372264/CONVOCATORIA_INTERNA_PARA LA_FINANCIACI\%C3\%93N_DE_PROYECTOS DE_EXTENSI\%C3\%93N_SOCIAL_CULTURAL_Y_ ART\%C3\%8DSTICO_INFORME_FINAL_NOMBRE_ DEL_PROYECTO. 


\title{
Astroviernes y los cien años de la Unión Astronómica Internacional
}

\author{
Kevin Johan Villegas Martínez \\ Jonathan Cardona Ramírez \\ Edwin Andrés Quintero Salazar \\ Yoselin López Restrepo \\ Daniela Espitia Mosquera \\ Luis Eduardo Salazar Manzano \\ Miguel Ángel Parra Patiño \\ Universidad Tecnológica de Pereira
}

Resumen

Desde los primeros momentos de la humanidad, los fenómenos y objetos presentes en el cielo nocturno han sido motivo de curiosidad. En vista de esta situación, la astronomía es hoy por hoy una de las ciencias que más despierta el interés del público en general. A pesar de ello, en Colombia no se encuentra incluida en el currículo de la educación básica y media, por lo que las personas acceden a ella dirigiéndose a planetarios y observatorios. En el 
caso de la ciudad de Pereira, la UTP cuenta con un planetario en el que los visitantes tienen la oportunidad de conocer un poco más de acerca sobre los cuerpos celestes, a través de la proyección realizada en una cúpula. Además, dicha institución tiene un observatorio astronómico que presenta, como valor agregado, el hecho que desde allí las personas pueden contemplar los cuerpos celestes de manera directa usando sus propios ojos y los instrumentos astronómicos allí dispuestos. Por esto, desde el año 2013 el Grupo de Investigación en Astroingeniería Alfa Orión, con sede en el Observatorio Astronómico de la Universidad Tecnológica de Pereira ha ejecutado el proyecto Astroviernes, el cual consiste en la apertura del observatorio al público en general, todos los viernes del año entre las 6:30 p. m y las 9:30 p. m.

Año tras año, dicho proyecto ha desarrollado actividades novedosas y diferenciadoras y ha permitido la visita constante del público en general. En este orden de ideas y al considerar que en el año 2019 la Unión Astronómica Internacional (IAU) celebró sus 100 años, el presente proyecto propuso la continuación de Astroviernes durante el mismo año estructurando su planeación en torno a las actividades propuestas por la IAU, las cuales son: el papel de la mujer en la astronomía, los cincuenta años del hombre en la Luna y Einstein en la escuela. La ejecución del programa, en articulación con las actividades propuestas por la IAU, permitió visibilizar a la universidad, a la ciudad y al Grupo de Investigación en Astroingeniería Alfa Orión en la esfera mundial de la divulgación científica; al igual que enaltecer el papel de la mujer en las ciencias del espacio y permitir el contacto directo entre la academia y el público en general.

Palabras clave: IAU100, observatorio, Astroviernes, Astronomía, divulgación. 


\section{Abstract}

From the first moments of humanity, the phenomena and objects present in the night sky have been a matter of curiosity. In view of this situation, astronomy is today one of the sciences that most arouses the interest of the general public. Despite the above, in Colombia astronomy is not included in the curriculum of basic and secondary education, so people access this science by going to planetariums and observatories. In the case of the city of Pereira, the UTP has a planetarium in which visitors have the opportunity to learn a little more about the celestial bodies through the projection made in a dome. In addition, the UTP also has an astronomical observatory, which presents as an added value the fact that from there people can contemplate the celestial bodies directly, using their own eyes, and through the astronomical instruments arranged there. That is why since 2013 the Alpha Orion Astroengineering Research Group based in the Astronomical Observatory of the Technological University of Pereira, has been running the Astroviernes project, which consists of opening the observatory to the general public every Friday of the year between 6:30 p.m and 9:30 p.m. Year after year, the Astroviernes project has developed the inclusion of innovative and differentiating activities allowing the constant visit of the general public. In this order of ideas, and considering that, in 2019, the International Astronomical Union (IAU) celebrated its 100th anniversary, the present project proposed the continuation of the Astroviernes project during the year 2019, structuring its planning around the proposed activities by the IAU, which are: The role of women in astronomy, 50 years of man on the moon and Einstein in school. The execution of the Astroviernes program in coordination with the activities proposed by the IAU, made it possible to make the city and the research group in Alpha Orion Astroengineering visible in the world sphere of scientific dissemination, in the same way, it exalted the role of the woman in space science and allowed direct contact between the academy and the general public 
Keywords: IAU100, Observatory, Astrofriday, Astronomy, Outreach.

\section{Introducción}

«La Unión Astronómica Internacional (IAU) [...] es una agrupación de las diferentes sociedades astronómicas nacionales y constituye el órgano de decisión internacional...» [Traducción propia] (International Astronomical Union, s.f.) en estándares y otras decisiones el campo de la astronomía. Para el año 2019 la IAU, en su centenario (IAU100), conmemoró este hito y organizó

... una celebración durante todo el año para aumentar la conciencia de un siglo de descubrimientos astronómicos, así como para apoyar y mejorar el uso de la astronomía como una herramienta para la educación, el desarrollo y la diplomacia bajo el tema central "Under One Sky" ("Bajo Un Cielo") (Sociedad Española de Astronomía [SEA], s.f.).

Desde esta perspectiva y teniendo en cuenta que la astronomía contribuye con el desarrollo humano (Chattopadhyaya, 1996), su objetivo principal es estimular el interés mundial en esta área y en las ciencias, para llegar a la comunidad astronómica mundial, a las organizaciones científicas nacionales, a las sociedades, a los responsables políticos, a los estudiantes, a las familias y al público en general. De acuerdo con García et al. (1997), la astronomía ha sido una de las ciencias más inquietantes y apasionantes para el ser humano, dado que a través de esta es posible comprender el mundo. Sin embargo, en Colombia, esta no está incluida dentro del currículo de la educación básica y media, de manera que la comunidad interesada se ve en la necesidad de visitar observatorios o planetarios ubicados en las diferentes ciudades del país, cuando desean resolver interrogantes acerca de los fenómenos que ocurren en el universo (Sierra et al., 2006). En el caso particular de la ciudad de Pereira, la Universidad Tecnológica de Pereira cuenta con un planetario en el cual se proyectan los cuerpos celestes sobre una construcción en forma de cúpula. 
No obstante, en este espacio no es posible realizar observación directa de dichos cuerpos existentes en el universo, debido a que su objetivo está centrado en la simulación del cielo a través de una proyección. Esta situación hace que las personas no logren ser testigos oculares de los fenómenos que ocurren en el universo a través de la observación directa (Faria et al., 2014).

En consecuencia, el presente documento evidencia cómo el Observatorio Astronómico de la Universidad Tecnológica de Pereira (OAUTP) en conjunto con el Grupo de Investigación en Astroingeniería Alfa Orión (GIA Alfa Orión) ejecutaron las actividades del proyecto Astroviernes 2019, en el marco de la celebración de la IAU100, aportaron a los objetivos propuestos por este evento y, en retroalimentación, obtuvieron visibilidad internacional en el campo de la divulgación astronómica.

\section{Objetivos}

\section{Objetivo general}

Desarrollar una estrategia para la divulgación de la astronomía entre el público en general a través de la observación directa de los cuerpos celestes desde el Observatorio Astronómico de la UTP, en el marco de las actividades propuestas por la Unión Astronómica Internacional en conmemoración de sus 100 años.

\section{Objetivos específicos}

Adecuar los espacios y la instrumentación disponible al interior del Observatorio Astronómico UTP para la recepción de visitantes y la realización de actividades de divulgación científica.

Socializar entre la comunidad en general de la región las diferentes investigaciones que se desarrollan al interior del Observatorio Astronómico UTP. 
Involucrar las actividades propuestas por la Unión Astronómica Internacional, para el 2019, en el marco de la conmemoración de sus cien años y en el conjunto de labores de divulgación de la ciencia desarrolladas en la ejecución del proyecto.

Vincular estudiantes de pregrado y posgrado, de las facultades de Ciencias Básicas e Ingenierías, en actividades de divulgación y de extensión social, de tal forma que fortalezcan sus competencias humanísticas y, de esta manera, logren adquirir una formación integral.

\section{Metodología}

El proyecto «Astroviernes y los cien años de la Unión Astronómica Internacional» fue ejecutado por el equipo de trabajo del Grupo de Investigación en Astroingeniería Alfa Orión (GIA Alfa Orión), con sede en el Observatorio Astronómico de la Universidad Tecnológica de Pereira (OAUTP).

La estrategia propuesta se aplicó durante el año 2019 en el Observatorio Astronómico UTP, todos los viernes desde el 1 de febrero hasta el día 13 de diciembre, entre las 6:30 p.m y las 9:30 p.m. Cada viernes, las actividades desarrolladas con los asistentes giraron en torno al objeto de la noche, el cual estaba enmarcado dentro de las categorías: sistema solar, kuna, espacio profundo y estrellas. Estas temáticas fueron abordadas desde la perspectiva de las actividades propuestas por la Unión Astronómica Internacional en conmemoración de sus cien años, los cuales eran sobre el papel de la mujer en la astronomía, los cincuenta años del hombre en la Luna y Einstein en la escuela. De esta forma, para los viernes en los que el objeto de la noche fue un cuerpo del sistema solar, las actividades giraron en torno al tema «Einstein en la escuela». Para el caso de las sesiones de Astroviernes asignadas a la Luna, se desarrollaron las actividades con el público centrados en la conmemoración de los cincuenta años de la llegada del hombre a 
la Luna. Finalmente, en aquellos días en que el objeto de la noche fue un cuerpo de espacio profundo o una estrella en particular, las actividades que se ejecutaron tuvieron un componente preponderante asociado con el papel de la gravedad en el universo a gran escala (Einstein en la escuela) y/o el papel de la mujer en el desarrollo de las ciencias del espacio.

La metodología propuesta fue puesta en marcha desarrollando las siguientes fases:

Fase nro. 1: en primer lugar, se realizó la conformación del equipo de trabajo para la ejecución del proyecto, el cual estuvo compuesto por el docente Edwin Andrés Quintero Salazar, en calidad de líder, y por el estudiante de Ingeniería de Sistemas y Computación Miguel Ángel Parra Patiño, integrante del Grupo de Investigación en Astroingeniería Alfa Orión, quien fue el coordinador del proyecto. Este comité estuvo encargado de programar la capacitación del equipo de trabajo, de aplicar la estrategia, de gestionar la logística, desarrollar las actividades y consolidar los productos e informes finales.

Fase nro. 2: en esta fase el equipo de coordinación se encargó de planear las actividades ejecutadas durante los viernes del año 2019. Se establecieron los objetos de la noche de acuerdo con su visibilidad en la bóveda celeste y según la época del año. También se planificaron las charlas a presentar a los visitantes, de acuerdo con la distribución de las temáticas propuestas por la IAU.

Fase nro. 3: acorde con la planeación, se realizó la capacitación de los estudiantes que participaron en la aplicación de las actividades, familiarizándolos en el manejo adecuado, las precauciones y las sugerencias de los diferentes instrumentos con los cuales cuenta el Observatorio Astronómico de la UTP. Además, se llevó a cabo una capacitación en manejo de público, en temáticas y técnicas que involucran las acciones a desarrollar. 
Fase nro. 4: en esta se adelantó la promoción y divulgación del proyecto para invitar a la comunidad en general a visitar el Observatorio Astronómico UTP en las diferentes jornadas programadas.

Fase nro. 5: durante esta fase se ejecutaron las actividades diseñadas en los espacios disponibles del observatorio:

- Entrada: en este espacio se controló el acceso al Observatorio Astronómico y se socializaron las diferentes actividades del mismo.

- Oficina: en ella se realizó la introducción a la temática de la IAU. Las charlas se apoyaron en material audiovisual, para hacer uso de las pantallas de la oficina del observatorio.

- Terraza: en este espacio se llevó a cabo un paseo por las constelaciones visibles en la respectiva época del año (se instruyó sobre las constelaciones y su origen). Se socializó acerca de los radiotelescopios, cámara de cielo completo y estación meteorológica, elementos con los cuales cuenta el observatorio. Se hizo observación por un telescopio secundario y se habló acerca del objeto de la noche y su actividad asociada propuesta por la Unión Astronómica Internacional.

- Cúpula: en este espacio se enfocó el telescopio principal con el fin de permitir la observación directa. También se orientaron charlas acerca del objeto de la noche y se socializaron los proyectos de investigación desarrollados al interior del observatorio mientras los visitantes realizan la contemplación.

Fase nro. 6: durante la realización de las actividades se tomaron registros fotográficos que complementaron el informe final del proyecto. Así mismo, se tomó nota de los comentarios y sugerencias planteadas por los visitantes. Dichos comentarios fueron utilizados como realimentación del proyecto. 
Fase nro. 7: al culminar las actividades en las fechas propuestas se realizó el informe final que, además de las estadísticas de asistencia, consignó la información recopilada en la Fase nro. 6. También se consolidaron los resultados del proyecto y se elaboraron los productos finales.

\section{Resultados}

Resultados de la planeación de la jornada:

Se consolidó el equipo de coordinación y el equipo de monitores satisfactoriamente. Estos se encontraron conformados por:

Equipo de coordinación

- Líder de proyecto: Edwin Andrés Quintero Salazar.

- Coordinador de proyecto: Miguel Ángel Parra Patiño.

- Instrumentista: Jairo Alberto Aguirre Galvis.

- Profesional: Daniela Espitia Mosquera.

Equipo de apoyo

- Ángela Cristina Cardona Ladino.

- Kevin Johan Villegas Martínez.

- Jonathan Cardona Ramírez.

- David Galeano.

- Nathalia Arias Santa.

- Miguel Ángel Salazar Manzano. 
- Valeria Puerta Rendón.

- Alexa Juliana Román.

- Oscar Orlando Alarcón.

- Luis Eduardo Salazar Manzano.

- Se realizaron cuarenta y cinco jornadas a lo largo del año 2019. Además, se establecieron los objetos de la noche y los temas relacionados con la IAU100 para todo el año.

- Se capacitaron los monitores en el proceso de ejecución del proyecto y en el manejo de telescopios y uso de la instrumentación.

TABla NRo. 1. Capacitaciones del equipo de Astroviernes.

\begin{tabular}{|l|l|l|l|}
\hline Nro. & Fecha & Capacitador & Tema de capacitación \\
\hline 1 & $\begin{array}{l}\text { 1 de febrero } \\
\text { de 2019 }\end{array}$ & $\begin{array}{l}\text { Edwin } \\
\text { Quintero, } \\
\text { Miguel Parra }\end{array}$ & $\begin{array}{l}\text { Proceso de la } \\
\text { ejecución del proyecto } \\
\text { Astroviernes }\end{array}$ \\
\hline 2 & $\begin{array}{l}\text { 5 de marzo } \\
\text { de 2019 }\end{array}$ & Jairo Aguirre & $\begin{array}{l}\text { Uso y manejo de } \\
\text { telescopios y uso de } \\
\text { la instrumentación } \\
\text { (Teórico) }\end{array}$ \\
\hline 3 & $\begin{array}{l}7 \text { de marzo } \\
\text { de 2019 }\end{array}$ & Jairo Aguirre & $\begin{array}{l}\text { Uso y manejo de } \\
\text { telescopios y uso de } \\
\text { la instrumentación } \\
\text { (Práctico) }\end{array}$ \\
\hline
\end{tabular}

Elaboración propia.

Publicación de la programación de Astroviernes en diferentes medios de comunicación:

- Pereira virtual. Página de eventos culturales en Pereira https:// pereiravirtual.com/es/eventos/2-eventos/1875-la-movidacultural-en-pereira-programacion-del-24-al-30-de-julio. 
- Ciudad cultural. Páginas de eventos culturales en Pereira. http://www.plancpereira.com/agenda/astroviernes/.

h t t p s:// m.facebook.com/story.php? story fbid $=2486064418091332 \& i d=412336728797455$.

- Redes sociales del Planetario y el Observatorio Astronómico. https://www.instagram.com/poautp/?hl=es-la.

https://www.facebook.com/ObservatorioAstronomicoUTP/.

- Página oficial del Observatorio Astronómico de la UTP. http:// observatorioenlinea.utp.edu.co/Astroviernes/.

Además, se logró promover las actividades a través de la emisora de la UTP: Universitaria Estéreo.

Resultados de la ejecución de las jornadas:

- En Astroviernes se alcanzó un total de 3619 visitantes al Observatorio Astronómico para el año 2019, tal como se observa en la Figura NRo. 1.

Figura NRO.1. Cantidad de visitantes al programa de Astroviernes.

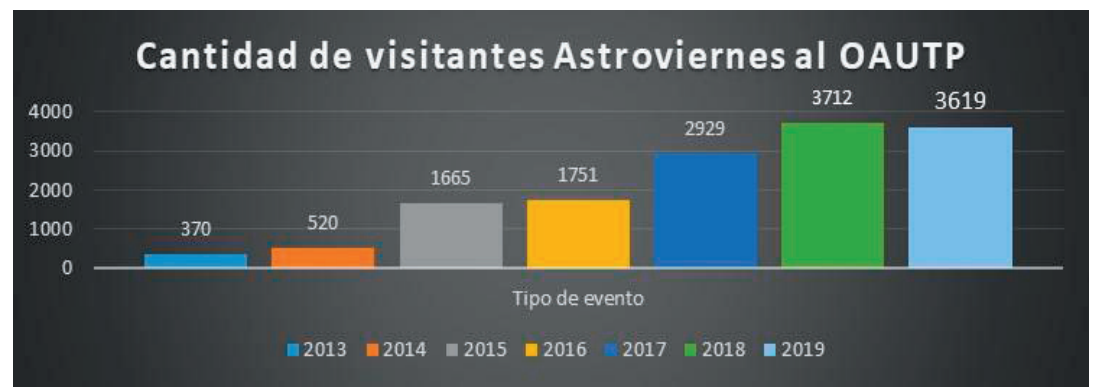

Elaboración propia. 
- El libro de visitantes consignó más de trecientos cincuenta comentarios, entre sugerencias y felicitaciones al equipo de Astroviernes. Estos no solo ayudaron como retroalimentación al generar cambios en las actividades, sino que motivaron al equipo a continuar trabajando por mejorar y continuar con la actitud tan masivamente aplaudida hasta ahora. La mayoría de las anotaciones fueron felicitaciones por parte del público como la siguiente: «Gracias por proporcionar espacios para el conocimiento del universo, aprendimos mucho sobre Albireo. Muy profesionales y empoderados los monitores. Seguir apoyando y propiciando estas actividades» [Tomado del libro de visitantes del proyecto].

Otros comentarios dejan posibles cambios para el futuro del proyecto, tales como el que dice: «Sería bueno que, antes de realizar las sesiones, uno pudiera leer o enterarse de antemano acerca del tema en cuestión, porque así uno tendría algo que preguntar y no solamente limitarse a escuchar» [Tomado del libro de visitantes del proyecto].

En resumen, las peticiones generales del público son darle continuidad al proyecto y mantener la calidad humana y el nivel de conocimiento que caracterizan a los monitores encargados.

- El proyecto Astroviernes también hizo parte de las actividades a nivel mundial convocadas por la Administración Nacional de Aeronáutica y el Espacio (NASA), con la «International Observe the Moon Night» (Noche internacional de observar la Luna). Para estas actividades participaron más de 102 países de todo el mundo y se realizaron 2104 eventos.

- Las celebraciones IAU100 «Bajo un mismo cielo» «...consisten en actividades coordinadas a nivel nacional, regional e internacional» (IAU, s.f). Se planean acciones para que personas de todas las edades y de todos los orígenes puedan apreciar el papel central de la astronomía en la educación, en el desarrollo, en la divulgación y en la diplomacia. El proyecto «Astroviernes y los cien años de la Unión Astronómica Internacional» hizo parte de esta celebración. Los eventos fueron registrados en la página de la IAU. 
- En conjunto con el Instituto de Lenguas Extranjeras (ILEX)-UTP y GIA Alfa Orión, el día 27 de septiembre del 2019 se llevó a cabo una jornada de actividades, en el marco del proyecto Astroviernes, donde se realizaron charlas y se respondió al público en los idiomas francés y español con ayuda de docentes del ILEX. Esta contó con una asistencia de 134 personas, por lo que se superó la expectativa que se tenía para el evento (UTP, 2019).

- El proyecto Astroviernes también poyó el Festival de Astronomía Noche de Las Estrellas Pereira 2019-IAU100, celebración de los cincuenta años de la llegada del hombre a la Luna. El mayor festival de astronomía del Eje Cafetero. Fue realizado el 16 de agosto del 2019 e ingresaron más de cien asistentes al Observatorio Astronómico.

- El día Internacional de los Asteroides, promovido por las Naciones Unidas, fue celebrado en el marco del proyecto Astroviernes el día 28 de junio de 2019. El telescopio principal se orientó a un cuerpo menor del sistema solar y, mediante instrumentación del observatorio, se observó dicho cuerpo; además de las actividades complementarias del proyecto y la exposición de meteoritos reales.

- Gracias a que el Grupo de Investigación en Astroingeniería Alfa Orión se encontró activo con las actividades de la IAU100 para el proyecto Astroviernes, se identificaron otras actividades en las que el Observatorio Astronómico participó y aumentó la visibilidad de la UTP y del grupo de investigación a nivel mundial. Entre los más representativos se encuentran los siguientes:

1. Celebración de los IAU100. Cien horas de Astronomía de la Unión Astronómica Internacional.

- Taller: Astronomía con todos los sentidos. Sala Conectando Sentidos del Centro Cultural Lucy Tejada. Realizado el 10 de enero de 2019 (Observatorio Astronómico UTP, 2019).

- Actividad: Observación nocturna por telescopios. Plaza Cívica Ciudad Victoria. Realizado el 11 de enero de 2019. 
- Charla: «La Luna y otros eventos astronómicos» a cargo de la estudiante de maestría en astrofísica del Instituto Nacional de Astrofísica, Óptica y Electrónica (INAOE), México, Luisa Fernanda Cardona. Plaza Cívica Ciudad Victoria. Realizado el 11 de enero de 2019.

- Obra de teatro para niños: «Viaje por el sistema solar». Biblioteca Pública Municipal «Ramón Correa Mejía» del Centro Cultural Lucy Tejada. Realizado el 11 de enero de 2019.

2. Celebración de los IAU100. El Día Internacional de la Mujer y la Niña en la Ciencia.

- Actividad: charlas, muestras didácticas y observación por telescopios. Plazoleta Planetario UTP. Realizado el 11 de febrero de 2019; Pereira.

- Conferencia: «De la quiralidad selectiva al diseño de nuevos materiales», a cargo de Yenny Patricia Ávila Torres, Ph.D. Planetario UTP. Realizado el 11 de febrero de 2019. Pereira.

3. IAU100. The Eratosthenes Experiment. Proyecto EratosthenesMidiendo la sombra en Equinoccio. Realizado el 20, 21 y 22 de marzo de 2019.

- Universidad Tecnológica de Pereira, Pereira.

- Institución Nacional Educativa Académico, Cartago.

- Liceo Taller San Miguel, Pereira.

- Institución Educativa La Inmaculada.

4. Taller para niños «Explorando la Luna»-IAU100. Celebración del día del niño y los cincuenta años de la llegada del hombre a la Luna. Biblioteca Pública Municipal «Ramón Correa Mejía» del Centro Cultural Lucy Tejada, 27 de abril de 2019. Pereira. 
5. La Fundación Níkola Tesla y GIA Alfa Orión celebran los cincuenta años del hombre en la Luna en la comunidad de Atuntaqui, Ecuador (Observatorio Astronómico UTP, 2020). Instalaciones de la Fundación Níkola Tesla.

- Charla: La astronomía y las constelaciones. Jornadas de observación nocturna por telescopios. 26 de julio de 2019.

- Charla: La Luna y las Misiones Apollo. Jornadas de observación nocturna por telescopios. 29 de julio de 2019.

- Charla: Vida y muerte de las estrellas. Jornadas de observación nocturna por telescopios. Taller Uso y manejo de telescopios. 30 de julio de 2019.

- Charla: Agujeros negros, gravedad y la IAU100. Jornadas de observación nocturna por telescopios. 31 de julio de 2019.

\section{Población beneficiada}

La población beneficiada por la ejecución del presente proyecto se constituyó por toda la comunidad en general que habitaba la zona de influencia de la Universidad Tecnológica de Pereira. Las actividades se planificaron de tal forma que, en ellas, pudo participar personas de edades mayores a 10 años. El hecho de que las sesiones fueran gratuitas propició la participación de individuos sin distinguir su condición económica. Durante el 2019 el proyecto Astroviernes benefició a 3619 personas.

\section{Conclusiones}

El desarrollo de la estrategia Astroviernes y los cien años de la Unión Astronómica Internacional permitieron que la comunidad se beneficiara al tener una experiencia didáctica astronómica y realizaran observación directa de los objetos celestes. También reseña al Grupo de Investigación en Astroingeniería Alfa Orión, al Observatorio Astronómico UTP y a la Universidad Tecnológica 
de Pereira como entidades comprometidas en la divulgación de la astronomía, reconociéndose su labor a nivel mundial. Además, el proyecto contribuye enormemente a que la ciudad de Pereira y Colombia fortalezcan su conocimiento y desarrollo en el área de las ciencias del espacio.

También cabe resaltar que los participantes de esta propuesta, los cuales pertenecen a diferentes programas de pregrado de la UTP y a grupos como la GIA Alfa Orión y del Club de Astronomía Orión, se beneficiaron con este proyecto al fortalecer y aumentar su conocimiento sobre cada tema y objeto de la noche. Además, mejoraron su oratoria, desempeño al presentarse al público, entre otras habilidades transversales.

\section{Referencias bibliográficas}

Chattopadhyaya, D. (1996). History of Science and Technology in Ancient India: Astronomy, Science and Society. Editorial South Asia Books.

Faria, R. Z.; Calil, M. R.; Perez, E. R.; Kanashiro, M.; Silva, L. C. P. y Calipo, F. (2014). «Planetário e Teatro Digital Johannes Kepler» and its Institutional Pedagogical Project. Revista Mexicana de Astronomía y Astrofísica (Serie de Conferencias), 44, 213-213.

García Barros, S. G.; Losada, C. M.; Mondelo Alonso, M. y Vega Marcote, P. (1997). La astronomía en textos escolares de educación primaria. Enseñanza de las ciencias, 15(2), 225-232. https://www.raco.cat/index.php/Ensenanza/article/ view/21493/93531.

International Astronomical Union [IAU]. (s.f.). Divulgación IAU (Noc)-España. https://iaunoc.blogs.uv.es/iau100/. 
International Astronomical Union [IAU]. (s.f.). About the IAU. https://www.iau.org/administration/about/. . (2018). Events. https://www.iau-100.org/events.

Observatorio Astronómico UTP. (2019). Observatorio Astronómico UTP participa en las 100 horas de astronomía de la Unión Astronómica Internacional. https:// observatorioastronomico.utp.edu.co/noticias/observatorioutp-en-las-100-horas-de-astronomia.html.

. (2020). Celebran los 50 años del hombre en la Luna en la comunidad de Atuntaqui, Ecuador. https:// observatorioastronomico.utp.edu.co/noticias/divulgacionastronomica-entre-ecuador-y-colombia.html.

Sierra Orduz, M.; Vega Vargas, E. y Pacheco Serrano, A. (2006). La enseñanza de la astronomía como actividad extracurricular en la educación básica. Revista Colombiana de Física, 38(4), 1431-1434. http://www.revcolfis.org/busqueda/ vol38_4/articulos/38041431.pdf.

Sociedad Española de Astronomía [SEA]. (s.f.). IAU 100. https://www.sea-astronomia.es/iau-100.

Universidad Tecnológica de Pereira [UTP]. (2019). Gestión de la comunicación y la promoción institucional. https:// comunicaciones.utp.edu.co/noticias/43947/astroviernes-enfrances. 


\title{
Sabores de Risaralda: construcción de un inventario intercultural del patrimonio gastronómico de la región
}

\author{
JHON JAIME CORREA RAMÍREZ \\ EDWIN MAURICIO López García \\ Natalia Agudelo Castañeda \\ Cristian Felipe Cardona Osorno \\ Juliana OSPINA TORO \\ ANDRÉs FELIPE RIVERA ECHEVERRI \\ Christian Javier Niño Posada \\ Cristian Ferney Cubides Palomares \\ Universidad Tecnológica de Pereira
}

\section{RESUMEN}

El proyecto Sabores de Risaralda: construcción de un inventario intercultural del patrimonio gastronómico de la región, nace de un interés por reconocer los elementos que hacen parte de la diversidad geográfica, económica, social, política y cultural del departamento y que recogen las nociones de identificación y 
diferenciación social a partir de la cocina; y crean relaciones del ser humano con sus tradiciones, saberes, nuevos hábitos de consumo, transformaciones culturales y situaciones sobre aprovisionamiento local y familiar para garantizar la seguridad alimentaria de las comunidades locales. Con este proyecto se pretende hacer un recorrido por los catorce municipios de Risaralda, con el fin de identificar la diversidad de la alimentación regional, al proceder desde las prácticas tradicionales y populares de cultivo, crianza, preparación, conservación, manejo y consumo para reconocer la diversidad de las prácticas culturales gastronómicas, por medio de la interacción con habitantes o portadores de los saberes convencionales. El proyecto se estructura metodológicamente desde la documentación, el trabajo de campo, los talleres de socialización con las comunidades y la posterior identificación e inventario de los elementos que hacen parte del patrimonio gastronómico del departamento y que a su vez servirán de guion para entregar un producto audiovisual.

Palabras clave: gastronomía, cocinas tradicionales, Risaralda, patrimonio inmaterial, diversidad cultural.

\section{Abstract}

The Sabores de Risaralda project: Construction of an intercultural inventory of the gastronomic heritage of the region, stems from an interest in recognizing the elements that are part of the geographical, economic, social, political and cultural diversity of the department and that collects the notions of identification and social differentiation from the kitchen, creating relationships of the human being with its traditions, knowledge, new habits of consumption, cultural transformations and situations about local and family supply to guarantee the food security of local communities. This project is intended to take a tour of the 14 municipalities of Risaralda, to identify the diversity of regional food, starting from traditional and popular cultivation, breeding, preparation, conservation, management 
and consumption practices to recognize the diversity of practices cultural cuisine through interaction with inhabitants or bearers of traditional knowledge. The project is methodologically structured from documentation, field work, socialization workshops with communities and subsequent identification and inventory of the elements that are part of the gastronomic heritage of the department and which in turn will serve as a script to deliver an audiovisual product.

\section{INTRODUCCIÓN}

\section{La gastronomía y el patrimonio cultural inmaterial}

Concebida como una disciplina que estudia la relación entre la cultura humana, el ambiente o entorno y la comida, la gastronomía ha empezado a ser catalogada como uno de los aspectos sobre los cuales se debe prestar una atención considerable en términos del rescate y la conservación del patrimonio cultural inmaterial de la humanidad. Según la Organización de las Naciones Unidas para la Educación, la Ciencia y la Cultura (Unesco), dicho patrimonio corresponde a todas las prácticas, expresiones, saberes y técnicas transmitidas por las comunidades humanas de generación en generación, las cuales propician el surgimiento de sentidos de identidad, de bienestar social y de gestión del entorno natural y social de la comunidad.

Otto Morales Benítez, uno de los historiadores regionales más relevantes para la región del centro-occidente colombiano, es claro cuando argumenta que la comida refleja, desde una perspectiva particular, los comportamientos más íntimos de las personas y sus entornos familiares y sociales, así como los que están relacionados con los grandes festejos y rituales públicos. En la práctica humana del comer entran en juego distintas fases y aspectos de un circuito socioeconómico y cultural bastante complejo, el cual abarca desde los cultivos a gran escala, las huertas caseras y la crianza de animales domésticos, hasta la preparación de las comidas en las 
cocinas, el consumo y la distribución en los mercados; Así como los significados, los hábitos, las mutaciones y los sincretismos presentes en las costumbres alimenticias. Todo esto está anclado en un entramado de relaciones sociales y prácticas culturales que, si bien se transmiten y revitalizan de generación en generación, también se ven transformadas por factores económicos, políticos y sociales. En palabras de Morales Benítez,

... la alimentación denuncia la estructura de una sociedad, pues hace relación con intensas actividades sociales. Ella implica un acto total. Se refiere a la cultura material y a otra, que obedece a otras reglas de conducta espiritual. Se come lo que se tiene, lo que se puede y lo que se elige. La alimentación depende de la geografía, de la historia. Revela las desigualdades de la historia económica, de los países, de las regiones ${ }^{3}$.

Esta relación entre la alimentación y la vida en colectivo de los seres humanos deja ver las múltiples formas en las que estos han interactuado con su medio geográfico y han instaurado un tipo de economía regional y local que les garantice su seguridad alimentaria, por lo que han transformado sus prácticas del cocinar y el comer, a lo largo del tiempo, en relación con las dinámicas de migración, urbanización y globalización, con las cuales han consolidado una idea de "comunidad imaginada» que no solo comparte dichas prácticas alimenticias y culinarias, sino que también teje, en torno a ellas, mundos simbólicos y sentidos de identidad, pertenencia e intercambio social.

Por todo esto, en la línea que plantea la Unesco se hace necesario investigar, proteger, promover y transmitir los conocimientos sobre la gastronomía como elemento del patrimonio cultural inmaterial; necesidad que debe empezar a ser suplida con estrategias y acciones de acercamiento y exploración frente a una primera fase: la elaboración de inventarios del patrimonio cultural.

3 Отto, Morales Benitez, Teoría y aplicación de las historias locales y regionales (Manizales: Universidad de Caldas, 1995), 72-73. 


\section{Políticas culturales y elaboración de inventarios del patrimonio cultural gastronómico}

A nivel nacional, el Ministerio de Cultura adoptó en el 2012 la Política para el Conocimiento, la Salvaguardia y el Fomento de la Alimentación y las Cocinas Tradicionales de Colombia, formulada con la participación de expertos sobre las gastronomías regionales del país. En este documento se concibe a las cocinas tradicionales como un conjunto complejo de saberes, usos y técnicas de transformación de los alimentos que constituyen un entramado de relaciones sociales con profundas cargas simbólicas, las cuales se adaptan a las condiciones geográficas y climáticas, a los sistemas productivos y a las particularidades regionales y locales ${ }^{4}$. Esta política sirve como punto de referencia inicial para contribuir en la valoración y salvaguardia de la diversidad y la riqueza cultural de los conocimientos, prácticas y productos alimenticios de las cocinas tradicionales de Colombia como factores fundamentales de la identidad, la pertenencia y el bienestar de la población. También exhorta a las instituciones públicas y privadas, así como a las comunidades y a la academia, para que de manera conjunta formulen estrategias locales y regionales en pos de hacer efectiva esta tarea cultural.

Entrelas acciones sugeridas por la política para el conocimiento y la preservación del patrimonio cultural de las cocinas y la alimentación tradicional está «... determinar, por medio de consultas a las regiones y localidades, el estado del patrimonio cultural culinario, elaborar un inventario y una estrategia para la investigación, el rescate y el fomento de las manifestaciones de las cocinas tradicionales en riesgo» $»^{5}$. En este punto, la elaboración de inventarios del patrimonio cultural gastronómico cobra especial relevancia, en tanto se constituyen en herramientas elaboradas a partir del trabajo conjunto con las comunidades

4 Ministerio de Cultura-Dirección de Patrimonio, Política para el conocimiento, la salvaguardia y el fomento de la alimentación y las cocinas tradicionales de Colombia (Bogotá: Ministerio de Cultura, 2012).

5 Ministerio de Cultura-Dirección de Patrimonio, Política para el conocimiento..., 85. 
locales y regionales, con las que se caracterizan y catalogan los ingredientes, las técnicas y las recetas de las cocinas tradicionales $y$, en algunos casos, otros aspectos que están relacionados con los anteriores (relaciones sociales, prácticas rituales y ceremoniales, transformaciones en las prácticas culinarias, entre otros). Para el Ministerio de Cultura, la elaboración de un inventario del Patrimonio Cultural Inmaterial (PCI) corresponde a

... un proceso participativo de identificación, documentación, diagnóstico, registro y divulgación de una o más manifestaciones del PCI que incluye la definición de medidas para su salvaguardia ${ }^{6}$.

El inventario permite dar cuenta de lo que hay en su contexto, de lo que existe y de su estado; ayuda a la construcción de un conocimiento profundo sobre las manifestaciones, contribuye a fortalecer la capacidad social de las comunidades para la gestión del patrimonio y representa un ejercicio de reflexión colectivo, participativo e incluyente que debe llevar a los habitantes de un lugar, comunidad, municipio, departamento o región a sentirse representados en él, por medio de todas aquellas manifestaciones que expresan su sentir y dan coherencia a su vida cotidiana como individuos y colectividades?

De tal manera que, como se verá en la estructura metodológica del proyecto, este inventario de la gastronomía risaraldense se elaborará en torno a un proceso etnográfico, tratará de abarcar toda la diversidad del territorio y sus gentes, y desarrollará un proceso de observación participativa con las comunidades que están diaria y directamente implicadas con el tema, puesto que así se puede generar una mayor apropiación en la sociedad sobre sus prácticas y conocimientos, y sobre su patrimonio cultural inmaterial; aspecto ligado a las estrategias y propósitos de la extensión universitaria en la UTP y a la proyección sociocultural de esta institución productora de conocimiento hacia el entorno local y regional.

6 Ministerio de Cultura, Inventarios de patrimonio cultural inmaterial. Proceso de identificación y recomendaciones de salvaguardia 2015 (Bogotá: Ministerio de cultura, 2015), 12.

7 Ministerio de Cultura, Inventarios de patrimonio...,16. 
El departamento de Risaralda: entre la diversidad geográfica, étnica y cultural

Situado en las estribaciones de las Cordilleras Central y Occidental, el departamento de Risaralda está asentado en un medio geográfico físico que varía entre los $890 \mathrm{msnm}$ en el municipio de La Virginia, y los $4500 \mathrm{msnm}$ en el Parque Nacional Natural Los Nevados. Sus tierras están bañadas por numerosos ríos y quebradas agrupadas en siete cuencas: la del río San Juan, del río Cauca, de los ríos Quinchía y Opiramá, del río Risaralda, del río Cañaveral, del río Otún y de los ríos Barbas y Consotá ${ }^{8}$. $\mathrm{Su}$ jurisdicción alcanza a abarcar territorios de dos parques nacionales naturales, cinco parques regionales naturales, once parques municipales naturales, un santuario de flora y fauna, cuatro áreas de manejo ambiental étnico, trece áreas de protección, recuperación e interés paisajístico, y tres áreas de protección del recurso hídrico ${ }^{9}$. Todas estas características hacen que los suelos risaraldenses tengan distintos usos: para la actividad ganadera, la agricultura, la protección y conservación de bosques, y un sinnúmero de reservorios de agua ${ }^{10}$.

Sumada a la diversidad del departamento en sus características geográficas físicas, está la multiculturalidad y la pluri-etnicidad que se hace manifiesta en la población risaraldense, la misma que, según explican Hugo Ángel Jaramillo y Alfredo Cardona Tobón, es producto de distintas olas migratorias y colonizadoras ${ }^{11}$.

Lo anterior hace que, cuando surja la pregunta por la existencia de una «identidad risaraldense» única, se embarque en una tarea bastante compleja, ya que, por un lado, la historia de

8 Gobernación de Risaralda, Risaralda, 40 años de grandeza (Pereira: Fondo Editorial Gobernación de Risaralda, 2007), 41

9 Gobernación de Risaralda, Risaralda $\ldots, 39$.

10 Gobernación de Risaralda, Atlas de Risaralda (Pereira: Fondo Editorial Gobernación de Risaralda, 2007), 53.

11 Hugo Ángel Jaramillo y Alfredo Cardona Tobón, «Unidad histórica». En Atlas de Risaralda, de la Gobernación de Risaralda (Pereira: Fondo Editorial Departamento de Risaralda, 1988), 108-116. 
este departamento está estrechamente ligada a procesos de larga duración enla región y, porotro, una delas principalescaracterísticas de este lugar radica en su diversidad étnica y cultural, lo que pone en cuestión cualquier criterio de homogeneización. Esta diversidad se manifiesta de manera explícita en la gastronomía de Risaralda, en relación con los ingredientes extraídos de los suelos cultivados, los cuales son utilizados para preparar los alimentos y, también, en torno a las formas de organizarlos - las tecnologías, los artefactos y los utensilios - y los lugares y momentos de consumirlos y distribuirlos. Desde las tres raciones diarias (desayuno, almuerzo y cena), al pasar por el tradicional "paseo de olla», el «fiambre» para los trabajadores, hasta las celebraciones y fiestas populares que se recrean en los ámbitos de lo público y lo privado (verbenas, celebraciones de cumpleaños, festividades religiosas, entre otros).

Esta propuesta de elaboración del inventario del patrimonio gastronómico de Risaralda es una forma de analizar, desde otra perspectiva, ese sincretismo cultural del cual son resultado las personas $y$, también, una forma de contribuir a la construcción y apropiación de otros referentes patrimoniales en relación con las políticas públicas frente al fomento del Paisaje Cultural Cafetero. Sobre esto último, si bien el Plan de Desarrollo 20162019 «Risaralda: verde y emprendedora», del actual gobernador Sigifredo Salazar, contempla dentro de sus programas la protección y promoción de la diversidad del patrimonio cultural del departamento de Risaralda, no hay claridades respecto a la preservación, promoción y difusión del patrimonio cultural gastronómico del departamento ${ }^{12}$.

Esta situación lleva a rastrear algunos referentes bibliográficos que, desde diferentes enfoques temáticos y metodológicos, hablan sobre la gastronomía risaraldense. Al hacer dicho rastreo, se encuentra que, a la fecha, no existe ninguna publicación sistemática

12 Gobernación de Risaralda-Secretaría de Planeación, «Plan de Desarrollo 2016-2019: Risaralda, verde y emprendedora» (plan de desarrollo, Gobernación de Risaralda, 2016), 56. 
sobre dicha gastronomía, pero sí registran estudios y proyectos, los cuales abordan este tema y resultan útiles para ingresar en este mundo tan complejo como es el de las cocinas del departamento.

\section{Objetivos}

\section{Objetivo general}

Reconocer la diversidad de las prácticas culturales gastronómicas de los catorce municipios del departamento de Risaralda, por medio de la interacción con habitantes o portadores de los saberes tradicionales, con el fin de consignarlos en un inventario gastronómico de la región.

\section{Objetivos específicos}

Catalogar las adaptaciones, variables y combinaciones alimenticias de las gastronomías locales, sus ingredientes y formas de preparación en cada uno de los catorce municipios de Risaralda.

Describir las mutaciones, transformaciones e hibridaciones de los gustos gastronómicos en el departamento de Risaralda.

Contribuir a la apropiación social y colectiva de la diversidad del patrimonio cultural de Risaralda mediante la socialización del inventario de prácticas culturales gastronómicas con las comunidades locales.

\section{Metodología}

La metodología propuesta para el presente proyecto de extensión social y cultural tendrá un enfoque interdisciplinario, el cual reúne técnicas cualitativas etnográficas de intervención cultural que permiten categorizar o inventariar la diversidad del patrimonio gastronómico del departamento de Risaralda. Para este efecto, la propuesta se basó en el documento titulado 
«Procesos de identificación y recomendación de salvaguardia 2015» sobre inventarios del patrimonio cultural inmaterial del Ministerio de Cultura ${ }^{13}$, en el cual se plantean cuatro procesos diferenciados que deben estar constantemente interrelacionados, en las siguientes fases:

\section{Fase nro. 1. Documentar y concretar}

Inicialmente se propone realizar un rastreo bibliográfico y documental, con el fin de obtener información relacionada respecto a los referentes gastronómicos de los distintos municipios del departamento y de la región. La documentación se halla en diversas fuentes y puede dar cuenta de contenidos históricos, etnográficos y recetarios tradicionales o populares que podrán nutrirse con nuevos hallazgos y nuevas fuentes, a medida que se va avanza en el proceso de recolección de información. De forma paralela, en esta fase se harán gestiones con entidades públicas como las casas de cultura, el área de cultura y las bibliotecas de Comfamiliar Risaralda, las cuales facilitan el acercamiento con personas o comunidades interesadas en este tipo de temáticas en cada uno de los municipios-, para socializar los alcances y objetivos de esta propuesta en las distintas fases.

Con esta proposición se busca dar continuidad a los proyectos de extensión cultural realizados por el Semillero de Investigación Formativa en Historia, Cultura Política y Educación y por Comfamiliar Risaralda desde el año 2015, a saber el «Mapa histórico-cultural de Risaralda: Fortalecimiento de los procesos organizativos en torno a la gestión y políticas culturales», la «Expedición Risaralda 50 años: exposición itinerante del mapa histórico cultural departamental» $\mathrm{y}$ «Semillas para la historia: bases para la investigación formativa en historia local y microhistoria en Risaralda». Todos los proyectos han contado con la financiación de la Vicerrectoría de Investigaciones, Innovación y Extensión

13 Ministerio De Cultura, Proceso de identificación y recomendaciones de salvaguardia 2015 (Bogotá: Ministerio de Cultura, 2015) 
de la Universidad Tecnológica Pereira y los resultados han sido socializados con las personas que brindaron información para los mismos y en otros escenarios como los encuentros de semilleros a nivel departamental y regional. Además, se obtuvo el primer puesto en el Concurso de Experiencias Significativas Docentes de 2017, en la categoría de Historia de Risaralda, con el libro «50/60. Una historia compartida. Investigación 50 años de Risaralda y 60 años de Comfamiliar. Mapa histórico cultural», el cual fue resultado del proyecto de extensión «Mapa histórico cultural de Risaralda».

\section{Fase nro. 2. Trabajo de campo}

Esta fase consta de una serie de visitas iniciales a los catorce municipios del departamento y contempla actividades de observación participativa (con la comunidad que se observa al visitar áreas de cultivo, crianza de animales, cocinas domésticas, galerías, plazas de mercado, entre otros), de entrevistas y de registro gráfico y audiovisual, para buscar identificar elementos propios del patrimonio gastronómico de cada municipio, los cuales podrán estar identificados dentro de lo denominado el circuito cultural gastronómico, el cual permite entender diversas fases que intervienen en el proceso de la gastronomía.

Cada uno de los participantes del proyecto llevará a cabo un diario de campo que permita describir las impresiones y la información obtenida en las visitas. A su vez, elaborará fichas de registro para hacer la caracterización de lo obtenido en dicha salida. Estas fichas tendrán como referente el formato sugerido por el Ministerio de Cultura, el cual propone incluir datos generales; descripción geográfica y económica; transformaciones sociales; cambios culturales; mecanismos de transmisión; relevancia de la manifestación patrimonial para la comunidad involucrada; riesgos o amenazas y documentación relacionada como fotografías, audios, videos, mapas, bibliografía, entre otras. 
En estas salidas de campo también se hará uso de un formato de consentimiento informado con los portadores de saberes tradicionales, con el fin de tener su autorización en el uso de la información y el registro de esta.

\section{Fase nro. 3. Desarrollo de los talleres de socialización y retroalimentación con los grupos de los municipios}

En este punto, con el propósito de comunicar lo obtenido en el proceso, se pretende conjugar la información recolectada, en la fase de la documentación y el trabajo de campo, para realizar una serie de talleres de socialización y valoración del patrimonio gastronómico con las personas interesadas de cada uno de los municipios. Estos encuentros tienen como objetivo retroalimentar de manera didáctica con los participantes la variedad, la diversidad y los hallazgos de su patrimonio gastronómico, como un elemento de identificación y diferenciación cultural que permita generar una mayor apropiación social del conocimiento. Se busca propiciar un diálogo abierto con la comunidad a través del cual se puedan rastrear recuerdos, sensaciones, creencias y costumbres con el enfoque de la teoría sociocultural de Vygotsky ${ }^{14}$, con el fin de generar una participación proactiva y destacar la interacción entre el desarrollo de las personas y su cultura, lo cual permita proponer y construir un inventario gastronómico en cada municipio del departamento de Risaralda.

Fase nro. 4. Evaluación de la información, registro e inventario del patrimonio gastronómico de los municipios

Como última fase del proyecto se hizo una revisión de la información recolectada en las distintas etapas del proceso para determinar el cumplimiento de los objetivos, sistematizar, generar reflexiones y conclusiones que determinan los resultados del inventario gastronómico de Risaralda, los cuales fueron

14 Lev Vygotsky, El desarrollo de los procesos psicológicos superiores (Barcelona: Crítica, 1979). 
consignados en la cartilla publicada por la Vicerrectoría de Investigación, Innovación y Extensión de la UTP y en un video documental - como productos finales del proyecto-. Adicionalmente, se elaboró un informe parcial y un informe final con las impresiones del proyecto.

\section{Resultados}

Tras el trabajo de campo en las localidades, donde se visitaron los portadores del saber gastronómico, se recopilaron ciento veintidós recetas como insumo principal para la realización del inventario y de los talleres de socialización. En estos últimos se presentó un microdocumental realizado específicamente en cada municipio del departamento, el cual muestra parte del patrimonio gastronómico local y da relevancia a alguna receta o producto de la gastronomía de la población, aquella que fue preparada con habitantes de la localidad y con el ánimo de difundir el patrimonio cultural del departamento. De esta forma, se realizaron catorce videos - microdocumentales - por cada uno de los municipios. Asimismo, se entregó un texto a la Vicerrectoría de Investigaciones, Innovación y Extensión de la UTP con el diseño metodológico del proyecto y con los resultados y las conclusiones obtenidas durante el desarrollo de esta iniciativa, todo ello para su publicación.

\section{Población beneficiada}

La TABLA NRO. 1 muestra el número de asistentes a los talleres de socialización realizados: 
Tabla NRO. 1. Asistentes a los talleres de socialización realizados.

\begin{tabular}{|l|l|l|}
\hline Fecha & Municipio & Asistentes \\
\hline Septiembre 17 & Apía & 12 \\
\hline Septiembre19 & Belén de Umbría & 41 \\
\hline Septiembre 23 & Quinchía & 26 \\
\hline Septiembre 24 & Balboa & 13 \\
\hline Octubre 10 & La Celia & 24 \\
\hline Octubre 11 & Santuario & 10 \\
\hline Octubre 16 & Mistrató & 40 \\
\hline Octubre 22 & Guática & 10 \\
\hline Octubre 24 & Pueblo Rico & 9 \\
\hline Octubre 25 & Santa Cecilia & 14 \\
\hline Noviembre 1 & Santa Rosa Cabal & 14 \\
\hline Noviembre 12 & La Virginia & 48 \\
\hline Noviembre 26 & Pereira-San Fernando & 12 \\
\hline Noviembre 27 & Pereira-Centro & 5 \\
\hline Noviembre 28 & Dosquebradas & 17 \\
\hline Noviembre 29 & Pereira-Guayacanes & 25 \\
\hline Total asistentes & & 320 \\
\hline
\end{tabular}

Elaboración propia.

\section{CONCLUSIONES}

La gastronomía regional abarca un conjunto de prácticas y saberes diversos que incluyen las labores agrícolas, el cultivo de los alimentos, la preparación en recetas y el consumo de estas; razón por la cual se configuran en un ámbito cultural multifacético y diverso. En este sentido, se destaca la importancia de las distintas zonas geográficas de Risaralda, por ejemplo, las hoyas de los ríos Risaralda, San Juan, Consotá y Cauca; y la zona montañosa de las cordilleras central y occidental, con sus diferentes pisos térmicos, que determinan la diversidad de alimentos disponibles, lo cual 
permite reseñar los cultivos dominantes y las dietas alimenticias de los pobladores del departamento. También se reconoce el rol central de la mujer en la alimentación como principales portadoras del saber gastronómico. Ellas conjugan sus conocimientos, los cuales han sido generalmente legados familiares, con sus posibilidades económicas, las cuales, junto con la creatividad y el gusto propio de las familias al alimentarse, logran articular elementos necesarios para desarrollar innovaciones culinarias y mantener al mismo tiempo las tradiciones gastronómicas.

Igualmente, se destaca que la comida se encuentra relacionada constantemente con otras dinámicas sociales y económicas. Muestra de ello son ciertos ciclos económicos, los cuales fueron detectados en cada municipio y que han influenciado históricamente las formas de cocinar los alimentos y los productos disponibles para el consumo. Por ejemplo, existen diferencias respecto de las dinámicas alimenticias que se dieron con la llegada de las fábricas, de la industrialización y con el crecimiento de la población urbana desde mediados del siglo xx. Estos procesos no solo cambiaron los productos que se consumían, sino también los horarios y los gustos alimenticios de sus pobladores. Así, dicho proceso industrial contrastó con el auge y la consolidación de la economía cafetera presente en gran parte del departamento - en la primera mitad del mencionado siglo-, la cual exigía una ingesta calórica mucho mayor por parte de los trabajadores, aquella que era rica en carbohidratos y que, adicionalmente, permitía su traslado por las zonas laborales, por lo que dio paso a la creación del famoso «fiambre», plato que además se ha transformado en sus usos y contenidos.

Ante este importante aspecto, cabe preguntar si la comida, o en este caso el fiambre como ejemplo, fue la misma para un mazamorrero o barequero de las minas, un arriero o un recolector de café que para las obreras de las trilladoras y las maquilas; lo cual permite señalar el hecho de que las llamadas «comidas típicas» sufren un proceso histórico de hibridación constante. Ante esta 
cuestión, se puede argumentar que existen platos o recetas con un nombre genérico (frijoles, bandeja paisa, entre otros), pero estos están sujetos a múltiples formas de prepararlos, en respuesta a diversos factores económicos y culturales.

Incluso, esas mismas dinámicas económicas y culturales se ven reflejadas en las ofertas de los supermercados locales y en la dieta de los trabajadores, las cuales han llevado a incorporar nuevos productos a la dieta alimenticia de acuerdo con la oferta de los distribuidores comerciales. Ejemplo de ello es la inclusión de las pastas o fideos, producto que es consumido cotidianamente en las cocinas de las familias y que, además, representa grandes facilidades, ahorro de tiempo y un bajo costo. También se plantea la cuestión de si en el caso de las plazas de mercado en los municipios, estas se configuran como el lugar de acopio, de reunión y de saberes tradicionales o, simplemente, existen como relegadas por otro tipo de dinámicas económicas como la proliferación de las cadenas de supermercados en la mayoría de los lugares de Risaralda.

Del mismo modo, se señala la importancia de la formación de empresarios alrededor de productos gastronómicos de la región como por ejemplo el chorizo santarrosano, el cual ha marcado la identidad de dicho municipio y el progreso del fenómeno de asociatividad a nivel departamental que, en la mayoría de los casos, se encuentra respaldado por los planes de desarrollo, aquellos que apuntan a fomentar concursos de comidas típicas con visiones patrimonializantes, las cuales persiguen versiones originales o puras de los productos como es el caso de «La calle del café» que se desarrolla en varios municipios del departamento.

El tema de la tradición ocupó muchas de las discusiones grupales. Si bien se puede hablar de una relación muy estrecha entre la usanza gastronómica y las identidades locales, al mismo tiempo se puede expresar la idea de arraigo cultural que excluye otros elementos presentes en la gastronomía regional o no permite 
ver grandes cambios en las formas de alimentación que, en el presente, no serían tan tradicionales. Otra situación para analizar, son los mitos alrededor de la alimentación, un ejemplo sobre esto es el plato de la «gallina enterrada» de Apía o los productos afrodisiacos - presentes en muchos de los municipios- que derivan de la fuerza que aún tiene el arraigo a la colonización antioqueña o la sobrevaloración de lo afrodescendiente en relación con la potencia sexual.

Esto invita a pensar que la gastronomía es resultado de la diversidad y la heterogeneidad contenida en el departamento. Esta no necesariamente responde a algún elemento dominante o característico dentro de ella. La cocina risaraldense es resultado de influencias antioqueñas, caucanas, afrodescendientes, indígenas, boyacenses, colonias extranjeras, ente otras.

Una observación final lleva a pensar en ciertas imposturas culturales de lo gastronómico y la idea de la «autenticidad» en la comida; discusiones muy propias de los debates multiculturales. Si bien, el formato del proyecto estaba, en gran medida, enfocado a lo tradicional, fue muy significativo evidenciar los cambios culturales, las hibridaciones de las comidas y el influjo de la globalización en las economías locales; fenómenos enmarcados en una expansión de cultivos que responde a la demanda de productos para la exportación y a la llegada de productos industrializados a los municipios, los cuales han acomodado las economías locales a los grandes cambios globales y generacionales.

\section{Bibliografía}

Anderson, Benedict. Comunidades imaginadas. Reflexiones sobre el origen y la difusión del nacionalismo. Trad. por Eduardo L. Suárez. México: Fondo de Cultura Económica, 1993. 
Club de Leones Pereira-Maraya, comp. Risaralda: Patrimonio cultural gastronómico, natural y arquitectónico. Pereira: Servimpresos Publicidad, Gobernación de Risaralda, 2010.

Correa Ramírez, Jhon Jaime; Anderson Paul Gil Pérez; Jhon Anderson Tascón Bedoya; Edwin Mauricio López García y Maribel Valencia López. 50/60, Una historia compartida. Investigación 50 años de Risaralda y 60 años de Comfamiliar. Mapa histórico cultural. Bogotá: Editorial Planeta, 2016.

Correa Ramírez, Jhon Jaime; Anderson Paul Gil Pérez; Jhon Anderson Tascón Bedoya; Christian Camilo Calderón Gil; Edwin Mauricio lópez García y Maribel Valencia López. Visión histórica y dinámica del mapa cultural de Risaralda. Documento de trabajo, Pereira: Universidad Tecnológica de Pereira, 2016.

Cubides Palomares, Cristian Ferney, Proyecto en curso terminado. Sabores de Risaralda: construcción de un inventario intercultural del patrimonio gastronómico de la región. https:// invessoft.com/ponencias2019/pdf/ponenciaEnCurso/ Cristian\%20Ferney\%20Cubides\%20Palomares.pdf.

Estrada, Julián, «Antioquia y Eje Cafetero, dedicación y carácter». En Colombia, cocina de regiones, dir. por María Lía Neira, 20-35. Bogotá: MNR Comunicaciones \& Ediciones S.A.S., Librería Nacional, 2012.

. Fogón antioqueño. Bogotá: Fondo de Cultura Económica, 2016.

Fundación para el Desarrollo Social Transformemos. Cocina palenquera para el mundo. Bogotá: Fundación para el Desarrollo Social Transformemos, 2014. 
García Nossa, Antonio. Geografía económica de Colombia. IV: Caldas. Bogotá: Contraloría General de la República, Imprenta Nacional, 1937.

Gobernación de Risaralda. Atlas de Risaralda. Pereira: Fondo Editorial Gobernación de Risaralda, 2007.

Atlas de Risaralda. Pereira: Fondo Editorial Departamento de Risaralda, 1988.

. Risaralda, 40 años de grandeza. Pereira: Fondo Editorial Gobernación de Risaralda, 2007.

Gobernación de Risaralda y Secretaría de Planeación. Plan de Desarrollo 2016-2019: Risaralda, verde y emprendedora. Gobernación de Risaralda, 2016.

Gutiérrez de Pineda, Virginia. Familia y cultura en Colombia: Tipologías, funciones y dinámica de la familia. Manifestaciones múltiples a través del mosaico cultural y sus estructuras sociales,

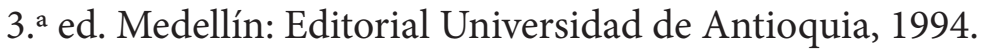

Jaramillo, Hugo Ángel y Alfredo Cardona Tobón, «Unidad histórica». En Atlas de Risaralda, de la Gobernación de Risaralda, 108-116. Pereira: Fondo Editorial Departamento de Risaralda, 1988.

Ministerio de Cultura-Dirección de Patrimonio. Política para el conocimiento, la salvaguardia y el fomento de la alimentación y las cocinas tradicionales de Colombia. Bogotá: Ministerio de Cultura, 2012.

. Inventarios de patrimonio cultural inmaterial. Proceso de identificación y recomendación de salvaguardia 2015. Bogotá: Ministerio de Cultura, 2015. 
Morales Benítez, Otto. Teoría y aplicación de las historias locales y regionales. Manizales: Universidad de Caldas, 1995.

Muzeum Gastronomie. «La gastronomía». Acceso el 25 de octubre de 2018. http://www.muzeumgastronomie.cz/es/ node/75.

Organización de las Naciones Unidas para la Educación, la Ciencia Y la Cultura [Unesco]. «Patrimonio inmaterial». Acceso el 18 de octubre de 2018. http://www. unesco.org/new/es/santiago/culture/intangible-heritage/.

. «Patrimonio cultural inmaterial». Acceso el 25 de octubre de 2018. https://es.unesco.org/themes/patrimonio-culturalinmaterial.

Osorio Velásquez, Jorge Enrique y Álvaro Acevedo Tarazona, eds. Paisaje cultural cafetero. Risaralda. Colombia. Pereira: Universidad Católica Popular del Risaralda, Universidad Tecnológica de Pereira, 2008.

Robledo Correa, Emilio. Geografía médica y nosológica del departamento de Caldas. Manizales: Imprenta Departamental, 1916.

Sánchez, Enrique y Carlos E. Sánchez. Paseo de olla: Recetas de las cocinas regionales de Colombia. Bogotá: Ministerio de Cultura, 2012.

SENA Caldas, Grupo de Investigación del Centro de Comercio y SERvicios [GRICS)]. «Patrimoniogastronómico de Caldas. Caldas, un amasijo de sabores y saberes». CD, SENA Caldas, s.f. 
Valencia Llano, Albeiro. Vida cotidiana y desarrollo regional en la colonización antioqueña. Manizales: Centro Editorial Universidad de Caldas, 1996.

Vygotsky, Lev. El desarrollo de los procesos psicológicos superiores. Barcelona: Crítica, 1979. 


\title{
Guapi «Guapi aprende haciendo»
}

\author{
José ANDRÉS CHAVÉs OSORIO \\ angie Tatiana Rengifo Oviedo \\ EDWARD ANDRÉS GONZÁLEZ RÍOS \\ JHON EDWAR VÉLEZ CORTES \\ MANUELA RESTREPO GALVIS \\ Grupo de Investigación Robótica Aplicada \\ Universidad Tecnológica de Pereira
}

\section{RESUMEN}

Guapi es un municipio ubicado en el departamento del Cauca y una representación neta del pacífico colombiano. Según el DANE [1], la población estimada para el 2011 fue de 29262 habitantes. La riqueza de los recursos naturales de este lugar centra las actividades económicas en el sector primario como labores de pesca, agricultura, minería y extracción de madera. Durante años, la violencia en Colombia, debido al conflicto armado, a la falta de inversión gubernamental y a la corrupción, ha golpeado al municipio; convirtiéndolo en una población vulnerable, de difícil acceso, sin oportunidades de empleo y desarrollo para su población. 
Las consecuencias de los problemas sociales y económicos de Guapi se ven reflejadas en la educación, la cual carece de avances tecnológicos y metodologías avanzadas de estudio. Esto debido; a que, actualmente, conocimientos en electrónica, mecánica y programación hacen que la sociedad tenga mejor calidad de vida y procesos más eficientes, todo ello al utilizar herramientas a nivel global que mejoran el rendimiento de su desarrollo económico y social; y al interactuar de manera constante, en escenarios con automatización, domótica (automatización de las casas y edificios), ascensores, computadores y miles de dispositivos que salen al mercado cada día.

La consolidación de una educación que relacione los avances tecnológicos a nivel global, los cuales permitan aumentar la calidad para el municipio de Guapi, inicia por el uso de herramientas que despierten en los estudiantes la preocupación y el interés por desarrollar proyectos que vayan en pro del desarrollo social. Es por esto por lo que, el proyecto «Guapi aprende haciendo» se enfoca en la enseñanza de conceptos básicos de electrónica, mecánica y programación a los alumnos de media técnica de la Institución Educativa San José del municipio, a través de herramientas didácticas y metodologías, como «aprender haciendo», que permitan a los educandos apropiar el conocimiento en estas áreas y desarrollar el pensamiento crítico para solucionar problemáticas de su comunidad a través de las TICS. Dicha metodología fue creada por el psicólogo estadounidense John Dewey [2] y consiste en el aprendizaje por medio de la experimentación, donde la estimulación del aprendizaje se realiza a través de la teoría unida a la práctica. Utilizando herramientas que permitan el desarrollo de proyectos, tales como el caso de las áreas mencionadas, se empleó la plataforma Arduino [3], la cual es multipropósito y se basa en software y hardware libre, flexible y fácil de usar, por lo cual ha sido bastante utilizada a través del mundo con el fin de dar una introducción a la programación, desde los colegios hasta las universidades. 
Palabras clave: robótica, STEAM, educación, Guapi.

\section{Abstract}

Guapi town is in the department of Cauca and a net representation of the Colombian pacific. According to Dane [1], the estimated dwellers for 2011 was 29,262 people. The wealth of natural resources of this municipality focuses economic activities in the primary sector with fishing, agriculture, mining and timber extraction. For years, violence in Colombia over the armed conflict, lack of government investment and corruption have hit the town, making it a vulnerable people, difficult to access, without employment and development opportunities for its dwellers.

The consequences of the social and economic problems of Guapi are reflected in education, the quality of technological advances and advanced study methodologies. This is because they currently have knowledge in electronics, mechanics and programming that make society have the best quality of life and most efficient processes using tools at a global level that improve the performance of their economic and social development, constantly interacting with the automation, domotic (home and building automation), elevators, computers and other devices that go on the market every day.

The consolidation of an education that relates the technological advances at a global level that will increase the quality for the municipality of Guapi, begins with the use of tools that arouse in students the concern and interest in developing projects that impact social development. This is why, "Guapi learn by doing" focuses on teaching basic concepts of electronics, mechanics and programming to technical media students of school Institución Educativa San José of the Guapi town, through didactic tools and methodologies such as "learning by doing", which adapt to students appropriate for knowledge in these areas and develop critical thinking to solve problematic problems in their 
community through the tics. The "learn by doing" methodology was created by the American psychologist John Dewey [2] and consists of learning through experimentation, where learning stimulation is carried out through the theory linked to practice using tools for the case of the identified areas will use the Arduino platform [3], the quality is multipurpose and is based on free and flexible software and hardware to use projects, so it has been quite complicated in the world to enter programming, since colleges to universities.

Keywords: Robotic, STEAM, Education, Guapi.

\section{Introducción}

«Guapi aprende haciendo» está enfocado en el desarrollo de una primera prueba piloto con estudiantes de media técnica de una institución educativa y de la comunidad de Guapi. Esta se enfoca en la enseñanza de los principios básicos de la robótica y de cómo la tecnología utilizada de manera correcta en la colectividad y en los espacios escolares, permiten dar solución, de manera más productiva, y mejorar la calidad de vida del mismo cuerpo social al que pertenecen.

El proyecto se desarrolló con un enfoque de «aprende haciendo» por lo cual, el curso se enfocó en dar los conceptos básicos y en generar prácticas que permitieran al estudiantado desarrollar las actividades y comprender los términos de manera activa. De igual modo, se elaboró una cartilla y un foro enfocados en la comunidad con la cual se trabajó, es decir, habitantes, docentes y estudiantes del municipio de Guapi, los cuales fueron el foco principal para cada actividad. 


\section{Objetivos}

\section{Objetivo general:}

Desarrollar actividades que promuevan la apropiación social del conocimiento en electrónica, mecánica y programación con los estudiantes de media técnica de la Institución Educativa San José, para disminuir las brechas tecnológicas y digitales en el municipio de Guapi.

\section{Objetivos específicos:}

Realizar un estudio de los conocimientos previos a la ejecución de la propuesta «Guapi aprende haciendo» que tienen los estudiantes frente a conceptos básicos de electrónica, mecánica y programación.

Diseñar guías de trabajo, con la metodología «aprender haciendo», que permitan orientar el desarrollo de las actividades a realizar.

Realizar un curso con los estudiantes de media técnica de la Institución Educativa San José que permita la apropiación de conocimiento en conceptos básicos de electrónica, mecánica y programación.

Realizar un espacio de interacción con docentes y estudiantes de la Institución Educativa San José, el cual promueva discusiones sobre la robótica y el uso de metodologías STEAM (Science, Technology, Engineering, Art, Mathematics) en la comunidad y en las aulas de clases. 


\section{Metodología}

Objetivo nro. 1.

Realizar un estudio de los conocimientos previos a la ejecución de la propuesta "Guapi aprende haciendo» que tienen los estudiantes frente a conceptos básicos de electrónica, mecánica y programación.

\section{Actividades:}

1. Revisión del estado del arte en materia a procesos, metodologías y herramientas implementadas para evaluar o validar un proceso de enseñanza-aprendizaje guiado para jóvenes de media técnica.

2. Formular y sistematizar las herramientas para el diagnóstico de conocimientos previos de los estudiantes como, por ejemplo, la formulación de pruebas, de encuestas, de entrevistas, entre otras.

3. Realizar y cumplir los requisitos para la herramienta de evaluación seleccionada.

4. Analizar la evaluación realizada a los estudiantes frente a conceptos básicos de electrónica, mecánica y programación. 
Figura NRo. 1. Prueba inicial y final realizada a los estudiantes en el curso.

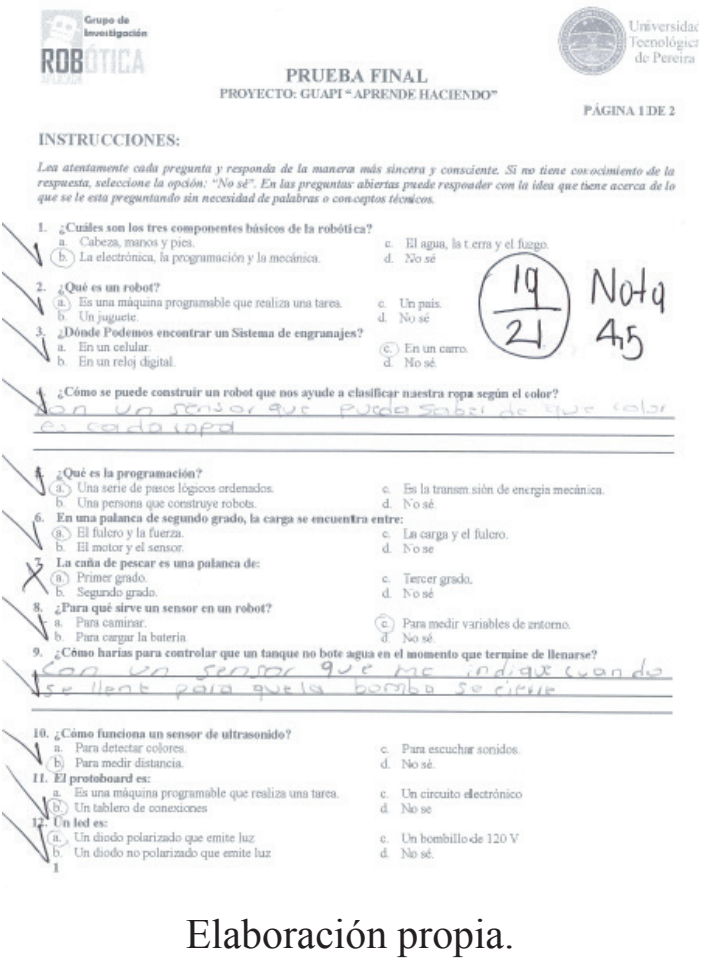

Objetivo nro. 2.

Diseñar guías de trabajo, con la metodología «aprender haciendo", las cuales permitan orientar el desarrollo de las actividades a realizar.

Actividades:

1. Planificación detallada del contenido temático y curricular orientado a la enseñanza de conceptos básicos en electrónica, mecánica y programación.

2. Determinar las fuentes, técnicas y herramientas de recolección de información para llevar registro de todos los resultados. 
3. Formular y sistematizar las herramientas para la evaluación de la propuesta didáctica a implementar.

4. Digitalizar el contenido temático y curricular, por medio de cartillas con las prácticas desarrolladas para el aprendizaje de los conceptos básicos en electrónica, mecánica y programación.

5. Generación impresa de la cartilla digitalizada en la actividad número cuatro.

Figura nRo. 2. Caratula de la cartilla digitalizada e impresa entregada a los docentes de Guapi.

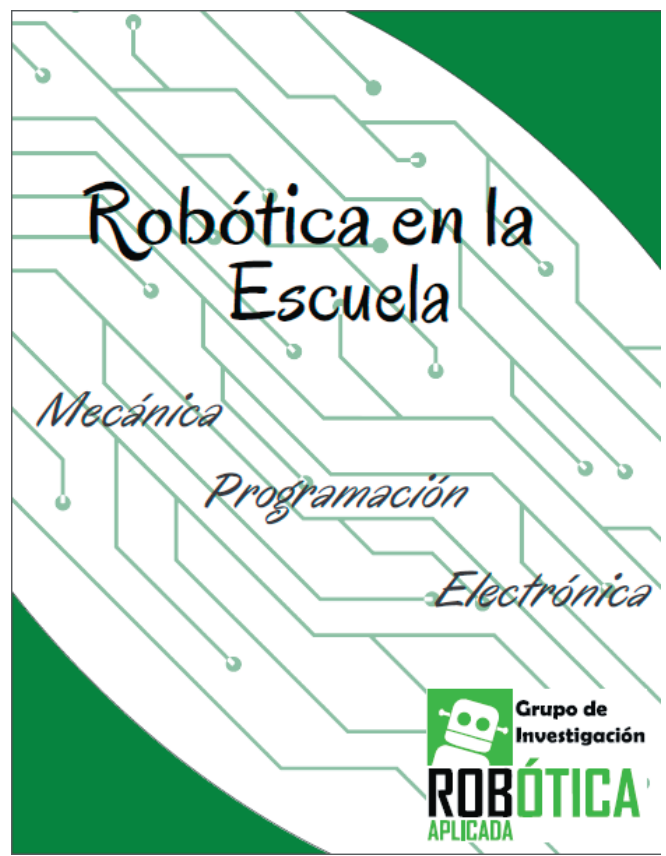

Elaboración propia.

Objetivo nro. 3.

Realizar un curso con los estudiantes de media técnica de la Institución Educativa San José que permita la apropiación de conocimiento en conceptos básicos de electrónica, mecánica y programación. 


\section{Actividades:}

1. Capacitar a los facilitadores y monitores en la parte técnica para el manejo de los equipos y kits de programación, electrónica y mecánica.

2. Capacitación a los facilitadores y monitores en la parte pedagógica para la interacción con los jóvenes mediante los distintos proyectos a implementar.

3. Realizar la selección de los participantes en las actividades a ejecutar, los cuales deben haber diligenciado el formulario de consentimiento y la autorización de uso de datos personales, estar matriculado en la Institución Educativa San José y tener un buen rendimiento académico.

4. Ejecución de la propuesta didáctica para jóvenes en grupos divididos por veinte participantes.

5. Aplicación de las distintas herramientas de diagnóstico y evaluación previamente seleccionadas en los objetivos nro. 1 y 2 .

6. Aplicación de las fuentes, técnicas y herramientas de recolección de información determinadas en el objetivo nro. 2.

7. Sistematización de los resultados e información obtenida en la ejecución de las actividades del curso.

8. Análisis cualitativo de los resultados obtenidos. 
Figura NRo. 3. Curso desarrollado con los estudiantes de la Institución Educativa San José.

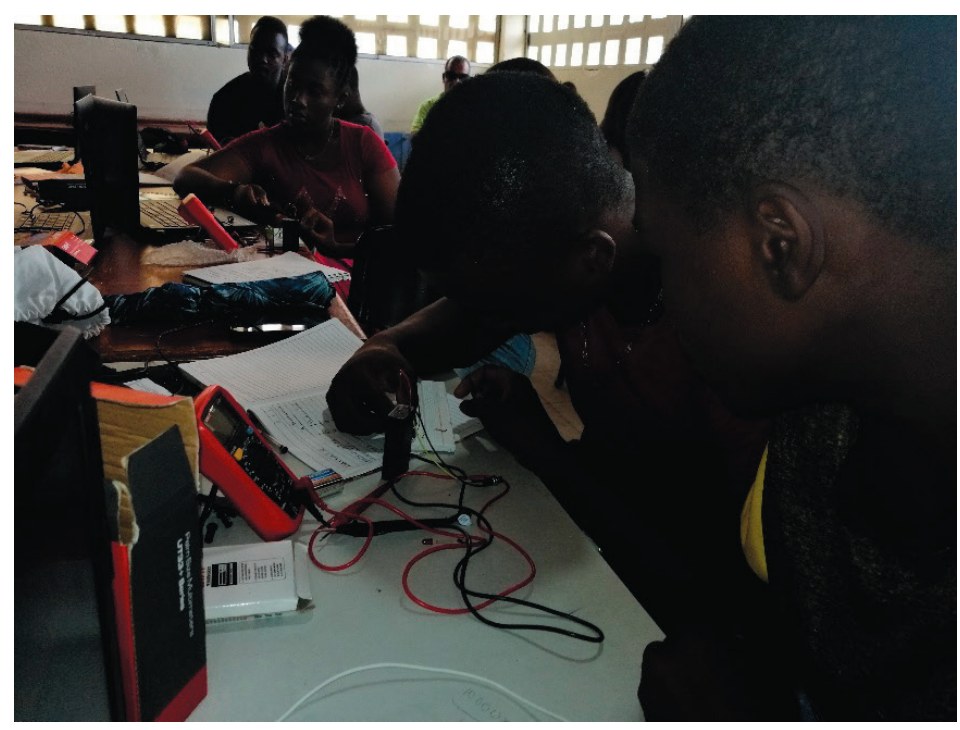

Elaboración propia.

FIGURA NRO. 4. Muestra del proyecto final del curso.

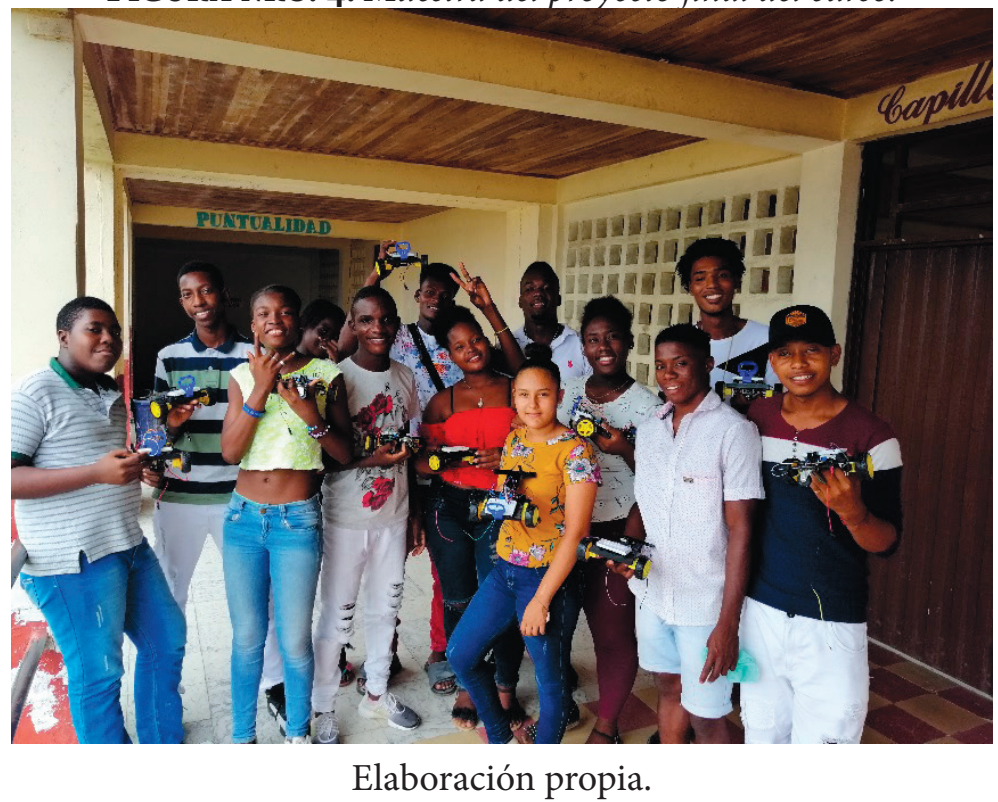


Objetivo nro. 4.

Realizar un espacio de interacción con docentes y estudiantes de la Institución Educativa San José, el cual promueva discusiones sobre la robótica y el uso de metodologías STEAM en la comunidad y en las aulas de clases.

Actividades:

1. Solicitar autorización del uso del auditorio de la Institución Educativa San José para realizar el foro de robótica y del uso de metodologías STEAM en la comunidad y en las aulas de clase.

2. Acordar con la dirección de la Institución Educativa San José, la hora y el día para realizar el foro.

3. Planificación detallada de la logística, el contenido temático del foro y las actividades a realizar dentro del mismo.

4. Difusión del foro con estudiantes y docentes de la Institución Educativa San José.

5. Registro de participantes en el foro y aplicación de las fuentes, técnicas y herramientas de recolección de información determinadas en el objetivo nro. 2.

6. Ejecución del foro de robótica y del uso de metodologías STEAM en la comunidad y en las aulas de clase.

7. Sistematización de los resultados e información obtenida en la ejecución del foro.

8. Análisis cualitativo de los resultados obtenidos. 
Figura NRO. 5. Inicio del Foro Robótica y STEAM en la comunidad y en las aulas de clase.

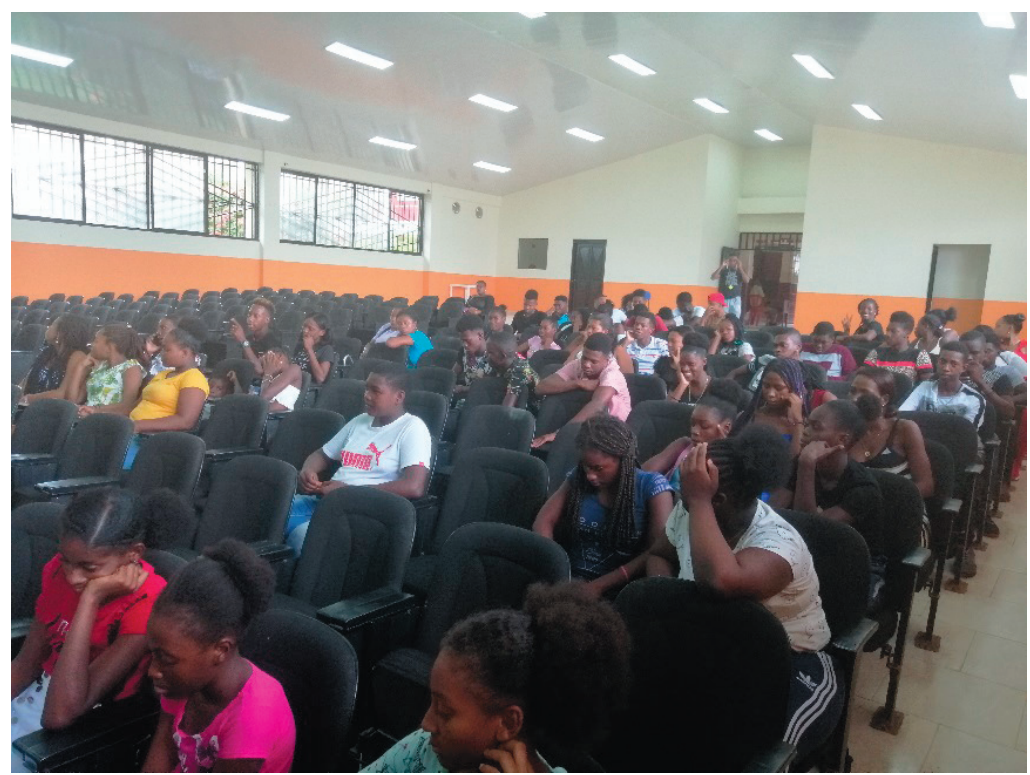

Elaboración propia.

Resultados.

\section{Educación continua}

Se desarrollaron dos cursos sobre los principios de la robótica con capacidad para veinte estudiantes cada uno, con un total de cuarenta estudiantes capacitados.

Eventos de divulgación académica y cultural

Se desarrolló un foro de robótica y del uso de metodologías STEAM en la comunidad y en las aulas de clase con más de ochenta asistentes. 


\section{Comunicación social del conocimiento}

Se desarrolló una cartilla con guías prácticas en electrónica, programación y mecánica. Esta fue llamada «Robótica en la escuela».

\section{Población beneficiada}

Se beneficiaron cuarenta y un jóvenes de la Institución Educativa San José del municipio de Guapi. Dicha jurisdicción cuenta con población vulnerable en el país y tiene difícil acceso al uso de tecnologías y a conocimientos en áreas como la electrónica, la programación y la robótica. Por ello se realizó un foro con los estudiantes y docentes de la institución anteriormente mencionada sobre temas relacionados con la robótica y el uso de metodologías STEAM en la comunidad y el aula clase. Este tuvo la participación de más de ochenta y cuatro personas.

\section{Conclusiones}

El desarrollo de cursos orientados al buen uso de la tecnología, en poblaciones donde esta es de difícil acceso, permite a la comunidad enfocar soluciones que posibilitan avanzar y ejecutar ideas para el mejoramiento de las herramientas utilizadas en las actividades diarias y elevar tanto su potencial en producción como, en calidad de vida.

Los jóvenes identifican cómo el desarrollo tecnológico puede potenciar su comunidad, al analizar cada una de las temáticas vistas frente al uso en el desarrollo de soluciones diarias.

Por medio del foro se permite visibilizar la importancia que los estudiantes, los docentes y los padres de familia le dan al buen uso de la tecnología. De esta manera, se posibilita el aprendizaje del desarrollo de prototipos robóticos para dar solución a problemáticas de la comunidad. 
El proceso desarrollado, en el cual se compartieron conocimientos con la comunidad y se escuchó el gusto por estas tecnologías, hacen que el llegar con la robótica a comunidades de difícil acceso, permita a la comunidad observar otras soluciones y modos de ver las problemáticas y vivencias diarias.

\section{Bibliografía}

[1] Departamento Administrativo Nacional de Estadística[DANE]. Datos censo 2005. [En línea]. Bogotá: DANE, 2007 [consultado 24 de octubre 2018]. Disponible: https://www.dane.gov.co/files/censo2005/perfil_pdf_ cg2005/19318t7t000.pdf.

[2] S. A. Schmidt. Inacap. Sabía usted que el «aprende haciendo» viene desde John Dewey. [En línea]. Lima: Ministerio de Ambiente, Gobierno de Perú, 2006. [consultado 24 de octubre 2018]. Disponible: http://www.minam.gob.pe/proyecolegios/ curso/curso-virtual/modulos/modulo2/3secundaria/m2_ secundaria/aprender_haciendo-john_dewey.pdf.

[3] Arduino. Teaching, inspiring and empowering. New York: Arduino, 2018 [consultado 24 de octubre 2018]. Disponible: https://www.arduino.cc/en/main/education.

[4] A. T. Rengifo Oviedo, «Robot de seguridad controlado por wifi "cerberus 1.0"» (proyecto de grado). Universidad Tecnológica de Pereira, Pereira, 2016.

[5] E. M. Sirpa Peredo, (2017, Abril. 10). «Robots: métodos de locomoción terrestre» [En línea]. Disponible en: https:// medium.com/@ericksirpa/robots-m\%c3\%a9todosdelocomoci\%c3\%b3n-terrestre-2964c68a9523. 
[6] F. Colque. Una guía práctica sobre el mundo de arduino, Disponible: Https://www.academia.edu/8875046/una gu\%c3\%ada_pr\%c3\%alctica_sobre_el_mundo_de_arduino.

[7] Instrumentación y CONTROL.NeT, Los instrumentos patrón en calibración: conceptos y características. Disponible: http:// instrumentacionycontrol.net/los-instrumentos-patron-encalibracion-conceptos-ycaracteristicas/.

[8] M. C. Rojas, «Piñones. Diente por diente y vuelta por vuelta». Disponible: https://www.ingenieriademetodos.com/app/ download/9156567369/pi\%c3\%blones.pdf?t=1508869357. 


\title{
Enseñar a hablar, leer y escribir. Una propuesta para la transformación didáctica de docentes en ejercicio del Eje Cafetero
}

\author{
JUAN MANUEL RAMÍrez RAVE \\ FABIÁN ANDRÉs CUELLAR VÉLEZ \\ Universidad Tecnológica de Pereira
}

Resumen

El presente informe tiene como finalidad exponer los alcances del proyecto Enseñar a hablar, leer y escribir y los ejes que lo articulan: el Diplomado en Didáctica de la Lectura y la Escritura (DILE) y el 1. ${ }^{\text {er }}$ Congreso Nacional en Didáctica de la Oralidad, Lectura y Escritura (DIoLEE). Los espacios creados para el desarrollo de dichas actividades cuentan con el apoyo de estudiantes de pregrado, docentes de instituciones educativas del departamento, egresados y estudiantes de posgrados en Literatura 
y Educación de la Universidad Tecnológica de Pereira, todos ellos pertenecientes al Grupo de Investigación en Literatura Latinoamericana y Enseñanza de la Literatura, esto con el fin de fomentar el diálogo centrado en la educación, la didáctica, los procesos de enseñanza de la lectura y la escritura, y la socialización de experiencias educativas en el aula y en entornos no convencionales.

Palabras clave: oralidad, lectura, escritura, escucha, didáctica.

\section{Abstract}

This report aims at exposing the scope of the project Teaching to speak, read and write and the axes that articulate it: The Diplomado in Didactics of the Reading and Writing and the first National Congress of Didactics of Orality, Reading and Writing. The spaces created for the development of these activities have the support of undergraduate students, educational institution teachers of Risaralda department, graduates and postgraduate students of Literature and Education of Universidad Tecnológica de Pereira, all of them belonging to the research group in Latin American Literature and the Teaching of Literature; this in order to foment the dialogue about education, didactics, reading and writing teaching processes, and the socialization of educational experiences into the classroom and into non-conventional environments.

Keywords: Orality, Reading, Writing, Listening, Didactics.

\section{Introducción}

La necesidad de reflexionar y transformar los procesos de enseñanza y aprendizaje en el aula se ve constantemente justificada por el bajo desempeño que presentan la mayoría de estudiantes, a nivel regional e incluso nacional, en las diferentes pruebas Saber y Saber Pro; pero más allá de esa mirada centrada en la evaluación, 
las competencias y los resultados de aprendizaje, se hace indispensable pensar de nuevo la educación y lo que se entiende -e intenta hacer - en los espacios escolares (jardines, colegios, universidades, bibliotecas, entre otros). Bajo este panorama, la apuesta por el mejoramiento en el desempeño y en el aprendizaje de los estudiantes debería ir ligada tanto con la transformación de las formas de entender la educación, como con las propuestas didácticas que permitan ampliar los conceptos de enseñanza y aprendizaje de la oralidad, la lectura, la escritura y la escucha.

La propuesta surge de las discusiones más recientes que sobre la calidad de la educación se han generado tanto a nivel nacional como continental, en donde se exhibe el bajo nivel [de desempeño] de [...] [los] estudiantes [respecto] a las competencias [desarrolladas] en las áreas de ciencias, pensamiento matemático y lenguaje (UTP, 2019).

En lo que respecta a esta última área, en un análisis comparativo realizado por el Instituto Colombiano para la Evaluación de la Calidad de la Educación (ICFES) sobre los resultados obtenidos en 2015 y 2018 en las pruebas PISA (Programa para la Evaluación Internacional de Alumnos) se muestra una disminución de 425 a 418 puntos, respectivamente. Pero no solo este, sino también el resultado de los diagnósticos de diversos estudios coincide en que los estudiantes colombianos tienen dificultades - inclusopara comprender y producir textos sencillos. Bajo las actuales circunstancias, no es factible esperar resultados más alentadores, pues en el medio académico y educativo, la investigación y aplicación de los avances en didáctica y pedagogía de la lectura y la escritura tienen poco arraigo y menos se piensa en integrar su enseñanza en todas las materias como una herramienta que pueda ayudar a pensar los contenidos conceptuales.

En este sentido, se requieren profesionales que, más que enseñar a decodificar la lengua, asuman el reto de convertir la escuela, el aula, el taller, el blog, el vídeo chat, entre una amplia diversidad de elementos en espacios de prácticas sociales de 
múltiples y complejas lecturas y escrituras, así como de diversas y profundas interpretaciones, las cuales ofrezcan a los estudiantes oportunidades de expresarse y reflexionar sobre su lengua materna en contextos diversos.

Bajo esta perspectiva, un enfoque transdisciplinar se hace fundamental, así como una mirada que, más allá de buscar explicaciones desde el déficit del estudiante $o$ en factores socioculturales, logre indagar al interior de la escuela (instituciones educativas) lo que hacen o potencialmente pueden llegar a realizar los profesores desde todas las asignaturas, para ayudar a que los alumnos avancen en su desarrollo de destrezas y habilidades implicadas en los procesos de oralidad, escucha, lectura y escritura.

\section{Objetivos}

\section{Objetivo general}

Fortalecer las prácticas de enseñanza y aprendizaje de docentes vinculados al sistema educativo y de estudiantes de último semestre de Licenciatura en torno a los procesos de lectura, escritura, oralidad y escucha en sus diversas modalidades, ciclos y niveles educacionales como una tarea articulada, transversal, situada e integral que acompañe las distintas instancias de aprendizajes de los niños, adolescentes y jóvenes.

\section{Objetivos específicos}

Desarrollar la tercera cohorte del Diplomado en Didáctica de la Lectura y la Escritura desde una perspectiva transdisciplinaria dirigido a docentes de educación básica y media del Eje Cafetero y el Norte del Valle.

Generar un espacio de diálogo y reflexión sobre los estudios actuales relacionados con los procesos de enseñanza/aprendizaje 
de la lectura y la escritura, en el cual se pueda ampliar la visión que se tiene de las nociones asociadas a dichos procesos y compartir las experiencias didácticas desarrolladas al interior del diplomado, con otras que se han construido en el contexto local, regional y nacional.

Desarrollar estrategias para el diagnóstico y la intervención en los procesos de lectura y escritura tanto en el aula como en otros espacios de formación.

Propiciar la creación de instrumentos, materiales y recursos didácticos que le permitan al docente mejorar las prácticas asociadas a la enseñanza de la lectura, la escritura, la oralidad y la escucha en el aula de clase y en espacios no formales de aprendizaje.

\section{Metodología}

En lo metodológico se desarrolló un proceso de planeación y organización de las diferentes actividades, así como una evaluación continua, durante y después de su ejecución, articulada al Diplomado en Didáctica de la Lectura y la Escritura (DILE) y al $1 .{ }^{\text {er }}$ Congreso Nacional en Didáctica de la Oralidad, Lectura, Escritura y Escucha (DIoLEE).

Para el desarrollo de la tercera cohorte de dicho diplomado se ejecutaron las siguientes acciones:

1. Convocatoria dirigida a docentes, talleristas y estudiantes de pregrado de instituciones educativas de Risaralda, los cuales fueron elegidos como becarios del diplomado DILE. Para ello se tuvo en consideración su trayectoria e impacto a partir del trabajo con comunidades rurales y urbanas.

2. Selección de docentes postulados y estudiantes pertenecientes a los Semilleros de Investigación en Narrativas Contemporáneas y al Semillero de Investigación en Literatura Amerindia. En total se 
presentaron más de ciento cincuenta postulaciones provenientes de los departamentos de Risaralda, Quindío, Caldas y el Norte del Valle. Al final, bajo varios criterios, se seleccionaron treinta personas: veinte docentes, cuatro talleristas y seis estudiantes de pregrado integrantes de.

3. Desarrollo de los módulos y contenidos establecidos en el programa del Diplomado entre los que se destacan:

- Taller de teatro colaborativo orientado por la magíster Kroll Ramírez.

- Didáctica del español por la doctora Ilene Rojas.

- Taller de libro álbum por la magíster Galia Ospina.

- Evaluación de la escritura por Fernando Vásquez Rodríguez.

- Taller de escritura creativa por los magísteres Jaiber Ladino y Leidy Montoya.

- Taller de crónica por el magíster Edison Marulanda.

- Taller de los sentidos por la magíster Ana Lucia Cardona y el artista Juan Eduardo Ángel (Fundación Materile).

- Taller Fundamentación y descubriendo lectores por el magíster Juan Manuel Ramírez y el doctor Fabián Andrés Cuéllar.

4. Socialización de las secuencias didácticas construidas en el desarrollo del diplomado e implementadas en las instituciones educativas. Este espacio fue programado en el marco del $1 .^{\text {er }}$ Congreso Nacional DIoLEE, durante tres días $(1,2$ y 3 de octubre de 2019). Se presentaron un total de quince secuencias didácticas elaboradas y ejecutadas por los estudiantes del diplomado en diferentes establecimientos educativos de los cuatro departamentos. 
El 1. ${ }^{\text {er }}$ Congreso Nacional de Didáctica de la Oralidad, la Lectura, la Escritura y la Escucha se realizó en las instalaciones de Expofuturo durante los tres primeros días del mes de octubre de 2019; en el marco de la Feria del Libro de Pereira. Entre los eventos desarrollados se cuentan los siguientes:

1. Jornadas de presentación de secuencias didácticas, experiencias formativas y proyectos de investigación por parte de:

Estudiantes y egresados del DILE (Diplomado en Didáctica de la Lectura y la Escritura).

Egresados de la Maestría en Literatura (con énfasis en enseñanza).

Estudiantes, grupos y semilleros de investigación.

2. Talleres abiertos con población específica:

Profesores de todas las áreas y en todos los niveles (EI, EBP, EBS, $\mathrm{M})$.

Estudiantes de básica primaria.

Estudiantes de básica secundaria y media.

Estudiantes universitarios.

3. Conversatorios con autores, profesores e investigadores:

Creación, ilustración e investigación (Galia Ospina y Enrique Lara).

4. Conferencias centrales:

El libro silente: poesía visual. Galia Ospina.

Educación en espiral. Fabián Andrés Cuéllar Vélez. 


\section{Resultados}

En el año 2017, con el inicio de la primera cohorte del Diplomado en Didáctica de la Lectura y la Escritura, se consolidó la propuesta de un grupo de docentes del Departamento de Humanidades preocupados por la enseñanza de la lectura, la escritura, la oralidad y la escucha en ambientes escolares formales y no formales. Desde el primer momento se adoptó el testimonio como principio articulador del diálogo que se pretendía tejer entre profesionales de la docencia, estudiantes de licenciatura, investigadores, jóvenes investigadores y promotores de lectura, entre otros.

Las evidencias recogidas con el transcurso de los años certifican, en algún grado, que en las prácticas educativas «... para ser viva la experiencia tiene que poder ser transmitida y, para ello, necesita del testimonio» (Mèlich, 2012, p. 91). Aquel que avive el reconocimiento del otro, sin pretender alcanzar una verdad, porque si algo se transmite es

... una experiencia indemostrable e incomprobable. El que da testimonio enlaza la experiencia pasada y la presente, y la abre a un futuro para que el pasado no quede en el olvido, y para que quien la reciba pueda rehacerla y aprender de ella (p. 91).

El educador, o quien pretende convertirse en ello, debe aspirar a ser un maestro en la medida en que, como dice Mèlich (2012), queda implicado en la transmisión; pero no de meros datos, información o simple conocimiento. «... es su experiencia la que pone a disposición del otro» (p. 92), porque los educadores viven todo el tiempo en las experiencias y, por tanto, son capaces de narrarlas y difundirlas. Así las cosas, la primera transformación didáctica, en todos los implicados en el proceso, ha sido reconocer que $« \ldots$ sin testimonio la educación no podría ser transmisión de experiencia, sino únicamente ciencia, un traspaso de conocimientos» (p. 92). 
En segundo lugar y derivado del anterior, está la permanente apertura al diálogo y a la entretejedura de voces. Durante meses, en el marco de la tercera cohorte del Diplomado en Didáctica de la Lectura y la Escritura, se invitó a las aulas a un grupo de expertos nacionales y regionales a hacer parte del proceso de transformación didáctica de treinta personas, todas becadas y seleccionadas de manera cuidadosa, a partir de sus propuestas pensadas para escenarios diversos, no solo por su ubicación geográfica -en cuatro departamentos-, sino por las comunidades hacia las que se orientan.

En el diálogo participaron expertos de la talla de Fernando Vásquez Rodríguez, sujeto reconocido por su importante contribución a nivel nacional e internacional en el ámbito de la enseñanza y, Galia Ospina, poeta y ensayista conocida por sus aportes en torno la didáctica de la lectura y el libro álbum. Además de un nutrido grupo de docentes investigadores expertos en didácticas específicas. Sin olvidar las voces experimentadas de cada uno de los participantes en el diplomado, en los talleres, en los seminarios, en los coloquios, entre otros espacios abiertos productos del proyecto «Enseñar a hablar, leer y escribir. Una propuesta para la transformación didáctica de docentes en ejercicio del Eje Cafetero».

El panorama general en cuanto a los resultados del proyecto, en primer lugar es frente a la transformación de las prácticas educativas en el aula, desde la relación enseñanza-aprendizajeevaluación para la formación de docentes que indaguen por su quehacer, por sus metodologías y herramientas de instrucción mediante el diálogo con otras disciplinas y otras formas de concebir la educación, para así potenciar la oralidad, la lectura y la escritura como elementos primordiales de los procesos didácticos en el aula.

De igual forma, pensar y transformarla escuela, los espacios, los tiempos y las maneras de hacer clase desde la formación de 
docentes debe incluir también al estudiante como parte activa de su propia transformación, de sus aprendizajes y de su atención a lo largo del proceso educativo. Lo cual implica propiciar la construcción y la socialización de experiencias formativas en el aula, en diversos espacios académicos, en los cuales la reflexión y retroalimentación del proceso formativo de la didáctica en el marco de la oralidad, lectura, escritura y escucha permita siempre el fomento a la investigación y el intento de otras formas de enseñar.

Uno de los resultados más importantes, además de los ya referidos, fue la realización del Congreso Nacional de Didáctica de la Oralidad, la Lectura, la Escritura y la Escucha, desarrollado en el marco de la Feria del Libro de Pereira (Expofuturo, 2019), ya que allí se desarrollaron jornadas de presentación tanto de las secuencias didácticas diseñadas por los estudiantes del diplomado, como de los proyectos investigativos de los integrantes del grupo de investigación (Literatura y Enseñanza de la Literatura) y de los semilleros (sobre narrativas contemporáneas y literatura amerindia), además de las conferencias centrales de los invitados nacionales y los talleres (oralidad, lectura y escritura) ofrecidos para los estudiantes de diferentes colegios de la ciudad.

No solo por el hecho de organizarlo, prepararlo y desarrollarlo como tal, sino por la participación activa de todas las personas que hicieron parte del proyecto (profesores, estudiantes, jóvenes investigadores, entre otros), se permitió, entre todos, escuchar, mirar, pensar e intentar hacer ejercicios alrededor de la escucha, la oralidad, la lectura y la escritura; orientados más hacia el estudio (el gusto, el amor, el deseo, la dedicación) que hacia el aprendizaje (simplificado en objetivos, competencias y resultados).

\section{Población beneficiada}

Como se ha mencionado, los primeros beneficiados de forma directa con la implementación de este proyecto fueron los docentes 
en ejercicio de diferentes municipios del Eje Cafetero (más de quince), quienes se desempeñan en diversas áreas del saber: docentes de primaria que orientan todas las áreas; profesores de español, literatura, geografía e inglés; maestros universitarios; agentes culturales y promotores de lectura que desarrollan talleres con comunidades; coordinadores académicos; directores de núcleo; entre otros. El segundo - y no menos importante- grupo de beneficiados son los estudiantes de las diferentes instituciones educativas donde tales profesionales se desempeñan y ejecutaron las respectivas secuencias didácticas.

Además, hubo un impacto positivo en los jóvenes que hacen parte de los semilleros de investigación en narrativas contemporáneas y literatura amerindia, muchos de ellos, futuros docentes, quienes además de realizar el diplomado, participaron activamente de las jornadas del congreso realizando ponencias, asistiendo a los talleres y conferencias, además apoyando las labores logísticas; lo que en definitiva constituye una gran experiencia.

\section{Conclusiones}

Fue satisfactorio congregar más de cuarenta voces y miradas de profesores y jóvenes investigadores para conversar, reflexionar, fundamentar y experimentar alrededor de los procesos de lectura, escritura, oralidad y escucha y poner de nuevo la atención en palabras que, tras su sencillez, ocultan la densidad de lo educativo que poco a poco se evapora bajo el manto de la cotidianidad (y el capitalismo cognitivo). Términos como educación, aprender, enseñar, leer, escribir, aula, biblioteca, curso, diseño y composición se convierten en cantos rodados, en superficies lisas; despojadas de sus complejidades semánticas, tras el paso del tiempo y de un sistema, a veces, más diseñado para la medición de indicadores que para la reflexión constante sobre lo que implica cada pequeña transformación de un individuo en el aula. En definitiva, convocar a docentes y mediadores del proceso educativo brindó 
la posibilidad de devolver los detalles a estos marcos de conceptos y dotarlos de otras potencias expresivas desde el ver/mirar, el oír/escuchar, la herencia como parte de los procesos cíclicos del enseñar y el aprender.

Además, se han podido reunir las voces ya transidas de experiencia - sean un poco cansadas, prejuiciosas, con ciertos hábitos...-, por el ejercicio adelantado del día a día, por la clase a clase y por las voces de los que recién se visualizan como profesores. En otras palabras, se pudo congregar las miradas, las sensaciones e ideas de los que han transitado por los terrenos movedizos de lo educativo y miran sus prácticas pasadas, las de los que apenas hacen su camino y miran hacia lo que viene. Tal vez ahí es donde se fragua el porvenir de nuestras escuelas como diría Nietzsche.

Por último, se desea resaltar que los docentes y personas en ejercicio de su profesión no solo se acercaron a nuevas propuestas didácticas para dinamizar su quehacer dentro del aula, también reflexionaron de manera sistemática y académica respecto a su propio desempeño, al impacto y al nivel de pertinencia de cada propuesta ejercida para propiciar la tan necesaria relación entre teoría y práctica, además de visibilizar dichas reflexiones en una de las ferias del libro más importantes del Eje Cafetero.

\section{Bibliografía}

BárCENa, F. (2012). El aprendiz eterno. Filosofía, educación y arte de vivir. Miño y Dávila.

. (2012). El alma del lector. La educación como gesto literario. Babel.

BÁrCena, F. Y MèLICH, J-C. (2000). La educación como acontecimiento ético. Natalidad, narración y hospitalidad. Paidós. 
Hoyos, G. (Ed.). (2008). Filosofía de la educación. Trotta.

MèLICH, J-C. (1994). Del extraño al cómplice. La educación en la vida cotidiana. Anthropos.

. (1996). Antropología simbólica y acción educativa. Paidós.

. (2006). Transformaciones. Tres ensayos de filosofía de la educación. Miño y Dávila.

. (2012). Filosofía de la finitud. Herder.

. (2015). La lectura como plegaria. Fragmenta.

Nietzsche, F. (2000). Sobre el porvenir de nuestras escuelas. Tusquets.

. (2016). La hora de clase. Por una erótica de la enseñanza. Anagrama.

Universidad Tecnológica de Pereira [UTP]. (2019). Diplomado en Didáctica de la Lengua y la Escritura. https:// artes.utp.edu.co/humanidades-idiomas/diplomadodidactica-de-la-lectura-y-la-escritura.html. 
Anexo nro. 1. Folleto Diplomado en Didáctica.

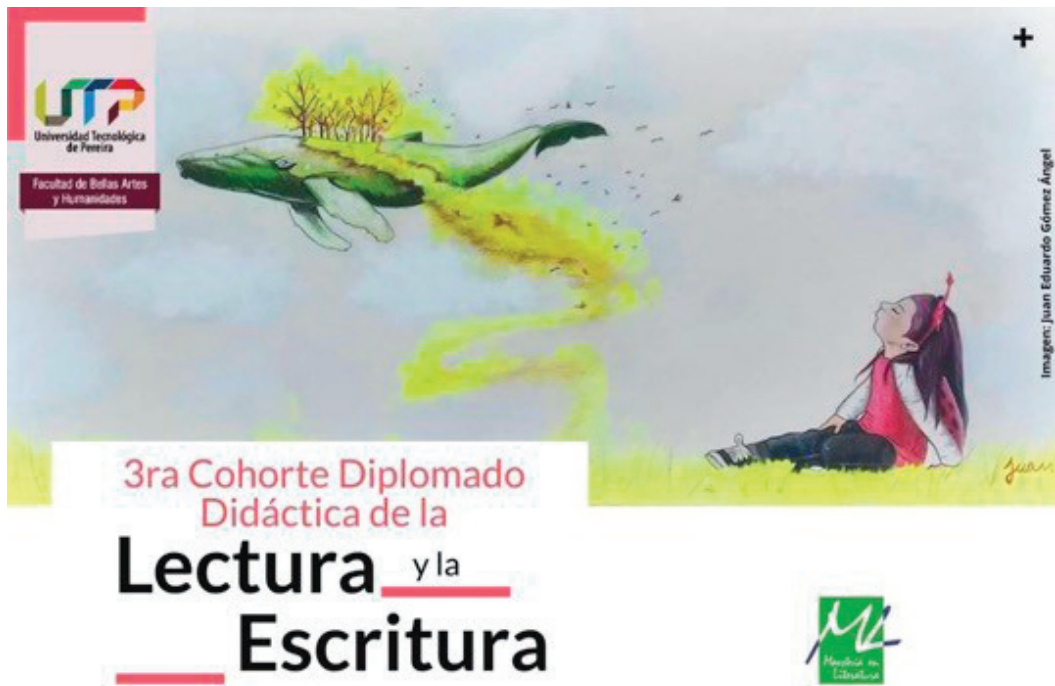

Inicio de clases Sábados de 23 de marzo-2019 Sábados de
8:00 a 4:00 p.m

Elaboración propia.

Anexo nro. 2. Fotografia: primera sesión de la $3 .^{a}$ cohorte del Diplomado en Didáctica.

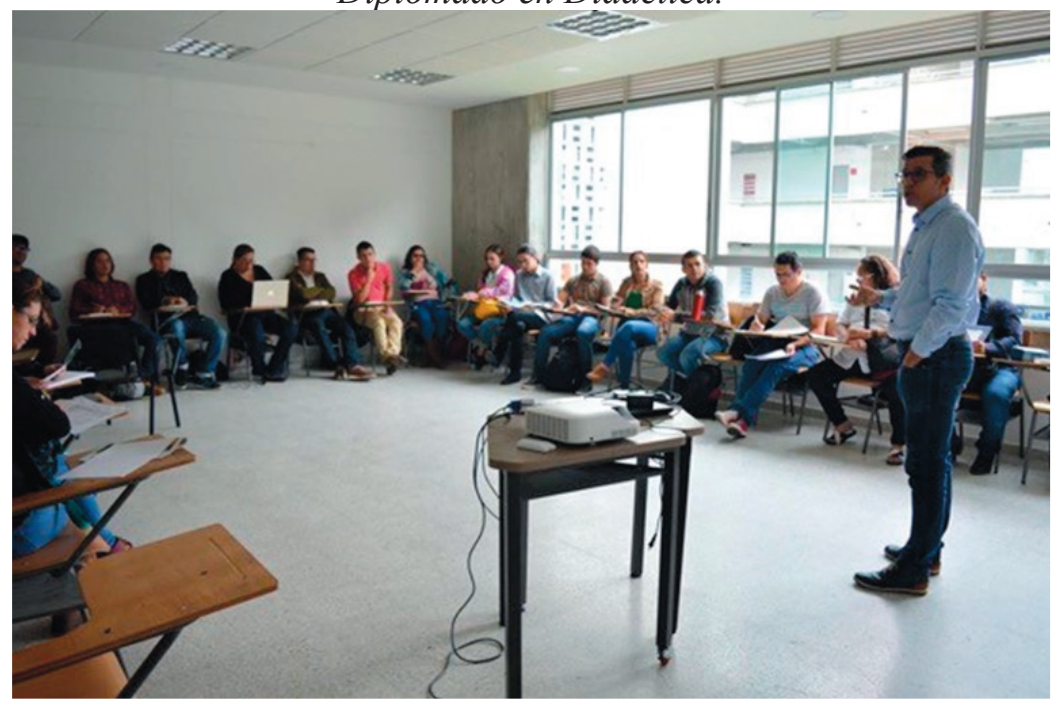

Elaboración propia. 
Anexo NRo. 3. Afiche conferencia.

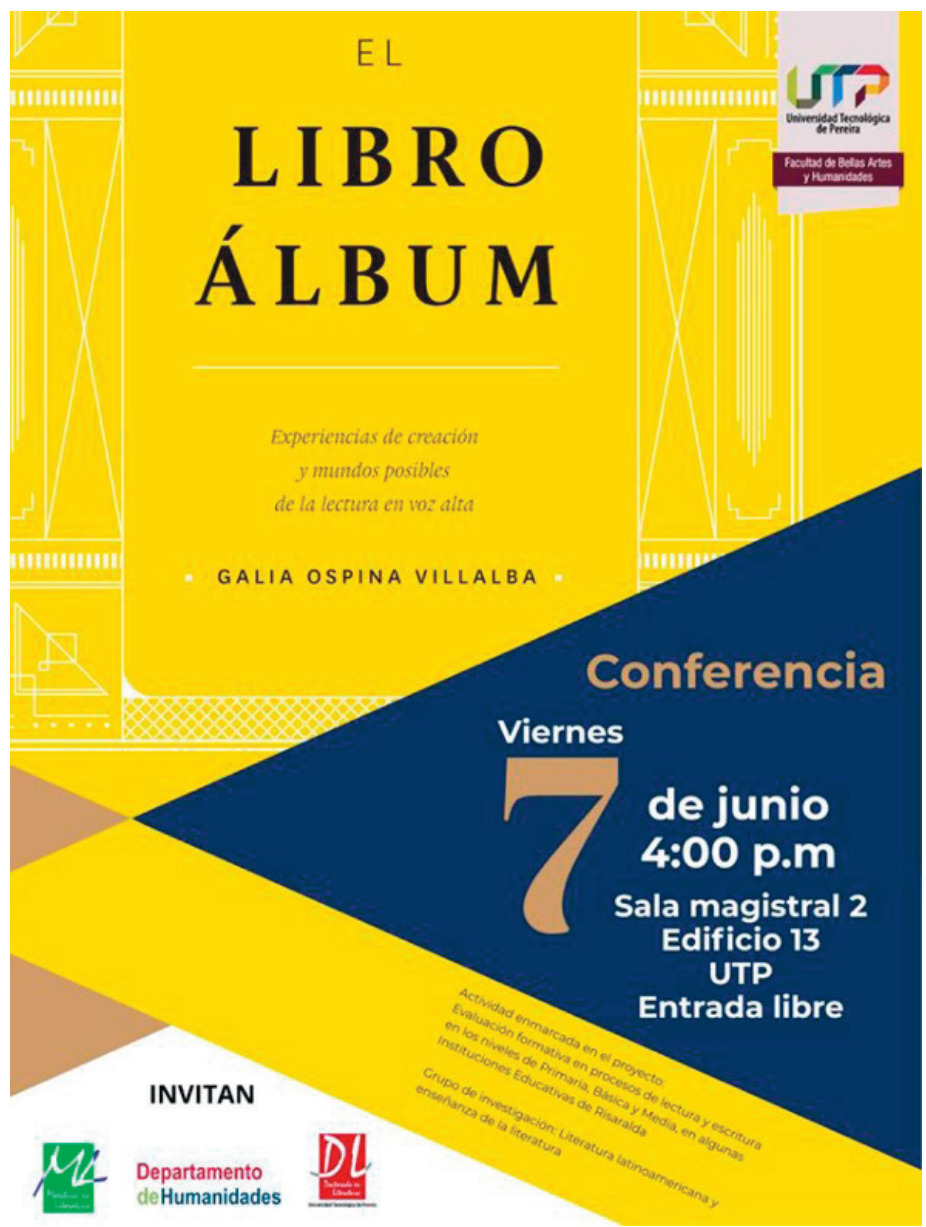

Elaboración propia. 
Anexo nro. 4. Afiche Primer Congreso Nacional DIOLEE.

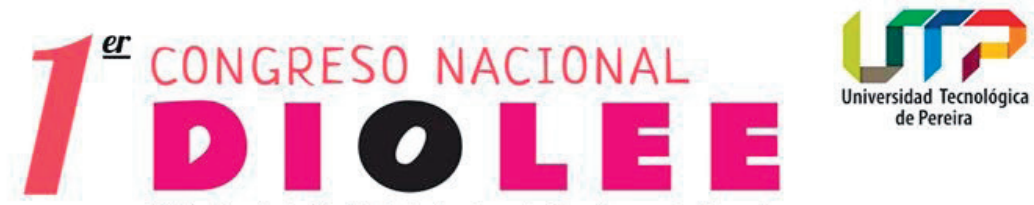

Didáctica de la Oralidad, la Lectura, la Escritura y la Escucha

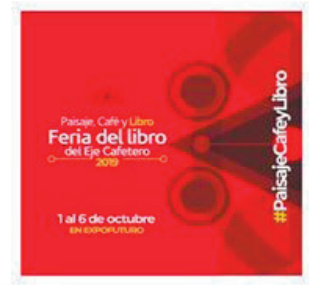

P E R E I R A OCTUBRE 1 AL 3 / 2019 EXPOFUTURO

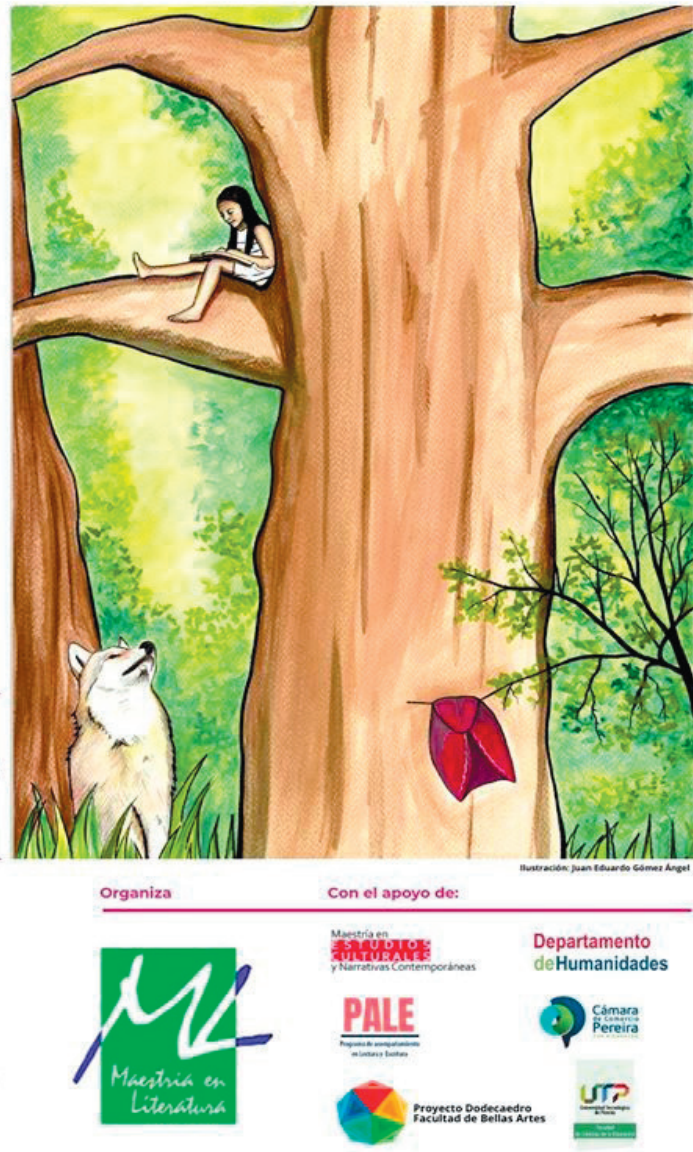

Elaboración propia. 


\title{
Curso herramientas para la gestión de la innovación: Design Thinking (pensamiento de diseño)
}

\author{
LUZ ESTELA VALENCIA \\ NATALIA RODRÍGUEZ \\ Universidad Tecnológica de Pereira
}

Resumen

En un entorno tan competido, donde se crean miles de productos cada día, se hace necesario que las empresas y los profesionales que hacen parte de ellas tengan conocimientos y habilidades, las cuales les permita crear productos y servicios para hacerlos competitivos en el mercado y en el entorno donde forjan presencia (local, nacional, mundial). Esta situación únicamente se logra al desarrollar soluciones que den respuesta a los deseos y necesidades de los clientes y usuarios de forma práctica, ya que en la mayoría de ocasiones dichas necesidades continuamente cambian [1] [6]. 
Para esto es indispensable contar con metodologías y herramientas, las cuales sirvan para el desarrollo de productos innovadores, para que identifiquen rápidamente las oportunidades del mercado y para que den respuesta, con el mismo ritmo, a dichos descubrimientos. Todo ello para permitir no solo la permanencia en el mercado, sino adquirir una participación favorable en el mismo siendo diferentes de sus competidores, sobre todo, teniendo como centro a las personas que son finalmente quienes harán uso de las soluciones generadas [1] [2].

La gestión de la innovación debe hacer parte del ADN de las empresas y del equipo humano que las integra. De la misma forma, el prototipado rápido hace parte de este proceso, debido a que - como se mencionó al comienzo- el foco, a fin de que una empresa sea comercialmente viable debe ser el cliente y sus necesidades, las cuales se transforman constantemente. Es allí donde las compañías tienen el reto de generar rápidamente productos que puedan ser validados en el mercado y ajustados de acuerdo a las peticiones del público [3] [4].

Se propone la creación de un curso que brinde a los participantes conocimientos, habilidades y herramientas de gestión en innovación y prototipado rápido, para así aportar en el fortalecimiento de las competencias de los profesionales; con las cuales puedan ser competitivos en el mercado. Se realiza el diseño del curso «Quick StartUp», además de la convocatoria. De esta manera, se imparten tres cursos, cada curso con una intensidad horaria de veinte horas distribuidas en dos semanas

Palabras clave: competencias, curso, habilidades, herramientas, innovación.

\section{Abstract}

In such a competitive environment, where miles of products are created every day, it is necessary that companies and 
professionals who are part of them have knowledge and skills that allow them to create products and services that make them competitive in the market, in the environment where they are present (local, national, worldwide) and this specifically achieves successful solutions solutions that respond to the wishes and needs of customers and users in a practical way and in most cases needs that continually change [1] [6].

For this it is essential to have methodologies and tools conducive to the development of innovative products, quickly identifying market opportunities and responding with the same pace to these discoveries, without needing to remain alone in the market but obtain a favorable participation in it, being different from its competitors, but above all having as its center the people, who are finally those who have use of the generated solutions [1] [2].

Innovation management must be part of the DNA of companies and the human team that is part of them, in the same way the rapid prototype is part of this process, because as mentioned at the beginning, the focus for a Commercially viable maritime company must be the customer and their needs that are constantly transformed and that is where companies have the challenge of quickly generating products that can be validated in the market and adjusted according to public requests [3] [4].

It is proposed to create a course that provides participants with knowledge, skills and innovation management tools and rapid prototype, thus contributing to the strength of the competencies of professionals, so that they can be competitive in the market. The "Quick StartUp" course is designed, the call is made and 3 courses are taught, each course with an hourly intensity of 20 hours each, distributed in 2 wees: 4 hours and 6 hours.

Keywords: Abilities, Competitions, Event, Innovation, Tools. 


\section{Introducción}

El presente documento hace referencia al curso "Quick Startup» impartido en la Universidad Tecnológica de Pereira durante el año 2019, el cual se centra en dar a conocer a los asistentes las herramientas para la gestión de la innovación «Design Thinking» y «Lean Startup» como estrategia para capacitar a estudiantes, trabajadores y emprendedores, los cuales desean desarrollar o desarrollan un modelo de negocio, dotándolos de mecanismos y conocimientos que les son útiles a la hora de emprender una idea de negocio y partir de lo general a los más particular.

Las características principales de este curso son el desarrollo de una estrategia que logre impactar la vida de los asistentes que se encuentran en el proceso de emprender, incentivándolos a ser creativos, curiosos e inclusive arriesgados, pero a partir de lineamientos base, los cuales ayudan a estructurar su modelo de negocio y a construir un prototipo de su producto o servicio para una validación con el mercado objetivo. Entre los temas planteados en el curso se encuentra identificar una necesidad, problema u oportunidad de un segmento de mercado, de esta forma, cuando se logra este procedimiento y los actores involucrados, se continúa con una fase de ideación donde se busca la manera de dar solución a la necesidad percibida en el mercado utilizando, para ello, diversas técnicas creativas entre las que se encuentran SCAMPER, el Método 635, Brainstorming, entre otras. Además, se diseña y se valida la propuesta de valor, canales, estrategias de relacionamiento - con los diferentes segmentos identificados- y las diversas maneras de generar ingresos, a la hora de convertir en realidad el negocio sobre el cual se trabaja. Finalmente, se procede con la creación del prototipo de baja fidelidad para efectos del curso; sin embargo, se comparten las indicaciones para el establecimiento de un Producto Mínimamente Viable (MVP) y se cierra el ciclo con las técnicas de validación y de desarrollo ágil de producto; según los lineamientos de la metodología «Lean Launchpad». 


\section{Objetivos}

\section{Objetivo general}

Facultar a los participantes con las herramientas de gestión de innovación «Design Thinking» y «Lean Startup», para que puedan utilizarlas en la ejecución de proyectos de emprendimiento e investigación aplicada y dar respuesta a necesidades reales de la sociedad.

\section{Objetivos específicos}

1. Convocar a estudiantes de programas de ingenierías de la Universidad Tecnológica de Pereira, con el fin de capacitarlos en el uso de metodologías ágiles en ideación y diseño de productos y servicios.

2. Sensibilizar a los participantes en habilidades de empatía, pensamiento integrador, experimentalismo y colaboración, las cuales son propias de un pensador de diseño.

3. Estimular en las participantes capacidades de observación del comportamiento y entorno de las personas (usuarios) y, de esta forma, reconocer sus necesidades y deseos.

4. Dar a conocer herramientas de generación de prototipos.

5. Socializar técnicas de validación de prototipos.

6. Evaluar el contenido impartido, el desempeño de los profesores y el impacto en los participantes.

\section{Metodología}

Para lograr los objetivos planteados se realizaron tres cursos de veinte horas cada uno. Estos se desarrollaron en dos semanas con sesiones de cuatro y seis horas donde se dieron a conocer los fundamentos del «Design Thinking» y el «Lean Startup» [5], 
a través de actividades teórico-prácticas que les permitieron, a los participantes, apropiar los conceptos y herramientas socializadas.

Las sesiones del curso se ejecutaron a través de clase magistral y ejercicios prácticos guiados desarrollados en grupos de trabajo conformados desde el primer encuentro.

Los asistentes se convocaron a partir de redes sociales, del correo y de los medios disponibles en la UTP como son Campus Informa; la emisora y carteleras en diferentes espacios de la ciudad de Pereira, entre ellos el Centro Cultural Lucy Tejada, la Cámara de Comercio y la Universidad Libre.

En los objetivos, del número 2 al 5, se describen las temáticas tratadas en cada una de las sesiones: 
TABla nRo. 1. Sesión número uno.

\begin{tabular}{|c|c|}
\hline Sesión nro. 1 & Intensidad: diez horas \\
\hline Temática & Introducción, inspiración, ideación. \\
\hline \multirow[t]{7}{*}{ Contenido } & - $\quad$ Presentación del curso. \\
\hline & $\begin{array}{l}\text { - Introducción a la gestión de la inno- } \\
\text { vación. }\end{array}$ \\
\hline & $\begin{array}{l}\text { Introducción al Design Thinking: } \\
\text { ¿Qué es? Generalidades, perfil de un } \\
\text { pensador de diseño. }\end{array}$ \\
\hline & - Socialización de caso de estudio. \\
\hline & $\begin{array}{l}\text { Empatizar: observar, analizar y com- } \\
\text { prender el usuario y su problemática } \\
\text { o identificar la oportunidad (mapa } \\
\text { de empatía). }\end{array}$ \\
\hline & $\begin{array}{l}\text { - Vigilancia estratégica: reconocer el } \\
\text { contexto. }\end{array}$ \\
\hline & $\begin{array}{l}\text { Definir e idear: diseñar la propuesta } \\
\text { de valor, lienzo de la propuesta de va- } \\
\text { lor, Brainstorming, creatividad visual } \\
\text { (mapa mental), } 635 \text {. }\end{array}$ \\
\hline \multirow{2}{*}{$\begin{array}{l}\text { Metodología } \\
\text { específica }\end{array}$} & Clase magistral. \\
\hline & $\begin{array}{l}\text { Ejercicios que permiten el acerca- } \\
\text { miento con el objetivo de aprendiza- } \\
\text { je. }\end{array}$ \\
\hline
\end{tabular}




\begin{tabular}{lll}
\hline Insumos & Presentación. \\
& - \\
& Lienzos: canvas observación, canvas \\
& de mapa de empatía, canvas de pro- \\
& puesta de valor. \\
& Post-it. \\
& - Marcadores, lapiceros. \\
& - Videobeam. \\
\hline
\end{tabular}

Elaboración propia.

Tabla nRo. 2. Sesión número dos.

\begin{tabular}{|c|c|}
\hline Sesión nro. 2 & Intensidad: diez horas \\
\hline Temática & Prototipado y validación \\
\hline \multirow[t]{9}{*}{ Contenido } & $\begin{array}{l}\text { Prototipar: prototipo de baja fide- } \\
\text { lidad, prototipo funcional, produc- } \\
\text { to mínimo viable. }\end{array}$ \\
\hline & $\begin{array}{l}\text { - Validar/testear: crear, medir, apren- } \\
\text { der. }\end{array}$ \\
\hline & - Iterar/rediseñar: SCAMPER. \\
\hline & - Lean Startup: \\
\hline & - Ver. \\
\hline & - Dirigir. \\
\hline & - Acelerar. \\
\hline & - Desarrollo de clientes. \\
\hline & - Desarrollo ágil de productos. \\
\hline \multirow{2}{*}{$\begin{array}{l}\text { Metodología } \\
\text { específica }\end{array}$} & Clase magistral. \\
\hline & $\begin{array}{l}\text { Ejercicios que permiten el acercamiento } \\
\text { con el objetivo de aprendizaje. }\end{array}$ \\
\hline
\end{tabular}




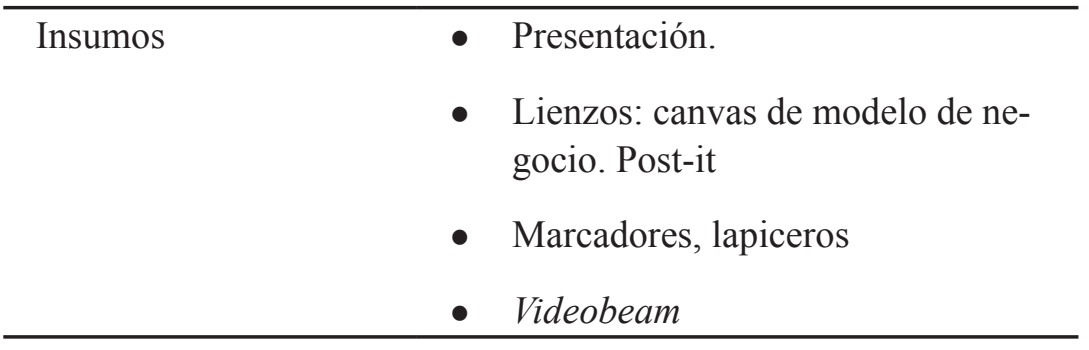

Elaboración propia.

Al finalizar el curso se realizó la evaluación del contenido impartido, del desempeño de los profesores y del impacto en los participantes que servirá de retroalimentación. La evaluación verifica los contenidos impartidos, la bibliografía suministrada, los medios usados y la metodología empleada. El desempeño de los profesores fue satisfactorio para los participantes.

\section{Resultados}

El curso llamó la atención de personas en distintos ámbitos como, por ejemplo, aquellas que contaban con una idea de negocio, las que tenían una idea en progreso, así como las que les interesaba la temática de emprendimiento y Startup. Los participantes fueron egresados, estudiantes, profesionales y emprendedores en el ámbito regional.

La estrategia de convocatoria se llevó a cabo mediante redes sociales y páginas oficiales de la universidad tales como:

- Agenda de eventos: https://eventos.utp.edu.co/informacionevento/347.

- Campus Informa: https://comunicaciones.utp.edu.co/ noticias/43147/invitacion-curso-gratuito-deemprendimientoquick-startup.

- Facebook: https://www.facebook.com/QuickStartupUtp/. 
- Instagram: https:/www.instagram.com/quick_startup/?hl=es-la.

También se promocionó a los estudiantes de Ingeniería de Sistemas y Computación de la UTP mediante el correo institucional, además de la promoción a través de afiches que se publicaron en las carteleras de este mismo establecimiento educativo, en todas las instituciones de educación superior de la ciudad de Pereira y en sitios como el Teatro Santiago Londoño y el Centro Cultural Lucy Tejada. Dicha publicidad permitió que se inscribieran, a través de un formulario en línea - el cual fue realizado por medio de Google Forms-, más de cien personas en total para los tres cursos dictados.

La metodología del curso considero la diversidad de los emprendedores, por ello los temas tratados a lo largo de todas las clases plantearon diferentes actividades y ejemplos. Durante el curso se promovió el trabajo en equipo, por lo cual, se formaron grupos donde decidieron trabajar sobre una idea de negocio hasta el final de las clases. Los participantes cooperaron y respetaron las distintas ideas, opiniones y sugerencias de sus compañeros. Para el desarrollo de estas actividades se entregaron materiales y formatos que apoyaron el desempeño de la actividad; situación que contribuyó a que las personas participaran activamente a lo largo de las tareas propuestas. Al final del curso se realizó una evaluación a los asistentes sobre el contenido impartido, el desempeño de los docentes y los aspectos personales; además se tuvo en cuenta un espacio para dar sugerencias. Frente a estos aspectos se pudo evidenciar que el material, las actividades propuestas y oratoria de las expositoras fueron del agrado de los participantes.

\section{Población beneficiada}

Estudiantes, trabajadores y emprendedores de la ciudad de Pereira interesados en adquirir habilidades, herramientas y conocimientos en la creación y desarrollo de ideas de negocio. 
En total participaron setenta personas en los tres cursos impartidos.

\section{Conclusiones}

El curso fue de interés tanto para personas que comenzaban a idear su propio negocio como para aquellos que ya contaban con uno en desarrollo. Los asistentes fueron egresados, estudiantes, profesionales y emprendedores en el ámbito regional.

La metodología del curso consideró la diversidad áreas de trabajo de los emprendedores, por ello los temas tratados a lo largo de todas las clases plantearon diferentes actividades y ejemplos.

A medida que avanzó el curso, se pudo identificar que hay desinformación sobre el tema expuesto, sin embargo, se evidenció interés entre los asistentes por adquirir nuevos conocimientos. $\mathrm{Al}$ igual que personas con ideas de negocio rentables para el desarrollo regional, se pudo identificar, entre los más comunes, restaurantes y locales comerciales (ropa, productos importados). Por otro lado, para la creación de empresas se necesitó tiempo y disposición, debido a que durante el proceso es indispensable hacer validación del proyecto (identificar rentabilidad y viabilidad), porque pueden surgir cambios o restructuraciones no receptivas para las personas, por ello deciden no continuar con el proyecto (idea de negocio).

\section{Bibliografía}

[1] ITMAdRID. (2020, Feb 6). ¿Qué es y para qué sirve Design Thinking? [En línea]. Disponible en: https://www.itmadrid. com/que-es-y-para-que-sirve-design-thinking/. 
[2] T. Brown. (2019, Jun.). «Design Thinking». Harvard Business Review [Online]. Available in: https://hbr.org/2008/06/ design-thinking.

[3] Strategyzer. (2019, Mar.). Siete preguntas para evaluar tu diseño del modelo de negocio. Disponible en: https://www. planetadelibros.com/libros_contenido_extra/30/29725_1_ Siete_preguntas_para_evaluar_tu_diseno_del_modelo_de_ negocio.pdf.

[4] M. Vianna, Y. Vianna, I. K. Adler, B. Lucena y B. Russo. (2013, Jun.). Design Thinking. Innovación en negocios [En línea]. Disponible en: https://aprendizajeenredeafit. files.wordpress.com/2015/08/librodt_1a_ed_20130603 espanhol_site.pdf.

[5] E. Ries, El método Lean Startup: Cómo crear empresas de éxito utilizando la innovación continua. Barcelona: Deusto, 2011.

[6] N. Wasserman, The Founder's Dilemmas: Anticipating and Avoiding the Pitfalls That Can Sink a Startup (The Kauffman Foundation Series on Innovation and Entrepreneurship). Nueva Jersey: Princeton University Press, 2013. 


\title{
Construyendo futuro fase dos
}

\author{
Natalia Bohórquez Bedoya \\ Universidad Tecnológica de Pereira
}

\section{Resumen}

Construyendo Futuro (CF) es un proyecto desarrollado por estudiantes y docentes de la Universidad Tecnológica de Pereira pertenecientes de la Asociación Nacional de Estudiantes de Ingeniería, Administración y Producción (ANEIAP) y al Grupo de Investigación de la Facultad de Ciencias Empresariales (GEIO), en el cual se trabaja con estudiantes de colegios públicos de la ciudad de Pereira sobre el desarrollo de habilidades blandas o competencias socioemocionales; todo ello a través de talleres cuyo principal elemento metodológico es la vivencia lograda a partir de juegos grupales (lúdicas) que promueven la interacción. Durante el año 2019, gracias al apoyo de la Vicerrectoría de Investigaciones, Innovación y Extensión, se llevaron a cabo ocho talleres en los cuales se trabajaron las habilidades blandas con aproximadamente sesenta y cinco estudiantes de diferentes colegios. Así mismo, se 
realizó un seminario de capacitación con apoyo de profesionales de psicología y trabajo social, el cual permitió 1) afinar aspectos metodológicos de los talleres; 2) diseñar un taller de orientación vocacional y 3 ) construir un esquema de evaluación de los talleres con el fin de visualizar el impacto del proceso en los jóvenes de los colegios y en los estudiantes facilitadores, así como identificar los aspectos a mejorar. Por último, se adicionaron actividades nuevas al banco de lúdicas disponibles para el diseño de los talleres.

Palabras clave: habilidades blandas, habilidades socioemocionales, evaluación, orientación vocacional, juegos.

\section{Abstract}

Construyendo Futuro (CF) is a project developed by students and professors of the Universidad Tecnológica de Pereira, who belong to ANEIAP (National Association of Engineering, Administration and Production Students) and to GEIO (Research Group of the Faculty of Business Sciences), which works with students from public schools in Pereira city, to develop soft skills or socio-emotional skills, through experiential workshops as the main methodological element, through group games (playful) that promote interaction between workshop participants. During the year 2019, thanks to the support of the Office of the Vicerrectoría de Investigaciones, Innovación y Extensión, eight workshops were conducted and soft skills were worked with approximately 65 students from different Pereira schools. Likewise, a training seminar was carried out with the support of psychology and social work professionals, which allowed 1) to refine methodological aspects of the workshops; 2) design a vocational guidance workshop and 3) build an evaluation scheme of the workshops in order to visualize the impact of the process on the youth of the schools and on the facilitating students, as well as identify the aspects to improve. Finally, new games were added to the bank of games available for the design of the workshops. 
Keywords: Soft Skills, Socioemotional Skills, Evaluation, Vocational Guidance, Games.

\section{Introducción}

Actualmente existe un creciente interés por parte del Estado, de investigadores, de educadores y de padres en que las instituciones de educación involucren, en sus proyectos educativos, el estímulo de habilidades no cognitivas llamadas habilidades socioemocionales, transversales o blandas que aporten al éxito en la vida de los educandos teniendo en cuenta lo siguiente: «... existen cada vez más evidencias de que lo que genera crecimiento y prepara a las personas para el trabajo y la vida son las capacidades adquiridas en la escuela» (Banco Mundial, 2017). En Colombia el Gobierno desarrolla y divulga herramientas para que los docentes trabajen estas competencias en el aula, una de ellas son las cartillas denominadas «Paso a paso», de las cuales se extrae el siguiente fragmento que expone su definición y algunas razones por las que es importante incluir las habilidades socioemocionales en los colegios:

Las competencias socioemocionales son aquellas que incluyen no solo el desarrollo de procesos cognitivos o mentales sino también áreas afectivas como la conciencia y gestión emocional, de relacionamiento con otros y de proyección hacia la sociedad. Así, les permiten a las personas conocerse mejor a sí mismas, manejar sus emociones, trazarse metas y avanzar hacia ellas, construir mejores relaciones con los demás, tomar decisiones responsables en su vida, disminuir la agresión y aumentar la satisfacción con su vida. El desarrollo de estas competencias es fundamental para lograr una salud mental positiva [...] En esta misma línea, las competencias socioemocionales promueven un mejor rendimiento académico y alejan a la persona de conductas de riesgo tanto individuales como grupales. Esto es especialmente importante en la adolescencia, en donde planear el futuro es una tarea fundamental que se puede ver afectada por la toma de decisiones apresuradas o poco pensadas (Mejía et al., 2017, p. 5). 
El equipo de Construyendo Futuro busca aportar a esta meta nacional de apoyar el sano desarrollo de los niños y jóvenes colombianos, quienes merecen una educación que aliente el desenvolvimiento de su potencial humano de manera integral. Así, las habilidades trabajadas hasta ahora son: comunicación asertiva, trabajo en equipo, liderazgo, innovación y pensamiento sistémico.

A partir de inquietudes constantes de los jóvenes con los cuales se ha trabajado y al reconocer que para los adolescentes $« . .$. su tarea básica es construir una identidad diferenciada, elaborar su propio proyecto vital, averiguando qué quieren hacer con su vida» (Diaz-Aguado, 2006, p. 2), se decide construir un sexto taller sobre orientación vocacional que pueda dar elementos a los estudiantes para identificar sus fortalezas, definir una visión y generar un plan de acción que les permita lograr lo que desean, además de motivarlos y mostrarles las alternativas para continuar su formación educativa en niveles superiores.

Gracias al apoyo de la Vicerrectoría de Investigaciones, Innovación y Extensión de la UTP, durante el año 2018 y 2019 se logró afinar aspectos metodológicos importantes que llevan a grandes aprendizajes expresados en este documento, algunos de ellos son:

- Inclusión de herramienta sociométrica para conocer el estado de integración del grupo.

- Revisión y ajuste de los objetivos y estructura de cada taller.

- Diseño del taller de orientación vocacional, el cual incluye la recolección de una serie de herramientas; algunas de ellas tipo test que pueden ser aplicadas a los jóvenes.

- Diseño de un esquema de evaluación, el cual permite percibir los impactos de los talleres, en los jóvenes que participan de ellos, así como identificar los aspectos a mejorar. 
- Diseño de encuesta que permite capturar los principales aprendizajes de los estudiantes de la ANEIAP y del GEIO, los cuales participan en la construcción y facilitación de los talleres.

- Recopilación de un catálogo de lúdicas que ponen en práctica las habilidades socioemocionales y que complementa el trabajo con la cartilla del año 2018.

Se agradece el apoyo que la Universidad Tecnológica de Pereira y la Facultad de Ciencias Empresariales brindaron para darle vida al proyecto Construyendo Futuro. Así mismo, se brinda reconocimiento a todos los estudiantes de Ingeniería Industrial, quienes son el alma de la propuesta y destinaron tiempo, creatividad, solidaridad y mucha energía en su planeación y ejecución.

Sin duda alguna, este proyecto ha aportado vivencias valiosas a estos personajes para su formación como seres humanos y profesionales, ellos son:

Ana María Correa González, Ana María Múnera Gutiérrez, Andrés Beltrán Moreno, Angee Manuela Castro Franco, Camila Cuenca Aguirre, Camilo Andrés Puentes Vásquez, Dana Paola Jiménez Aristizábal, Daniela Idárraga García, Elissa Mariana Ruiz Cardona, Fabián Andrés Quiroga Espinosa, Isabela Potes Cifuentes, Iván Andrés Gallo Jaramillo, Juan Andrés Morales, Juan Esteban Giraldo Guevara, Julián Andrés Gutiérrez Castaño, Julio César Murillo Arango, Laura Andrea Ramos Ríos, Lloyd David Morris Salazar, Luz María Ochoa Salinas, María José Cardona Restrepo, Rafael Gálvez, Santiago Pescador Sáenz, Sara María Osorio Cruz, Sofía Miranda Parra y Valentina Román Ramírez. 


\section{Objetivos}

\section{Objetivo general}

Diseñar y ejecutar, en forma de talleres, un programa con metodologías activas y colaborativas que fortalezca las habilidades blandas de estudiantes de noveno, diez y once en colegios públicos de Pereira y de estudiantes con capacidades especiales y que aporte a su orientación vocacional.

\section{Objetivos específicos}

Capacitar al equipo de trabajo de facilitadores, para así permitir la consolidación de bases axiológicas y metodológicas en el diseño y ejecución de los talleres de 1) comunicación, 2) liderazgo, 3) creatividad e innovación, 4) pensamiento sistémico y 5) trabajo en equipo.

Diseñar taller sobre orientación vocacional y ejecutarlos en el marco del proyecto.

Diseñar un esquema evaluativo de los talleres que permita identificar y reflexionar sobre la evolución de los estudiantes.

Socializar los resultados y lecciones aprendidas por medio de actividades de extensión. 


\section{Metodología}

\section{En la TABLA NRo. 1 se detalla la metodología propuesta para el logro los objetivos.}

TABLA NRO. 1. Metodología para el logro de los objetivos.

\begin{tabular}{|c|c|}
\hline Objetivo general & Metodología \\
\hline $\begin{array}{l}\text { Diseñar y ejecutar un } \\
\text { programa con metodologías } \\
\text { activas y colaborativas (talleres), } \\
\text { que fortalezca las habilidades } \\
\text { blandas de estudiantes de } \\
\text { grados noveno, diez y once en } \\
\text { colegios públicos de Pereira y } \\
\text { de estudiantes con capacidades } \\
\text { especiales, las cuales aporten a } \\
\text { su orientación vocacional. }\end{array}$ & $\begin{array}{l}\text { Realizar capacitaciones al equipo } \\
\text { de facilitadores. } \\
\text { Diseñar los talleres. } \\
\text { Seleccionar y visitar los colegios } \\
\text { con el fin de acordar condiciones de } \\
\text { ejecución de los talleres. } \\
\text { Ejecutar los talleres. } \\
\text { Evaluar. }\end{array}$ \\
\hline Objetivo específico & Met \\
\hline $\begin{array}{l}\text { Capacitar al equipo } \\
\text { de trabajo, compuesto por } \\
\text { facilitadores, el cual permita } \\
\text { consolidar las bases axiológicas } \\
\text { y metodológicas para el diseño } \\
\text { y ejecución de los talleres de } \\
\text { 1) comunicación, 2) liderazgo, } \\
\text { 3) creatividad e innovación, } \\
\text { 4) pensamiento sistémico y 5) } \\
\text { trabajo en equipo. }\end{array}$ & $\begin{array}{l}\text { Capacitar al equipo en las bases } \\
\text { axiológicas y metodológicas, para el } \\
\text { diseño y ejecución de los talleres. } \\
\text { Diseñar y ejecutar capacitaciones } \\
\text { internas de las metodologías del grupo } \\
\text { GEIO. } \\
\text { Socializar las lecciones aprendidas } \\
\text { en la ejecución de la fase nro. } 1 \text {. } \\
\text { Ejecutar al menos diez talleres. }\end{array}$ \\
\hline $\begin{array}{l}\text { Diseñar un taller } \\
\text { sobre orientación vocacional } \\
\text { y ejecutarlo en el marco del } \\
\text { proyecto. }\end{array}$ & $\begin{array}{l}\text { Contratar asesoría técnica en } \\
\text { orientación vocacional que capacite y } \\
\text { asesore en el diseño y ejecución de los } \\
\text { talleres. } \\
\text { Diseñar el taller. } \\
\text { Ejecutar el taller. }\end{array}$ \\
\hline $\begin{array}{l}\text { Diseñar un esquema } \\
\text { evaluativo de los talleres que } \\
\text { permita identificar y reflexionar } \\
\text { sobre la evolución de los } \\
\text { estudiantes. }\end{array}$ & $\begin{array}{l}\text { Investigar modelos de evaluación } \\
\text { de habilidades blandas. } \\
\text { Diseñar la propuesta de } \\
\text { evaluación. }\end{array}$ \\
\hline $\begin{array}{l}\text { Socializar los resultados } \\
\text { y lecciones aprendidas por } \\
\text { medio de actividades de } \\
\text { extensión. }\end{array}$ & $\begin{array}{l}\text { Elaborar cartilla. } \\
\text { Realizar y subir al blog de GEIO, } \\
\text { al menos dos videos sobre habilidades } \\
\text { blandas. }\end{array}$ \\
\hline
\end{tabular}

\section{Elaboración propia.}




\section{Resultados}

\section{Afinación de la metodología de los talleres}

Esta fase dos del proyecto Construyendo Futuro (CF), en la cual se cuenta con la asesoría de la psicóloga Olga Forero Trejos y la trabajadora social Alba Nelly Chica, permitió hacer reflexiones y plantear algunos aspectos a tener en cuenta para la planeación y ejecución de los talleres con dos objetivos puntuales: 1) Afinar la coherencia entre los objetivos de los talleres y las actividades seleccionadas, lo cual lleva a 2) lograr una mayor eficacia en el fortalecimiento de las habilidades en los niños participantes del proyecto.

Se presenta a continuación el afinamiento de la metodología de los talleres en dos partes: la inclusión de una herramienta sociométrica y una estructura para guiar su planeación y ejecución.

\section{Uso de una herramienta sociométrica}

Con los objetivos de conocer el grado de integración existente entre los estudiantes del grupo con el que se va a trabajar e identificar educandos excluidos - a los cuales haya que prestar atención y apoyar su inclusión-y líderes, se propone usar procedimientos sociométricos, los cuales consisten en proporcionar

... la posibilidad de evaluar en poco tiempo y con gran validez las relaciones entre compañeros, permitiendo obtener información tanto del nivel de integración de cada individuo como de los contextos en los que se desarrolla. Consisten en preguntar a todos los miembros de un determinado grupo acerca del resto; y conocer, así, el estatus medio o nivel de popularidad, las oportunidades para el establecimiento de relaciones de amistad y los atributos perceptivos por los que más destaca (Días-Aguado, 2006, p. 19).

Se plantea entonces un cuestionario sociométrico tomado de Díaz-Aguado (2006), el cual debe ser llenado en la primera o antes 
de la primera sesión y se debe hacer su respectiva interpretación y socialización con los facilitadores de los talleres, con el fin de que todos estén sensibilizados frente a la realidad del grupo con el cual se va a trabajar.

\section{Planeación y ejecución de los talleres}

La planeación es fundamental para el éxito de las actividades y el logro de los objetivos. Los talleres de CF requieren una cuidadosa planificación realizada en equipos y que implica dedicar tiempo y poner en juego habilidades de trabajo en grupo, creatividad y mucha consciencia, ya que son actividades que buscan impactar de manera positiva la vida de niños y jóvenes.

Objetivos para cada taller. Según la metodología SMART (por sus siglas en inglés), en la formulación de cada objetivo del taller se deben tener en cuenta los siguientes aspectos: ser específico (Specific), medible (Measurable), factible (Achievable), realista (Realistic) y especificado en el tiempo (Time-related) (De Miguel et al., 2019)

Es preciso preguntarse ¿Qué necesitan aprender los participantes? ¿Qué serán capaces de hacer los participantes como resultado de la capacitación? También es necesario redactar los objetivos en términos de los asistentes, por ejemplo, al utilizar la frase «al finalizar el taller los asistentes estarán en capacidad de...».

Durante el año 2019 se hizo la revisión de los objetivos de los talleres, a continuación se muestra la TABLA NRO. 2 con el compendio de este trabajo para cada una de las habilidades trabajadas. 
TABLA NRO. 2. Objetivos para cada taller.

\begin{tabular}{|c|c|c|}
\hline \multicolumn{3}{|l|}{ Comunicación } \\
\hline $\begin{array}{l}\text { Competencia } \\
\text { general }\end{array}$ & $\begin{array}{l}\text { Compet en cia } \\
\text { específica }\end{array}$ & Objetivos de desempeño \\
\hline \multirow[t]{3}{*}{ Verbal } & $\begin{array}{l}\text { Elocuencia } \\
\text { fluidez }\end{array}$ & $\begin{array}{l}\text { Expresar de una manera } \\
\text { clara y precisa un mensaje. }\end{array}$ \\
\hline & \multirow[t]{2}{*}{ Respeto-empatía } & $\begin{array}{l}\text { Respetar turnos a la hora } \\
\text { de hablar, permitir que otros se } \\
\text { expresen. }\end{array}$ \\
\hline & & $\begin{array}{l}\text { Usar el lenguaje adecuado } \\
\text { (evitar malas palabras y palabras } \\
\text { hirientes). }\end{array}$ \\
\hline \multirow[t]{2}{*}{ No verbal } & \multirow[t]{2}{*}{ Escucha activa } & $\begin{array}{l}\text { Escuchar con atención a los } \\
\text { otros. }\end{array}$ \\
\hline & & $\begin{array}{l}\text { Ser capaz de seguir } \\
\text { instrucciones. }\end{array}$ \\
\hline \multicolumn{3}{|l|}{ Trabajo en equipo } \\
\hline $\begin{array}{l}\text { Competencia } \\
\text { general }\end{array}$ & $\begin{array}{l}\text { Competencia } \\
\text { específica }\end{array}$ & Objetivos de desempeño \\
\hline \multirow[t]{3}{*}{ Sinergia } & \multirow[t]{2}{*}{$\begin{array}{l}\text { Consciencia de sí } \\
\text { mismo }\end{array}$} & $\begin{array}{l}\text { Reconocer y valorar las } \\
\text { competencias que yo puedo } \\
\text { aportar en el trabajo grupal. }\end{array}$ \\
\hline & & $\begin{array}{l}\text { Asumir responsabilidades } \\
\text { para alcanzar el objetivo grupal. }\end{array}$ \\
\hline & Consciencia social & $\begin{array}{l}\text { Reconocer y valorar las } \\
\text { competencias que el otro puede } \\
\text { aportar en el trabajo grupal. }\end{array}$ \\
\hline Adaptabilidad & Flexibilidad & $\begin{array}{l}\text { Ser flexible en las acciones } \\
\text { para alcanzar el objetivo grupal. }\end{array}$ \\
\hline \multicolumn{3}{|l|}{ Liderazgo } \\
\hline $\begin{array}{l}\text { Competencia } \\
\text { general }\end{array}$ & $\begin{array}{l}\text { Compet en cia } \\
\text { específica }\end{array}$ & Objetivos de desempeño \\
\hline \multirow[t]{2}{*}{ Motivación } & Iniciativa & $\begin{array}{l}\text { Expresar ideas y acciones } \\
\text { que buscan aportar al avance del } \\
\text { grupo. }\end{array}$ \\
\hline & Motivación & $\begin{array}{l}\text { Animar al grupo a trabajar } \\
\text { juntos por el objetivo. }\end{array}$ \\
\hline \multirow[t]{2}{*}{$\begin{array}{l}\text { Habilidades de } \\
\text { relación }\end{array}$} & Negociación & $\begin{array}{l}\text { Conciliar diferentes } \\
\text { alternativas de acción escuchando } \\
\text { las partes }\end{array}$ \\
\hline & Coordinación & $\begin{array}{l}\text { Coordinar diferentes } \\
\text { actores y recursos para el alcance } \\
\text { de objetivos. }\end{array}$ \\
\hline
\end{tabular}




\begin{tabular}{|c|c|c|}
\hline \multicolumn{3}{|c|}{ Pensamiento sistémico } \\
\hline $\begin{array}{l}\text { Competencia } \\
\text { general }\end{array}$ & $\begin{array}{l}\text { Com pet e n cia } \\
\text { específica }\end{array}$ & Objetivos de desempeño \\
\hline \multirow{4}{*}{$\begin{array}{l}\text { Toma re de } \\
\text { decisiones y resolución } \\
\text { de problemas }\end{array}$} & $\begin{array}{l}\text { Análisis } \\
\text { situaciones }\end{array}$ & $\begin{array}{l}\text { Cambiar de perspectiva } \\
\text { para ampliar el entendimiento. }\end{array}$ \\
\hline & & $\begin{array}{l}\text { Considerar las } \\
\text { consecuencias a corto y largo plazo } \\
\text { de las acciones. }\end{array}$ \\
\hline & Consciencia social & $\begin{array}{l}\text { Reconocer que las } \\
\text { estructuras de los sistemas generan } \\
\text { un comportamiento. }\end{array}$ \\
\hline & $\begin{array}{l}\text { Consciencia de sí } \\
\text { mismo }\end{array}$ & $\begin{array}{l}\text { Reconocer que los modelos } \\
\text { mentales o creencias influyen en las } \\
\text { decisiones. }\end{array}$ \\
\hline \multicolumn{3}{|l|}{ Innovación } \\
\hline $\begin{array}{l}\text { Competencia } \\
\text { general }\end{array}$ & $\begin{array}{l}\text { Competencia } \\
\text { específica }\end{array}$ & Objetivos de desempeño \\
\hline \multirow[t]{2}{*}{$\begin{array}{l}\text { Innovación } \\
\text { adaptabilidad }\end{array}$} & $\begin{array}{l}\text { Ciudadanía activa, } \\
\text { participativa y crítica }\end{array}$ & $\begin{array}{l}\text { Ampliar el concepto de } \\
\text { innovación, incluir elementos de } \\
\text { responsabilidad social y ambiental. }\end{array}$ \\
\hline & Innovación & $\begin{array}{l}\text { Transformar una idea en } \\
\text { valor: crear un producto o servicio } \\
\text { que responda a una necesidad } \\
\text { identificada. }\end{array}$ \\
\hline \multicolumn{3}{|c|}{ Orientación vocacional } \\
\hline $\begin{array}{l}\text { Competencia } \\
\text { general }\end{array}$ & $\begin{array}{l}\text { Com pe t e n cia } \\
\text { específica }\end{array}$ & Objetivos de desempeño \\
\hline \multirow[t]{3}{*}{ vida } & $\begin{array}{l}\text { Consciencia de sí } \\
\text { mismo }\end{array}$ & $\begin{array}{l}\text { Reconocer el estado actual } \\
\text { de la propia vida: fortalezas, } \\
\text { oportunidades, aspectos a mejorar, } \\
\text { gustos }\end{array}$ \\
\hline & $\begin{array}{l}\text { Iniciativa } \\
\text { optimismo } \\
\end{array}$ & Visualizar futuro deseado. \\
\hline & $\begin{array}{l}\text { Motivación } \\
\text { logro }\end{array}$ & $\begin{array}{cc}\text { Identificar caminos } & \mathrm{o} \\
\text { procesos para lograr ese futuro. }\end{array}$ \\
\hline
\end{tabular}

Elaboración propia.

Estructura de los talleres. A continuación, se presenta una estructura de seis momentos, propuesta para el diseño y la ejecución de los talleres.

Inclusión. Cada persona que pertenece al grupo es única en cuanto a su experiencia de vida y percibe la nueva situación desde 
una compleja y personal diversidad de necesidades y expectativas, por ello es importante que cada una de ellas sea incluida y escuchada. Es un momento en el que el grupo se sienta en círculo, todos presentes y todos al mismo nivel. Los integrantes se presentan, expresan expectativas, hacen acuerdos de convivencia y los facilitadores hacen reconocimientos. Se tendrán en cuenta tres elementos básicos de la inclusión:

- Cada persona necesita poder presentarse a sí misma.

- Cada persona necesita poder expresar sus expectativas acerca de lo que va a suceder.

- Cada persona necesita ser reconocida por el grupo al recibir la oportunidad de ser apreciada, escuchada y bienvenida.

Nombrar objetivos. Tanto los participantes como los facilitadores deben conocer claramente los objetivos del taller. Se comunican al inicio de este.

\section{Implementación estratégica.}

- Actividad rompehielo: tiene el objetivo de generar un ambiente de confianza y distensión, así como también de incluir a todos y motivar a la participación.

- Charla inicial: es una conferencia breve y bien estructurada sobre la habilidad que se va a tratar, la cual tiene como objetivo mostrar su importancia y motivar a través de ejemplos de vida que el orador comparta con los estudiantes. Debido a que se cree que en el «hacer» se genera un mayor aprendizaje, entonces se sugiere que además de la escucha activa y la interacción generada durante la charla, se produce un mecanismo para que los estudiantes pongan en práctica otras habilidades útiles para la vida como: tomar notas adecuadamente, sintetizar, hacer mapas mentales, entre otros.

Lúdicas de aprendizaje 
- Es esencial, seleccionar las lúdicas al cuidar la coherencia con los objetivos que se buscan con el taller.

- Las lúdicas deben ser inclusivas, retadoras y procurar la interacción en escenarios colaborativos.

- Las lúdicas pueden buscar la comprensión conceptual de la habilidad, pero en primer lugar deben buscar la vivencia, es decir, la puesta en práctica en el propio cuerpo de esa habilidad blanda a trabajar. Luego, en la fase de reflexión, se hace consciencia y se dialoga sobre lo vivido.

Reflexión. En cada etapa del taller se propiciarán momentos de reflexión personal y grupal, a través de preguntas que se plantean a nivel individual, en grupos pequeños y/o en todo el grupo. Tipos de indagaciones las cuales pueden hacerse se encuentran enfocadas en el contenido, en la interacción del grupo y en lo aprendido o sentido.

Reflexión final: es el momento de cierre en el que se motiva a los estudiantes a expresar - verbalmente, por escrito, a través de un dibujo, o de alguna expresión creativa- los principales aprendizajes durante el taller.

Reconocimiento. Es importante invitar a hacer declaraciones de reconocimiento en todos los momentos del taller, esto fortalece la identidad de los participantes al sentirse reconocidos y también fortalece la capacidad de ver lo bueno en el otro, además contribuye al sentido de pertenencia en el grupo. Por ello son importantes tres elementos clave: reconocer y valorar en el grupo las ideas y actitudes de los niños, celebrar siempre los logros y aprendizajes, y nunca descalificar a los niños y procurar que no se descalifiquen entre ellos.

Recolección y archivo de evidencias.

- Tomar fotografías. 
- Llenar los listados de asistencia.

- Llevar a cabo el esquema evaluativo propuesto.

- Archivar adecuadamente las evidencias.

\section{Taller de orientación vocacional}

La orientación profesional o vocacional es un proceso, en el que intervienen familia, escuela, comunidad, el cual busca dar al joven información sobre el medio educativo, laboral y social; así como inducir vivencias y reflexiones que le permitan autoconocerse e identificar motivaciones y afinidades propias únicas, relacionadas con las alternativas que ofrecen estos medios y que lo prepara para la elección, la formación y la actuación profesional (Carpio et al., 2007).

Es importante tener en cuenta que debido a que la orientación vocacional es un trabajo profundo, de observarse y sentirse a sí mismo, se pueden adelantar algunas actividades desde sesiones anteriores, con el fin de trabajarlo progresivamente. En algunos casos es necesario proponer la actividad con anterioridad, como algunas pruebas que se deben realizar con miembros de la familia. También puede ser interesante considerar la posibilidad de que el taller sea vivenciado en el campus de la UTP, con el fin de motivarlos a continuar sus estudios de educación superior.

\section{Estructura del taller de orientación vocacional}

Con base en la estructura propuesta en el ítem anterior, se presenta un esquema para el diseño y ejecución del taller de orientación vocacional. 


\section{Inclusión.}

Objetivos. Enunciar los objetivos del taller a los participantes en un lenguaje motivante y entendible. Estos deben corresponder con las necesidades del grupo, el nivel de información, los intereses, la edad, entre otros aspectos.

Implementación estratégica. Las siguientes son las etapas planteadas para el taller de orientación vocacional. Para llevarlas a cabo se recopilaron una serie de herramientas vivenciales y tipo test que están disponibles para el diseño de los talleres.

- Identificación de habilidades y potencialidades: responde la pregunta ¿dónde estoy ahora? (Elegir o identificar herramientas para definir estos elementos). Esencia, bendición y misión, rueda de la vida y los diferentes instrumentos.

- Definición de visión: técnica de visualización y descripción del sueño o de cómo se quieren ver en cierta cantidad de tiempo.

- Reflexión y diálogo: sobre creencias limitantes o potenciadoras, llave o candado (miedos y esperanzas).

- Plan de acción: responde a la pregunta ¿qué puedo hacer para alcanzar mi meta o aproximarme al ideal?

\section{Reflexión.}

\section{Reconocimiento.}

Recolección de evidencias.

\section{Esquema de evaluación del proyecto}

Como lo señalan Díaz-Barriga y Hernández (2010) la evaluación es parte integral y necesaria del proceso de enseñanzaaprendizaje, al aportarle al docente o facilitador mecanismos de 
autorregulación y de conocimiento de los factores y problemas que impulsan o perturban dicho proceso. Por ello dijeron:

... sin la actividad evaluativa difícilmente podríamos asegurarnos de que ocurra y progrese algún tipo de aprendizaje, y nos costaría conocer algo sobre los resultados y la eficacia de la acción docente y de los procedimientos de enseñanza utilizados, en tanto actividades necesarias para mejorar la actividad constructiva de los alumnos (p. 307).

Debido a esto se podría decir que las acciones evaluativas se encaminan a reflexionar, interpretar y mejorar el proceso de enseñanza-aprendizaje desde el interior del mismo (Díaz-Barriga y Hernández, 2010, p. 309), por tanto, debe estas deben ser continuas.

Al proseguir con la perspectiva de estos dos autores, la evaluación implica seis aspectos centrales, los cuales serán aplicados a la evaluación del proceso de los estudiantes que participan en los talleres de CF. Esta información se muestra en la TABLA NRO. 3. 
TABLA NRo. 3. Conceptualización del esquema evaluativo de Construyendo Futuro.

\begin{tabular}{|c|c|}
\hline Aspecto & $\begin{array}{c}\text { Aplicación } \\
\text { Construyendo Futuro }\end{array}$ \\
\hline $\begin{array}{l}\text { La demarcación del objeto o } \\
\text { situación a evaluar: qué se quiere } \\
\text { evaluar sobre los aprendizajes de los } \\
\text { alumnos. }\end{array}$ & $\begin{array}{l}\text { Se quiere evaluar: } \\
\text { El progreso percibido por cada } \\
\text { estudiante en sus propias habilidades } \\
\text { socioemocionales, a través de cambios en } \\
\text { sus actitudes. } \\
\text { El progreso del grupo. } \\
\text { El aprendizaje de los facilitadores. }\end{array}$ \\
\hline $\begin{array}{l}\text { «Uso de determinados criterios } \\
\text { para orientar la evaluación y de } \\
\text { indicadores para realizarla. Los criterios } \\
\text { se derivan de las intenciones educativas } \\
\text { predefinidas [...] } \\
\text { Los indicadores se definen para } \\
\text { valorar las ejecuciones de los alumnos } \\
\text { en términos de presencia-ausencia y de } \\
\text { modalidad o calidad de esta» (Díaz y } \\
\text { Hernández, como se citaron en Idrogo, } \\
\text { 2018, p. 29). }\end{array}$ & $\begin{array}{l}\text { Criterios: los objetivos definidos } \\
\text { para cada taller. } \\
\text { Indicadores: } \\
\text { Resultados de autoevaluación al } \\
\text { inicio y al final del proceso. } \\
\text { Observación del proceso grupal por } \\
\text { parte de los facilitadores-bitácora. } \\
\text { Recolección de reflexiones de los } \\
\text { estudiantes y facilitadores al final de cada } \\
\text { taller. } \\
\text { Resultados de autoevaluación de los } \\
\text { facilitadores al final del proceso. }\end{array}$ \\
\hline $\begin{array}{l}\text { «Sistematización mínima para } \\
\text { la obtención de la información. Se } \\
\text { consigue a través de la deliberación } \\
\text { sobre la aplicación de los diversos } \\
\text { procedimientos e instrumentos } \\
\text { evaluativos que hagan emerger los } \\
\text { indicadores en el objeto de evaluación» } \\
\text { (Idrogo, 2018, p. 30) }\end{array}$ & $\begin{array}{l}\text { Sistematización de los resultados de } \\
\text { las diferentes herramientas de evaluación. }\end{array}$ \\
\hline
\end{tabular}




\begin{tabular}{|c|c|}
\hline $\begin{array}{l}\text { Representación de lo más } \\
\text { fidedigna del objeto de evaluación. } \\
\text { Se logra a partir de la obtención de la } \\
\text { información y a través de la aplicación } \\
\text { de las técnicas. } \\
\text { Es objetiva por «a) la precisión } \\
\text { y claridad de objetivos e indicadores } \\
\text { [...] b) la pertinencia y validez de } \\
\text { los procedimientos e instrumentos } \\
\text { evaluativos que permiten determinar la } \\
\text { presencia o ausencia de los indicadores } \\
\text { de evaluación en los aprendizajes» } \\
\text { (Díaz-Barriga y Hernández, 2010, p. } \\
\text { 309). }\end{array}$ & $\begin{array}{l}\text { Presentación de los resultados- } \\
\text { indicadores del proceso evaluativo. }\end{array}$ \\
\hline $\begin{array}{l}\text { «Emisión de juicios. A partir } \\
\text { de la confrontación entre los criterios } \\
\text { predefinidos en las intenciones } \\
\text { educativas y los indicadores emergerá } \\
\text { este juicio valorativo» (Díaz-Barriga y } \\
\text { Hernández, 2010, p. 309). Los juicios se } \\
\text { realizan también para ser comunicados } \\
\text { a distintos destinatarios (alumnos, } \\
\text { padres, docentes, instituciones, entre } \\
\text { otros) }\end{array}$ & $\begin{array}{l}\text { Juicios cualitativos sobre los } \\
\text { aprendizajes de los estudiantes y de los } \\
\text { facilitadores sobre cómo y hasta qué punto } \\
\text { han sido alcanzados los criterios evaluados. } \\
\text { Estos juicios se comunicarán a: } \\
\text { Estudiantes como retroalimentación } \\
\text { del proceso. } \\
\text { ANEIAP y GEIO como informe } \\
\text { final del proyecto. }\end{array}$ \\
\hline $\begin{array}{l}\text { «Toma de decisiones [...] Se } \\
\text { realiza a partir del juicio construido, } \\
\text { constituye sin duda el por qué y el para } \\
\text { qué de la evaluación. Las decisiones } \\
\text { [...] pueden ser: [a)] de carácter [...] } \\
\text { pedagógico (para lograr ajustes y } \\
\text { mejoras de la situación de aprendizaje } \\
\text { y/o enseñanza); [...] [b)] de carácter } \\
\text { social[-institucional] ([...] tienen que } \\
\text { ver con asuntos como la [calificación], } \\
\text { la acreditación, [la certificación] y la } \\
\text { promoción)» (Araujo, 2005, p. 4). }\end{array}$ & $\begin{array}{l}\text { En el caso de CF la toma de } \\
\text { decisiones será de carácter pedagógico para } \\
\text { lograr ajustes en el proceso de aprendizaje } \\
\text { y/o enseñanza, en las acciones y estrategias } \\
\text { educativas. } \\
\text { En este proyecto no hay evaluación } \\
\text { con función social o acreditativa. }\end{array}$ \\
\hline
\end{tabular}

Adaptada de Araujo (2005), Díaz-Barriga y Hernández (2010) e Idrogo (2018).

\section{Evaluación de los jóvenes de colegios}

Evaluación inicial y final (pre-post). La siguiente encuesta debe hacerse antes de hacer la primera sesión y al finalizar la última, 
ello con el fin de identificar transformaciones en las actitudes de los jóvenes después de haber participado en los talleres de Construyendo Futuro. Las preguntas se formularon de acuerdo con los objetivos para cada uno de los talleres (ver TABLA NRO. 2), lo cual indica que, si los objetivos cambian, se deberían hacer los cambios correspondientes en la herramienta de evaluación.

Se usó una escala Likert, la cual consiste en preguntas o afirmaciones definidas y de opción múltiple que ofrecen un abanico de posibilidades que pueden ser contestadas con facilidad, a la vez que permite una medición de datos sencilla de interpretar por métodos estadísticos. Dicha escala, definida para esta prueba, se tomó del artículo de Cañadas y Sánchez (1998) debido a que la aplicación de la herramienta es con jóvenes; adicionalmente se agregaron emoticones para facilitar la evaluación. En la TABLA NRO. 4 se presenta la herramienta de autoevaluación construida.

Tabla nro. 4. Autoevaluación de habilidades socio-emocionales

\begin{tabular}{|c|c|c|c|c|c|}
\hline $\begin{array}{l}\text { Autoevaluación de mis } \\
\text { habilidades } \\
\text { Responde esta prueba } \\
\text { con sinceridad, para que puedas } \\
\text { identificar tus grandes fortalezas } \\
\text { y seguir practicándolas, así como } \\
\text { reconocer aquellos aspectos en los } \\
\text { que podrías mejorar. }\end{array}$ & 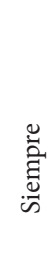 & 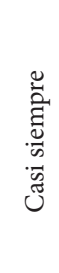 & 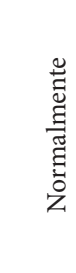 & 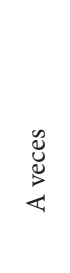 & 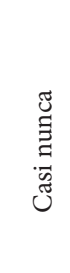 \\
\hline & & 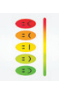 & $\underset{\$}{\$} \mid$ & $\begin{array}{l}8 \\
: 1 \\
8\end{array}$ & 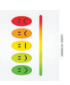 \\
\hline $\begin{array}{l}\text { Expreso de manera clara y } \\
\text { precisa un mensaje. }\end{array}$ & & & & & \\
\hline $\begin{array}{l}\text { Respeto los turnos a la hora de } \\
\text { hablar. }\end{array}$ & & & & & \\
\hline $\begin{array}{l}\text { Permito que los otros } \\
\text { compañeros se expresen libremente. }\end{array}$ & & & & & \\
\hline $\begin{array}{l}\text { Uso el lenguaje } \\
\begin{array}{l}\text { evitando } \\
\text { evitasuado } \\
\text { ofensivas. }\end{array}\end{array}$ & & & & & \\
\hline
\end{tabular}




\begin{tabular}{|c|c|c|c|c|}
\hline $\begin{array}{l}\text { Escucho con atención a mis } \\
\text { compañeros. }\end{array}$ & & & & \\
\hline $\begin{array}{l}\text { Soy capaz de seguir } \\
\text { instrucciones. }\end{array}$ & & & & \\
\hline $\begin{array}{l}\text { Reconozco y valoro las } \\
\text { habilidades que puedo aportar en el } \\
\text { trabajo grupal. }\end{array}$ & & & & \\
\hline $\begin{array}{l}\text { Asumo responsabilidades para } \\
\text { alcanzar el objetivo grupal. }\end{array}$ & & & & \\
\hline $\begin{array}{l}\text { Reconozco y valoro las } \\
\text { habilidades que los otros compañeros } \\
\text { pueden aportar en el trabajo grupal }\end{array}$ & & & & \\
\hline $\begin{array}{l}\text { Soy flexible en las acciones } \\
\text { para alcanzar el objetivo grupal, sin } \\
\text { imponer a los demás lo que yo quiero. }\end{array}$ & & & & \\
\hline $\begin{array}{l}\text { Propongo ideas y acciones que } \\
\text { buscan aportar al avance del grupo. }\end{array}$ & & & & \\
\hline $\begin{array}{l}\text { Animo al grupo a trabajar } \\
\text { juntos por el objetivo. }\end{array}$ & & & & \\
\hline $\begin{array}{l}\text { Genero acuerdos entre } \\
\text { diferentes alternativas de acción } \\
\text { escuchando las ideas de los demás. }\end{array}$ & & & & \\
\hline $\begin{array}{l}\text { Coordino diferentes personas } \\
\text { y recursos para el alcance de los } \\
\text { objetivos grupales. }\end{array}$ & & & & \\
\hline $\begin{array}{l}\text { Cambio de punto de vista para } \\
\text { entender mejor las situaciones. }\end{array}$ & & & & \\
\hline $\begin{array}{l}\text { Tengo en cuenta las } \\
\text { consecuencias a corto y largo plazo de } \\
\text { mis acciones. }\end{array}$ & & & & \\
\hline $\begin{array}{l}\text { Reconozco que la manera en } \\
\text { que se organizan las cosas genera } \\
\text { ciertos comportamientos. }\end{array}$ & & & & \\
\hline $\begin{array}{l}\text { Reconozco que las creencias } \\
\text { influyen en las decisiones que toman } \\
\text { las personas. }\end{array}$ & & & & \\
\hline $\begin{array}{l}\text { Cuando pienso en innovación } \\
\text { incluyo elementos de responsabilidad } \\
\text { social y ambiental. }\end{array}$ & & & & \\
\hline $\begin{array}{l}\text { Soy capaz de transformar } \\
\text { una idea en valor, es decir, soy capaz } \\
\text { de crear un producto o servicio } \\
\text { que responda a una necesidad } \\
\text { identificada. }\end{array}$ & & & & \\
\hline $\begin{array}{l}\text { Puedo identificar cuáles son } \\
\text { mis fortalezas como persona. }\end{array}$ & & & & \\
\hline
\end{tabular}




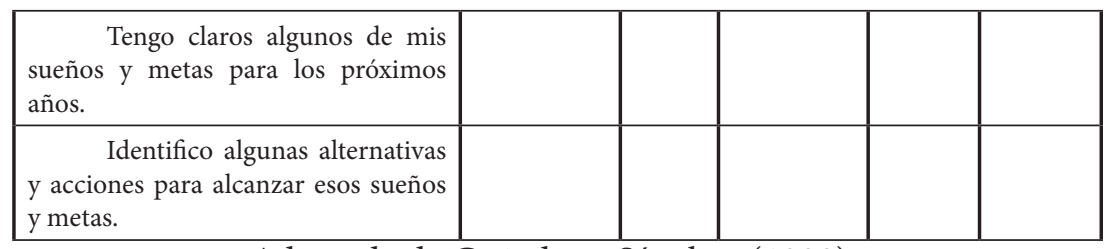

Adaptada de Cañadas y Sánchez (1998).

Evaluación del proceso. Con el fin de evaluar el progreso de los estudiantes y hacer las mejoras pertinentes en cada taller se deben llevar a cabo las siguientes dos actividades:

- Al final de cada taller se reparten post-its, tanto a estudiantes como a facilitadores. Para los primeros se hace la siguiente pregunta ¿qué aprendiste hoy? Y, para los segundos, ¿qué observaste hoy en el grupo? Estas se recogen y se sistematizan.

- En cada taller debe haber alguien que, voluntariamente, asuma un rol de relator; en un cuaderno-bitácora del proyecto, anote lo que observa, siente y escucha durante el taller; y permita visualizar los progresos y aspectos a mejorar del proceso.

\section{Evaluación de los jóvenes universitarios facilitadores}

Se diseñó una encuesta con el fin de conocer las percepciones de los estudiantes que participaron, de una u otra manera, en el proyecto. En ella se abarcan los siguientes aspectos: a) desarrollo de habilidades socioemocionales o blandas, b) desarrollo de habilidades como ingeniero industrial, c) aprendizajes en los aspectos metodológicos de los talleres, d) aprendizajes de vida, e) impacto que observó en los niños de los colegios, f) aspectos para mejorar del proyecto y propios.

\section{Población beneficiada}

Con el proyecto Construyendo Futuro hay dos poblaciones beneficiadas de manera directa: los jóvenes de los colegios que participaron en los talleres y los jóvenes universitarios que 
gestionaron el proyecto y diseñaron y ejecutan los talleres. Durante el año 2019 fueron aproximadamente doscientos jóvenes de colegios los que participaron en los talleres para el fortalecimiento de habilidades socioemocionales y aproximadamente veinticinco jóvenes estudiantes de Ingeniería Industrial, los cuales estuvieron involucrados en el desarrollo del proyecto. Más allá de los beneficiados directos, se podría hablar de que toda la sociedad se favorece con las transformaciones y aprendizajes logrados por estos jóvenes.

\section{Conclusiones}

- El apoyo de la Vicerrectoría de Investigaciones, Innovación y Extensión de la UTP fue importante para llevar a cabo el proyecto Construyendo Futuro-Fase dos y para avanzar hacia el mejoramiento de los talleres, así como la creación de nuevos elementos alineados con las necesidades que se han observado en años anteriores, tales como el taller de orientación vocacional y el esquema de evaluación.

- El enfoque experiencial, tanto desde la metodología de los talleres con herramientas pedagógicas como la lúdica, como desde la vivencia de la gestión y la ejecución del proyecto por parte de los universitarios, es clave para el aprendizaje y el fortalecimiento de las habilidades para la vida. Aprender haciendo en equipo, acompañado de la reflexión y el reconocimiento, es el núcleo metodológico que permite el despliegue de habilidades deseadas.

- Los proyectos de extensión social solidaria promueven la consciencia social y la empatía de estudiantes y docentes, además permiten comprender que al trabajar en equipo es posible llevar a cabo acciones transformadoras en la sociedad y que la universidad tiene mucho por aportar. 


\section{Referencias bibliográficas}

Araujo DíAz, D. (2005). Evaluación integral. Diplomado: desarrollo de habilidades docentes para el nuevo modelo educativo del IPN. Instituto Politécnico Nacional, Escuela Superior de Computo. http://www.geocities.ws/daraujo12/ dip_2.pdf.

Banco Mundial. (2017). Panorama general. https://www. bancomundial.org/es/topic/education/overview.

Carpio-Camacho, A. y Guerra-Rubio, L. M. (2007). La Orientación Profesional de los Alumnos que Ingresan a la Educación Superior. Revista Brasileira de Orientação Profissional, 8(2), 11-24. https://www.redalyc.org/ pdf/2030/203016901003.pdf.

Cañadas Osinski, I. y Sánchez Bruno, A. (1998). Categorías de respuesta en escalas tipo Likert. Psicothema, 10(3), 623-631. http://www.psicothema.es/pdf/191.pdf.

De Miguel, M. J.; Catalá, P. D.; Santamarina, C. V. y Carabal, M. A. (2019). Aprendiendo liderazgo y trabajo en equipo mediante el juego fuera del aula. En IN-RED 2019. V Congreso de Innovación Educativa y Docencia en Red (pp. 1316-1322). Editorial Universitat Politècnica de València. https://riunet. upv.es/handle/10251/129064.

Díaz-Aguado, M. J. (2006). Convivencia escolar y Prevención de la violencia. Centro Nacional de Educación y Comunicación Educativa. Ministerio de Educación, Cultura y Deporte, Instituto de Tecnologías Educativas. https://www. researchgate.net/publication/299741297_Convivencia_ escolar_y_prevencion_de_la_violencia. 
Díaz-Barriga, F. y Hernández Rojas, G. (2010). Estrategias docentes para un aprendizaje significativo: una interpretación constructivista (3. ${ }^{a}$ ed.). McGraw-Hill Interamericana.

Idrogo Cubas, R. N. (2018). Modelo de evaluación por competencias en Educación Física (MECEF), para docentes de la Región Lambayeque 2016 [Tesis doctoral, Universidad Cesar Vallejo]. https://repositorio.ucv. edu.pe/bitstream/handle/20.500.12692/33254/idrogo_ cr.pdf? sequence $=1$ \&isAllowed $=\mathrm{y}$.

Mejía, J. F.; Rodríguez, G. I.; Guerra, N.; Bustamante, A.; Chaparro, M. P. y Castellanos, M. (2017). Paso a paso: estrategia de formación de competencias socioemocionales en la educación secundaria y media. Departamento Nacional de Planeación, Ministerio de Educación Nacional y Banco Mundial https://www.mineducacion.gov.co/1759/ articles-385321_recurso.pdf. 


\title{
Creating Culturally Enriched Environments to Foster English Reading and Writing Habits Among Students in the Bilingual English Teacher Preparation Program
}

\author{
Nora LuCía MARULANDA ÁNGEL \\ Universidad Tecnológica de Pereira
}

\section{Resumen}

El propósito del proyecto es explorar estrategias en escenarios auténticos de habla inglesa para el mejoramiento de la escritura en estudiantes de la Licenciatura en Bilingüismo con énfasis en inglés, en donde la literatura y las artes dramáticas son usadas como medios para motivar los estudiantes a expresarse.

Dos tipos de talleres culturalmente orientados fueron ofrecidos en inglés por el Centro de Escritura Académica de la Universidad Tecnológica de Pereira, un club literario y un club de 
artes dramáticas. El objetivo de crear estos espacios alternativos fue doble: involucrar a los estudiantes en ejercicios de lectura y escritura alrededor de temas culturales que abarcan historias cortas, obras de teatro y ensayos; al igual que proporcionar un espacio en donde los estudiantes estén cómodos y dispuestos a usar el inglés auténticamente, dada la riqueza y accesibilidad del material pedagógico.

El club literario se estableció para involucrar a los educandos en conexiones sistemáticas de lectura y escritura que derivaran en productos escritos de diferentes géneros como resúmenes, reflexiones y reseñas. Estos leerán los mismos textos con la ayuda de pautas acerca de cómo responder al contenido de estas obras literarias de forma escrita. Así, después de leer cada pieza literaria y basados en las conexiones previamente establecidas con el texto, escriben productos cortos. Además, el club de artes dramáticas dio a los estudiantes un espacio para explorar una variedad de obras modernas y películas en las que se analizaron incidentes culturales como diálogos, autorreflexiones, monólogos, escenas y escenarios. A través de estos actos, los asistentes pudieron practicar aspectos suprasegmentales de la lengua como la prosodia, la cadencia, y la entonación; al igual que aspectos paralingüísticos como el lenguaje corporal que contribuye a interacciones en inglés más casuales y auténticas. De esta manera, la automaticidad en la producción de lenguaje de los alumnos pudo incrementar, al igual que su deseo de usar inglés como un medio natural de comunicación, lo cual facilitó la creación y recreación de piezas con contenidos culturales.

Paralelamente, el protocolo de asistencia sistematizada que fue previamente establecido en el Centro de Escritura Académica se amplió para apoyar sujetos de todo el programa. La razón por la cual se incluyeron estudiantes de cursos inferiores fue para exponerlos a lecturas basadas en literatura y a ejercicios de escritura, para usar materiales ricos en contenido y lingüísticamente ajustados a los diferentes niveles de suficiencia. 
Monitores académicos de cursos desde inglés básico hasta inglés avanzado en la Licenciatura en Bilingüismo con Énfasis en Inglés fueron capacitados por los tutores del Centro de Escritura, sobre cómo mejorar los productos escritos que les son requeridos a los estudiantes a través de la identificación de macro y micro componentes necesarios en la composición de textos.

Palabras clave: dramaturgia, literatura, lectura, escritura, cultura.

\section{Abstract}

The purpose of the project is to explore strategies within authentic English-speaking scenarios to engage students into writing across the English Teacher Preparation program, where literature and performing arts are used as means for enticing students to express themselves so they improve their writing competences. Two types of culturally oriented workshops will be offered in English by the Universidad Tecnológica de Pereira's Academic Writing Assistance Center (AWAC), a book and a performing arts club. The goal of creating these alternative spaces is twofold: to engage students into reading and writing exercises around cultural affairs that encompass short stories, plays and essays, and to provide a space where students are comfortable and eager to use the English language authentically given the richness of the materials and their language accessibility. Ultimately, the idea is that students become naturally inclined to engage in English interchanges inside and outside academic settings.

The book club will be established to engage students into systematic read-write connections that will derive in written products of different genres such as summaries, reflections, and reviews. Students will read the same texts with the support of guidelines on how to react in writing to the input, so they later share their insights in weekly discussions. After reading each piece of literature, and based on the previously made connections with 
the text, short products will be written in the shape of summaries, reflections and reviews. Furthermore, the performing arts club will provide a space for students to be exposed to a variety of modern plays and films to analyze cultural occurrences such as dialogs, self-reflections, monologues, scenes and settings. Through these occurrences, learners can practice suprasegmental aspects of language such as prosody, cadence and intonation as well as paralinguistic features like body language that can contribute to casual and authentic English language interactions. In this way, language production automaticity can increase as well as learners' willingness to use English as a natural means of communication, which will facilitate the creation or recreation of culturally-aligned pieces.

In a parallel fashion, the systematized peer-assistance protocol that has already been established in the AWAC will continue supporting students from seventh semester and above in their academic writing tasks, and will also support students from beginning semesters of the program. The rationale for including students early on in their preparation program is to expose them to rich, literature-based reading and writing practices with materials that are enriching in content and linguistically adjusted to different proficiency levels.

Monitors from basic to advanced English courses in the Teacher Preparation program will be trained by AWAC tutors on how to strengthen students' required writing pieces by learning to identify macro and micro features needed in text composition.

Keywords: Performing Arts, Literature, Reading, Writing, Culture.

\section{Introducción}

El proyecto de extensión denominado «Creando ambientes enriquecidos culturalmente para fomentar hábitos de lectura 
y escritura en inglés entre estudiantes de la Licenciatura en Bilingüismo con énfasis en inglés» nació de la necesidad de mejorar el nivel de escritura de los estudiantes de dicho programa, el cual fue identificado en proyectos anteriores (Marulanda y Martínez, 2017; 2019). En dichas investigaciones se descubrió que es esencial la asistencia continua y sistematizada en el proceso de escritura en una segunda lengua; sin embargo, se determinó que también es necesario contar con espacios culturales auténticos, en los cuales los estudiantes refuercen la lectura y la escritura de forma natural. Por esta razón, se concibieron dos espacios que pudieran atender los diferentes intereses del estudiantado, un club literario y un club de artes dramáticas. El material usado en cada sesión tomaba como referencia obras literarias y de teatro pertenecientes a la cultura angloparlante, este les permitía a los alumnos desarrollar sus habilidades corporales y crear hábitos de lectura. Así, las sesiones finalmente resultaban en la producción de textos escritos de diferentes géneros en los que, los estudiantes, mostraban su capacidad de reflexión y pensamiento crítico. Además de los clubes, otro componente importante del proyecto fueron las sesiones personalizadas de tutoría brindadas a los educandos de la Licenciatura, con el fin de mejorar sus textos escritos. En ellas, se identificó que los tutores con los cuáles contaba el Centro de Escritura Académica no eran suficientes para cubrir la demanda de la Licenciatura. Es por esto que se decidió entrenar a los monitores de los cursos básicos de inglés del programa y así poder garantizar continuidad en el proceso.

Todos estos esfuerzos fueron destinados al fortalecimiento del impacto del Centro de Escritura Académica, por medio de la ampliación del personal con tutores entrenados, al igual que por el alcance de una población más grande de la Licenciatura en Bilingüismo con Énfasis en Inglés, a través de actividades culturalmente atractivas que apuntan a mejorar las competencias comunicativas de los estudiantes en esta área. 


\section{Objetivos}

\section{Objetivo general}

Promover el desarrollo de habilidades avanzadas de escritura entre los aprendices de lengua inglesa de la Licenciatura en Bilingüismo con Énfasis en Inglés a través de la creación de espacios culturales donde los estudiantes se involucren de forma natural en producción auténtica de lenguaje y tareas de escritura académica.

\section{Objetivos específicos}

Motivar a los estudiantes a explorar culturas angloparlantes a través de la literatura y la dramaturgia por medio del establecimiento de un escenario de uso auténtico del lenguaje donde los participantes puedan definir objetivos para leer, discutir y escribir textos de diferentes géneros.

Guiar a los estudiantes en el desarrollo de conexiones lectoescritoras para que sus respuestas a la lectura deriven en prácticas de escritura.

Incrementar la conciencia y participación de los estudiantes en las actividades previas y recientemente diseñadas del Centro de Escritura Académica.

Crear y recrear piezas de escritura culturalmente alineadas como diálogos, autorreflexiones, monólogos y escenas basadas en obras de teatro y películas analizadas con antelación.

Mejorar la calidad de las producciones escritas requeridas en los cursos que involucran escritura académica a lo largo de la Licenciatura en Bilingüismo con Énfasis en Inglés. 
Entrenar monitores de los cursos básicos de inglés para que apoyen a los estudiantes que necesiten mejorar sus producciones escritas.

\section{Metodología}

\section{Campaña de concientización del Centro de Escritura Académica}

Para asegurar el éxito del proyecto, las nuevas iniciativas del Centro de Escritura Académica fueron lanzadas a través de una campaña multimedial diseñada para informar y persuadir a los estudiantes acerca de la importancia de participar en las nuevas actividades del centro. La información se propagó a través de una reunión inicial de publicaciones en redes, de volantes y de pósters. Una encuesta preliminar fue llevada a cabo para conocer la percepción inicial que tenían los estudiantes acerca del proyecto y sus iniciativas. Esta fase de lanzamiento fue grabada en video y compartida con la comunidad educativa del programa. Para mantener informados a los estudiantes y los miembros de la facultad, a lo largo del año, fueron enviadas publicaciones periódicas. Estos mecanismos sirvieron para informar a la población y mantener un registro de su participación en las iniciativas del Centro de Escritura Académica.

\section{Preparando el escenario}

Dada la importancia del aprendizaje periférico (Lozanov, 1978), era necesario crear un ambiente donde los aprendices de lengua estuvieran expuestos a una variedad de materiales exhibidos con mensajes relacionados a temas de cultura inglesa y a frases motivacionales acerca de la lectura y la escritura. Lugares específicos en el Centro de Escritura Académica fueron asignados y adaptados para ambos, al igual que en el club de literatura y el club de artes dramáticas con el fin de promover el desarrollo de competencias culturales y conciencia acerca de la 
importancia de involucrarse en actividades ofrecidas en el centro. De esta manera, las paredes de dicho centro incluyeron artefactos decorativos y auténticos como murales, carteles y señales, los cuales fueron diseñados para hacer este espacio más atractivo y para incluir a los estudiantes en conversaciones en inglés acerca de libros, obras de teatro y películas en un ambiente cómodo y libre de estrés. El impacto de estos espacios fue medido a través de la implementación de una encuesta, la cual se enfocó en recolectar las percepciones de los estudiantes acerca de la originalidad del ambiente y su participación en los clubes.

\section{Club literario:}

Se llevaron a cabo sesiones semanales para discutir los textos de diferentes géneros literarios (ficción o no ficción) que habían sido previamente asignados en relación a los temas, la trama, los personajes, los escenarios y otras características. Se esperaba que los participantes compartieran sus percepciones y reflexiones a través de actividades especialmente diseñadas por el encargado de liderar las sesiones. Así, cada sesión derivó en escritos de los estudiantes, los cuales fueron de carácter creativo o reflexivo donde se registraron los pensamientos de cada uno de ellos. Estas producciones escritas fueron organizadas en un portafolio en forma de muestras de escritura, en diarios literarios y en imágenes para monitorear los objetivos de lectura y escritura de los estudiantes.

\section{Club de artes dramáticas:}

Obras de teatros fueron escogidas para el estudio y práctica de varios elementos relacionados con la actuación, los cuales son relevantes para las habilidades del lenguaje como la prosodia (entonación, cadencia) y aspectos paralingüísticos (gestos, lenguaje corporal). Al destacar la subjetividad y los roles de pertenencia de los participantes, ellos establecieron conexiones con los textos, aquellas que los llevaron a producir escenas, 
diálogos e, incluso, libretos de forma escrita. Artefactos como textos, fotos, audios y videos fueron recolectados en un portafolio para hacer el seguimiento de la participación y el progreso de los estudiantes. Al final, los individuos fueron entrevistados para capturar sus opiniones acerca de la relevancia y efectividad de ambos espacios culturales.

\section{Unir experiencias de lectura con producciones escritas}

Como los participantes del club literario y del taller de artes dramáticas interactuaron constantemente con textos de diferentes tipos, ambos espacios proporcionaron con oportunidades y apoyo a los estudiantes, para que estos pudieran producir escritos de diferentes géneros que reflejaran su creatividad artística, habilidades de pensamiento crítico y capacidad de reflexión. Dichos participantes fueron instruidos en cómo componer sus textos con modelos estructurados y tips composicionales derivados del protocolo de asistencia del Centro de Escritura Académica. La persona o líder a cargo de las sesiones culturales proporcionó retroalimentación a cada producto escrito y, subsecuentemente, los recolectó como evidencia. Dentro de los diferentes documentos que fueron escritos en ambos espacios culturales se encuentran bitácoras, historias cortas, monólogos, diálogos, descripciones de escenas, ensayos cortos y diarios reflexivos.

\section{Adoptar un enfoque cultural en las sesiones del Centro de Escritura Académica}

Una vez los estudiantes entregaban sus trabajos escritos, ellos recibían retroalimentación del profesor y se les pedía atender a una sesión de treinta minutos donde se les brindaba asistencia personalizada y consejos basados en los comentarios hechos por sus docentes. Las sesiones de tutoría consistían en muchos pasos que empezaban con un procesamiento de los comentarios del instructor para asegurarse que los educandos entendieran la naturaleza de sus errores. A continuación, los 
tutores sugerían diferentes maneras de prevenir estas falencias a través de la revisión de reglas gramaticales o de oraciones con otras estructuras sintácticas. De hecho, esta asistencia apuntaba a ayudar a los aprendices de lengua a ajustar sus textos de acuerdo a sus necesidades académicas y a desarrollar conciencia metalingüística entre ellos mismos.

Para documentar el progreso de los estudiantes en relación a las tutorías recibidas, a las versiones iniciales y finales de sus escritos y a sus respectivas rúbricas de calificación, estas fueron organizadas en un portafolio para analizarlas mensualmente y tomar en cuenta una lista de errores hecha en base de las inconsistencias escriturales encontradas en sus textos. Además, la asistencia por semana fue recogida y organizada con el fin de monitorear la participación de los alumnos. Al final de cada semestre, una encuesta fue implementada para explorar las percepciones de estos mismos acerca de la efectividad de los pasos seguidos en las sesiones de tutoría y el tiempo y lugar utilizados para llevarlas a cabo.

\section{Construir capacidad y sostenibilidad}

Los monitores que apoyaban los cursos de inglés básico fueron entrenados por los tutores del Centro de Escritura Académica sobre técnicas de revisión en pares para que ellos pudieran proporcionar apoyo en los trabajos escritos requeridos en dichos cursos. Dos encuentros diferentes tomaron lugar a lo largo de cada semestre, uno con el fin de entrenar a los monitores y otro para recolectar información acerca de su experiencia. Todo ello con la finalidad de revisar el impacto y sacar conclusiones respecto a la sostenibilidad de la ampliación del personal. Los materiales diseñados para el entrenamiento fueron organizados en portafolios, a fin de que pudieran ser usados en sesiones futuras. De la misma manera, la asistencia de los monitores a las capacitaciones fue registrada para hacer reuniones de seguimiento y para tratar aspectos fundamentales del proceso. Finalmente, 
los cuestionarios realizados por los participantes, acerca de su percepción sobre las sesiones de tutorías, fueron llevados a cabo con el propósito de incorporar sugerencias en los talleres, los cuales se implementarán en los próximos años.

\section{Resultados}

\section{Talleres}

1. Talleres de capacitación de monitores: se realizaron tres talleres de capacitación en los cuales se trataron las siguientes temáticas: 1) los fundamentos de AWAC, su razón de ser, su funcionamiento e integrantes y los resultados obtenidos en el proyecto, al igual que los principios para lograr una tutoría de escritura exitosa; 2) gramática de nivel intermedio que cubría condicionales y modales; 3) gramática avanzada que hacía referencia a los apositivos y oraciones sustantivas. Se logró capacitar el $100 \%$ de los monitores académicos y se completó el $75 \%$ de las 4 sesiones planeadas. Dichas sesiones se realizaron de 2 p.m. a 4 p.m. en tres aulas asignadas en el bloque de bellas artes y humanidades.

2. Club de literario: se realizaron cinco sesiones en las cuales se abordaron textos literarios y ensayísticos para promover, en sus asistentes, intercambios de ideas y reflexiones. Los encuentros tomaron lugar los viernes de 2 a 4 de la tarde en la sala de audiovisuales de la Biblioteca Jorge Roa Martínez. Cada sesión se desarrolló al seguir este patrón: 1) introducción del texto; 2) imaginario al ser un ejercicio de carácter creativo para generar una atmósfera de discusión literaria; 3 ) discusión del título del texto; 4) discusión guiada con preguntas formuladas por el facilitador de la sesión; 5) discusión abierta centrada en aspectos personales de la lectura; 6) lectura complementaria leída por todos en voz alta; 7) cierre escrito en el que los participantes condensaron, en un párrafo, pensamientos o conclusiones sobre la sesión. Se logró la asistencia de alrededor de 5 personas por espacio de tiempo. A pesar de que se planearon 28 encuentros, debido a que se limitó la asistencia a estudiantes de la Licenciatura en Bilingüismo y a que el día en el que ocurrían las sesiones (viernes) no resultó ser el más apropiado para ejecutar el club literario, solo se pudo llevar a cabo el $20 \%$ de los talleres esperados. 
3. Club de teatro: se realizaron ocho sesiones en las cuales se buscaba desarrollar competencias lingüísticas y performativas a través de la enseñanza de técnicas artísticas y teatrales. Estas tomaron lugar en el salón de espejos de la Facultad de Bellas Artes y Humanidades. Los talleres se llevaron a cabo de la siguiente forma: 1) calentamiento inicial para activar las partes del cuerpo que se utilizarían en la sesión; 2) exploración de técnica y/o concepto teatral de la sesión; 3 ) práctica conjunta e individual de dicha técnica y/o concepto; 4) reflexión final escrita. A pesar de que se planearon 28 encuentros, debido a que se limitó la asistencia a estudiantes de la Licenciatura en Bilingüismo y a que el horario en el que ocurrían las sesiones ( 1 p.m. a 3 p.m.) no resultó ser el más apropiado para ejecutar el club de teatro, solo se pudo llevar a cabo el $25 \%$ de los talleres esperados.

\section{Cartilla}

Se realizó una cartilla en la cual se compilaron los aspectos más importantes del proyecto de extensión tales como los objetivos, la metodología, los resultados, la población beneficiada, las conclusiones y la evidencia recolectada a lo largo del proceso. Se cumplió el $100 \%$ de este producto esperado.

\section{Población beneficiada}

La población beneficiada por este proyecto fue la mayoría de los estudiantes de la Licenciatura en Bilingüismo con Énfasis en Inglés cuyas edades oscilan entre los dieciséis y los veinticinco años y su nivel de suficiencia en inglés varía entre A2 y C1. El grupo beneficiado incluye los monitores de los cursos de inglés: básico, pre-intermedio, intermedio y avanzado, estudiantes que cursan materias que requieran escritos académicos y alumnos interesados en participar en los talleres culturales. 


\section{Conclusiones}

Para concluir, uno de los aspectos más importantes del proyecto es que se logró que los estudiantes pudieran reconocer la lectura y la escritura como hábitos que trascienden los contextos académicos. Esto se debe a la efectividad que tuvo el ofrecer dos espacios enriquecidos culturalmente, libres de la presión que normalmente se ejerce sobre ellos en ambientes de enseñanza tradicional.

Debido a la extensa campaña publicitaria que se realizó acerca del Centro de Escritura Académica al inicio del año, los profesores de los cursos que requerían textos académicos empezaron a promover la asistencia de sus estudiantes a este espacio. Esta situación causó la participación masiva de aprendices, de todos los semestres del programa, a las tutorías personalizadas. Gracias a que los horarios del Centro de Escritura Académica eran más extensos y la cantidad de monitores era más alta que en años pasados, se logró atender a la mayoría de estudiantes. Sin embargo, el club literario y el club de artes dramáticas no contaban con la misma flexibilidad horaria lo que afectó directamente el número de estudiantes beneficiados.

Por otro lado, los monitores de los cursos básicos de inglés, los cuales fueron capacitados, expresaron que ahora las monitorias eran más claras, puesto que tenían criterios definidos en cuanto a cómo abordar cada texto y cómo convertir dichos espacios en un proceso de aprendizaje a través de la reflexión sobre los errores cometidos en los escritos. De esta forma, se unificó la manera en la que las tutorías eran abordadas, además de lograr que los monitores prestaran más atención al diseño de las tareas de escritura y a los métodos de evaluación usados en sus respectivos cursos. 
Figura NRO. 1. Club literario.

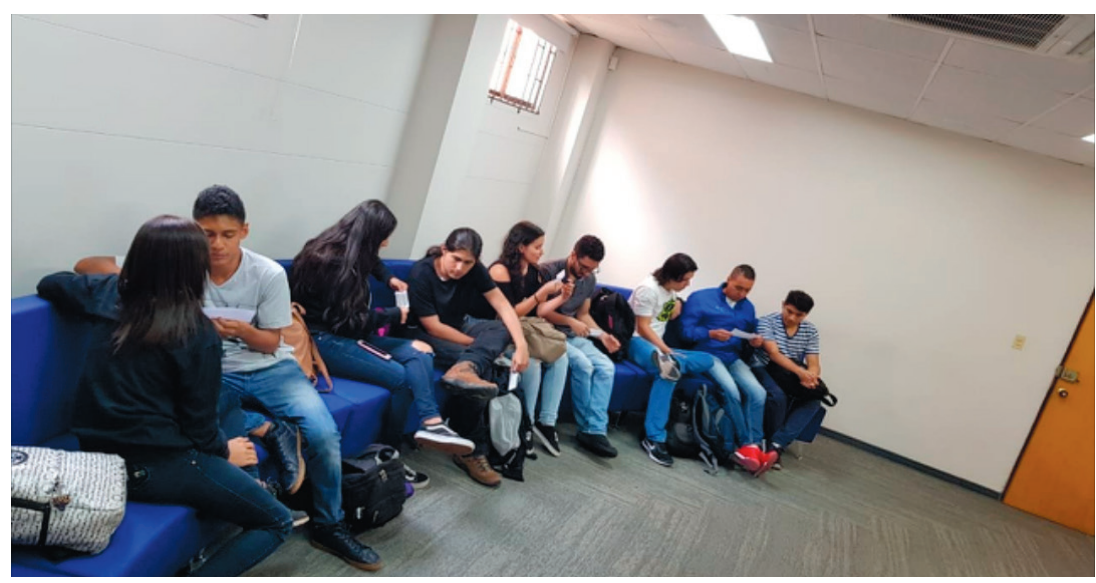

Elaboración propia.

Figura NRo. 2. Club de teatro.

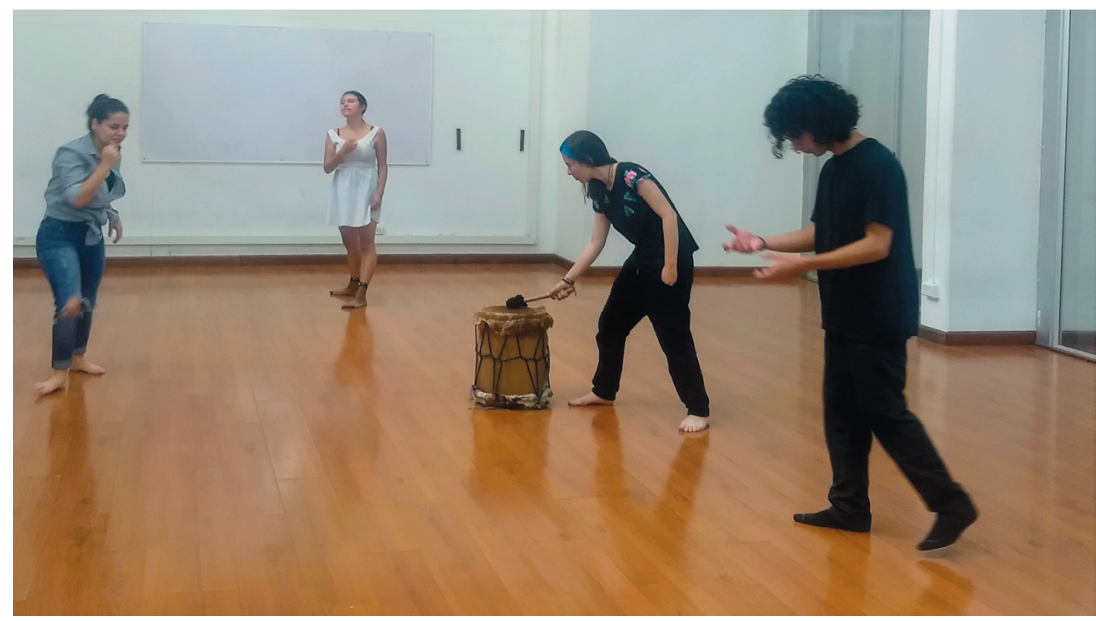

Elaboración propia. 
Figura NRO. 3. Actividades club de teatro.

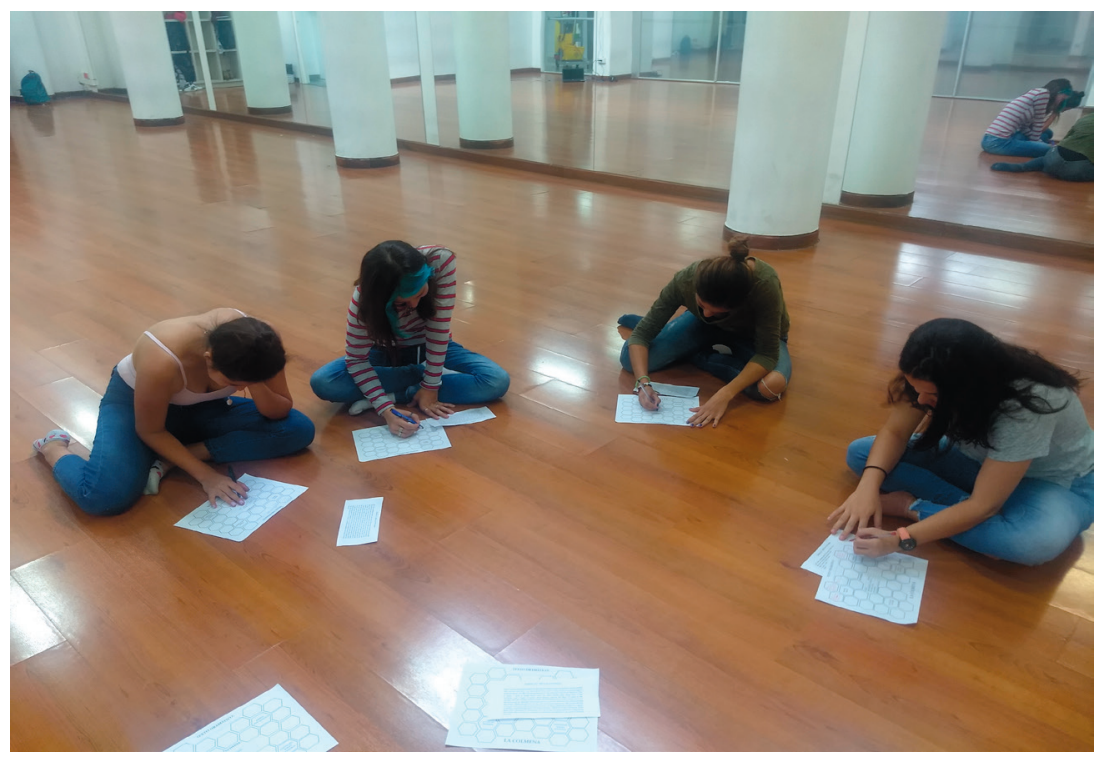

Elaboración propia.

\section{Bibliografía}

Beaven, A. \& Álvarez, I. (2014). Non-Formal Drama Training for In-Service Language Teachers. Scenario, 8(1). 5-18. https://journals.ucc.ie/index.php/scenario/article/view/ scenario-8-1-2/pdf-en.

Buitrago Escobar, C. J. (2010). Literary Show: A Space to Share Students' Compositions. Enletawa Journal, (3), 47-68. https:// revistas.uptc.edu.co/index.php/enletawa_journal/article/ view/1939/1931.

Daniels, H. (2002). Literature Circles: Voice and Choice in Book Clubs and Reading Groups. Stenhouse Publishers. 
DBI Network. (s.f.). Drama-Based Instruction. Activating Learning Through the Arts! University of Texas at Austin. http://www.utexas.edu/cofa/dbi/about.

Guthrie, J. T. \& Wigfield, A. (Ed.). (1997). Reading Engagement: Motivating Readers Through Integrated Instruction. International Reading Association.

Hugues, J. \& Wilson, K. (2004). Playing a Part: The Impact of Youth Theatre on Young People's Personal and Social Development. Research in Drama Education: The Journal of Applied Theatre and Performance, 9(1), 57-72.

Keene, E. \& Zimmerman, S. (1997). Mosaic of thought. The Power of Comprehension Strategy Instruction. Heinemann.

Krashen, S. (2004). The Power of Reading: Insights from the Research. Libraries Unlimited.

Lozanov, G. (1978). Suggestology and Suggestopedy. http:// lozanov.hit.bg/.

Marulanda Ángel, N. L. \& Martínez García, J. M. (2017). Improving English Language Learners' Academic Writing: A Multi-Strategy Approach to a Multi-Dimensional Challenge. GiST Education and Learning Research Journal, (14), 49-67. https://doi.org/10.26817/16925777.367.

. (2019). Supporting English Language Learners' Academic Writing Development Through a Systematized Assistance Model. Lenguaje, 47(2), 453-478.

McMahon, S. I. \& Raphael, T. (1997). The Book Club Connection: Literacy Learning and Classroom Talk. Teachers College Press. 
Özmen, K. S. (2010). Fostering Nonverbal Immediacy and Teacher Identity Through an Acting Course in English Teacher Education. Australian Journal of Teacher Education, 35(6). 10.14221/ajte.2010v35n6.1.

Shelton-Strong, S. J. (2012). Literature Circles in ELT. ELT Journal, 66(2), 214-223. https://doi.org/10.1093/elt/ccr049.

Smith, M. (1996). Conversations About Literacy Outside Classrooms: How Adults Talk About Books in Their Book Clubs. Journal of Adolescent \& Adult Literacy, 40(3), 180-186.

Vaille, B. \& Quinn Williams, J. (2005). Creating Book Clubs in the English Language Classroom: A Model for Teachers of Adults. University of Michigan Press. 


\title{
Desarrollo de estrategias de motivación para fomentar la participación de mujeres en carreras de ciencia y tecnología
}

\author{
Sandra Milena PÉRez Londoño \\ CARLOS SALDARRIAGA \\ KAREN SOFÍA SÁNCHEZ \\ LUISA MARÍA MILLÁN \\ ELEANY RESTREPO \\ FELIPE MORENO \\ Universidad Tecnológica de Pereira
}

Resumen

Debido a múltiples factores, las mujeres no se encuentran representadas adecuadamente en los campos de la ciencia, la tecnología, la ingeniería y las matemáticas (STEM, por sus siglas en inglés Science, Technology, Engineering and Maths), en comparación con la participación de los hombres en las mismas áreas. Esta tendencia mundial refleja que las mujeres escogen 
generalmente carreras relacionadas con las humanidades, las ciencias sociales, el cuidado y la atención tales como: medicina, terapia física o profesiones afines. En comparación, los hombres se muestran más interesados por las ciencias exactas y carreras relacionadas con tecnología.

Una de las razones de esta tendencia está relacionada con la percepción de los jóvenes respecto al campo de acción de las carreras STEM, el cual está directamente relacionado con la falta de información, aunada a ideas o estereotipos que plantean que las mujeres no tienen las capacidades o habilidades suficientes. Por esta razón, en este proyecto, el grupo de afinidad «Mujeres en Ingeniería» (WIE, por sus siglas en inglés Women in Engineering) de la Universidad Tecnológica de Pereira, plantea la necesidad de realizar campañas de sensibilización, divulgación y promoción en instituciones educativas secundarias de la región, mediante el trabajo colaborativo entre profesores y estudiantes de los programas de la universidad motivados e interesados en presentar, a los alumnos de los tres últimos años de educación secundaria, detalles del quehacer de un ingeniero, referentes femeninos y talleres o prácticas pedagógicas relacionadas con experimentación de fenómenos físicos o temas afines que incentiven una mayor participación activa de las mujeres en carreras de ciencia y tecnología. Por otra parte, en este proyecto también se considera pertinente facilitar los espacios para que las que ya se encuentran en su proceso de estudio en este tipo de carreras consoliden su confianza y empoderamiento mediante la realización de estrategias de motivación como foros y conversatorios, donde se presenten e interactúen con referentes femeninos que se han destacado en dichas áreas.

Palabras clave: ciencia y tecnología, mujeres en ingeniería, estrategias de motivación. 


\begin{abstract}
Women are underrepresented in careers related to Science, Technology, Engineering and Maths areas (STEM) compared to men participation. This worldwide tendency shows that generally, women are more interested in human studies, social sciences and care careers such as medicine, physical therapy, among others. Science and technologies careers are preferred for men.
\end{abstract}

A possible reason for this behaviour is related to the perception of young people that is related to the lack of reliable information, the presence of stereotypes, which define that the capabilities or abilities of women are insufficient for STEAM careers.

Considering the previous ideas, the "Women in Engineering group (WIE)", proposes several tasks related to sensibilization and promotion of the women empowerment. The teamwork composed of teachers and students of the Universidad Tecnológica de Pereira belief that is necessary to present to the young people, the role of an engineer, female referents and experimental workshops related to the electromagnetic physic phenomenon, aimed to increase the women participation in STEM areas. Otherwise, the project considers that it is crucial to increase the confidence and empowerment of the actual engineering woman students, through the forums, workshops and talks, where they can interact with outstanding female engineers.

Keywords: Science and Technology, Women in Engineering, Motivation Strategies.

\title{
Introducción
}

Las cifras entregadas por la National Science Foundation [1] demuestran que, aunque la inserción de las mujeres en la educación superior se ha incrementado a través de los últimos años, existen áreas del conocimiento como las ciencias exactas y 
la tecnología donde se presentan diferencias sustanciales entre la participación de las ellas respecto a los hombres. La importancia de analizar este fenómeno radica en que, si no se consigue fomentar la participación, representación y liderazgo de mujeres en todos los ámbitos, específicamente de la ciencia y la tecnología; no se conseguirá participar en la adopción de políticas, marcos o estrategias que minimice cada vez más la brecha en estos campos de acción, los cuales, actualmente, influyen de manera tan fuerte en el desarrollo de una sociedad [2] [4]. Con la participación de mujeres en estos campos se conseguiría plantear soluciones a diferentes problemáticas, desde un alto nivel que impactaría de forma positiva la consecución de sociedades más equitativas [5]. Adicionalmente, se lograría aportar en la consecución de uno de los diecisiete objetivos de desarrollo sostenible propuestos por la Organización de Naciones Unidas (ONU) para el plazo 20152030, el cual está relacionado con la equidad de género [6].

En este proyecto se aborda una de las posibles razones por las que las mujeres no se inclinan por carreras del tipo STEM, las cuales están relacionadas con la falta de información o motivación sobre determinadas áreas del conocimiento o el perfil profesional de las personas que las desarrollan. Todo ello aunado a ideas o estereotipos en los cuales se plantea que, las mujeres no tienen las suficientes capacidades o destrezas para desempeñarse en dichas áreas. Por tanto, la clave es divulgar que dichas carreras son accesibles y representan un gran futuro para las ellas mediante intervenciones que aumenten el interés y compromiso de estas sujetas en carreras STEM.

El presente informe presenta las estrategias de motivación desarrolladas que abordaron dos poblaciones específicas: la primera corresponde a la población juvenil que se encuentra en la etapa de elección profesional, es decir, jóvenes de los grados noveno y once de colegios de la ciudad de Pereira y municipios cercanos como Cartago y Santa Rosa; y la segunda a la población estudiantil de la Universidad Tecnológica de Pereira, 
específicamente mujeres que se encuentran cursando programas de pregrado y posgrado en áreas de la ingeniería. Todo ello para buscar incentivar la permanencia y el fortalecimiento de su papel como mujeres estudiantes en áreas de gran desarrollo.

Así, este informe presenta una breve referencia de las estadísticas de la participación de las mujeres en carreras afines a STEM, a nivel nacional y a nivel de la UTP, con el fin de visibilizar una realidad inminente que debe ser analizada. En una segunda parte se documentan todas las actividades desarrolladas que comprendieron, desde el diseño de charlas y talleres informativos, capacitación y motivación del equipo de trabajo, ejecución de la estrategia, evaluación de la estrategia implementada y presentación de las principales conclusiones.

\section{Objetivos}

\section{Objetivo general}

Desarrollar una estrategia motivacional y experimental con jóvenes de escuelas secundarias de la ciudad, como mecanismo para incentivar la participación de mujeres en carreras relacionadas con la ciencia y la tecnología.

\section{Objetivos específicos}

Documentar y analizar los índices de participación femenina en carreras afines a ciencia y la tecnología, específicamente aquellas relacionadas con ingenierías en la Universidad Tecnológica de Pereira.

Diseñar charlas informativas para estudiantes de secundaria, acompañadas de un componente práctico relacionado con la experimentación de fenómenos físicos o temáticas afines (programación, manejo de software y hardware libre, robótica, entre otros), para contextualizarlos en áreas de ciencia y tecnología. 
Ejecutar la estrategia en colegios de la región con el acompañamiento de estudiantes y profesores de la Universidad Tecnológica de Pereira.

Aplicar herramientas de evaluación para medir el impacto de la estrategia a corto y mediano plazo.

Realizar eventos de divulgación como jornadas académicas y herramientas de comunicación social del conocimiento como cartillas que permitan presentar las experiencias adquiridas o conclusiones obtenidas en el desarrollo del proyecto.

\section{Metodología}

El proyecto tuvo cinco etapas de desarrollo más una etapa adicional relacionada con la realización de eventos divulgativos, como estrategia de comunicación social del conocimiento.

Durante la primera etapa se desarrolló la fundamentación teórica del proyecto mediante una revisión bibliográfica y la recopilación de información con estadísticas a nivel local y nacional, sobre la participación de las mujeres en carreras STEM. Posteriormente, en la segunda etapa, se analizaron estrategias pedagógicas relacionadas con la realización de presentaciones informativas, capacitación del equipo de trabajo y la elaboración de talleres experimentales de fenómenos físicos. La tercera etapa estuvo dedicada a la ejecución de la estrategia de difusión y motivación en colegios con el apoyo de profesores y estudiantes de la universidad, específicamente con el grupo Women in Engineering (WIE). En la cuarta etapa se definieron herramientas cuantitativas y/o cualitativas que permitieron definir el impacto del proyecto. Finalmente, se realizaron eventos de divulgación como foros, conversatorios y ponencias con el fin de presentar referentes femeninos en las áreas STEM y las principales conclusiones obtenidas en el desarrollo del proyecto. 
A continuación, se presenta una descripción corta de cada una de las etapas desarrolladas:

\section{Revisión bibliográfica}

Con el fin de sustentar la problemática definida en este proyecto, se realizó una recopilación de estadísticas de ingreso y graduación de mujeres en carreras de ingeniería, específicamente en áreas físico-mecánicas y de informática, en las bases de datos con las que cuenta el Ministerio de Educación Nacional (entre los años 2001 y 2017) [6] [7] y la Universidad Tecnológica de Pereira (del 2010 al 2019) [8].

FIGURA NRO. 1. Estudiantes inscritos en pregrado por género en la UTP.

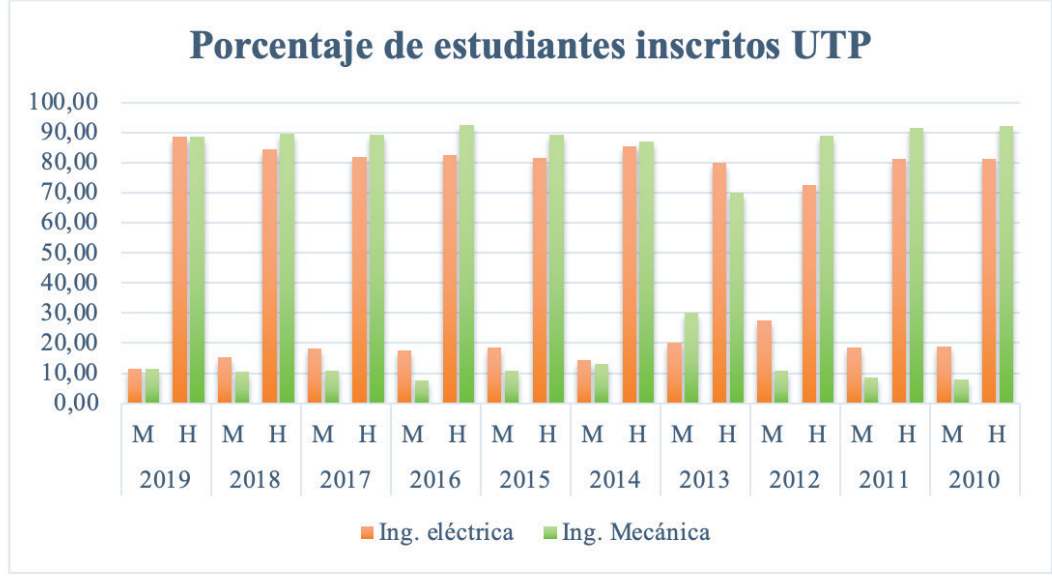

Tomada de [8].

Las cifras de la Figura NRO. 1 permiten visibilizar la baja inscripción de las mujeres en la UTP —en promedio no supera el $20 \%$ - en carreras como Ingeniería Eléctrica, Ingeniería Mecánica e Ingeniería en Sistemas durante los últimos 9 años. Una de las razones puede estar asociada a la falta de información de las estudiantes de colegios respecto a estos programas y el área 
de desempeño laboral, lo cual se ve traducido en desinterés por estas áreas del conocimiento. Estas cifras motivaron el desarrollo del presente proyecto.

Respecto al número de mujeres graduadas durante los últimos 19 años (2000-2019) en la UTP, también se observa, a partir de la Figura NRO. 2, una baja participación de ellas en las áreas de las ingenierías (Eléctrica, Electrónica, Física y Sistemas) y la mecánica. Es importante aclarar que los programas de electrónica - desde el 2009- y física - a partir del 2008-, en dicha universidad, son programas recientes comparados con los demás, lo cual incide sobre las cifras.

FIGURA NRO. 2. Mujeres graduadas en la UTP en ingenierías (Eléctrica, Electrónica, Física y Sistemas) y mecánica.

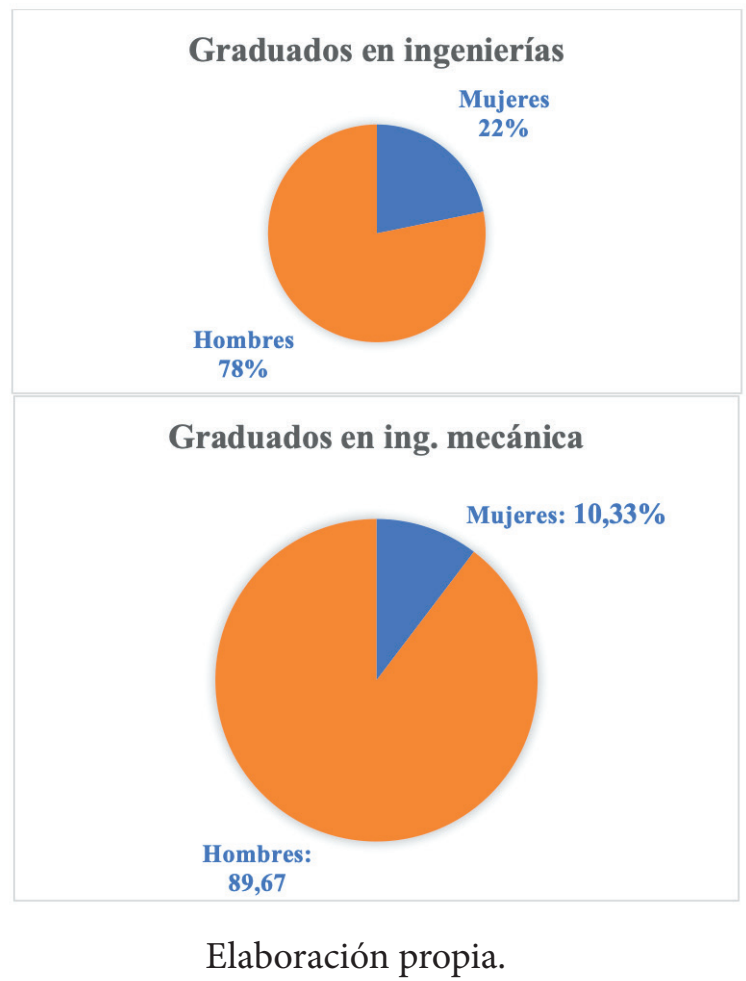


Si las cifras son bajas a nivel de pregrado, a nivel de posgrado se acentúan aún más las diferencias entre hombres y mujeres. Según la Figura NRO. 3 muy pocas mujeres se especializan en las áreas analizadas.

FIGURA NRO. 3. Mujeres graduadas en la UTP en posgrados STEM (2002-2019).

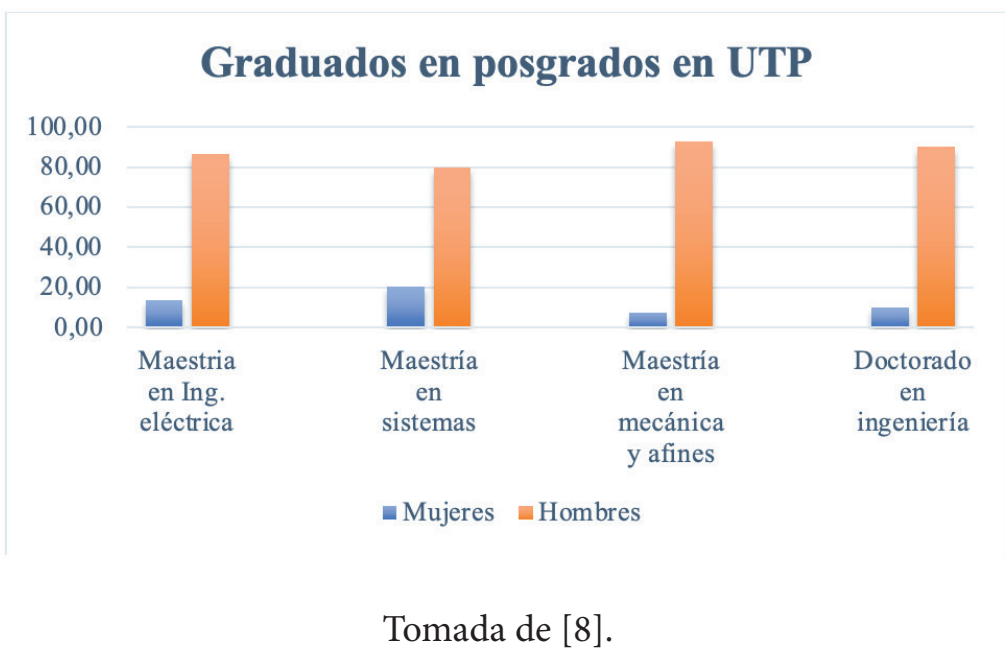

A continuación, se muestran algunas estadísticas proporcionadas por el Sistema Nacional de Información de la Educación Superior del Ministerio de Educación, en las que se aprecia el número de estudiantes graduados por género en el periodo 2001-2017, sobre algunos programas académicos de pregrado a nivel nacional, en los cuales predomina la presencia masculina, lo cual está acorde con lo que se presenta en la UTP. 
FIGURA NRO. 4. Porcentaje de graduados a nivel nacional de Ingeniería Eléctrica y afines según género.

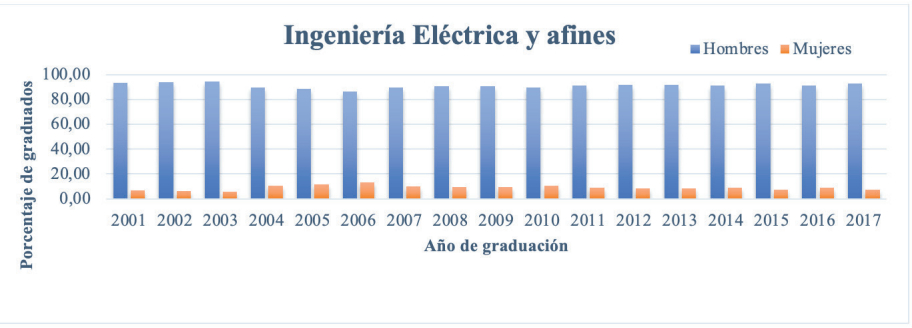

Tomada de [7].

Figura NRo. 5. Porcentaje de graduados a nivel nacional en Ingeniería en Sistemas, telemática y afines según género.

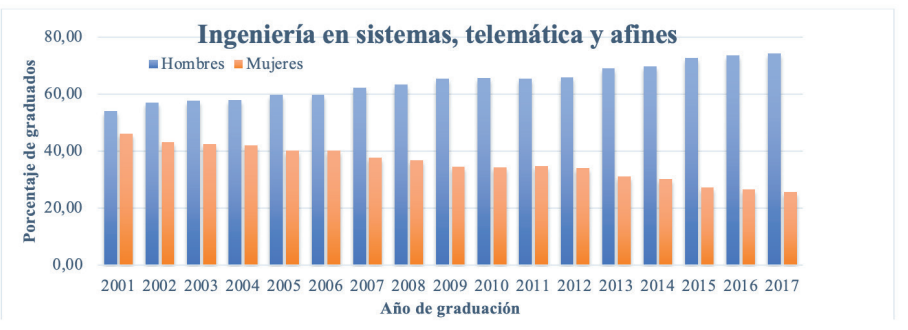

Tomada de [7].

FIGURA NRO. 6. Porcentaje de graduados a nivel nacional de Ingeniería Mecánica y afines según género.

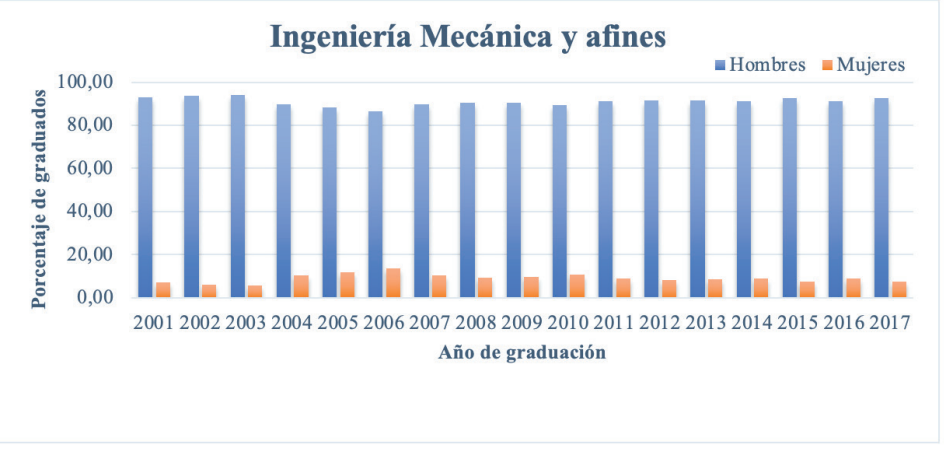

Tomada de [7]. 
De la Figura nro. 5, Figura nro. 6 y Figura nro. 7 se puede concluir que, en los programas de ingeniería a nivel nacional, se ve una grande y clara diferencia entre hombres y mujeres graduados. Se puede analizar cómo el programa que posee los índices más bajos de mujeres inscritas durante el periodo analizado es Ingeniería Mecánica - lo cual concuerda con las cifras de la UTP presentadas previamente-, mientras que Ingeniería de Sistemas, Telemática y áreas afines es la que posee índices más altos; sin embargo, suelen ser valores muy inferiores comparado con la cantidad de hombres que se gradúan por año. Se observa en las cifras, como los estereotipos influyen considerablemente en la escogencia de la carrera al considerar, en forma equivocada, que la mecánica es para hombres.

De estas cifras se concluye que es indispensable realizar una labor informativa entre los jóvenes, específicamente mujeres, donde se presente realmente cual es el quehacer de un ingeniero en dichas áreas.

\section{Diseño de charlas informativas}

En esta etapa se planearon las actividades a desarrollar en los colegios, las cuales tienen dos componentes: uno informativo, a través de una charla ilustrativa del quehacer de un profesional en carreras de ciencia y tecnología - específicamente de un ingeniero-, en el cual se hace una presentación de referentes femeninos. Y uno pragmático relacionado con talleres prácticos y experimentales con los estudiantes donde se analizan fenómenos físicos o conceptos importantes en la fundamentación científica. Fenómenos como la inducción electromagnética, las corrientes de Eddy y experimentos con electroimanes y la bobina de Tesla fueron considerados en el diseño de dichos talleres. En cuanto al diseño e implementación de charlas informativas orientadas a población estudiantil de grados noveno, décimo y undécimo, principalmente, se empleó la estructura general que se presenta a continuación: 
- Presentación del grupo WIE.

- Datos estadísticos (nacionales, regionales y locales) relacionados con la baja participación de mujeres en la ciencia e ingeniería.

- Explicación de los factores (sociales, culturales y educativos) que influyen en la baja participación femenina en carreras relacionadas con la ciencia, la tecnología y la ingeniería.

- Posibles soluciones a los anteriores factores entre los que se incluye la visibilización de referentes femeninos a lo largo de la historia y en Colombia, además de la importancia de estudiar carreras STEM para enfrentar problemas sociales, ambientales y económicos.

- Presentación de los programas académicos que ofrece la UTP relacionados con ingeniería.

- Componente experimental con los estudiantes de diferentes fenómenos relacionados con electricidad.

- Conclusiones y reflexiones sobre la importancia de las mujeres en la ingeniería.

Con los recursos del proyecto se adquirieron módulos didácticos relacionados con energías alternativas, con el fin de realizar talleres guiados en los colegios y visibilizar una de las áreas de acción de la ingeniería.

Adicionalmente, se desarrollaron folletos con la información básica referente a la ingeniería, los cuales se entregan a los estudiantes de los colegios y les permite conocer en forma ágil y breve el quehacer de la profesión (ver FIgURA NRO. 7). 
FIGURA NRO. 7. Creación de folletos informativos para estudiantes de colegios.

¿Te animas a escoger una carrera de ingenieria?

$\$$ deseas mis informucisa al respecto ingresa. nowivutpeduce doede potas encontras enlaces a las cleventes

Acerca de WIE - UTP

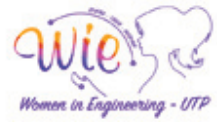

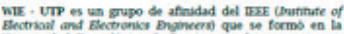

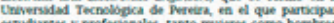

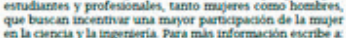

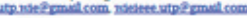
f. WIE UT
y Utp-wite
(2) wie_utp

\section{¿Qué es ingeniería?}

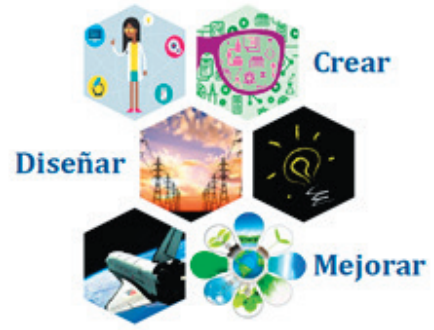

La ingensieria so ocupa del dueto bolucion de un o el mejoramiento de un groxero.

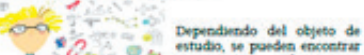

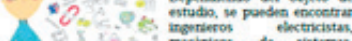

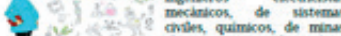

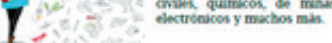

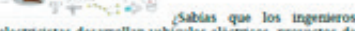

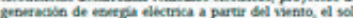

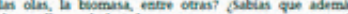
desirrollan toda la infraeteructura pura que evia energia ente dipontible en es cane?

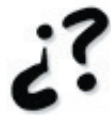

:Por qué

estudiar ingenierias?

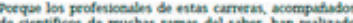
de cientificos de machas ramas del waber, han rwalizado grandes contribuciones a maetro mando Gacias a elloh.

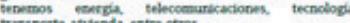

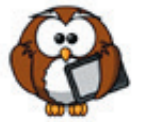

QQué materias están relacionadas con la ingenieria?

A wants de drerrus minenus que vas ateediendo en to colvga, podris vislumbrie un poco el campo de wocion de

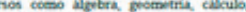

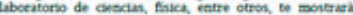

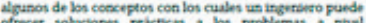
indratral econtertico o socis

¿Reconoces a alguna de estas mujeres?

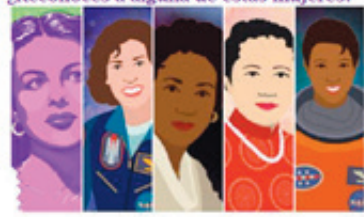

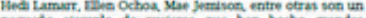
pequeto vimplo de majeres que ban becto gandes

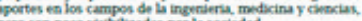

Elaboración propia. 
Capacitación y motivación del equipo de trabajo

Los estudiantes que conforman el equipo de trabajo de WIE-UTP representan una parte fundamental en el desarrollo de la estrategia propuesta. Por tanto, es necesario brindarles espacios de reflexión y capacitación que permitan afianzar sus habilidades técnicas y blandas. Específicamente, como una actividad de difusión y motivación para la comunidad académica de la universidad relacionada con el papel de la mujer en las carreras STEM se realizó, durante el mes de marzo de 2109, el conversatorio "Mujeres UTP en la ciencia», espacio donde se compartieron experiencias de mujeres profesionales que laboran en la Universidad Tecnológica de Pereira en áreas de ciencia, tecnología e ingeniería; ello con el fin de visibilizar su trabajo. Por tanto, con la visibilización de referentes femeninos - en este caso de la UTP - se pretende empoderar a las asistentes que cursan carreras afines a la ciencia y la tecnología. Se contó con la asistencia de estudiantes, administrativos y profesionales de diversas áreas (ver Figura NRO. 8).

Figura NRo. 8. Conversatorio mujeres UTP en la ciencia, Marzo 2019.

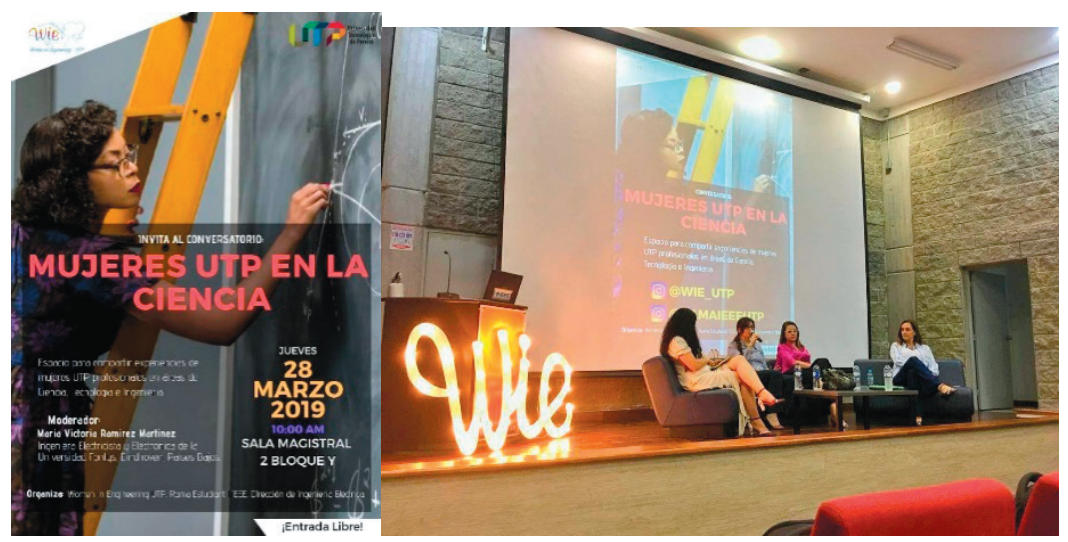

Elaboración propia. 
Adicionalmente el 6 de septiembre del 2019 se realizó el foro: «Mujeres en la ciencia, mujeres que transforman» en el Auditorio Jorge Roa Martínez. En este se contó con la participación de cuatro mujeres ingenieras que laboran en el sector energético a nivel nacional, las cuales relataron parte de sus experiencias laborales, educativas y familiares para así incentivar y empoderar a las mujeres de la comunidad académica para que participen y culminen carreras STEM (ver FigURA NRO. 9).

FIGURA NRO. 9. Foro: Mujeres ingenieras, mujeres que transforman.

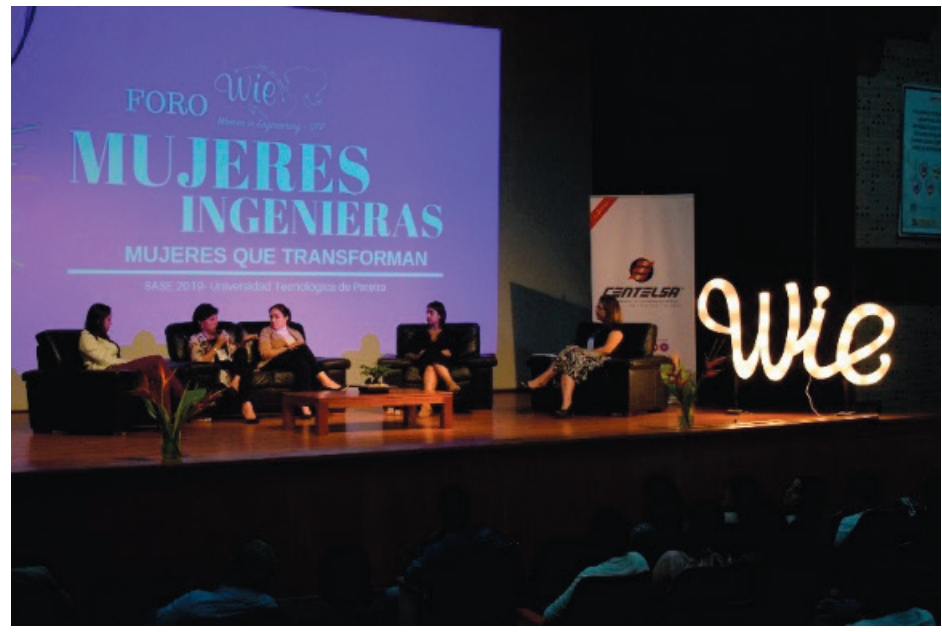

Elaboración propia.

Por otra parte, también se realizaron sesiones de capacitación al equipo de WIE-UTP que se hicieron extensibles a la comunidad académica de la universidad y otras universidades relacionadas con realización de presentaciones efectivas e inteligencia emocional.

Como parte de la estrategia de revisión y visibilización del papel de la mujer se realizó un mural informativo en el programa de ingeniería eléctrica el día 11 de febrero, fecha internacional de la mujer en la ciencia, donde se presentaron biografías de referentes femeninos en diversas áreas científicas, con el fin de mostrar su aporte a la comunidad universitaria. 
Ejecución de la estrategia en colegios

Una vez definidas las actividades con el equipo de trabajo, se seleccionaron los colegios considerando criterios como entidades con mayor porcentaje de población femenina, entidades públicas, en lo posible población de estratos uno, dos y tres, entre otros. En las instituciones de educación básica se realizaron las charlas informativas y experimentales. Entre las que se visitaron se encuentran: el colegio Ciudad Cartago, el Byron Gaviria, el Liceo Francés, la Institución Educativa La Bella, entre otros. También se participó en dos ferias universitarias: Mi Uxperiencia 2019 realizada en el Gimnasio Pereira en el mes de julio, donde participaron más de veinte colegios públicos y privados, entre ellos el Calasanz, el Anglo Americano, el Saint Andrews, el Salesiano, el San José y la VIII Feria de las oportunidades en la Institución Educativa Indalecio Pinilla de la ciudad de Cartago en el mes de agosto, donde participaron más de diez colegios.

Las instituciones educativas que se abordaron en el proyecto fueron las siguientes:

TABLA NRO. 1. Instituciones educativas abordadas en el proyecto.

\begin{tabular}{|l|l|}
\hline Colegio & Fecha \\
\hline Institución Educativa La Bella & 31 de Mayo de 2019 \\
\hline Institución Educativa Ciudad Cartago & 13 de Junio de 2019 \\
\hline Escuela San Juan Bosco & 13 de Junio de 2019 \\
\hline Liceo Francés & 18 Junio de 2019 \\
\hline $\begin{array}{c}\text { I Feria Regional MiUxperiencia Gimnasio } \\
\text { Pereira }\end{array}$ & 26 de Julio de 2019 \\
\hline Institución Educativa Byron Gaviria & 23 de Agosto de 2019 \\
\hline $\begin{array}{c}\text { VII Feria de Posibilidades Institución } \\
\text { Indalecio Pinilla }\end{array}$ & 23 de Agosto de 2019 \\
\hline Instituto Tecnológico Santa Rosa de Cabal & 30 de septiembre de 2019 \\
\hline Colegio Lorencita Villegas & 4 de Octubre de 2019 \\
\hline Técnico Superior Cartago & 4 de Octubre de 2019 \\
\hline
\end{tabular}

$$
\text { Elaboración propia. }
$$


En la Figura NRO. 10 se presentan evidencias graficas de las charlas/talleres impartidas en los diferentes colegios.

FIGURA NRO. 10. Charlas y talleres desarrollados en diversos colegios de la región.
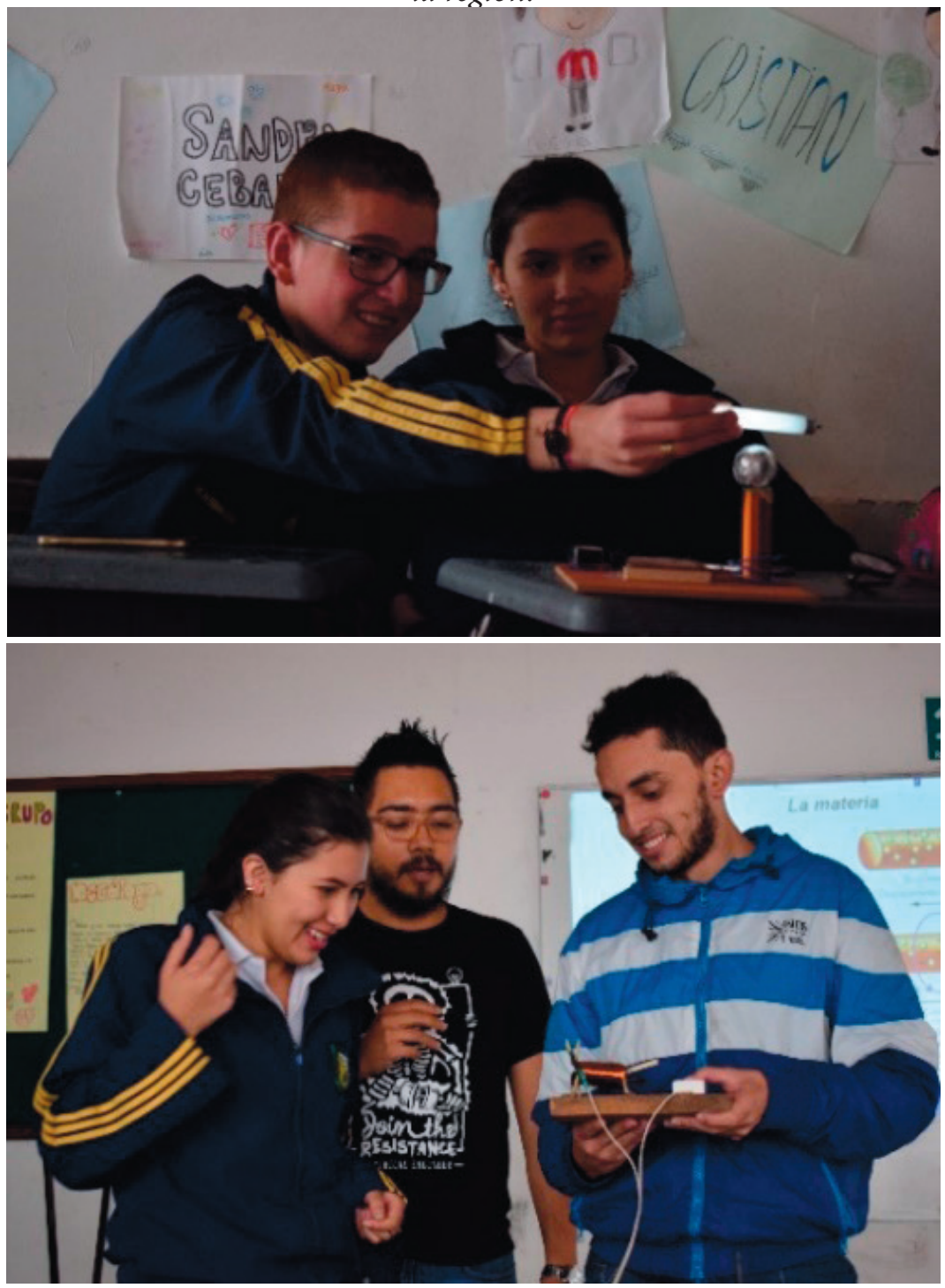

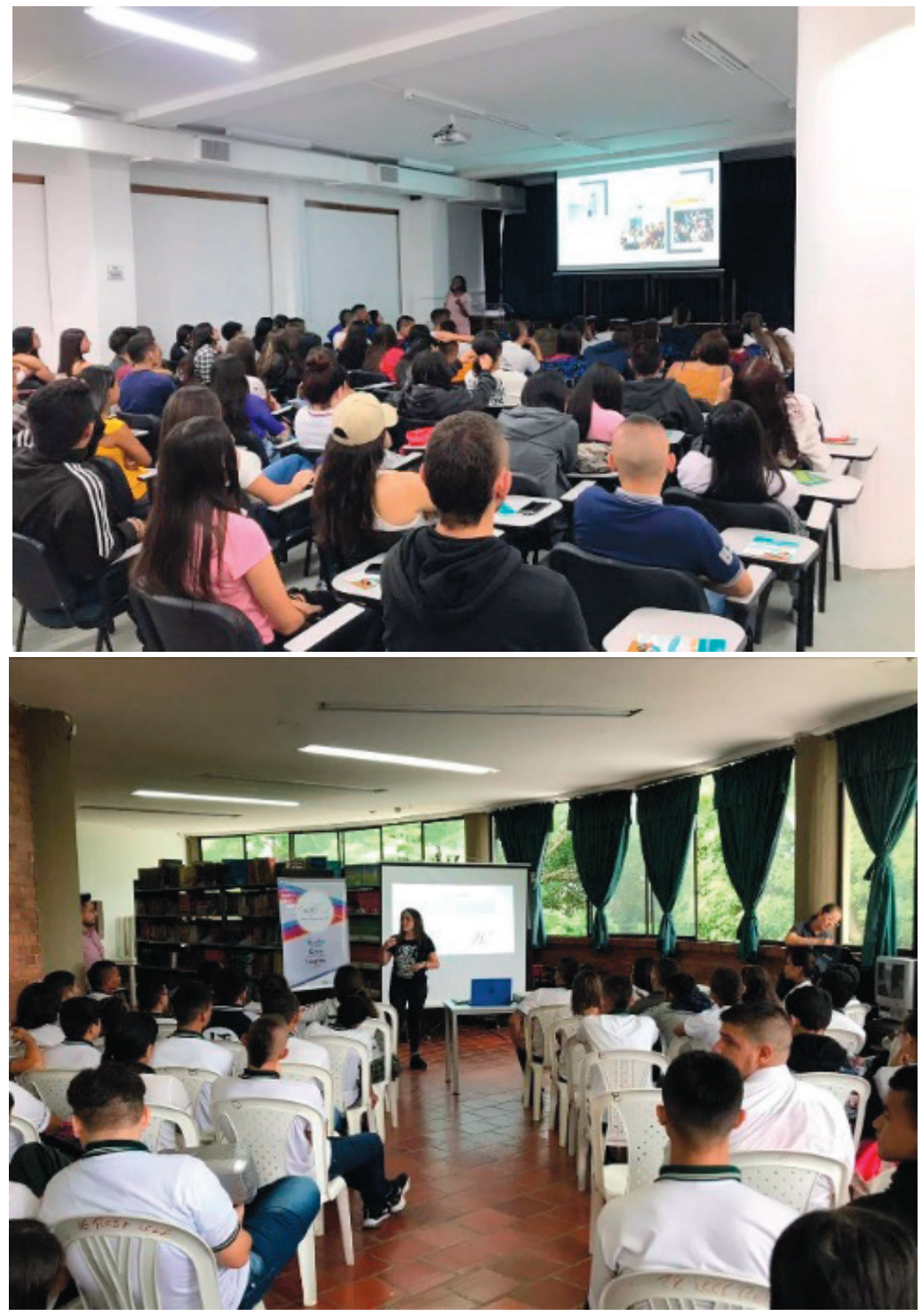

Elaboración propia.

Divulgación en redes sociales e Internet: se utilizaron diferentes plataformas de comunicación como Facebook, Instagram, además de la creación de un blog en academia UTP (http://academia.utp.edu.co/wieutp/) para compartir diferentes 
tipos de contenido tales como: eventos y capacitaciones, fotos de las actividades realizadas, datos curiosos e información sobre referentes femeninos, reflexiones y frases motivacionales e interacción con páginas relacionadas con WIE.

\section{Evaluación de la estrategia implementada}

Como una parte fundamental del proyecto se encuentra la evaluación del impacto de la estrategia mediante la realización de encuestas digitales a las estudiantes de colegios - a quienes se les impartió la charla-, con el fin de recopilar información acerca de las preferencias profesionales, la calidad y cantidad de información que tienen al respecto, al igual que la apropiación que tuvieron de la información impartida en las charlas/talleres. A continuación, se anexan algunos resultados obtenidos de la encuesta.

En la FIgURA NRO. 11 se presenta la orientación profesional de algunas de las estudiantes, quienes manifiestan un marcado interés por carreras de cuidado como la psicología y la pedagogía. También se observa una inclinación similar en carreras de ingeniería. Al indagar por las razones que las motivan a esa selección, un 87 \% mencionó que conocen el campo de acción de la carrera y un $8.7 \%$ por la publicidad que ofrecen las universidades; el resto por referencias familiares, costos y ninguna otra opción disponible. Esto también se ve respaldado al preguntarles cuáles fueron las materias preferidas, donde matemáticas arrojó un 30.4 $\%$, seguida por un $21.7 \%$ perteneciente a humanidades y filosofía, un $13 \%$ tanto para física como ciencias sociales y un $8.7 \%$ para química y biología. El resto hizo parte de las áreas de español e idiomas. 
Figura NRO. 11. Orientación profesional de estudiantes en colegios intervenidos.

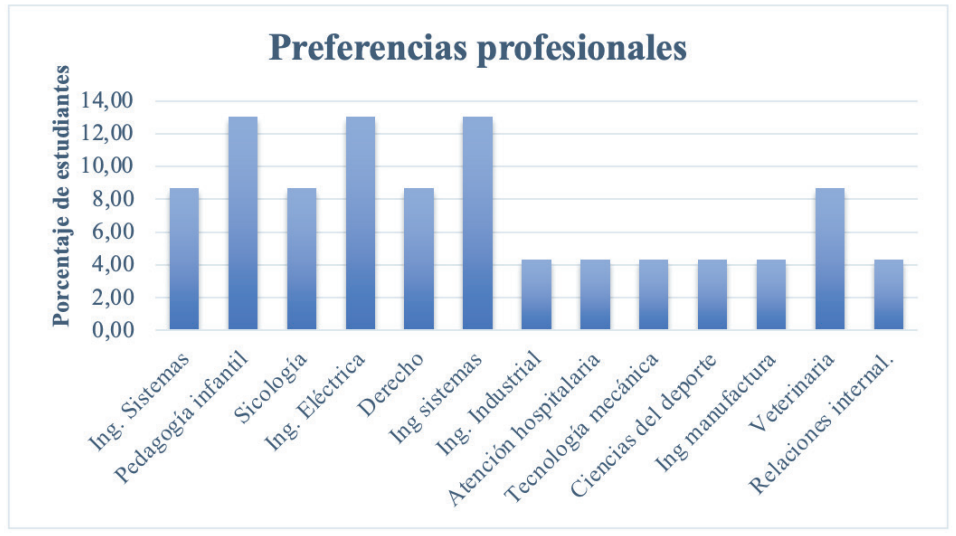

Elaboración propia.

Al preguntarles que información preliminar tenían del quehacer de un ingeniero, el $91.3 \%$ manifestó que era un trabajo interesante, respecto a un $4 \%$ que lo considera una labor muy difícil y un $4.7 \%$ que lo tiene presente como una carrera para hombres. Después de realizar la charla, se les pregunto si la información que se les suministro les permitió comprender un poco más del campo de acción de un ingeniero y se obtuvo un leve, pero muy significativo, incremento al pasar a un $95.7 \%$.

Con la encuesta se pudo evidenciar un aumento en la escogencia de carreras afines a ingeniería. Después del taller dictado por los integrantes del grupo WIE, se presentó un mayor interés por parte de los encuestados en carreras afines a esta área. Sin embargo, arroja que los hijos de padres con carreras STEM, ven más viable estudiar uno de estos programas debido a la influencia familiar. Así, se considera importante incentivar a más mujeres para que escojan estas carreras, ya que, en parte, el desconocimiento de la labor de un ingeniero hace que estas áreas no sean atractivas. 


\section{Resultados}

Respecto a los compromisos adquiridos del proyecto se tienen:

Una actividad de educación continua: se desarrollaron talleres/ charlas en más de ocho colegios de la región, por tanto, se alcanzó una población de más de trescientos cincuenta estudiantes. Se anexa el aval dado por el Consejo de Facultad.

Varias actividades de comunicación social del conocimiento: se realizó un foro y un conversatorio en los auditorios de la Universidad, como se mencionó en la metodología, con la asistencia de más de cincuenta y doscientas personas respectivamente. Adicionalmente, se participó como ponente de los resultados del proyecto en el II Encuentro de Investigación en Género organizado por la Red de Educación Superior por la Equidad de Género, Risaralda, realizado el 15 de octubre de 2019. Se anexa el aval dado por el Consejo de Facultad.

Generación de cartilla con los resultados: se entrega al finalizar el proyecto.

\section{Población beneficiada}

Se logró impactar a una población de más de cuatrocientos estudiantes de colegios públicos y privados de la región y de los grados noveno, diez y once. Además, se realizó una socialización con estudiantes de tercero y cuarto de primaria, además de prejardín.

También se benefició parte de la población femenina universitaria que participaban en las capacitaciones, foros y talleres organizados por WIE (aproximadamente trecientos cincuenta asistentes). 


\section{Conclusiones}

Es de suma importancia que se trabaje en la igualdad de oportunidades para hombres y mujeres en las áreas de ciencia y tecnología. Esto se logra mediante la entrega de información detallada sobre el quehacer de un profesional de dichas áreas y por la visibilización del papel de las mujeres, el cual se ha destacado en las mencionadas áreas a nivel nacional e internacional y en los estudiantes que cursan los últimos grados de secundaria. Además, se debe patrocinar el acercamiento de los jóvenes a la ciencia a través de experiencias sencillas, de fenómenos físicos que despierten la curiosidad e inciten a seguir dichos conocimientos mediante el desarrollo de talleres prácticos en los colegios. Por medio la interacción con jóvenes de las instituciones se comprobó que, a pesar de la gran cantidad de información que ellos tienen y que brindan los medios de comunicación o redes sociales, aún existe un desconocimiento del quehacer de un ingeniero y son muy pocos los que consideran las ingenierías ofrecidas por la UTP como opciones para su futuro desarrollo profesional.

Otro aspecto relevante del desarrollo de los talleres estuvo relacionado con la oportunidad que se le brindó al equipo de trabajo (WIE-UTP), específicamente a las estudiantes de la universidad que participaron en el proyecto, al ser y presentarse ellas mismas como un referente femenino que ha decidido ingresar en carreras de ciencia y tecnología y hablar desde su experiencia académica y formativa. Esto constituye una oportunidad de aprendizaje en ambos sentidos. Por una parte, se reafirma el papel que asume el estudiante universitario como portador de un mensaje que él mismo vive y, por otra, la posibilidad que tendría el receptor del recado, en este caso el joven de colegio, de conocer de primera mano las particularidades y características de dichas carreras a través de modelos femeninos.

La mayoría de los talleres/charlas se realizaron con estudiantes de los grados diez y once, entre los quince y diecisiete años. A estas 
edades, la mayoría de estudiantes se encuentran permeados por estereotipos o procesos culturales relacionados con las carreras. Por ejemplo, en aquellas relacionadas con el cuidado de los otros tales como medicina o fisioterapia presentan una gran acogida por parte de las mujeres. En cambio, los hombres prefieren ingenierías, diseño industrial, entre otras. Por esta razón y como una conclusión, se puede decir que este estudio podría extenderse al planteamiento de otro proyecto relacionado con la visibilización de las carreras STEM para mujeres, lo cual estaría relacionado con la importancia de realizar el abordaje desde edades más tempranas. Se realizaron dos talleres con niños/niñas de cinco y seis años de colegios y se comprobó que el impacto a nivel motivacional puede ser mucho mayor, comparado con estudiantes que se encuentran cursando los años finales de secundaria.

\section{Referencias bibliográficas}

[1] National Science Foundation. (2016). Science and Engineering Indicators 2016 [Online]. Avaliable in: http:// www.nsf.gov/statistics/2016/nsb20161/\#/.

[2] J. S. Brotman \& F. M. Moore. «Girls and Science: A Review of Four Themes in the Science Education Literature». Journal of Research in Science Teaching, vol. 45, no. 9, pp. 971-1002, 2008.

[4] M. A. Oliveros, E. Cabrera, B. Salas y M. Schorr. «La motivación de las mujeres por las carreras de ingeniería y tecnología». Entreciencias, vol. 4, no. 9, pp. 89-96, 2016.

[5] Organización de las Naciones Unidas para la Educación, la Ciencia y la Cultura [Unesco]. (2019). Descifrar el código: la educación de las niñas y las mujeres en ciencias, tecnología, ingeniería y matemáticas (STEM) [En línea], 2019. Disponible en https://dds.cepal.org/redesoc/ publicacion?id=5166. 
[6] Organización de las Naciones Unidas [ONU]. (2015). Objetivos de desarrollo sostenible [En línea]. Disponible en https://www.un.org/sustainabledevelopment/es/objetivosde-desarrollo-sostenible.

[6] Ministerio de Educación Nacional. (2016). SNIES, Sistema Nacional de Información de la Educación Superior [En línea]. Disponible en https://www.mineducacion.gov.co/ sistemasinfo/snies.

[7] _ (2017). Anuario estadístico de la educación superior colombiana [En línea]. Disponible en https://ole. mineducacion.gov.co/1769/articles-380420_recurso_1.pdf.

[8] Universidad Tecnológica de Pereira. (2020). Boletín estadístico Planeación UTP [En línea]. Disponible en https:// www.utp.edu.co/estadisticas-e-indicadores/. 


\title{
Cartillas para la calidad de vida de los padres y/o cuidadores de pacientes con enfermedad de Hirschsprung o malformaciones anorrectales ${ }^{15}$
}

\author{
JUAN JOSÉ OSPINA RAMÍREZ \\ Estefanía GutiérRez OCAMPo \\ Universidad Tecnológica de Pereira
}

Luis MaUricio Figueroa GutiérRez Universidad del Valle

Mercy Soto CHAQUIR Universidad Libre, sede Pereira

Jorge M. EstradA ÁlVAREZ Comfamiliar Risaralda, Salud Familiar

15 Este proyecto hace parte de una reescritura del mismo escrito presentado en el Noveno Encuentro Regional de Semilleros de Investigación RRESSI. Figueroa Gutiérrez, Luis Mauricio, Juan José Ospina Ramírez, Mercy Soto Chaquir, Jorge M. Estrada Álvarez y Estefanía Gutiérrez Ocampo, «Cartillas para la calidad de vida de los padres y/o cuidadores de pacientes con enfermedad de Hirschsprung o malformaciones anorrectales», RREDSI Red Nacional de Semilleros de Investigación. https://invessoft.com/ponencias2019/pdf/poster/Estefan\% $\% 3 \% \mathrm{ADa} \% 20$ Guti\%C3\%A9rrez\%20Ocampo.pdf. 


\section{Resumen}

Para el papel de padre y/o cuidador (pyc) de un niño con necesidades de atención médica especial (nname), como enfermedad de Hirschsprung (eh) y malformaciones anorrectales (mar); este proyecto buscó elaborar material educativo para mejorar su calidad de vida. Dirigido a padres de niños en seguimiento por cirugía pediátrica con diagnóstico eh o mar, en el periodo comprendido entre julio de 2011 y mayo de 2019 en institución de alta complejidad en Pereira, Colombia.

Momento nro. 1, se realizó el cuestionario whoqol-bref para valorar calidad de vida y se identificaron aspectos más afectados para elaborar cartilla. Momento nro. 2, se conformaron grupos de cuidadores que actuaron como editores para la construcción definitiva. Momento nro. 3, intervención social, evento de divulgación académica y/o presentación de ponencia o póster para garantizar la circulación del conocimiento.

Al realizar el cuestionario se estableció el dominio de relaciones sociales como el más afectado. Esta situación permitió priorizar aspectos que afectan su calidad de vida y formar cuatro grupos: 1) saber sobre la enfermedad, 2) los cuidados más difíciles, 3) enfermedades que transforman la vida, 4) ocupar la mente. Así se definieron los temas mínimos a abordar por la cartilla. Se obtuvieron los resultados según los productos esperados, con lo cual se logró la constitución de dicho material, además, la presentación de ponencia en un congreso internacional y exposición de un póster en eventos locales. También se llevó a cabo una jornada pedagógica en torno a la presentación de la cartilla para los pyc de forma oral y por lecturas guiadas.

Palabras clave: cuidado del niño, calidad de vida, malformaciones anorrectales, enfermedad de Hirschsprung, cuidadores 


\section{Abstract}

For the role of a parent and/or caregiver (poc) of a child with special health care needs ( $(\mathrm{shcn})$, such as hirschsprung disease (hscr) and anorectal malformations (arms); this project sought to develop educational material to improve their quality of life. addressed to parents of children undergoing pediatric surgery, with diagnosis of hscr or arms, period July 2011-May 2019, in a tertiary care hospital in Pereira, Colombia. $1^{\text {st }}$ moment, the whoqol-bref questionnaire was carried out to assess quality of life and identify their most affected aspects to prepare a booklet. $2^{\text {nd }}$ moment, formed groups of caregivers who acted as editors for final construction. $3^{\text {rd }}$ moment, social intervention event and oral presentation or poster to guarantee the spread of knowledge. Carrying out the questionnaire established the domain of social relationships as the most affected and this allowed prioritizing aspects that affect their quality of life, forming four groups: 1) knowing about the disease; 2) the most difficult care; 3 ) diseases that transform life; 4) occupy the mind; Thus, defined the minimum topics to be addressed by the booklet. The results were obtained according to the expected products, achieving the booklet, oral presentation at an international conference and presentation of poster at local events, in addition to the pedagogical day around the presentation of the booklet to the poc orally and by guided readings.

Keywords: Childcare, Quality of Life, Anorectal Malformations, Hirschsprung Disease, Caregivers

\section{INTRODUCCIÓN}

La eh ylas mar son patologías que afectan población pediátrica, en un porcentaje importante están asociadas a alteraciones en otros órganos o sistemas (36\% y $60 \%$ respectivamente) por lo que el paciente, al mismo tiempo, se ve comprometido por la enfermedad y la carga de las secuelas y dificultades propias 
de su resolución. La eh está caracterizada por la ausencia de células ganglionares parasimpáticas en el intestino distal (aganglionosis) $)^{16}$; las mar, por su parte, involucran el ano, el recto distal, los tractos urinario y genital por lo que el rango de estos defectos va desde menores, fácilmente tratados y con un excelente pronóstico funcional, a aquellos con complejos con manejos más difíciles y con un pobre pronóstico funcional. Se presentan en, aproximadamente, 1 de cada 5000 nacidos vivos, ajustándose a la definición de enfermedades huérfanas en el país, las cuales, por su gravedad, amenazan la vida y son crónicamente debilitantes ${ }^{17}$. Los afectados se convierten en nname, lo que exige a sus padres y al personal de la salud respuestas diferentes a la de aquellos con enfermedades de menor complejidad, esto significa que para su resolución van a requerir de diversos procedimientos quirúrgicos $\mathrm{y}$ abordaje intrahospitalario por grupos interdisciplinarios ${ }^{18}$.

Como se ha demostrado en otras enfermedades de este tipo, los efectos de tener en la familia un nname compromete el bienestar físico, mental, emocional y social - la calidad de vidade los encargados del cuidado, a la vez que disminuye la seguridad alimentaria de todo el grupo y las posibilidades de acceder a un empleo estable, lo que genera la perpetuación de la pobreza con todos sus efectos ${ }^{19}$. Recientemente, en la literatura se ha comenzado a dar importancia a qué tanto afecta a los pyc que sus niños sean diagnosticados con estas enfermedades y se ha demostrado que presentan graves dificultades para hacer frente a estos desórdenes

16 Alberto, Peña, y Andrea Bischoff A. Surgical Treatment of Colorectal Problems in Children. (New York: Springer, 2015).

17 Timothy Bradnock et al., «Hirschsprung's Disease in the UK and Ireland: Incidence and Anomalies", Archives of Disease in Childhood 102, n. 8 (2017): 7227. Marc Levitt y Alberto PeÑA, «Anorectal Malformations», Orphanet Journal of Rare Diseases 2, n. ${ }^{\circ}$ 33, (2007): 1-13.

18 Merle McPherson et al., "A New Definition of Children with Special Health Care Needs», Pediatrics 102, n. ${ }^{\circ}$ 1, (1998):137-9.

19 Paul Chung et al., "Access to Leave Benefits for Primary Caregivers of Children with Special Health Care Needs: A Double Bind», Academic Pediatrics 13, n. ${ }^{\circ} 3$, (2013): 222-8. Betty L. Lucas, Sharon A. Feucht y Lynn Grieger. Children with Special Health Care Needs: Nutrition Care Handbook. (American: Dietetic Associati, 2004). 
expresando necesidades de apoyo, ya que incluso pueden llegar a altos niveles de ansiedad, principalmente en las madres y cuando el niño está en una edad temprana ${ }^{20}$.

Los estudios sobre los efectos en la calidad de vida de los cuidadores de pacientes con enfermedades gastrointestinales crónicas, raras y debilitantes son escasos. Jelenova et al. ${ }^{21}$, al estudiar los efectos de las enfermedades inflamatorias intestinales (eii), reportaron que afectan y restringen la vida de los cuidadores a causa de la enfermedad de sus hijos y demarcan la necesidad de políticas públicas y de un soporte psicosocial para mejorar su estado mental y el funcionamiento de sus familias ${ }^{22}$. Respecto a eh y mar se tienen referenciados tres estudios ${ }^{23}$ en los cuales se concluye que hay un descenso en la calidad de vida y una mayor presencia de ansiedad y depresión en las madres luego del diagnóstico, hasta la edad escolar, comparados con padres de niños sanos ${ }^{24}$. Al día de hoy, existe una caracterización en Colombia sobre las condiciones de cuidadores de pacientes con discapacidad severa realizada en Bogotá D.C. por Gómez-Galindo et al. ${ }^{25}$, esta concluye que se evidencian alteraciones en sus condiciones de salud y bienestar, las cuales urgen respuestas no solo desde el actuar profesional a la luz del reconocimiento cultural y fortalecimiento de dichas labores, sino también en el ámbito de la acción pública, ya que dada la complejidad de las problemáticas identificadas se deben

20 S. Somanadhan, y P. Larkin., «Parents' Experiences of Living with and Caring for Children, Adolescents and Young Adults with Mucopolysaccharidosis (MPS)», Orphanet Journal of Rare Diseases 11, n. ${ }^{\circ} 1$, (2016): 138. Maria Stella, Epifanio et al., «Parenting Stress and Impact of Illness in Parents of Children with Coeliac Disease», Pediatric Reports 5, n. ${ }^{\circ} 4$, (2013).

21 Daniela Jelenova et al. «Quality of Life and Parental Styles Assessed by Adolescents Suffering from Inflammatory Bowel Diseases and Their Parents», Neuropsychiatric Disease and Treatment 12, (2016): 665.

22 Jelenova, et al., «Quality of Life and Parental...»

23 Syunichi Funakosi et al., «Psychosocial Liaison-Consultation for the Children Who Have Undergone Repair of Imperforate Anus and Hirschsprung Disease», Journal of Pediatric Surgery 40, n. ${ }^{\circ}$ 7, (2005): 1156-62. Marieke Witvliet et al., "Anxiety and Quality of Life of Parents with Children Diagnosed with an Anorectal Malformation or Hirschsprung Disease», European Journal of Pediatric Surgery 24, n. ${ }^{\circ}$ 1, (2014): 70-4.

24 Syunichi et al., «Psychosocial Liaison-Consultation...»

25 Ana María Gómez-Galindo, Olga Peñas-Felizzola, y Eliana Parra-Esquivel, "Caracterización y condiciones de los cuidadores de personas con discapacidad severa en Bogotá», Revista de Salud Pública 18, n. ${ }^{\circ}$ 3, (2016): 367-78. 
incorporar acciones interdisciplinarias e intersectoriales que impacten positivamente y lleven a reales transformaciones en la vida cotidiana de estas personas ${ }^{26}$.

En la sociedad, en el sistema de salud, en el nivel de escolaridad y los aspectos culturales, entre otros se conlleva a diferentes formas de afrontamiento en los pyc de niños con eh y mar. Estos factores pueden ser intervenidos a través de su capacitación, es por esto, que al diseñar una herramienta didáctica que actúe como guía de fácil consulta se puede orientar e impactar la calidad de vida de los cuidadores. Esta cartilla será un instrumento educativo de utilidad a las redes de apoyo existentes para estas enfermedades y el inicio de una estrategia de atención denominado cuidado transicional ${ }^{27}$.

\section{Objetivos}

\section{Objetivo general}

Elaborar material educativo que permita mejorar la calidad de vida de los padres y/o cuidadores de pacientes con enfermedad de Hirschsprung o malformaciones anorectales.

\section{Objetivos específicos}

Realizar una jornada pedagógica entorno al mejoramiento en la presentación de la cartilla de los padres y/o cuidadores de niños con eh o mar, de forma oral y por lecturas guiadas.

Ejecutar una presentación de ponencia o póster en un evento nacional y/o internacional al presentar la cartilla y sus efectos.

26 Gómez-Galindo, Peñas-Felizzola, y Parra-Esquivel, «Caracterización y condiciones...».

27 Luis M. Figueroa-Gutiérrez, y Mercy Soto-Chaquir, "Cuidado de transición de la adolescencia a la edad adulta», Revista de Salud Pública 20, n. ${ }^{\circ}$ 6, (2018): 791-3. 


\section{Metodología}

Este proyecto tuvo como población a los pyc de niños que se encontraban en el registro de seguimiento de cirugía pediátrica con diagnóstico de eh o mar, en el periodo comprendido entre julio de 2011 y mayo de 2019, de una institución de alta complejidad de atención en la ciudad de Pereira-Risaralda, Colombia y que aceptaron a participar de la convocatoria. Con el aval del Comité de Bioética de la Universidad Tecnológica de Pereira con código ex5-19-02 para la Vicerrectoría de Investigación, Innovación y Extensión (convocatoria interna para la financiación de proyectos de extensión social, cultural y artístico).

- Momento nro. 1. Se realizó una entrevista y un cuestionario para valorar su calidad de vida, en este caso whoqol-bref, los cuales actuaron como instrumentos para recolectar información y así identificar los aspectos más afectados en este grupo. Luego se elaboró un material educativo (cartilla), cuyo contenido orienta en métodos para mitigar el impacto que tiene ser padre y/o cuidador de un nname. Lo anterior se fundamentó en la publicación del texto "Vivencias de los padres y/o cuidadores de niños con enfermedad con enfermedad de hirschsprung o malformaciones anorrectales en seguimiento por cirugía pediátrica» ${ }^{28}$, en la cual se concluyó que la calidad de vida y el bienestar se ven alterados por tres experiencias comunes que son: un diagnóstico difícil, la complejidad del tratamiento y el contexto; situaciones que establecen la necesidad de redes de apoyo. Estos elementos pueden ser intervenidos con capacitación dirigida a los pyc.

- Momento nro. 2. Acción participativa. Se conformaron grupos focales de pyc quienes realizaron la evaluación de la cartilla y se discutió la construcción definitiva de la misma. Ellos modificaron, interactuaron y actuaron como editores e incorporaron nuevos textos, eliminaron párrafos y estructuraron escritos que para ellos fueran más claros.

28 Luis Mauricio Figueroa, Mercy Soto, y Jaime Martínez, «Vivencias de los padres o cuidadores de niños con enfermedad de Hirschsprung o con malformaciones anorrectales, bajo seguimiento después de la cirugía», Biomédica 39, n. ${ }^{\circ}$ 1, (2019): 147-56. 
- Momento nro. 3. Se llevaron a cabo actividades de intervención social: un evento de divulgación académica y cultural como jornada pedagógica en torno a la presentación de la cartilla para los pyc de niños con eh o mar, de forma oral y por lecturas guiadas. Además de circulación del conocimiento por medio de presentación de ponencia en evento local e internacional.

\section{Resultados}

Al aplicar el cuestionario whoqol-bref a los cuidadores, se estableció que el dominio más afectado de su calidad de vida fue el de relaciones sociales, seguido por el dominio psicológico. Estos evalúan la satisfacción con su vida sexual y el apoyo que obtienen de sus amigos, además de si disfrutan de la vida y aceptan su apariencia física y su estado emocional.

La entrevista a los cuidadores permitió priorizar los aspectos que afectan su calidad de vida. Al respecto se conformaron cuatro grupos:

\section{Saber sobre la enfermedad}

- «... no tuve a nadie que me enseñara cómo tratarlo, parecía que nadie conocía este problema, no tuve documento alguno que me explicara que esto era un mal conocido y que no éramos los únicos que lo padecemos».

- «... la cartilla debe enseñar sobre estas enfermedades y así salen del anonimato y los padres podemos documentarnos más al respecto».

Los cuidados más difíciles

- «Los dilatadores», «la colostomía», el «cierre de la colostomía», «la alimentación», el «estreñimiento», la «enterocolitis».

Estas enfermedades transforman la vida 
- «... es una condición que demanda mucha atención y transforma la forma de vida y las costumbres de los padres».

- «... limitan en tiempo, porque primero y último son los cuidados del niño y para salir a la calle esto genera molestias...».

- «... en cuanto a los recursos, se limitan porque hay prioridades. Ya no hay recreación».

\section{Ocupar la mente}

- «... para ayudar con el estrés hay que ocupar la mente; leer, caminar, hacer sopas de letras».

- «... reunirnos con los abuelos, tías y hacer actividades familiares, jugar, ver películas».

- «... salir a pasear y orar».

\section{La cartilla}

\section{Conocimiento sobre la enfermedad}

Enfermedad de Hirschsprung. Caracterizada por la ausencia de células ganglionares en el intestino distal (aganglionosis), lo que resulta en fallas en el movimiento del intestino y estancamiento de su contenido. Ocurre 4 veces más frecuentemente en hombres. Los defectos asociados ocurren aproximadamente en el $29 \%$ de los casos y afectan principalmente los sistemas cardiovascular y gastrointestinal. En el $5 \%$ de los casos pueden tener síndrome de Down.

Las primeras manifestaciones clínicas del recién nacido con eh son la distensión abdominal, el vómito y el retardo para la expulsión de meconio en las primeras, 24 a 48 horas de vida. Hay que tener en cuenta que cada vez, y con más frecuencia, los 
estudios plantean que hasta el $25 \%$ de los pacientes a quienes en el futuro se les diagnostica esta enfermedad presentaron paso de meconio en las primeras 24 horas, lo cual le resta validez a esta única variable. Por lo anterior y porque hay pacientes que no tienen las manifestaciones clínicas obvias, hasta un tercio son dados de alta sin diagnóstico, situación que hace que los médicos de cuidado primario tomen papel preponderante para detectar los pacientes posteriores al nacimiento.

Una vez los estudios han confirmado el diagnóstico el paciente debe ser llevado a una corrección quirúrgica en la cual y en la mayoría de los casos si se logra detectar oportunamente y no se requiere de una colostomía. El procedimiento puede llevarse a cabo en los primeros meses de vida por cirugía de mínima invasión.

El manejo posterior a la cirugía exige un seguimiento adecuado, ya que pueden existir secuelas a corto y largo plazo que deben ser manejadas por el grupo interdisciplinario tratante y que serán más o menos complejas de acuerdo con las condiciones asociadas a cada caso.

Malformaciones anorrectales. Son un grupo de enfermedades que afectan a niños y niñas y que involucran el ano y el recto distal como también los tractos urinario y genital.

El diagnóstico precoz y las decisiones terapéuticas adecuadas requieren de un alto índice de sospecha por parte del personal de salud involucrado (médicos, enfermeras, pediatras, neonatólogos, cirujanos pediatras, genetistas). Por lo tanto, debe enfatizarse que el examen anorrectal del neonato, al momento de nacer, es de vital importancia. Para un niño que no tiene ano al nacer deben movilizarse todos los esfuerzos y responder dos preguntas iniciales: 
- ¿Tiene el niño un defecto serio asociado que pueda llevarlo a la muerte en las próximas pocas horas o días de vida?

- ¿Necesita el niño algún tipo de reparación primaria colostomía- y una reparación secundaria?

Posterior a los estudios en las primeras veintic0atro horas de vida, de acuerdo con el tipo de malformación anorrectal se debe resolver si se lleva a cabo una cirugía (reparación primaria o anoplastia) o una colostomía y una reparación secundaria.

\section{Los cuidados más difíciles}

Colostomía. Procedimiento diseñado para crear una abertura del colon hacia la pared abdominal y, de esta manera, permitir la expulsión de la materia fecal al exterior. Esta cirugía se realiza para liberar la obstrucción del intestino ocasionada por problemas congénitos.

Los pyc deben solicitar información completa sobre el cuidado de la colostomía por parte del grupo interdisciplinario tratante en cuanto a la alimentación, el manejo con respecto a la materia fecal, la adquisición de las barreras y bolsas para su correcta recolección, los cuidados de la piel y las complicaciones potenciales y signos de alarma que los deben llevar a consultar en caso de ser necesario.

Dilatación anal. Consiste en introducir un dispositivo metálico o plástico (dilatador de hegar) a través del ano del paciente. Este busca que la zona de la cirugía en donde se implanta el ano en las mar o en donde se une el intestino sano al recto en eh, por los efectos de la cicatrización normal, no se cierre (estenosis) $y$, por lo tanto, no se ponga en riesgo el buen resultado de la cirugía. Este procedimiento debe cumplir un programa que dura en promedio seis meses y cuyo protocolo ${ }^{29}$ debe ser entregado y

29 Peña y Bischoff. Surgical Treatment... 
explicado al cuidador junto con el entrenamiento para adquirir las habilidades antes del alta del paciente.

Estreñimiento. Resultado más común de los pacientes correctamente operados por malformaciones anorrectales. Evitar el estreñimiento y manejarlo debe ser una de las obligaciones del seguimiento postoperatorio.

Colitis asociada a Hirschsprung. Es una inflamación del intestino que puede llevar a la muerte en neonatos antes de determinar el diagnóstico. También se presenta luego de la resolución quirúrgica. La causa en los pacientes ya operados no está clara pero sus manifestaciones son distensión, dolor abdominal, fiebre, diarrea fétida y compromiso del estado general con vómito y sangrado rectal. El tratamiento debe ser iniciado por los pyc tempranamente con irrigaciones rectales y, en caso necesario, consultar al servicio de salud para adicionar antibióticos y líquidos endovenosos.

Irrigaciones rectales. Procedimiento en el que se pasa a través de una sonda suero fisiológico para limpiar el colon dilatado y evacuar gas, se debe entrenar sobre esta técnica a todos los pyc antes del alta para evitar y tratar las colitis.

«Estas enfermedades transforman la vida»

El cuidador familiar.

- Es el miembro de un grupo familiar o social quien asume la responsabilidad de cuidar al enfermo sin que se haya llegado, en muchos casos, a un acuerdo explícito entre los miembros de la familia.

- Modifica su vida para asumir tareas especiales. Esta situación lleva a que tenga una mayor frecuencia de sobrecarga emocional, la cual desencadena más preocupaciones y estrés; dado que tiene que enfrentar la cotidiana toma de decisiones que afectan la propia 
existencia, al igual que la del ser querido; sin recibir un beneficio económico ${ }^{30}$.

Calidad de vida. Según la organización mundial de la salud es definida como:

- «... la manera en que el individuo percibe el lugar que ocupa en el entorno cultural y el sistema de valores en que vive, así como en relación con sus objetivos, expectativas, criterios y preocupaciones. Todo ello matizado, por supuesto, por su salud física, su estado psicológico, su grado de independencia, sus relaciones sociales, los factores ambientales y sus creencias personales» ${ }^{31}$.

Existen unos factores de riesgo que la afectan:

- El grado de dependencia: la atención y los cuidados que precisan las personas que no pueden realizar por sí mismas las actividades esenciales de la vida cotidiana, como son: bañarse, vestirse, movilizarse, comer.

- La carga interpersonal: son los sentimientos de cansancio (impacto del cuidado), la indecisión sobre el cuidado (expectativas de autoeficacia) y la sensación de ser el único cuidador (dependencia) $^{32}$.

- Sobrecarga del cuidador: la sobrecarga es un estresor de respuesta emocional a los cuidados que tienen implicaciones relevantes sobre el bienestar del cuidador. Hay dos tipos de estresores que pueden generar la sobrecarga:

30 Natividad Pinto Afanador, Lucy Barrera Ortiz, y Beatriz Sánchez Herrera, "Reflexiones sobre el cuidado a partir del programa "Cuidando a los cuidadores"», Revista Aquichan 5, n. ${ }^{\circ} 1,(2005)$ : 128-37.

31 Organización Mundial de la Salud, «La gente y la salud ¿qué calidad de vida?», Foro Mundial de la Salud 17, (1996): 385. https://apps.who.int/iris/bitstream/handle/10665/55264/ WHF_1996_17_n4_p385-387_spa.pdf? sequence=1

32 Ángela Pilar Albarracín Rodríguez, Ara Mercedes Cerquera Córdoba, y Daysy Katherine Pabón Poches, «Escala de sobrecarga del cuidador zarit: estructura factorial en cuidadores informales de Bucaramanga», Revista de Psicología Universidad de Antioquía 8, n. ${ }^{\circ}$ 2, (2016): 87-99. 
- Los estresores primarios: situaciones directas del cuidado, por ejemplo, cuando el niño presenta las «crisis». Para estos casos de patologías de colon y recto pueden ser las enterocolitis, las cuales pueden implicar una hospitalización, nuevas cirugías y complicaciones.

- Los estresores secundarios: se refiere a situaciones indirectas del cuidado, involucra las percepciones emocionales de las consecuencias del cuidar en el desempeño de otros roles asumidos por el cuidador, por ejemplo, ser ama de casa y cumplir con el cuidado de otros hijos, además de responder con la atención del niño o desempeñarse en un empleo, mientras el pequeño esté hospitalizado.

«Ocupar la mente»

La familia como apoyo social. Es el núcleo donde nace el apoyo y se facilita el proceso de superación. Para el caso de niños con discapacidad, la madre es la más afectada en la aceptación de la situación, pero si ella lo supera conseguirá la integración social del infante.

Apoyo social. La posibilidad de acceder a recursos de apoyo por parte de las personas cercanas con quienes se tiene interacción en un círculo social próximo, el cual puede ser instrumental, educativo y emocional.

Hacer parte de una red de apoyo social. «... conjunto de personas que rutinariamente asisten a un individuo en caso de necesidad ${ }^{33}$. La función de esta es poner a disposición de otros la experiencia propia y conjugar esta diversidad en la cooperación y brindar recursos como:

- Conductas de apoyo.

33 Castro Roberto, Campero lourdes y Bernardo Hernández, «La investigación sobre apoyo social en salud: situación actual y nuevos desafíos», Revista de Saúde Pública 31, n. ${ }^{\circ} 4$ (1997): 427. 
- Valoración del apoyo (evaluación subjetiva respecto a la cantidad y contenido de los recursos de apoyo disponibles).

- Orientación del apoyo (percepción sobre la utilidad y los riesgos de buscar y encontrar ayuda en una red social).

Practicar el autocuidado. El cuidador frecuentemente es la madre, la esposa, la hija, la ama de casa y la trabajadora, lo que tradicionalmente lleva a asumir la postura de que «primero están los otros» e implica que se olvide del cuidado de sí mismo. Por tanto es necesario tener en cuenta las siguientes recomendaciones:

- Compartir el cuidado: es importante que otros miembros de la familia ayuden con el cuidado del paciente, al recibir el entrenamiento y al actuar como depositarios de confianza para el cuidador principal. Compartir funciones que se requieren en la cotidianidad para reemplazar al cuidador principal en caso de ser requerido.

- Planificar las actividades: para permitir que se puedan satisfacer las necesidades en forma oportuna y sin fatigar al cuidador, es necesario establecer rutinas de actividades diarias con tiempos establecidos y en orden de prioridad. Permite que el cuidador pueda tener control sobre el tiempo y tomar espacios de reposo.

- Conocer acerca de la enfermedad del niño: hoy se habla de "paciente experto», pero es necesario trascender a «cuidadores familiares expertos» para alcanzar el bienestar del paciente. Sobre todo, si el cuidador se capacita y se entrena podrá afrontar con mayor serenidad los momentos de crisis, para esto es importante consultar fuentes confiables de información como esta cartilla y las páginas web de organizaciones reconocidas a nivel internacional.

- Reconocer sus límites: cuando una persona desea realizar una actividad, debe reconocer si cuenta con las capacidades físicas, psicológicas y emocionales para realizarla, así como su disposición para llevarla a cabo; por ejemplo, si tiene que cargar a su paciente, verificar si su capacidad física es suficiente o pedir ayuda cuando se sienta emocionalmente saturado, cansado, confundido. 
- Disponer de tiempo para usted: muchos cuidadores familiares asumen que el rol de cuidador es el centro sobre el cual deben girar sus prioridades, al posponer su propio yo y al aplazar sus necesidades, por lo tanto, es prioritario que, como ser humano, reconozca que para brindar un buen cuidado se requiere del buen autocuidado, es decir, tener presente que hay necesidades como el descanso, la alimentación, la recreación, el ocio, la espiritualidad y el crecimiento personal.

- Fomentar los vínculos afectivos: el afecto actúa como motivación para afrontar todas las situaciones de la vida. No es una prioridad establecer una relación de pareja, pero sí es importante tener cercanía con personas significativas a quien dar y recibir afecto, compartir alegrías, tristezas, triunfos y fracasos, así como los progresos en la enfermedad y los momentos de las crisis de los pacientes.

- Fortalecer la relación de pareja: estudios han demostrado que en una familia donde se tiene un hijo con una situación de enfermedad o algún grado de discapacidad se puede presentar deterioro de las relaciones de pareja, por lo tanto, es necesario fortalecer los vínculos afectivos y compartir las emociones, las preocupaciones, las cargas, además de utilizar la comunicación asertiva, es decir, expresar sus ideas, sentimientos y emociones de manera tranquila, tanto en un lenguaje verbal como no verbal.

\section{Promoción de la calidad de vida de padres y cuidadores de niños con eh o mar en el contexto escolar}

\section{Conocer acerca de los cuidados de la enfermedad del niño}

Existe una correlación significativa entre las estrategias de afrontamiento (factores protectores, como actividades de promoción) y un mayor bienestar psicológico en los cuidadores informales y familiares tales como: 
- Motivar la participación familiar en el cuidado del niño. Solidaridad entre los miembros de la familia. Información a la familia y cuidador. Habilidad para el cuidado.

\section{Cuidados generales del niño con patologías de colon y recto}

Entrenamiento para ir al baño y guía para la escuela

- Establecer buenas rutinas de alimentación y evacuación.

- Educar y suministrar al niño una dieta adecuada de acuerdo a sus necesidades (laxante o astringente).

- Comenzar a educar al niño para hacer deposición desde los seis meses de edad.

- Llevarlo a los controles médicos puntualmente.

- Educar a sus maestros para garantizarle flexibilidad académica.

- Ser paciente frente a los logros del niño.

- Mantener al niño bien hidratado suministrándole más líquidos.

- Mantener al niño educado y preparado para los accidentes de manchado por la pérdida del control de esfínteres.

- Fortalecer en los niños la autonomía y la autoestima.

- Nunca negar el acceso al baño.

- Aceptar la discapacidad del niño que cuida.

- Practicar la valentía y la paciencia.

- Afianzar la espiritualidad. 


\section{Población beneficiada}

La cartilla permitirá a los nuevos padres de niños con eh o mar reconocer y afrontar la enfermedad desde la vivencia a priori con una mayor sensibilidad. Situación presente al permitir que esas emociones sean moduladas por el contenido de esta. Además, la sensibilización desde la medicina transicional también sirve para que los médicos especialistas, tratantes de este grupo de pacientes, tengan un abordaje desde las vivencias que se encuentran documentadas en la cartilla.

El proyecto llegó a beneficiar una población conformada por cuarenta padres y/o cuidadores de niños en seguimiento por cirugía pediátrica que se vincularon debido a la convocatoria. Estos recibieron capacitación y sus aportes fueron tenidos en cuenta para la construcción de la cartilla.

Figura NRo. 1. Población beneficiada del proyecto.

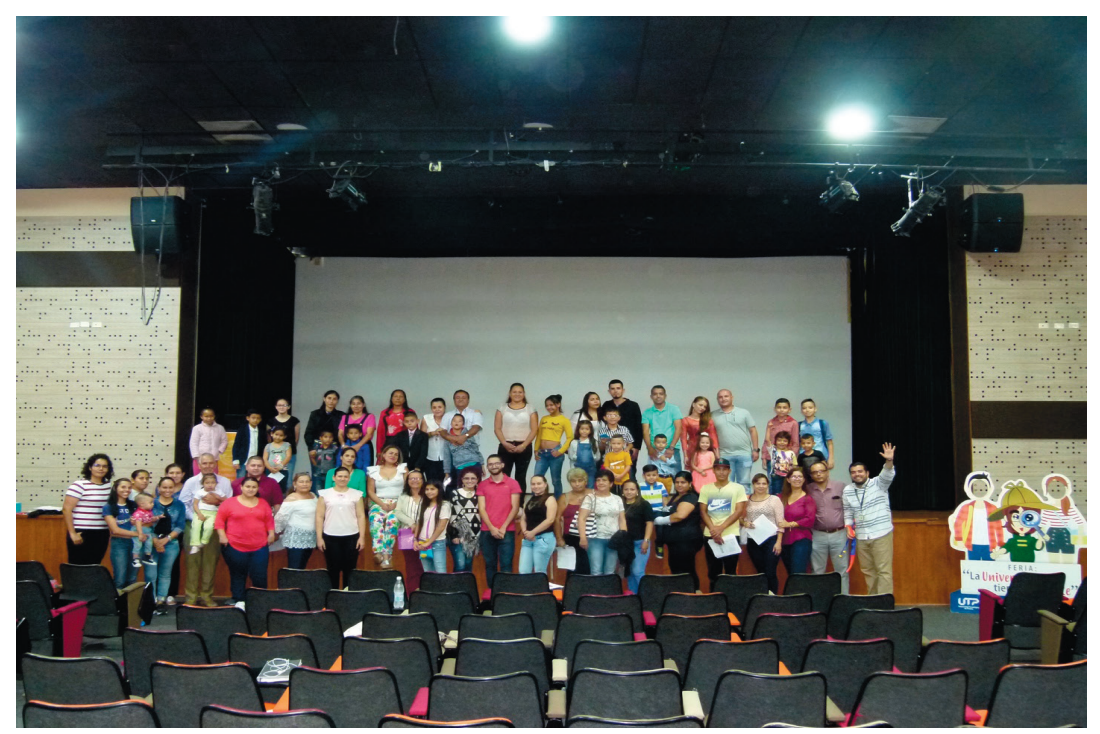

Elaboración propia. 


\section{Conclusiones}

Esta cartilla es un producto de construcción colectiva desde las voces de los participantes (pyc), quienes desde su experiencia han querido aportar al conocimiento para que otros pyc superen las dificultades en la atención de los niños que nacen con estas anomalías, permitiéndoles acceder a una herramienta de información y consulta útil tanto para el cuidado de su niño como para su autocuidado.

\section{Bibliografía}

Albarracín Rodríguez Ángela Pilar, Ara Mercedes Cerquera Córdoba, y Daysy Katherine Pabón Poches. «Escala de sobrecarga del cuidador zarit: estructura factorial en cuidadores informales de Bucaramanga», Revista de Psicología Universidad de Antioquía 8, n.o 2 (2016): 87-99.

Bradnock, Timothy, et al. «Hirschsprung's Disease in the UK and Ireland: Incidence and Anomalies», Archives of Disease in Childhood 102, n. ${ }^{\circ} 8$ (2017):722-7.

Castro Roberto, Campero lourdes y Bernardo Hernández, «La investigación sobre apoyo social en salud: situación actual y nuevos desafíos», Revista de Saúde Pública 31, n. ${ }^{\circ} 4$ (1997): 427.

Chung, Paul. et al. "Access to Leave Benefits for Primary Caregivers of Children with Special Health Care Needs: A Double Bind», Academic Pediatrics 13, n. ${ }^{\circ} 3$ (2013): 222-8.

Epifanio, Maria Stella, et al. «Parenting Stress and Impact of Illness in Parents of Children with Coeliac Disease», Pediatric Reports 5, n. ${ }^{\circ} 4$ (2013): 19. 
Figueroa, Luis Mauricio, Mercy Soto, y Jaime Martínez. «Vivencias de los padres o cuidadores de niños con enfermedad de Hirschsprung o con malformaciones anorrectales, bajo seguimiento después de la cirugía», Biomédica 39, n. ${ }^{\circ} 1$ (2019): 147-56.

Figueroa-Gutiérrez, Luis M., y Mercy Soto-Chaquir. "Cuidado de transición de la adolescencia a la edad adulta», Revista de Salud Pública 20, n. ${ }^{\circ} 6$ (2018): 791-3.

Funakosi Syunichi, et al. «Psychosocial Liaison-Consultation for the Children Who Have Undergone Repair of Imperforate Anus and Hirschsprung Disease», Journal of Pediatric Surgery 40, n. 7 (2005): 1156-62.

Gómez-Galindo, Ana María, Olga Peñas-Felizzola, y Eliana PARra-Esquivel. "Caracterización y condiciones de los cuidadores de personas con discapacidad severa en Bogotá», Revista de Salud Pública 18, n.o 3 (2016): 367-78.

Gutiérrez Figueroa, Luis Mauricio, Juan José Ospina Ramírez, Mercy Soto Chaquir, Jorge M. Estrada Álvarez, y Estefanía Gutiérrez Ocampo. «Cartillas para la calidad de vida de los padres y/o cuidadores de pacientes con enfermedad de Hirschsprung o malformaciones anorrectales», RREDSI Red Nacional de Semilleros de Investigación. https://invessoft.com/ponencias2019/pdf/ poster/Estefan\%C3\%ADa\%20Guti\%C3\%A 9rrez\%20 Ocampo.pdf.

Jelenova, Daniela, et al. "Quality of Life and Parental Styles Assessed by Adolescents Suffering from Inflammatory Bowel Diseases and Their Parents», Neuropsychiatric Disease and Treatment12, (2016): 665. 
Levitt, Marc, y Alberto Peña. "Anorectal Malformations", Orphanet Journal of Rare Diseases 2, n. 33 (2007): 1-13. https://link.springer.com/content/pdf/10.1186/1750-1172-233.pdf.

Lucas, Betty L.; Sharon A. Feucht y Lynn Grieger. Children with Special Health Care Needs: Nutrition Care Handbook. American Dietetic Associati, 2004.

Malcolm, C. et al. "Challenging Symptoms in Children with Rare Life-Limiting Conditions: Findings from a Prospective Diary and Interview Study with Families», Acta Paediatrica 101, n. ${ }^{\circ} 9$ (2012): 985-92.

Malcolm, Cari, et al. "Challenging Symptom Profiles of Life-Limiting Conditions in Children: a Survey of Care Professionals and Families», Palliative Medicine 25, n. ${ }^{\circ} 4$ (2011): 357-64.

McGarvey, Bernadette, y Caroline Hart. An Investigation Into the Social Support Needs of Families Who Experience Rare Disorders on the Island of Ireland. Dublin: RehabCare, 2008.

McPherson, Merle, et al. "A New Definition of Children with Special Health Care Needs», Pediatrics 102, n. ${ }^{\circ} 1$ (1998):1379.

Organización Mundial de la Salud. «La gente y la salud ¿qué calidad de vida?», Foro Mundial de la Salud 17, (1996): 385. https://apps.who.int/iris/bitstream/handle/10665/55264/ WHF_1996_17_n4_p385-387_spa.pdf? sequence $=1$.

Peña, Alberto, y Andrea Bischoff A. Surgical Treatment of Colorectal Problems in Children. New York: Springer, 2015. 
Pinto Afanador Natividad, Lucy Barrera Ortiz, y Beatríz SÁnCHEZ Herrera. «Reflexiones sobre el cuidado a partir del programa "Cuidando a los cuidadores"», Revista Aquichan 5, n. ${ }^{\circ} 1$ (2005): 128-37.

Rose-Jacobs, Ruth et al. "Children with Special Health Care Needs, Supplemental Security Income, and Food Insecurity», Journal of Developmental \& Behavioral Pediatrics 37, n. 2 (2016): 140-7.

Somanadhan, S. y P. LARKIn. «Parents' Experiences of Living with and Caring for Children, Adolescents and Young Adults with Mucopolysaccharidosis (MPS)», Orphanet Journal of Rare Diseases 11, n. ${ }^{\circ} 1$ (2016):138.

Witvliet, Marieke J., et al. "Quality of Life and anxiety in parents of children with an anorectal malformation or Hirschsprung disease: the first year after diagnosis", European Journal of Pediatric Surgery 26, n. ${ }^{\circ} 1$ (2016): 2-6.

Witvliet, Marieke, et al. «Anxiety and Quality of Life of Parents with Children Diagnosed with an Anorectal Malformation or Hirschsprung Disease», European Journal of Pediatric Surgery 24, n. ${ }^{\circ}$ (2014): 70-4. 


\title{
La apropiación social del conocimiento de la avifauna en la Institución Educativa Hugo Ángel Jaramillo como estrategia de educación ambiental
}

\author{
Docentes \\ Jorge Hugo García Sierra \\ JULIANA MUÑOZ LÓPEZ \\ JAIME ANDRÉs SuAREZ Mejía \\ Estudiantes \\ Juan Sebastián Arango González \\ Alba LuCía Villa \\ VALENTINA RODRÍGUEZ SOLARTE \\ LINA MARCELA ARBOLEDA \\ JHON ENRÍQUEZ CALDERÓN \\ SONIA MARÍN LONDOÑO \\ JHOAN SANTIAgo VÁSQUEZ \\ Apoyo administrativo y logístico \\ Tatiana Carmona Gómez \\ JAVIER ANDRÉS CUAYAL \\ AlbEIRo PAVA \\ SARAY KATERINE RÍOS \\ Nathalya EUgenia Ospina \\ Grupo de Investigación en Gestión de Agroecosistemas Tropicales \\ Andinos \\ (Jardín Botánico UTP-Semillero de Investigación en Aves Andinas) \\ Universidad Tecnológica de Pereira
}




\section{Resumen}

El proyecto Apropiación social de la avifauna como estrategia de educación ambiental en la Institución Educativa Hugo Ángel Jaramillo de Pereira de la comuna del café, municipio de Pereira, fue financiado por la Vicerrectoría de Investigaciones, Innovación y Extensión, a través de la Convocatoria interna de extensión social, cultural y artística del año 2019; fue ejecutado por el Semillero de Investigación en Aves Andinas y el Jardín Botánico de la UTP adscritos al Grupo de Investigación en Gestión de Agroecosistemas Tropicales Andinos (GATA) de la Facultad de Ciencias Ambientales. El proyecto tuvo como objetivo proponer una estrategia de educación ambiental a través de la conformación de un grupo de observadores de aves, de la identificación participativa de la avifauna del colegio y de la generación de espacios de difusión y apropiación social. Para ello se llevaron a cabo talleres de capacitación sobre el conocimiento de las aves locales, así como talleres de dibujo y pintura. Además, se desarrollaron jornadas de observación de aves en el área de influencia de la institución educativa y en el mencionado jardín botánico. Como parte de la generación de espacios para la difusión del conocimiento, se desarrolló una exposición de dibujo y pintura en las instalaciones de este espacio de la universidad, se elaboró un mural en la institución educativa y se publicó un folleto ilustrado llamado "Las aves de mi colegio». Como resultados adicionales del proyecto se elaboró un video que recoge el proceso y se presentó una ponencia oral en el $4 .{ }^{\circ}$ Congreso Nacional de Ciencias Ambientales. Esta última actividad permitió divulgar los resultados con otro tipo de público. Adicionalmente, las deducciones derivadas del inventario de aves del colegio fueron cargados en la plataforma iNaturalist ${ }^{34}$.

34 Proyecto de ciencia ciudadana y red social en línea de naturalistas, científicos ciudadanos y biólogos basada en el concepto de mapeo e intercambio de observaciones de biodiversidad a través del mundo. Se puede acceder al proyecto a través de su sitio web o de aplicaciones móviles. 
Jorge Hugo García Sierra - Juliana Muñoz López - Jaime Andrés Suarez Mejía - Juan Sebastián Arango González Alba Lucía Villa - Valentina Rodríguez Solarte - Lina Marcela Arboleda - Jhon Enríquez Calderón - Sonia Marín Londoño Jhoan Santiago Vásquez - Tatiana Carmona Gómez - Javier Andrés Cuayal - Albeiro Pava Saray Katerine Ríos - Nathalya Eugenia Ospina

En este proceso estuvieron vinculados estudiantes entre los ocho y catorce años y desde el grado segundo a décimo. Estos tuvieron la posibilidad de interactuar con integrantes del Semillero de Investigación en Aves Andinas, en el cual participan docentes y estudiantes de la Facultad de Ciencias Ambientales y Artes Visuales quienes contribuyeron con un proceso de formación sobre el conocimiento de las aves, así como la generación de herramientas artísticas para llevar a cabo la elaboración de dibujos y pinturas relacionadas con las mismas.

La metodología para el desarrollo del proyecto se basó en tres fases complementarias entre sí que permitieron organizar la comunidad estudiantil, caracterizar las aves locales de forma participativa y divulgar la información recolectada partiendo de un enfoque interdisciplinario materializado en los diferentes métodos y herramientas aplicados desde la ecología, las artes y la comunicación.

En este sentido, a través del conocimiento de las aves locales de forma participativa, se generaron actitudes de interpretación del entorno y reconocimiento de las diversas relaciones entre las personas y la naturaleza las cuales se comunicaron de forma trasversal con diferentes públicos.

Palabras clave: apropiación social, educación ambiental, arte, comunicación, ciencia ciudadana.

\section{Abstract}

The project of social appropriation of birdlife as an environmental education strategy at the Hugo Ángel Jaramillo Educational Institution of the municipality of coffee commune, municipality of Pereira, was financed by the Vicerectory of research innovation and extension, through the internal Call for social, cultural extension and artistic of the year 2019; It was carried out by the Andean Bird Research Seedbed and the UTP 
Botanical Garden, attached to the Research Group on Management of Tropical Andean Agroecosystems (GATA) of the Faculty of Environmental Sciences. The project's objective was to propose an environmental education strategy through the formation of a group of bird watchers, the participatory identification of the school's avifauna and the generation of spaces for dissemination and social appropriation; to do this, training workshops were held on the knowledge of local birds, as well as drawing and painting workshops and birdwatching sessions were held in the area of influence of the educational institution and in the Botanical Garden of the University. As part of the generation of spaces for the dissemination of knowledge, an exhibition of drawing and painting was developed in the facilities of the Botanical Garden, a mural was produced in the Educational Institution, and it was published an illustrated brochure: "Las aves de mi colegio". As additional results of the project, a video was compiled that includes the process and an oral presentation was made at the 4th Congreso Nacional de Ciencias Ambientales; this last activity allowed the results to be disseminated with other types of audiences. Additionally, the results derived from the school's bird inventory were uploaded to the iNaturalist ${ }^{35}$ platform.

In this process, students between the ages of 8 and 14, from the second to the tenth grade, were linked, who had the opportunity to interact with members of the Research Seedbed in Andean Birds, in which teachers and students from the Faculty of Environmental Sciences and Visual Arts participate, who contributed to a training process on the knowledge of birds, as well as the generation of artistic tools to carry out the elaboration of drawings and paintings related to birds.

The methodology for the development of the project was based on three mutually complementary phases that allowed organizing the student community, characterizing local birds in

35 Citizen science project and online social network of naturalists, citizen scientists, and biologists based on the concept of mapping and exchanging observations of biodiversity throughout the world. The project can be accessed through its website or mobile applications. 
Jorge Hugo García Sierra - Juliana Muñoz López - Jaime Andrés Suarez Mejía - Juan Sebastián Arango González Alba Lucía Villa - Valentina Rodríguez Solarte - Lina Marcela Arboleda - Jhon Enríquez Calderón - Sonia Marín Londoño Jhoan Santiago Vásquez - Tatiana Carmona Gómez - Javier Andrés Cuayal - Albeiro Pava

Saray Katerine Ríos - Nathalya Eugenia Ospina

a participatory way and disseminating the information collected, based on an interdisciplinary approach, materialized in the different methods and tools applied from ecology, the arts and communication.

In this sense, through participatory knowledge of local birds, attitudes of interpretation of the environment and recognition of the various relationships between people and nature were generated, which were communicated cross-sectionally to different audiences.

Keywords: Social Appropriation, Environmental Education, Art, Communication, Citizen Science.

\section{Introducción}

La apropiación social del conocimiento es un tema de reciente preocupación para las comunidades científicas, los gobiernos y los medios de comunicación que ha sido asumida como un compromiso social para la comunidad (Marín, 2012). Según Minciencias (2019), este es un proceso intencionado de comprensión e intervención de las relaciones entre ciencia, tecnología y sociedad para generar conocimiento.

En este sentido, el presente proyecto de extensión social universitaria buscó proponer una estrategia de educación ambiental en Pereira Risaralda al consolidar un grupo de observadores de aves, con quienes se identificó participativamente la avifauna y se divulgaron los resultados obtenidos: Lo anterior se enmarcó en un proceso de ciencia participativa que además de generación de conocimiento permite desarrollar, en la comunidad involucrada, comportamientos de interpretación, sensibilización y comprensión del entorno dirigido hacia la transformación de la realidad, tanto en sus aspectos naturales como sociales $\mathrm{y}$ al desarrollar habilidades $\mathrm{y}$ aptitudes necesarias para dicha transformación. 
De acuerdo con Noguera (2004) «Para poder resignificar los valores que constituyen el tejido del complejo cultural urbano es necesario comprender los imaginarios y las imágenes desde la ética y la estética ambiental» (p. 157); para ello se decide además de desarrollar esta propuesta de educación ambiental, comprender cómo se da la apropiación social del conocimiento de las aves en la Institución Educativa Hugo Ángel Jaramillo de Pereira, Risaralda.

Vale la pena mencionar que el proyecto se deriva de la necesidad de pensar la educación ambiental como un proceso complejo y permanente mediante el cual la comunidad educativa tiende a tomar conciencia de su realidad, del tipo de relaciones que la sociedad establece entre sí y con la naturaleza, de los problemas derivados de dichas relaciones y de sus causas profundas (Carrizosa, 2014).

Bajo este contexto y teniendo en cuenta que la institución educativa representa un área de influencia de la Serranía Alto del Nudo, considerada de interés ambiental para el municipio de Pereira, se constituye además en un escenario propicio para que se den una serie de problemas ambientales asociados al cambio del uso del suelo, a la fragmentación de los bosques y a la pérdida de la biodiversidad; problemas que, en el marco del propósito que busca la educación ambiental, podrían ponerse en contexto con la enseñanza de las ciencias naturales y sociales a través de la observación de aves.

\section{OBjetivos}

\section{Objetivo general}

Proponer una estrategia de educación ambiental en la Institución Educativa Hugo Ángel Jaramillo. 
Jorge Hugo García Sierra - Juliana Muñoz López - Jaime Andrés Suarez Mejía - Juan Sebastián Arango González

\section{Objetivos específicos}

Consolidar un grupo de observadores de aves para procesos de ciencia ciudadana.

Identificar participativamente la avifauna.

Generar espacios para la difusión y apropiación social de las aves.

\section{Metodología}

La metodología que se desarrolló para dar cumplimiento a los objetivos fue planteada de forma multidisciplinaria (artes, comunicación, ciencias naturales), las cuales se articularon en tres fases complementarias desde el enfoque de la educación ambiental compleja planteado por Carrizosa (2014).

\section{Fase de formación}

En esta fase se fortalecieron los lazos de confianza entre los diferentes actores que conforman el grupo de observadores de aves, además fue posible desarrollar habilidades artísticas y creativas a través del conocimiento de las aves. Para esto se desarrollaron ocho talleres teórico prácticos: 1) socialización del proyecto, 2) introducción a la observación de aves, 3) principales características (formas, sonidos y colores de las aves), 4) realización de introducción al dibujo de aves, 5) realización del segundo taller de dibujo de aves, 6) realización del primer taller de pintura, 7) realización de taller final de pintura.

\section{Fase de interpretación}

Con el grupo de observadores de aves, conformado en la fase anterior, se identificó participativamente la avifauna tomando como referencia la guía de aves de Colombia (Ayerbe, 2019). Para ello se llevaron a cabo cuatro jornadas de observación en 
el área de estudio y una en el Jardín Botánico de la UTP. Estas actividades de observación fortalecieron las capacidades en el uso de herramientas como binoculares, guías y libreta de campo.

\section{Fase de divulgación}

En esta fase se dieron a conocer las aves del área de estudio a través de diferentes espacios de socialización tales como la realización de una exposición de dibujo y pintura en las instalaciones del Jardín Botánico de la UTP, la elaboración de un mural en la institución educativa y un folleto ilustrado titulado «Las aves de mi colegio», además de un video como pieza comunicativa.

Vale la pena aclarar que, aunque este proyecto no es de investigación sino de extensión social, se obtuvieron resultados adicionales enfocados a la divulgación científica como la presentación de una ponencia oral titulada: «Apropiación social del conocimiento sobre avifauna como estrategia de educación ambiental en Pereira Risaralda», la cual fue presentada en el $4 .^{\circ}$ Congreso Nacional de Ciencias Ambientales. Dicha ponencia permitió que la información recolectada, organizada, analizada y sintetizada, de forma participativa, permeara otros espacios académicos donde se dio el dialogo de saberes con estudiantes y comunidad participante de este evento procedente de diversas regiones del país. 
Jorge Hugo García Sierra - Juliana Muñoz López - Jaime Andrés Suarez Mejía - Juan Sebastián Arango González Alba Lucía Villa - Valentina Rodríguez Solarte - Lina Marcela Arboleda - Jhon Enríquez Calderón - Sonia Marín Londoño Jhoan Santiago Vásquez - Tatiana Carmona Gómez - Javier Andrés Cuayal - Albeiro Pava

Figura NRO. 1. Matriz metodológica.

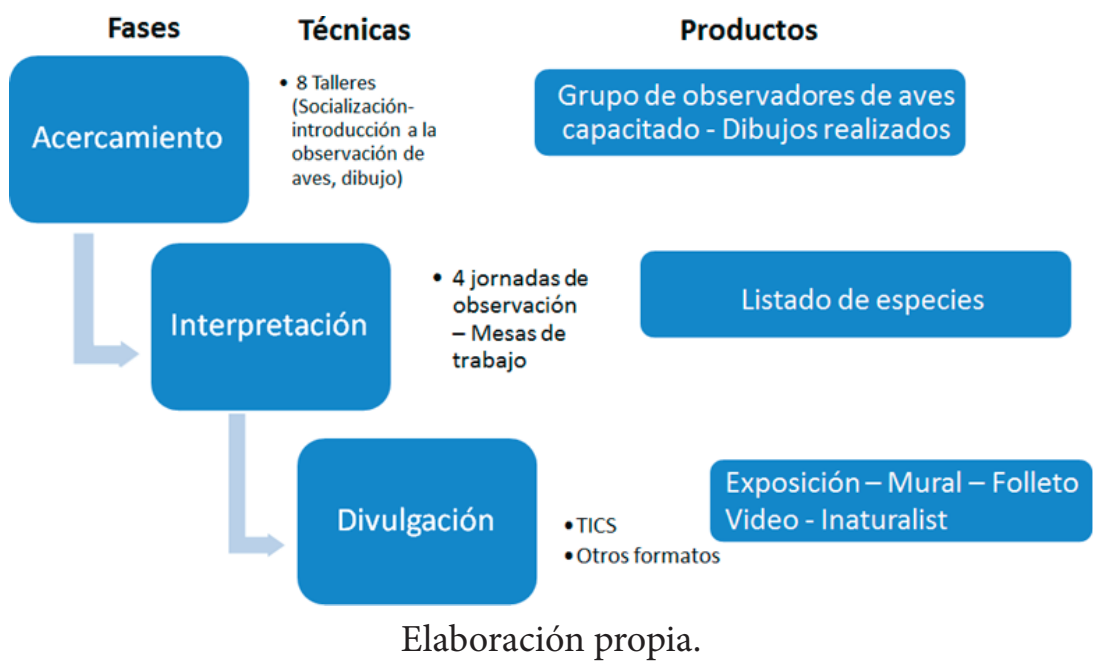

\section{Resultados}

Los resultados correspondieron a cada una de las fases metodológicas. En este sentido, en la primera fase de formación se consolidó y se capacitó al grupo de observadores de aves «Hugo Arte ¡a Crear!» a través de diferentes jornadas de capacitación que permitieron dar a conocer los alcances del proyecto mediante una socialización inicial. Además, se realizaron cuatro charlas teórico-prácticas sobre la introducción a la observación de aves - principales características de estas especies (formas, sonidos y colores)—, dos talleres de dibujo y dos de pintura. 
FIGURA NRO. 2. Ilustraciones realizadas por los estudiantes de la Institución Educativa Hugo Ángel Jaramillo.

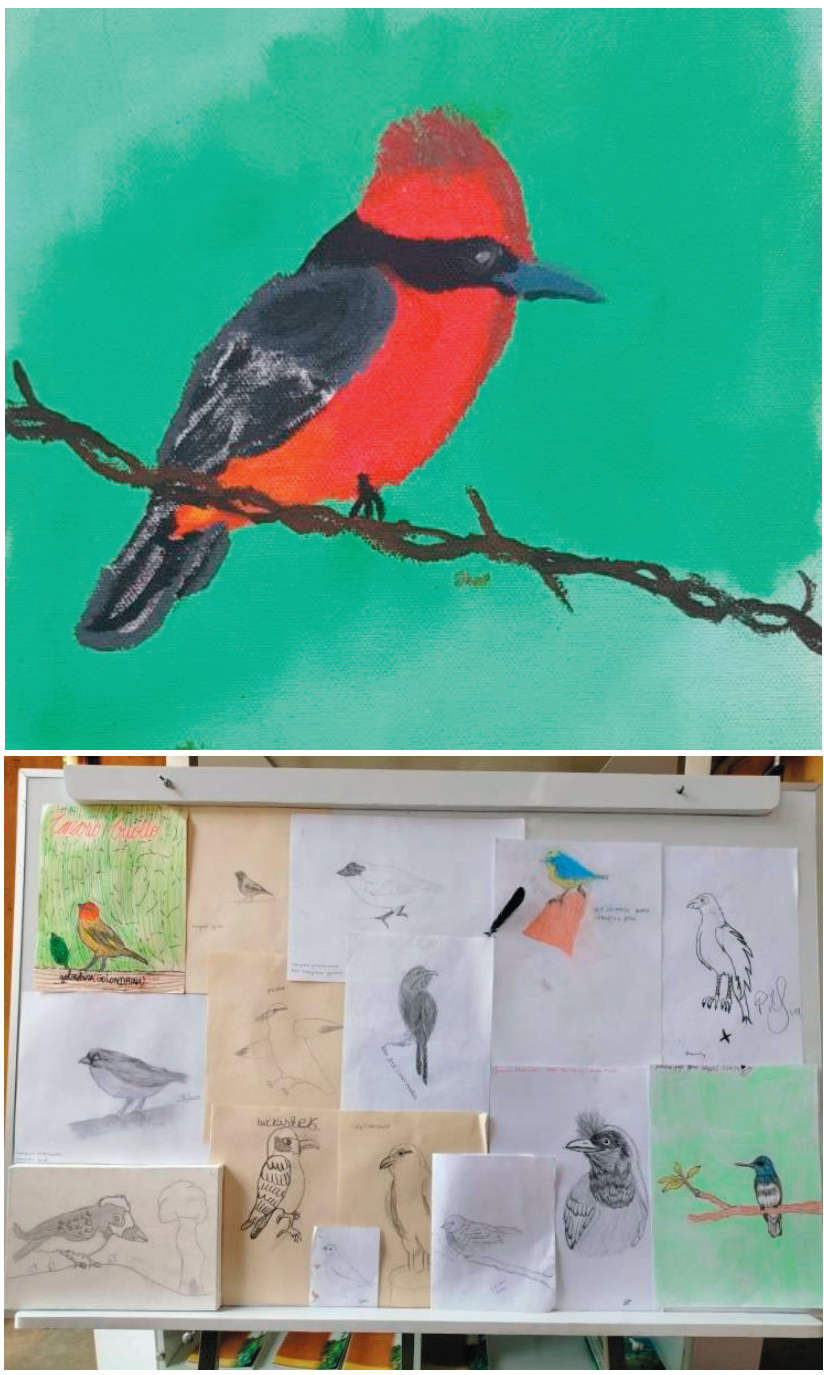

Elaboración propia. 
Jorge Hugo García Sierra - Juliana Muñoz López - Jaime Andrés Suarez Mejía - Juan Sebastián Arango González Alba Lucía Villa - Valentina Rodríguez Solarte - Lina Marcela Arboleda - Jhon Enríquez Calderón - Sonia Marín Londoño Jhoan Santiago Vásquez - Tatiana Carmona Gómez - Javier Andrés Cuayal - Albeiro Pava

Figura NRo. 3. Visita de estudiantes de la Institución Educativa Hugo Ángel Jaramillo al Jardín Botánico de la UTP.

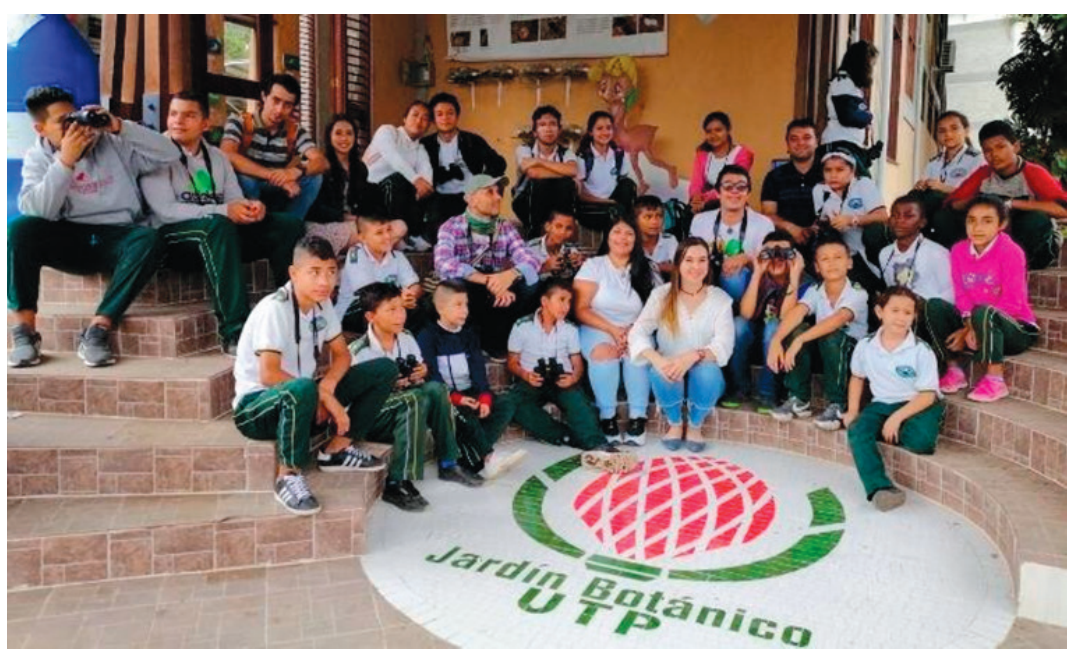

Elaboración propia.

La segunda fase de interpretación tuvo como principales actividades la realización de recorridos de observación, en los cuales fue posible la identificación de cincuenta especies y se resaltó la presencia del vencejo tijereta mayor (Panyptila sanctihieronymi) -que se constituye en una especie no muy común-y la reinita amarilla (Setophaga petechia), la cual es una especie migratoria boreal. 
Figura NRO. 4. Observación de aves en el Jardín Botánico de la UTP.
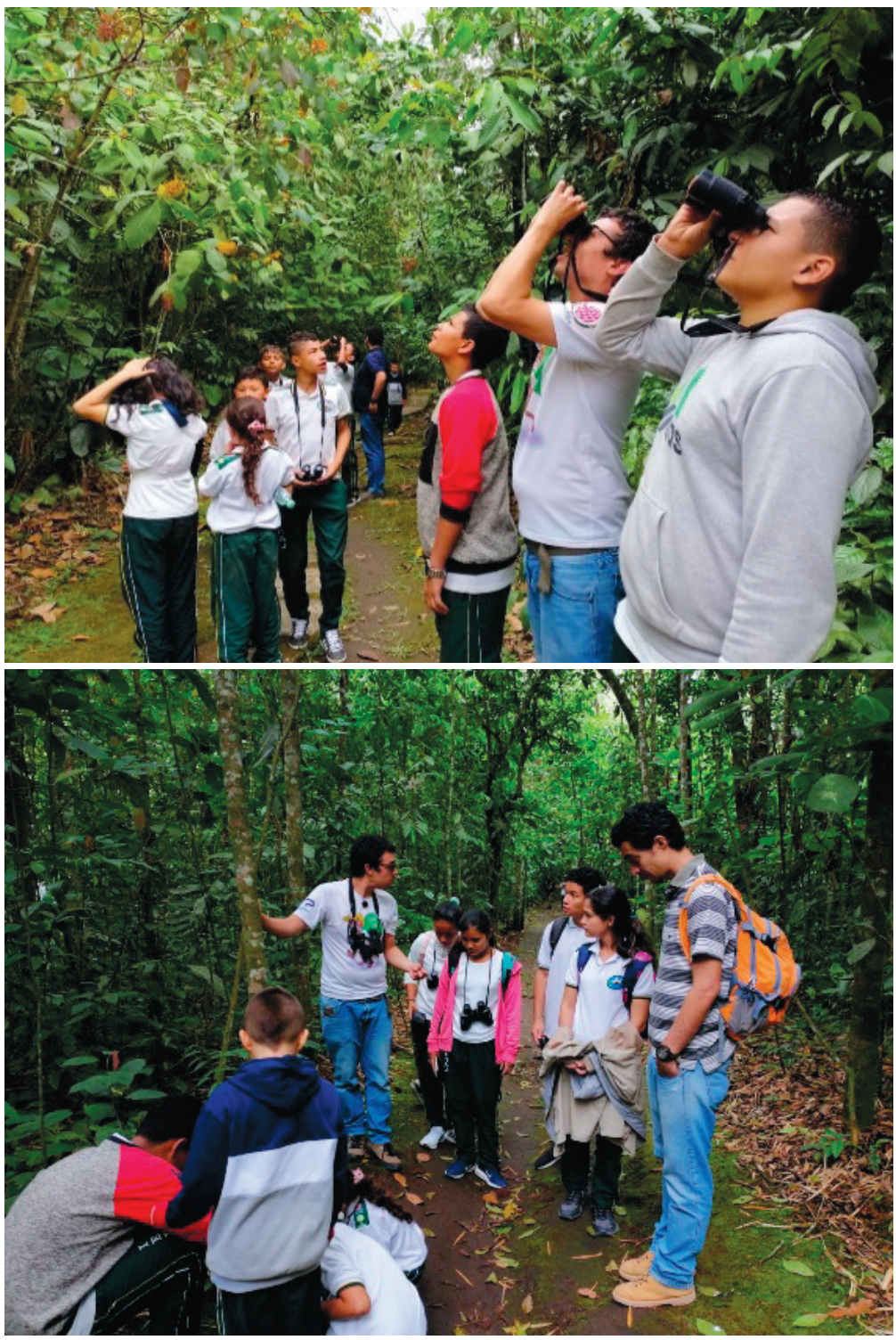

Elaboración propia. 
Jorge Hugo García Sierra - Juliana Muñoz López - Jaime Andrés Suarez Mejía - Juan Sebastián Arango González Alba Lucía Villa - Valentina Rodríguez Solarte - Lina Marcela Arboleda - Jhon Enríquez Calderón - Sonia Marín Londoño Jhoan Santiago Vásquez - Tatiana Carmona Gómez - Javier Andrés Cuayal - Albeiro Pava Saray Katerine Ríos - Nathalya Eugenia Ospina

Figura NRO. 5. Exposición de dibujo y pintura en el Jardín Botánico UTP.

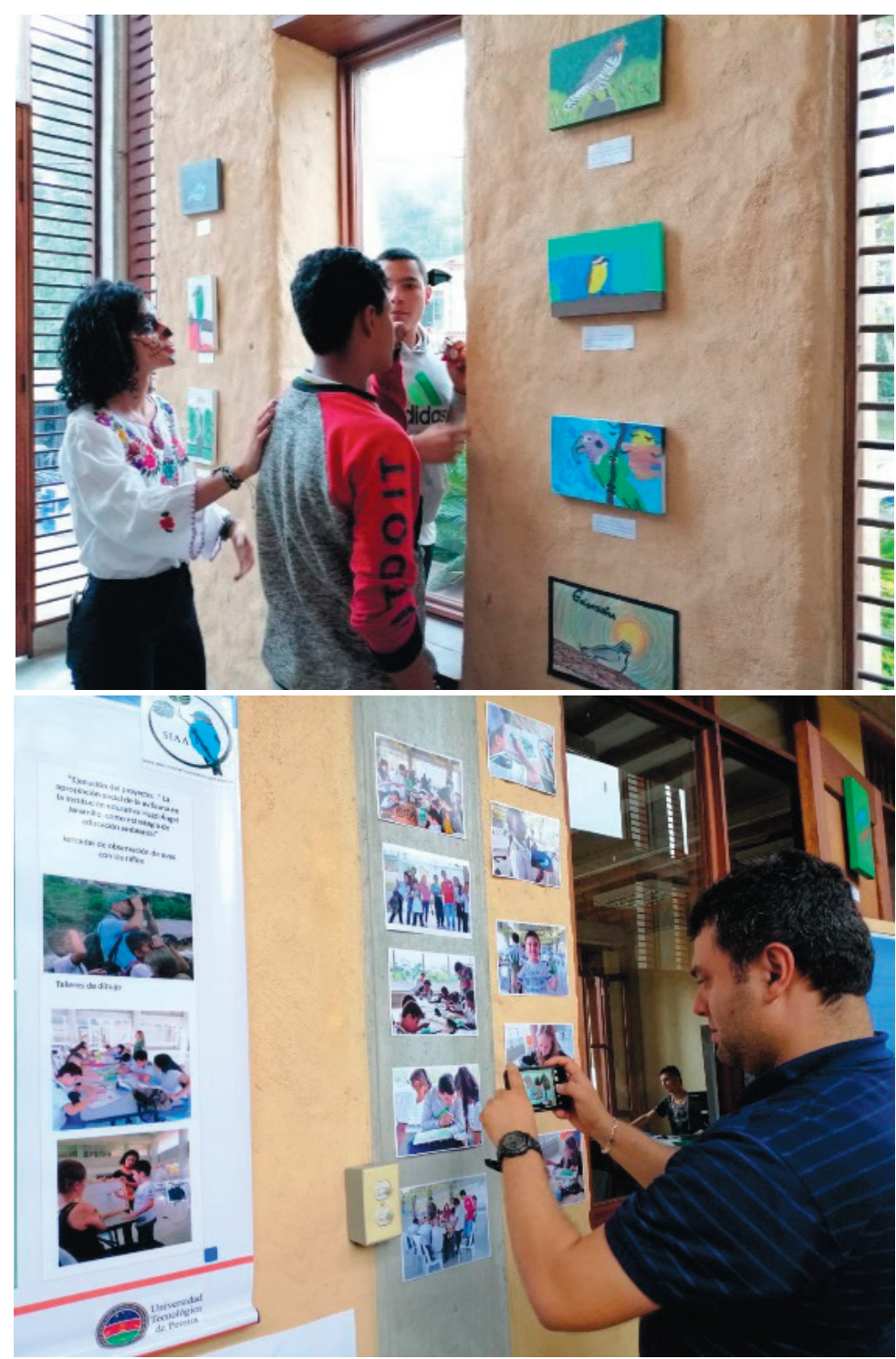

Elaboración propia. 
En la fase de divulgación se realizó una exposición de dibujo y pintura en el Jardín Botánico de la UTP, un mural en la Institución Educativa Hugo Ángel Jaramillo y un folleto impreso denominado "Las aves de mi colegio», el cual fue ilustrado por algunos de los niños participantes en el proyecto, el docente de artes de la institución educativa y estudiantes de artes visuales que son integrantes del Semillero de Investigación. Estos utilizaron las técnicas de grafito sobre papel y vinilo sobre lienzo. Además, se generó un video como pieza comunicativa que dio cuenta del proceso, del cargue de las especies de aves identificadas en la plataforma iNaturalist y de la presentación de una ponencia oral con los resultados del proyecto en el $4 .{ }^{\circ}$ Congreso Nacional de Ciencias Ambientales.

Figura nRo. 6. Ponencia oral: apropiación social del conocimiento sobre avifauna como estrategia de educación ambiental en Pereira Risaralda, presentada en el $4 .{ }^{\circ}$ Congreso Nacional de Ciencias Ambientales.

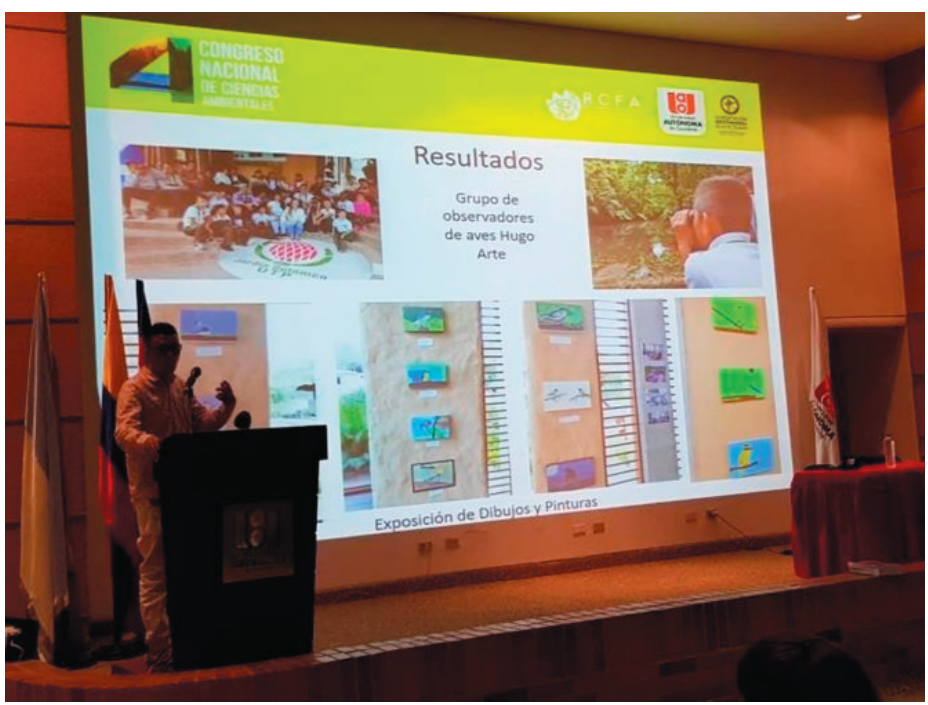

Elaboración propia. 
Jorge Hugo García Sierra - Juliana Muñoz López - Jaime Andrés Suarez Mejía - Juan Sebastián Arango González Alba Lucía Villa - Valentina Rodríguez Solarte - Lina Marcela Arboleda - Jhon Enríquez Calderón - Sonia Marín Londoño Jhoan Santiago Vásquez - Tatiana Carmona Gómez - Javier Andrés Cuayal - Albeiro Pava Saray Katerine Ríos - Nathalya Eugenia Ospina

FigURA NRo. 7. Portada del folleto ilustrado: «Las aves de mi colegio».

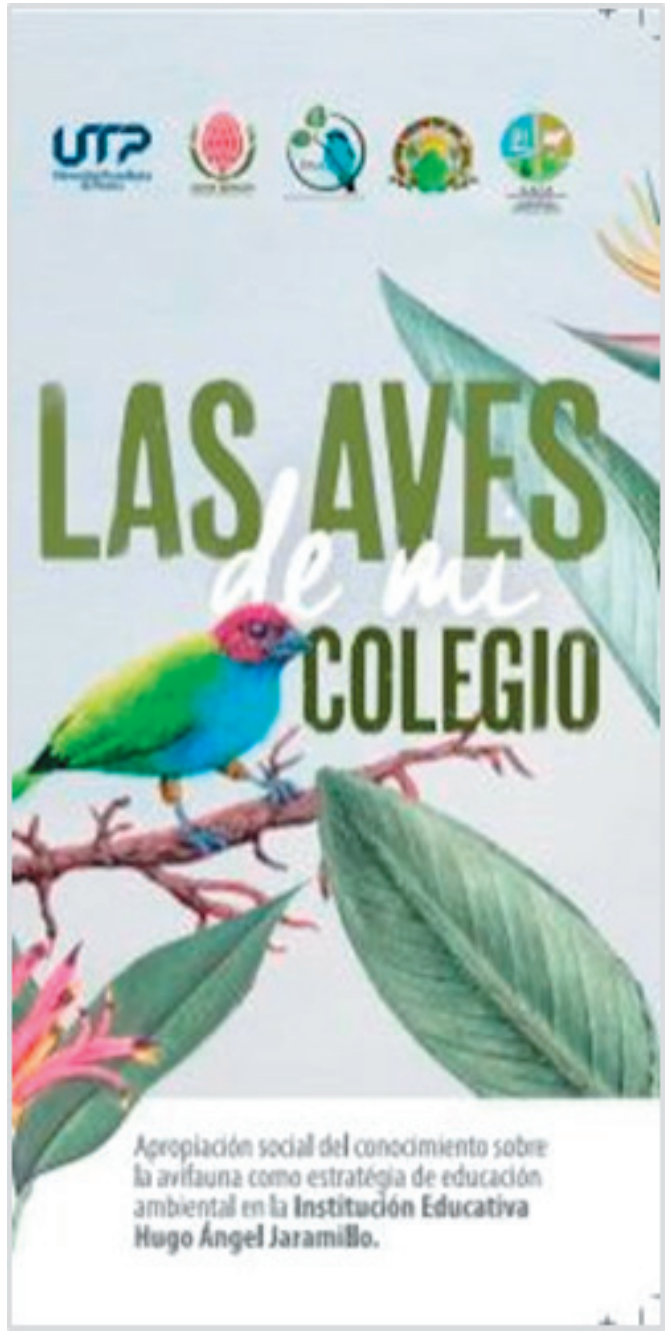

Elaboración propia. 
Figura NRo. 8. Proceso de elaboración de mural.

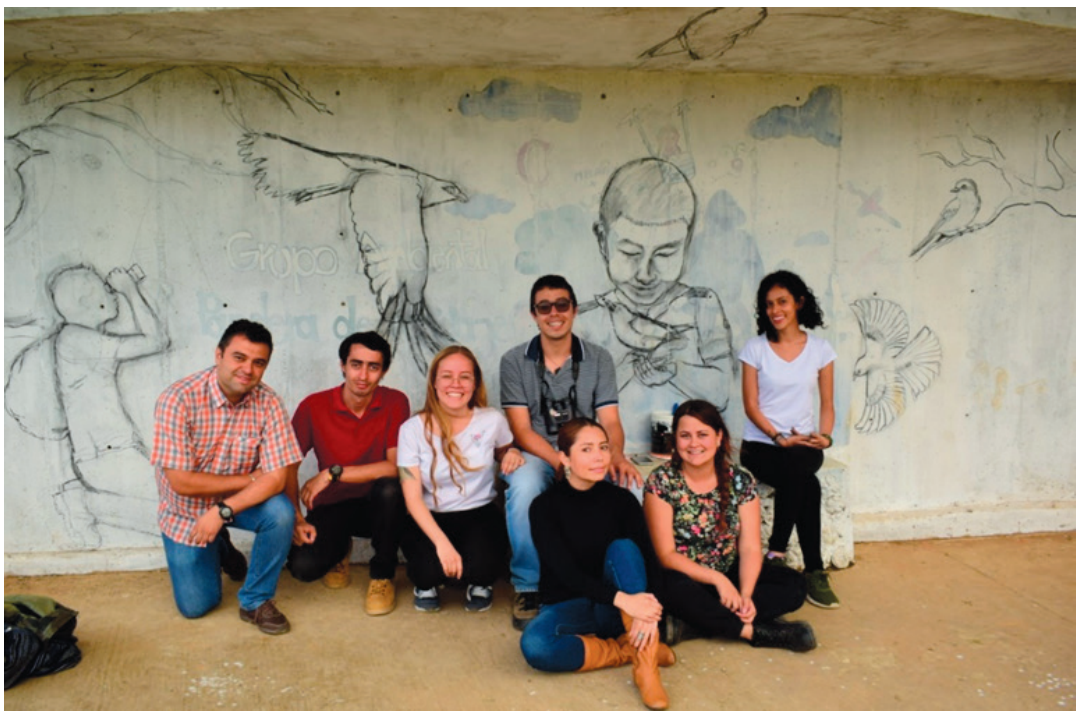

Elaboración propia.

Figura NRO. 9. Mural elaborado en la Institución Educativa Hugo Ángel Jaramillo.

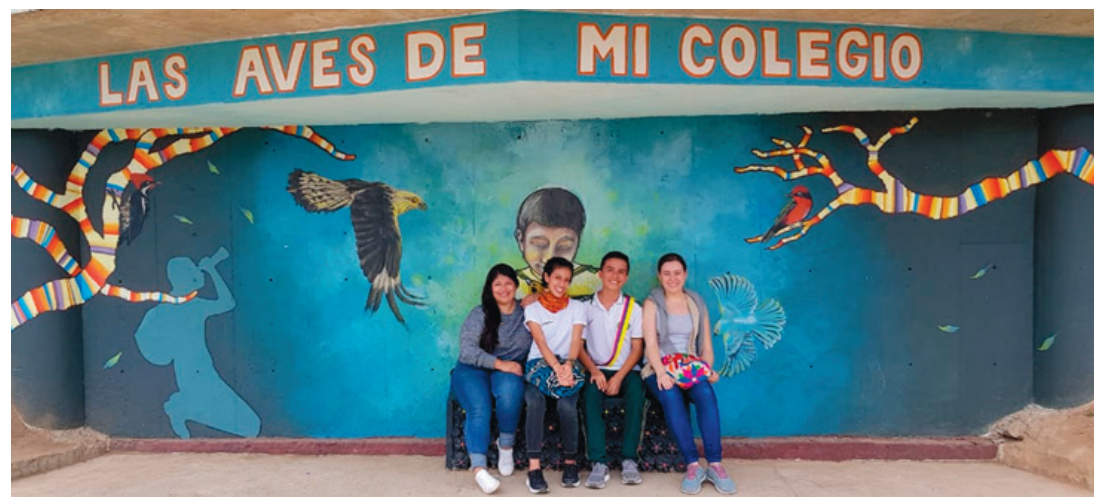

Elaboración propia. 
Jorge Hugo García Sierra - Juliana Muñoz López - Jaime Andrés Suarez Mejía - Juan Sebastián Arango González Alba Lucía Villa - Valentina Rodríguez Solarte - Lina Marcela Arboleda - Jhon Enríquez Calderón - Sonia Marín Londoño Jhoan Santiago Vásquez - Tatiana Carmona Gómez - Javier Andrés Cuayal - Albeiro Pava Saray Katerine Ríos - Nathalya Eugenia Ospina

FIgURA NRO. 10. Presentación de video a los estudiantes de la Institución Educativa.

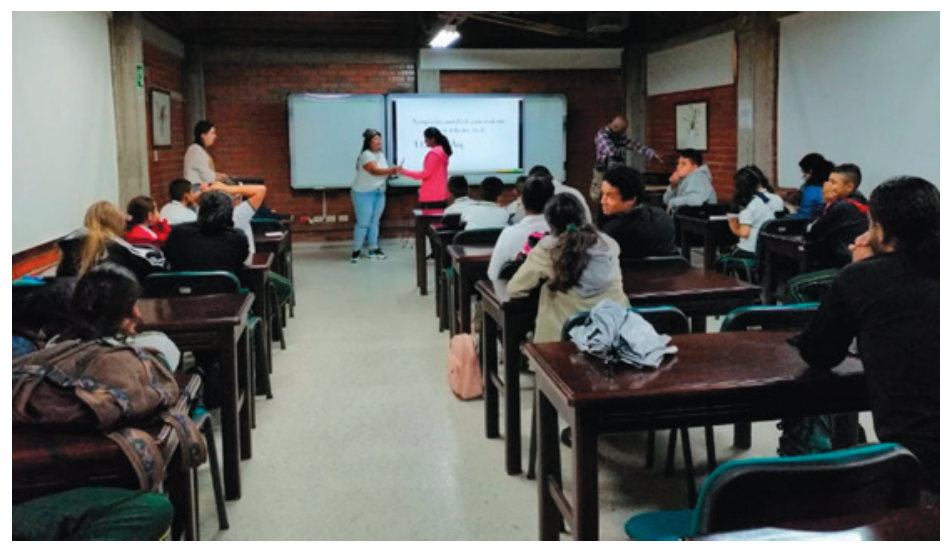

Elaboración propia.

FIGURA NRO. 11. Entrega de certificados de participación en el proyecto a los estudiantes de la Institución Educativa.

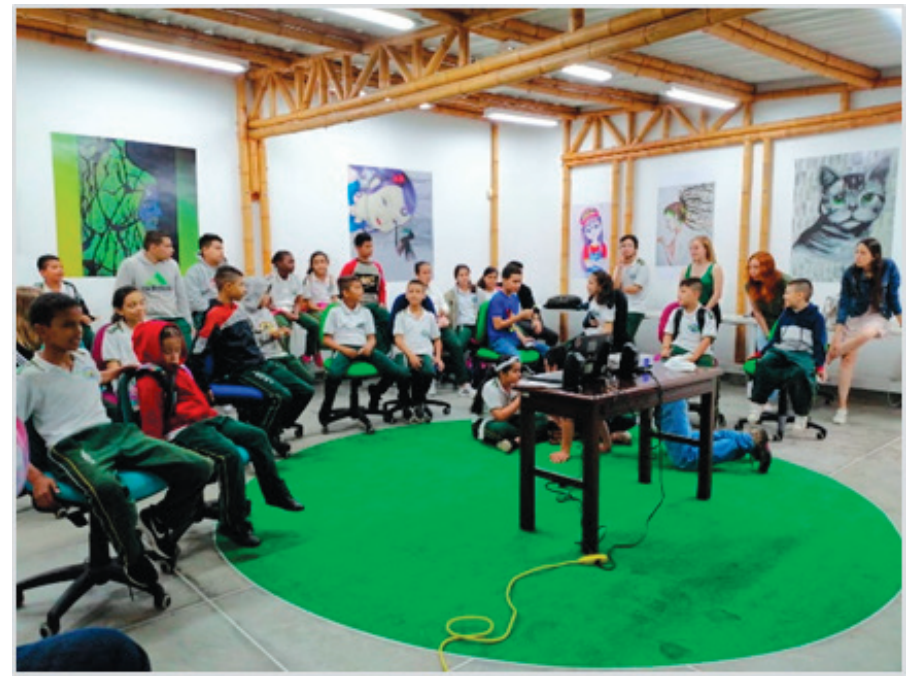

Elaboración propia. 


\section{Población beneficiada}

La población beneficiada fueron veinte niños entre los ocho y los catorce años pertenecientes a los estratos uno y dos, habitantes de la comuna del Café y estudiantes de la Institución Educativa Hugo Ángel Jaramillo en el municipio de Pereira Risaralda. Sin embargo, otros miembros de la comunidad estudiantil como profesores, administrativos y alumnos del semillero de investigación se vieron beneficiados por el proyecto.

\section{Conclusiones}

La sensibilización en educación ambiental con comunidades socialmente vulnerables requiere de estrategias que transversalicen las diferentes áreas del conocimiento, todo ello a través experiencias prácticas, lúdicas y espontáneas que conecten dicha comunidad con sus realidades.

La apropiación social del conocimiento sobre biodiversidad, específicamente sobre las aves, permitió la ambientalización de la educación en la institución educativa por medio del arte, la comunicación y la ciencia participativa. Con este proceso se permearon diferentes actores de la comunidad académica tales como el grupo de observadores de aves «Hugo Arte $; A$ Crear!», la rectora, los profesores, los padres de familia, el personal administrativo - como la bibliotecaria y el personal de vigilancia-, así como vecinos e integrantes del Semillero de Investigación en Aves Andinas.

Agradecimientos: A los estudiantes, profesores y directivos de la Institución Educativa Hugo Ángel Jaramillo y, muy especialmente, al docente de artes Ronald Holguín por la disposición permanente para el desarrollo del proyecto. A Lina Marcela Arboleda y Albeiro Pava, respectivamente estudiante y licenciado en Comunicación e Informática Educativa de la UTP, por la elaboración y edición del video que da cuenta del 
Jorge Hugo García Sierra - Juliana Muñoz López - Jaime Andrés Suarez Mejía - Juan Sebastián Arango González Alba Lucía Villa - Valentina Rodríguez Solarte - Lina Marcela Arboleda - Jhon Enríquez Calderón - Sonia Marín Londoño Jhoan Santiago Vásquez - Tatiana Carmona Gómez - Javier Andrés Cuayal - Albeiro Pava Saray Katerine Ríos - Nathalya Eugenia Ospina

proceso; al Jardín Botánico de la UTP, al Grupo de Investigación en Gestión de Agroecosistemas Tropicales Andinos (GATA) y a la Vicerrectoría de Investigaciones, Innovación y Extensión de la Universidad Tecnológica de Pereira por su financiación a través de la Convocatoria interna de extensión social, cultural y artística del año 2019.

Yo de pequeño, en vez de cazar pájaros,

construía jaulas para atrapar nubes.

Las observaba en el cielo y me parecían las aves más exóticas; porque podían de un momento a otro transformarse en más animales

o tomar diferentes formas.

Ahora que sé que no hay musas o hadas; construyo palabra, para atrapar del aire lo que dice el silencio

Carlos Héctor Trejos Reyes

Poeta Riosuceño

\section{Referencias bibliográficas}

Ayerbe Quiñones, F. (2019). Guía ilustrada de la avifauna colombiana. WCS Colombia-Wildlife Conservation Society.

Carrizosa Umaña, J. (2014). Colombia compleja. Jardín Botánico de Bogotá José Celestino Mutis. 
MarínAgudelo, S. A. (2012). Apropiación social del conocimiento: una nueva dimensión de los archivos. Revista Interamericana de Bibliotecología, 35(1), 55-62. http://www.scielo.org.co/ pdf/rib/v35n1/v35n1a5.pdf.

Minciencias. (2019). ¿Qué es la apropiación social de la ciencia, la tecnología y la innovación? http://minciencias.gov.co/ cultura-en-ctei/apropiacion-social/definicion.

Noguera de Echeverri, A. P. (2004). El reencantamiento del mundo. Programa de las Naciones Unidas para el Medio Ambiente (PNUMA), Oficina Regional para América Latina y el Caribe, Universidad Nacional de Colombia-IDEA. 


\title{
Reconstruyendo la historia desde adentro. Una experiencia significativa en la ciudad de Pereira, Risaralda: San Isidro, Puerto \\ Caldas
}

\author{
Docente \\ Claudia Viviana Hurtado loaiza \\ MARCIA VALENCIA ÁlVAREZ \\ Elizabeth ANaYa HeNaO \\ Diego Alejandro Chaves Obando \\ Semillero de Investigación Familia, Educación y \\ Comunidad \\ Universidad Tecnológica de Pereira
}

Resumen

El proyecto «Reconstruyendo la historia desde adentro. Una experiencia significativa en la Ciudad de Pereira, Risaralda: San Isidro, Puerto Caldas» fue una apuesta del Semillero de 
Investigación Familia, Educación y Comunidad para generar una articulación de tres conceptos considerados fundamentales en la formación integral en el sujeto como lo son: la familia, la educación y la comunidad que en esta oportunidad se enmarcaron en la reconstrucción de historia de vida de esta última, acompañada por instituciones que contemplan, dentro de sus áreas de responsabilidad social, el desarrollo comunitario.

El proyecto tuvo un carácter formativo tanto para los estudiantes de la Universidad Tecnológica de Pereira, como para la comunidad, dada la metodología prevista de reconstrucción de experiencias con el otro que contempló la formación de actores de la comunidad y que ellos fueran partícipes de todo el proceso de investigación extensión. Se esperó con este proyecto que la comunidad de San Isidro adquiriera metodologías que le permitieran mejorar sus conocimientos y habilidades para el reconocimiento de su realidad social; que describieran las particularidades históricas, las trayectorias, las problemáticas y la visión a largo plazo, que interpretaran de forma crítica la experiencia de ocupación del territorio y del acompañamiento institucional que les admitiera dar sentido a sus historias de vida a la comunidad de San Isidro.

Palabras clave: experiencias significativas, familia, educación, comunidad, realidad social.

\section{Abstract}

The project "Reconstructing history from within-A significant experience in the City of Pereira, Risaralda: San Isidro, Puerto Caldas" was a bet of the Research Seedbed Family, Education and Community to generate in articulation of 3 concepts considered fundamental in comprehensive training in the subject such as: The family, education and the community, which this time were framed in the reconstruction of the life history of a community, accompanied by institutions that consider development within 
their areas of social responsibility community. The project had a formative character both for the students of the Technological University of Pereira, and for the community, given the planned methodology for the reconstruction of experiences with the other, which contemplates the training of community actors and that they were participants in everything. The investigation process. It was hoped with this project that the community of San Isidro would acquire methodologies that would allow them to improve their knowledge and skills for the recognition of their social reality; that describe the historical particularities, the trajectories, the problems and the long-term vision, a critical interpretation of the experience of occupation of the territory and the institutional accompaniment that would allow them to give meaning to their life stories to the community of San Isidro.

Keywords: Significant Experiences, Family, Education, Community, Social Reality.

\section{Introducción}

El proyecto de extensión implementado permitió evidenciar los niveles y alcances que adquirió la comunidad de San Isidro para el reconocimiento de sus realidades sociales a partir de su propio nombre «Reconstruyendo la historia desde adentro, una experiencia significativa en la ciudad de Pereira, Risaralda: San Isidro, Puerto Caldas», al desarrollar las tres fases del proyecto mencionado, fase nro. 1 «Recorriendo los caminos del tren», fase nro. 2 «Diagnóstico comunitario participativo» $y$, por último, la fase nro. 3 «Sistematización de experiencias».

La comunidad de San Isidro ha realizado diferentes procesos de ocupación y adaptación al entorno que les ha permitido crecer colectivamente y empoderarse de sus procesos socio-culturales, con una lectura más crítica y clara de su colectividad. Este proyecto potenció procesos de crecimiento al identificar las luchas y labores 
de responsabilidad social, los rasgos socioculturales, la diversidad, el empoderamiento, la identidad social y las historias de vida que allí se han construido a lo largo del tiempo.

Igualmente, se develó el empoderamiento de la comunidad de San Isidro con la interpretación crítica de la experiencia de ocupación del territorio y del acompañamiento institucional que les permitió dar sentido a sus historias de vida por medio de las tres fases mencionadas. Por tanto, más adelante se van a detallar cada una de ellas. También al forjar nuevas relaciones sociales, las cuales facilitaron la interpretación de los hitos sociales y el desarrollo de prácticas reflexivas para los licenciados en formación que hicieron parte del proyecto mismo y que aumentaron el nivel de articulación de estudiantes de pregrado con procesos sociales vigentes y de impacto social.

Es importante reconocer y agradecer a dicha comunidad y a la Corporación El Comienzo del Arco Iris por la decidida participación que tuvieron en todo el proceso, donde lograron reconocer y evidenciar un espacio de investigación acción que se activó al construir con el otro.

\section{Objetivos}

\section{Objetivo general}

Identificar las influencias de la intervención institucional en el proceso de la construcción de la historia de vida de la comunidad de San Isidro, Puerto Caldas.

\section{Objetivos específicos}

Orientar a la comunidad de San Isidro, Puerto Caldas, en el proceso de reconocimiento de las experiencias significativas. 
Caracterizar a la comunidad de San Isidro desde una mirada social, demográfica, histórica y prospectiva.

Recopilar las experiencias que reflejan rasgos identitarios de la comunidad de San Isidro, Puerto Caldas-Pereira.

\section{Metodología}

La metodología orientadora del proyecto giró en torno a la sistematización de experiencias, la cual buscó generar una recopilación de los procesos históricos y sociales de la comunidad de San Isidro desde su propia mirada y evidenciar así sus rasgos identitarios y particularidades colectivas. Estrategias para transformar aquella colectividad y generar más empoderamiento en la misma.

La sistematización de experiencias hizo que la comunidad tuviera un crecimiento colectivo y crítico en la construcción y producción de sus saberes, lo cual les permitió aprendizajes internos y externos sobre el sentido y la dinámica de sus procesos y poder compartir sus experiencias con otros actores sociales. Sin embargo, para cada fase planteada se recolectó la información de diversas formas, con el fin de apostar a sus visiones, sus formas de entender y comprender desde sus necesidades colectivas. Por ello a continuación se muestra, detalladamente, cada fase con sus respectivos métodos de recolección de información. 
TABLA NRO. 1. Resumen de la metodología del proyecto.

\begin{tabular}{ll}
\hline Fase & Descripción \\
\hline Fase nro. 1 & Diagnostico comunitario participativo \\
& En esta fase se sucintó un acercamiento a la \\
& $\begin{array}{l}\text { comunidad donde se realizó una descripción clara del } \\
\text { proceso y del carácter informativo, para generar en la } \\
\text { comunidad expectativa y motivación. Por ello se propuso el } \\
\text { diagnostico comunitario participativo en respuesta a unas } \\
\text { necesidades de caracterización del entorno, en ese sentido, } \\
\text { se inició con este mecanismo que fortalecía la autogestión, } \\
\text { la participación democrática y el trabajo en equipo, ya } \\
\text { que para la población fue de gran ayuda complementar el } \\
\text { proceso investigativo. }\end{array}$ \\
\hline
\end{tabular}

Fase nro. 2

\section{Caracterización}

Se propuso una caracterización que evidenciara las historias, los procesos de constitución y las particularidades de la población de San Isidro del corregimiento de Puerto Caldas.

Fase nro. 3

\section{Sistematización de experiencias}

Como respuesta a las necesidades de visibilizar los procesos de la comunidad, se presentó la sistematización como mecanismo de organización de la información y de las acciones o experiencias vividas.

\section{Elaboración propia.}

Para lograr el desarrollo de cada una de estas fases, se capacitó a todo el equipo de trabajo conformado para la implementación del proyecto, aspecto de gran relevancia para la integración y ejecución de actividades de recolección de información directamente en la comunidad. Este momento de inicio generó interesantes espacios de intercambio y aprendizaje colectivo. 
FiguRA NRO. 1. Capacitación en técnicas de trabajo comunitario para estudiantes, integrantes de la comunidad y miembros de la Corporación El Comienzo del Arco Iris, en la Universidad Tecnológica de Pereira.
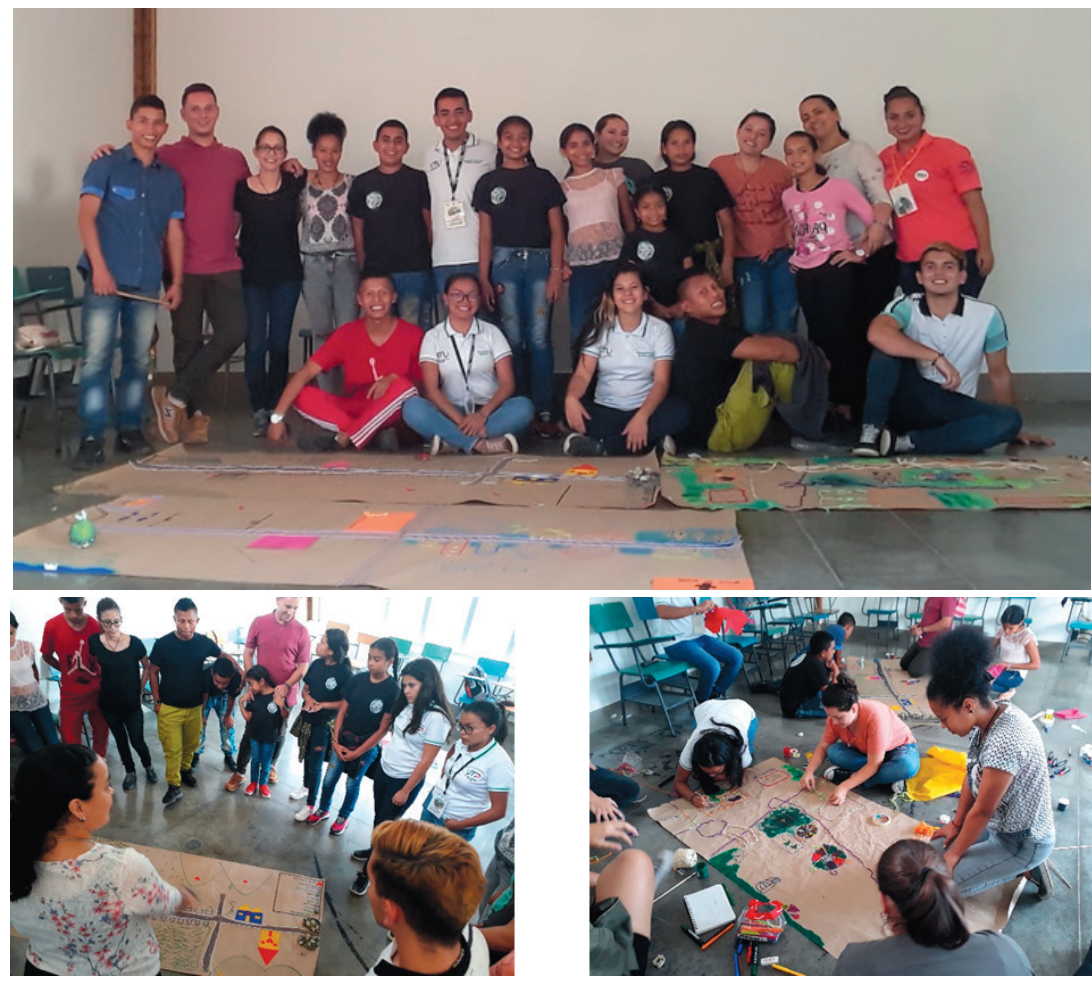

Elaboración propia

Surgieron como objetivos de la sistematización recuperar el proceso vivido y socializar los aprendizajes para, finalmente, dar sentido a la experiencia. Se asumió que la sistematización es el proceso de interlocución entre actores, instituciones, generaciones que negocian discursos, teorías y construcciones culturales diversas. Invita a ver lo siguiente:

Toda sistematización, como modalidad colectiva de producción de sentidos, es siempre una experiencia inédita, dado que lo que se pone en juego no son un conjunto de procedimientos y técnicas estandarizadas, sino las vivencias, sueños, visiones y opciones de 
individuos y grupos que la asumen como posibilidad de auto comprensión y transformación (Cendales et al., 2003, s. p.).

En este sentido se hizo relevante plasmar las historias de vida de la comunidad. Por tanto, fue necesaria una agrupación de ideas de carácter democrático con la intención de recolectar información, la cual permitió encontrar enfoques o líneas temáticas que fueron la estructura central de la sistematización, de manera tal que, al final de la misma, se logró hacer una evaluación de los aspectos más relevantes.

Se propuso entonces romper con las formas tradicionales y lineales de la producción de conocimiento, de modo que, se pudieran incluir elementos como la reflexión, el diálogo, la acción y el aprendizaje con la intención de fortalecer estas habilidades en la población.

FigURA NRO. 2. Técnicas interactivas de investigación social implementadas en el desarrollo del proyecto.
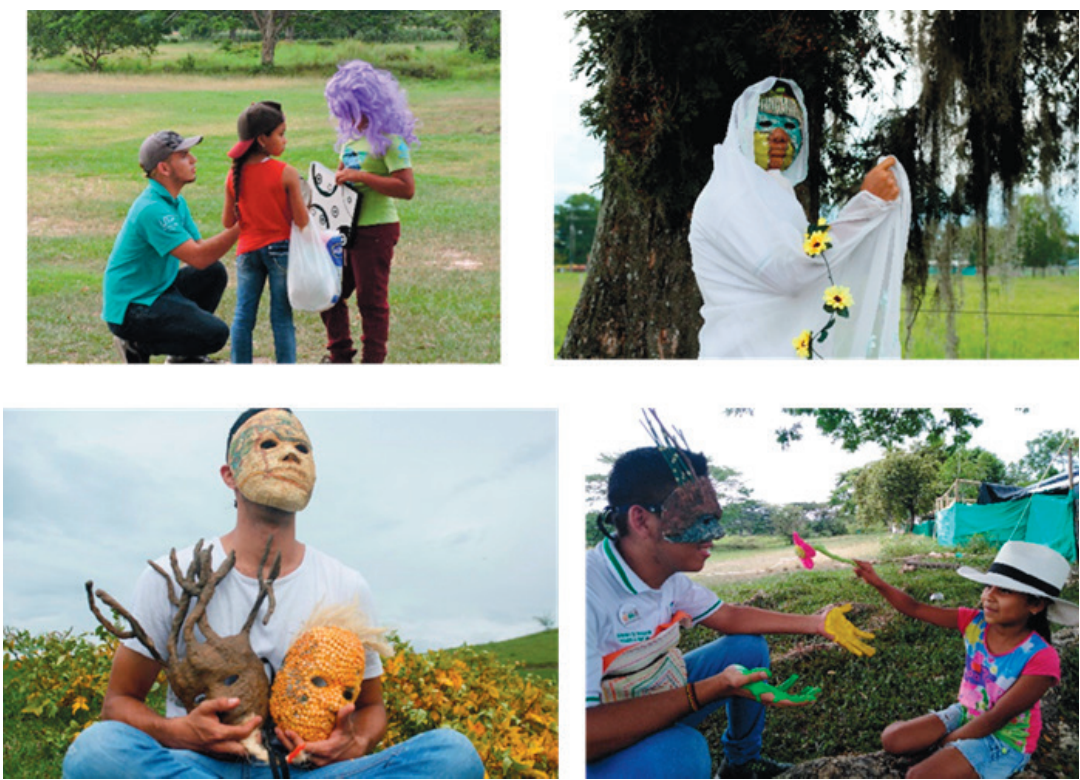

Elaboración propia 
Deestamanera, se pudo dar una mirada delastransformaciones que ha tenido la comunidad desde su conformación por medio de diferentes técnicas, las cuales permitieron evaluar el pasado, pensar en el presente y proyectarse hacia el futuro por medio de diálogos generacionales.

Durante el trabajo de campo se aplicaron diversas técnicas interactivas para la investigación social que permitieron involucrar al otro y lograr la articulación entre la Investigación Acción Participación y la sistematización de experiencias que era clave en este proceso de acompañamiento a la comunidad.

Figura NRo. 3. Técnicas interactivas de investigación social que permitieron la articulación entre la Investigación Acción Participación y la sistematización de experiencias.
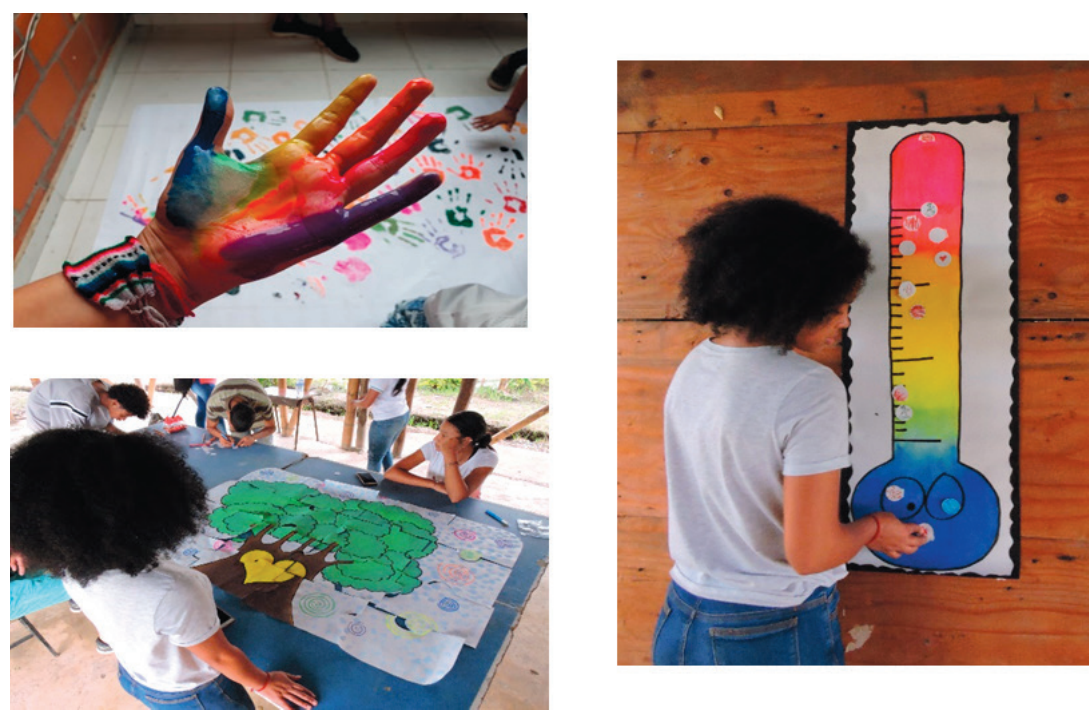

Elaboración propia

Para lograr este propósito se conformó un equipo de trabajo diverso e incluyente, el cual permitió realizar un ejercicio de construcción colectiva con el otro. 
Se eligió un grupo de personas vinculadas a la Corporación al Comienzo del Arco Iris y otros actores de la comunidad. Aquellos se denominaron «Equipo base de trabajo» y fueron las personas que, acompañadas por integrantes del Semillero de Investigación Familia, Educación y Comunidad (SIFEC), se capacitaron en herramientas de diagnóstico, caracterización e interpretación de información y sistematización de experiencias y se convirtieron en los coinvestigadores del proyecto.

Se conformó un grupo de cinco estudiantes integrantes de Licenciatura en Etnoeducación, de la Licenciatura en Etnoeducación de Desarrollo Comunitario y de la Licenciatura en Comunicación e Informática Educativa de la Universidad Tecnológica de Pereira. Todos ellos pertenecientes a diferentes semestres, en edades de veinte a veinticuatro años y con la particularidad de poseer diferentes capacidades y cualidades como la responsabilidad, el compromiso y el compañerismo.

Figura NRo. 4. Equipo de trabajo de la Universidad Tecnológica de Pereira.

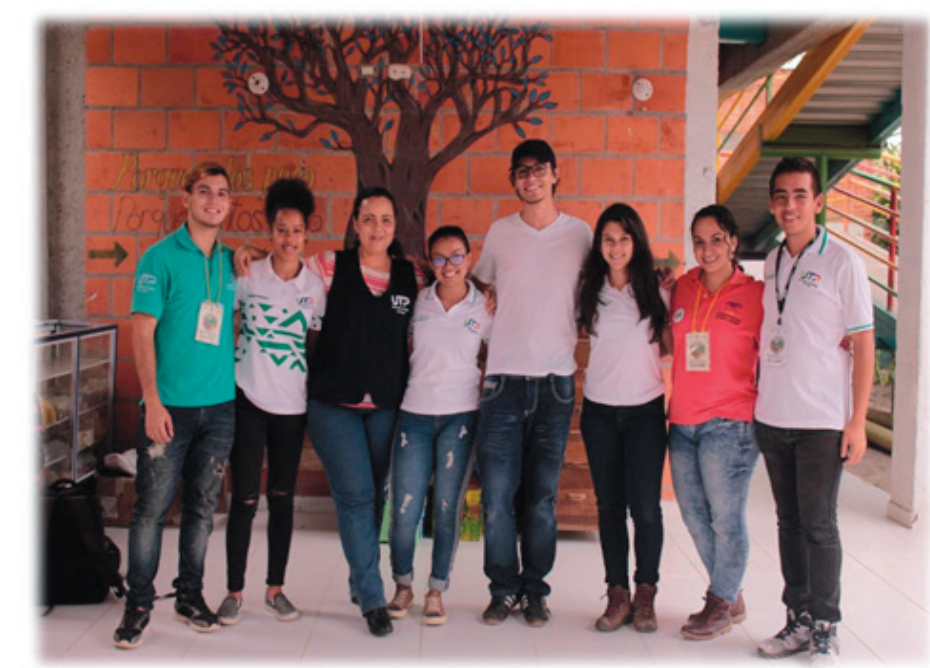

Fotografia 5. Equipo de Investigación U.T.P (Corporación Comienzo del Arco Iris-San Isidro)

Elaboración propia 
Para el desarrollo de cada una de las fases del proyecto, se contó con una participación de la comunidad, se conformó un grupo de diez jóvenes líderes entre los diez y los veinte años, los cuales se encontraban vinculados a diferentes procesos comunitarios de la Corporación El Comienzo del Arco Iris. Estos fueron capacitados para el desarrollo de las diversas actividades, con la intención de ser los futuros gestores de su comunidad.

Producto de este proceso de reconocimiento entre los mismos y la presentación de la metodología se generó una imagen que identificó el proyecto. Esta corresponde al sentido de pertenencia y construcción territorial que se tiene en torno a las carrileras del tren.

Este logo se creó entre los integrantes del equipo, quienes justificaron que la creación y conformación de la comunidad giró, en mayor parte, alrededor de la carrilera. En este sentido, recorrer los caminos del tren implica algo simbólico en cuanto a la conformación de las familias y las historias de vida de la comunidad (ver FIGURA NRO. 5).

FIGURA NRO. 5. Logo elaborado para el material usado en el proyecto.

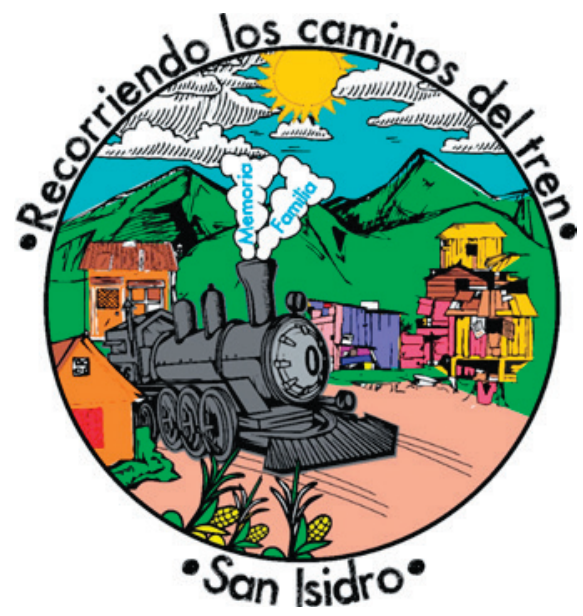

Elaboración propia 
Este equipo se encargó de realizar las actividades con autonomía y dedicación apoyando todo el proceso y generando, de esta manera, la confianza e interés del resto de la colectividad.

El grupo de jóvenes para la fase nro. 3 ascendió a trece de la comunidad y mantuvo para la fase nro. 1 y la fase nro. 2 la misma cantidad de actores, cada uno desde contextos diversos y comprometidos en las actividades. Desde sus perspectivas se proyectaron trabajaron individualmente y colectivamente en sus reflexiones desde las historias de vida apoyadas en las construcciones a partir del territorio, de la experiencia y de las vivencias del mismo.

Figura NRO. 6. Equipo de trabajo conformado por integrantes de la comunidad de San Isidro, de la Corporación El Comienzo del Arco Iris y de la Universidad Tecnológica de Pereira.

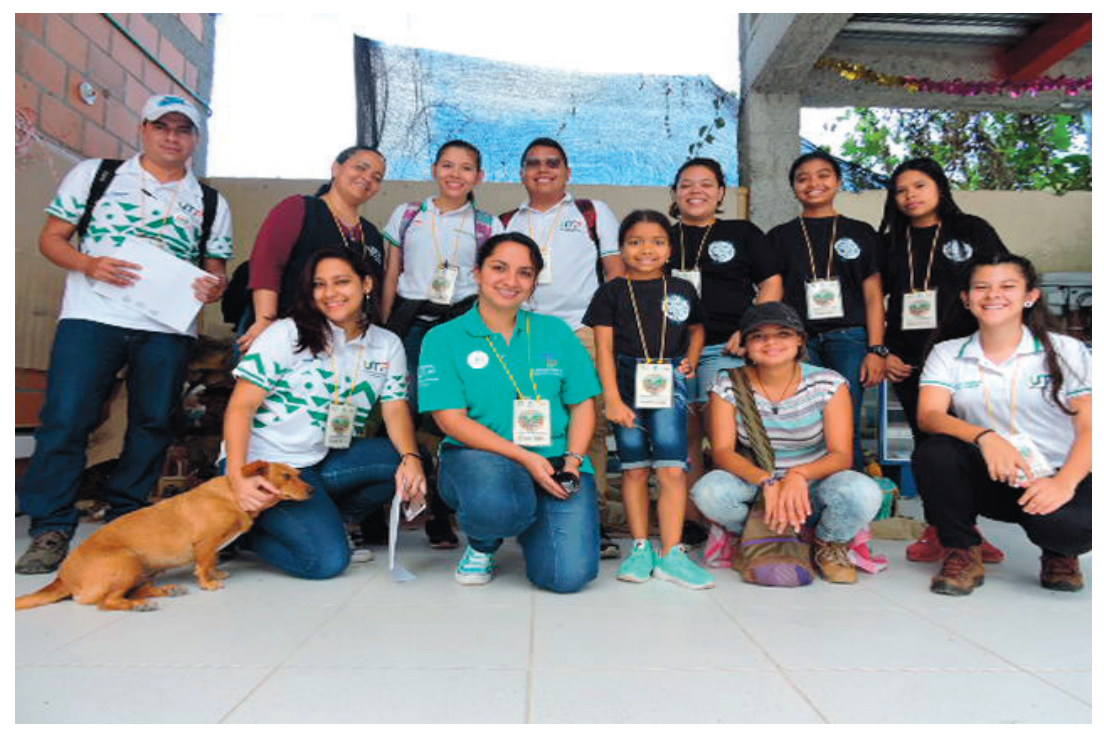

Elaboración propia 
Resultados

Por medio de actividades de formación en diagnóstico comunitario participativo, la comunidad de San Isidro adquirió habilidades, técnicas y metodologías que le permitieron identificar aspectos positivos, problemáticas y dinámicas de su comunidad para el reconocimiento de sus rasgos socioculturales. Todo orienta a tener una visión integral de su propia comunidad, de su organización y de su visión como pobladores del territorio.

A partir de la información recopilada en el diagnóstico comunitario participativo, se realizó una interpretación con el fin de realizar una caracterización a nivel social, demográfico, histórico y prospectivo de la comunidad de San Isidro entendiendo momentos coyunturales que permitan identificar las categorías centrales para la reflexión sobre la intervención institucional, la adaptación al territorio y la construcción de las historias de vida.

La comunidad se apropió de las herramientas diseñadas y aplicadas en este proyecto, todo ello para la implementación en futuros procesos de investigación y de aprendizaje. Los jóvenes también tuvieron un empoderamiento sobre sus historias de vida y entendieron los cambios significativos que han tenido en su trasegar.

Los líderes sociales han sido un elemento clave para la movilización de ideales que sensibilizan a la comunidad. Ellos evidencian formas de resistencia ante las necesidades particulares. Por tanto, la simbología construida por acciones populares han sido un mecanismo para fortalecer la autogestión, la participación democrática y el trabajo en equipo.

Visibilizar las experiencias de vida de los jóvenes de San Isidro permitió salir de los esquemas tradicionales, generar empoderamiento sobre sus formas de concebir la vida y construir nuevas concepciones sobre su cotidianidad para romper automáticamente con su actuar en los paradigmas establecidos. 


\section{Población beneficiada}

Este proyecto benefició específicamente y en forma directa a ciento doce familias del sector de San Isidro, a los sectores aledaños y a veinte integrantes que hacen parte de a la Corporación Al Comienzo del Arco Iris, los cuales participaron en el proceso de formación y fueron coinvestigadores. Por tanto, en total se beneficiaron quinientas ochenta personas de forma directa $y$ seiscientas cincuenta personas de manera indirecta.

Está compuesto por los sectores de San Isidro, El Cofre, María Auxiliadora, Las Camelias, Los Almendros, El Porvenir, Puente Blanco, El Cafetalito y El Progreso.

Ubicado en los linderos de Pereira y bajo la jurisdicción de Risaralda se encuentra el corregimiento de Puerto Caldas. Este limita con el municipio del Valle-Cauca y queda aproximadamente de treinta-cuarenta minutos caminando o a quince en moto taxi o chocho - como comúnmente se le nombra a este tipo de transporte- de la vía principal Pereira-Cartago.

\section{Conclusiones}

Para el Semillero de Investigación ha sido un espacio de aprendizaje la construcción colectiva con el otro, donde la sistematización entendida como la interpretación crítica de una o varias experiencias, a partir de su ordenamiento y reconstrucción, descubre o explica la lógica del proceso vivido, los factores que han intervenido, cómo se han relacionado entre sí y porqué lo han hecho de ese modo. Todo ello ha permitido orientar a la comunidad de San Isidro en el reconocimiento de sus experiencias significativas que se convierten en identidades vinculadas a sus territorios.

A partir del diagnóstico comunitario participativo se establecieron las categorías e intereses de la comunidad para la 
recuperación de sus historias. Así se logró la caracterización de la población desde una mirada social, demográfica, histórica y prospectiva de la comunidad. Por ello, la implementación de las diferentes técnicas sociales en la comunidad llevó a entender, al grupo de investigación SIFEC, los cambios tan significativos tenidos por los jóvenes a partir de los apoyos brindados por la Corporación El Comienzo del Arco Iris y por la misma disponibilidad de estos por hacer parte de los procesos sociales que llegan a su comunidad. Con ello se han podido enriquecer y empoderar de diferentes herramientas para su vida cotidiana.

El aprendizaje no solo se fomentó en una sola dirección. Este comprendió que la educación es en doble sentido y entreteje las enseñanzas a través de las diferentes experiencias de vida. Así, individualmente, se reconstruye un trabajo en comunidad.

Las relaciones tejidas en cada actividad fueron fundamentales a la hora de entender las dinámicas sociales que se gestan en la comunidad de San isidro, ya que son los jóvenes y actores quienes han logrado empoderarse del proceso de transformación que quiere lograr la comunidad. De esta forma, desde sus relatos y saberes propios se pudo encontrar que han logrado unir esfuerzos para seguir en el camino de soñar, construir y re-existir en la sociedad. La motivación, el compromiso, la fuerza, la tenacidad, la fe y la esperanza, son algunos elementos que día a día se laboran en el territorio porque con ellos ven siempre El Comienzo del Arco Iris.

Desde la acciones y roles que desempeñan los actores de esta comunidad se camina en un andar de experiencias y cada uno visiona un futuro diferente para su territorio. Pero a la hora de contrastar esas visiones se difuminan en una sola, como un tejido que se articula para hacerse más fuerte. La comunidad de San Isidro continuará su camino de sueños que, aunque no es fácil, logra descifrar las adversidades y transformarlas en las bonitas experiencias. 
Desde el papel del licenciado en etnoeducación y desarrollo comunitario, el análisis del territorio y el contexto se vuelve un foco de atención, ya que mediante ellos se genera una cercanía con la comunidad que permite realizar interpretaciones coherentes con su realidad social. La producción de conocimiento en contexto es fundamental para el crecimiento de las poblaciones en sus territorios. Posibilitar entonces que estas expresen y generen experiencias significativas, contribuye inmensamente en el campo de las ciencias sociales y ayuda a disminuir las grandes brechas sociales en las cuales se encuentran inmersos.

Por tanto,

... desde la experiencia investigativa se ve la importancia de articular la investigación como eje transversal en el ciclo de intervención profesional. La intervención entendida como proceso consciente, reflexivo, ético y político que asume a los seres humanos como sujetos sociales protagonistas en la construcción de sus historias e integra [...] los contextos desde lo experiencial (Quiroz et al., s.f., p. 104)

La Participación en un proceso de investigación permitió como profesionales [...] avanzar en diversos aspectos de la intervención social, la cual fue abordada crítica y reflexivamente, posibilitando la retroalimentación y el fortalecimiento de la vida académica, confrontando y llevando al campo los conocimientos teóricos (Quiroz et al., s.f., p. 101),

y a la vez, para buscar nuevas alternativas de aprendizaje que apoyan y refuerzan los conocimientos adquiridos. 
Figura NRo. 7. Encuentro juvenil. San Isidro-Puerto Caldas.

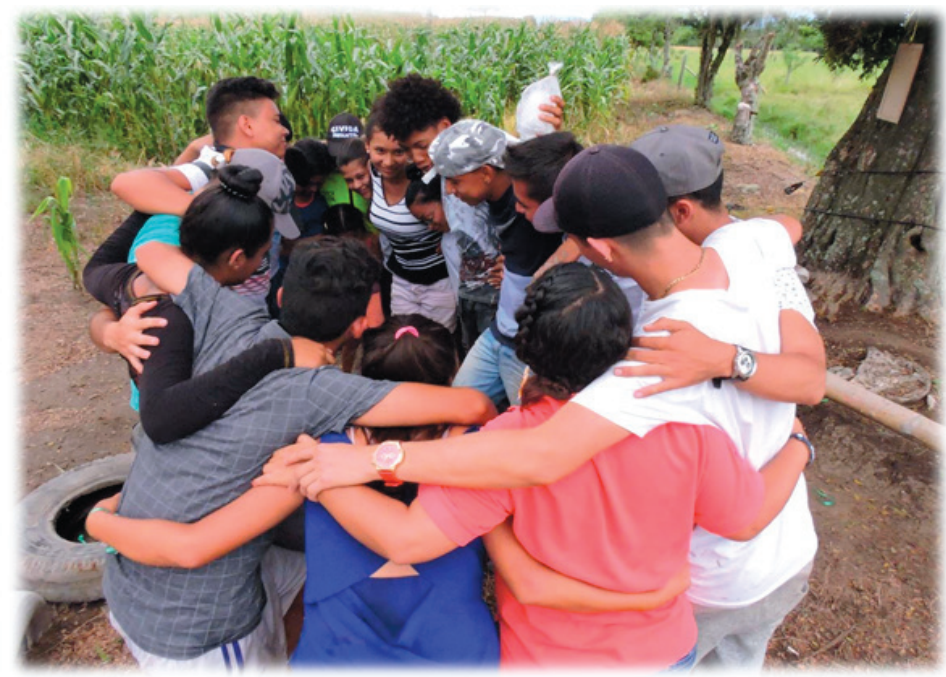

Fotografia 1. Encuentro juvenil (Equipo coinvestigador) - San Isidro Puerto Caldas

Tomada por Dylan Montoya, Estudiante de Licenciatura en Comunicación e Informática Educativa.

URA NRO. 8. Encuentro con líderes de la comunidad (San Isidro-Puerto Caldas).

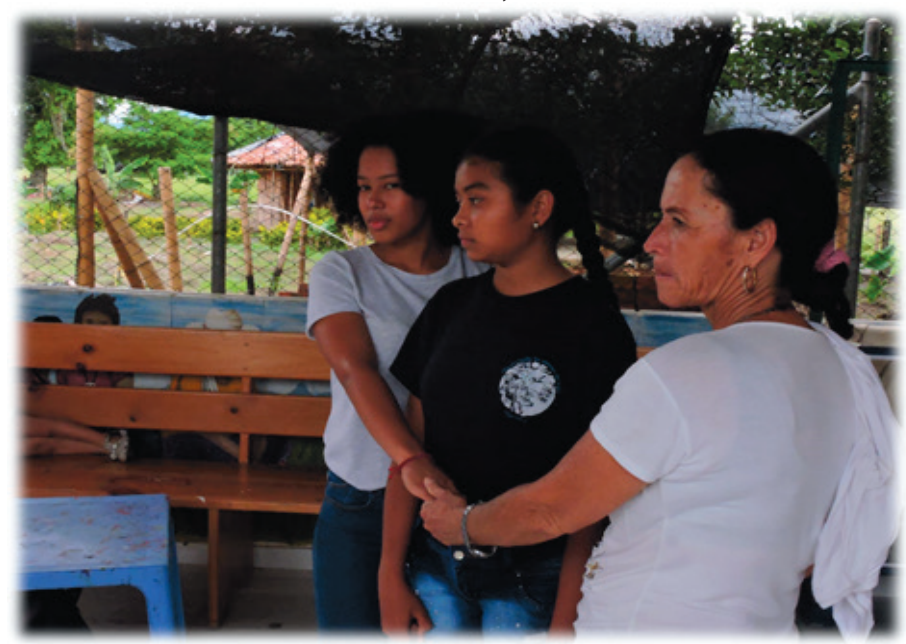

Fotografia 2. Encuentro con Líderes Sociales (San Isidro - Puerto Caldas)

FigTomada por Dylan Montoya, Estudiante de Licenciatura en Comunicación e Informática Educativa. 
Figura NRO. 9. Análisis e interpretación del territorio (San IsidroPuerto Caldas).

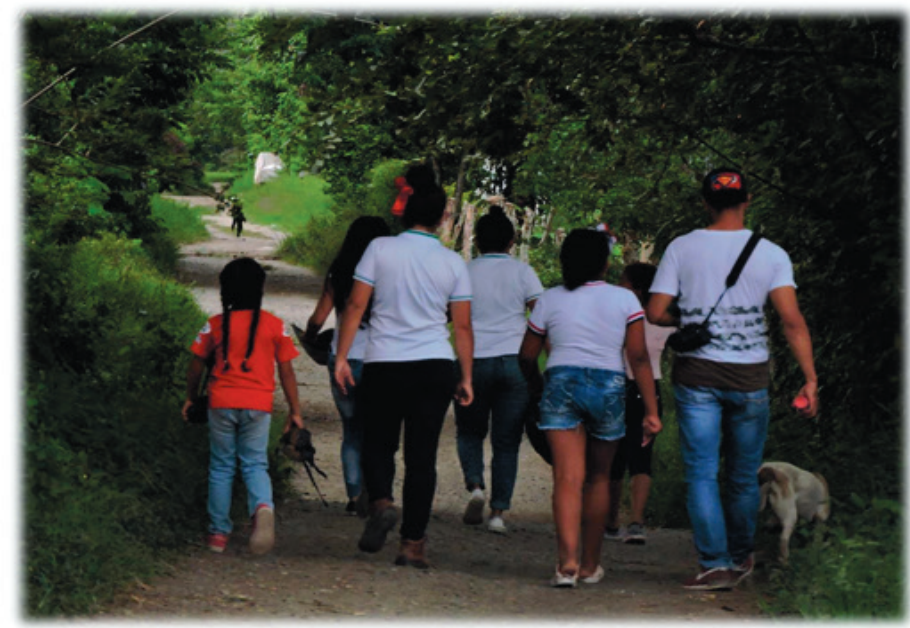

Fotografia 3. Análisis e interpretación del territorio (San Isidro - Puerto Caldas)

Tomadas por Dylan Montoya, Estudiante de Licenciatura en Comunicación e Informática Educativa.

FIGURA NRO. 10. Sistematización de experiencias (San Isidro PuertoCaldas).

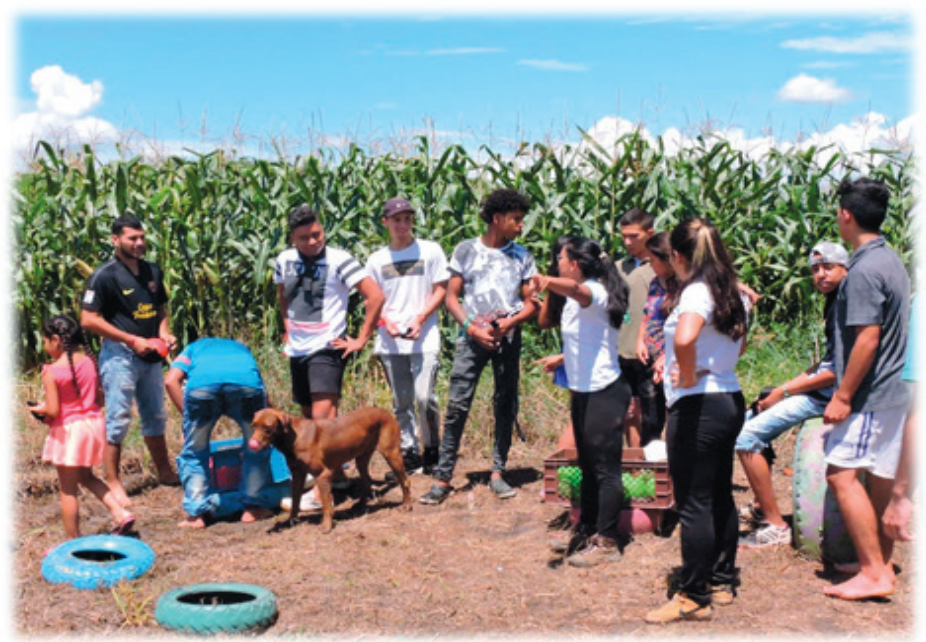

Fotografia 4. Sistematización de experiencias (San Isidro Puerto - Caldas)

Tomadas por Dylan Montoya, Estudiante de Licenciatura en Comunicación e Informática Educativa. 


\section{Bibliografía}

Cendales, L.; Díaz, E.; Rapacci, M. L.; Pino, A. C.; Lozano, J. y Martínez, I. (2003). La metodología de la sistematización: una construcción colectiva. Agencia Canadiense para el Desarrollo Internacional [ACDI]. http://centroderecursos. alboan.org/ebooks/0000/0750/6_CEN_MET.pdf.

FAls Borda, O. (1999). Orígenes universales y retos actuales de la IAP. Análisis Político, (38), 71-88.

García, B.; González, S.; Quiroz, A.; Velásquez, A. y Ghiso, A. M. (2002). Técnicas interactivas para la investigación social cualitativa. Funlam.

Giménez, G. (1996). Territorio y cultura. Estudios sobre las culturas Contemporáneas, 2(4). 9-30. https://www.redalyc. org/pdf/316/31600402.pdf.

JARA, O. (2011). La sistematización de experiencias: aspectos teóricos y metodológicos. Revista Decisio, (28). 67-74. http://www.cepalforja.org/sistem/documentos/decisio28_ testimonios1.pdf.

Mejía, M. R. (s.f.). Atravesando el espejo de nuestras prácticas. A propósito del saber que se produce y como se produce en la sistematización. http://www.cepalforja.org/sistem/sistem_ old/espejo_practicas.pdf.

Mercado Maldonado, A. y Hernández Oliva, A. V. (2010). El proceso de construcción de la identidad colectiva. Convergencia, 17(53), 229-251. http://www.scielo.org.mx/ pdf/conver/v17n53/v17n53a10.pdf. 
Quiroz Trujillo, A.; Velásquez Velásquez, A. M.; García Chacón, B. E. y González Zabala, S. P. (s.f.). Técnicas interactivas para la investigación social cualitativa. http://proyectos.javerianacali.edu.co/cursos_virtuales/ posgrado/maestria_asesoria_familiar/proyectos_I/ m\%C3\%B3dulo\%202/Tecnicas\%20Interactivas\%20-\%20 Quiroz.pdf.

Sosa Velásquez, M. (2012). ¿Cómo entender el territorio? Editorial Cara Parens. https://www.rebelion.org/ docs/166508.pdf. 
La Universidad Tecnológica de Pereira a través de la Vicerrectoría de Investigaciones, Innovación y Extensión realiza anualmente la Convocatoria Interna para la Financiación de Proyectos de Extensión Social, Cultural y Artístico, la cual tiene como objetivo incentivar la generación de propuestas que contribuyan a la solución y transformación de problemáticas del entorno a través de componentes sociales, culturales 0 artísticos. La presente publicación muestra los resultados obtenidos por los proyectos financiados a nivel institucional que involucran a diferentes estamentos de la sociedad civil en torno al planteamiento y discusión de las problemáticas, conflictos y sus posibles soluciones, así como la identificación de oportunidades de desarrollos y solución de problemas ambientales, educativos 0 de creación artística que involucren o beneficien sectores de diferentes comunidades, ejecutados en el año 2019.

\section{Vicerrectoría de Investigaciones, Innovación y Extensión Colección Trabajos de Investigación}

